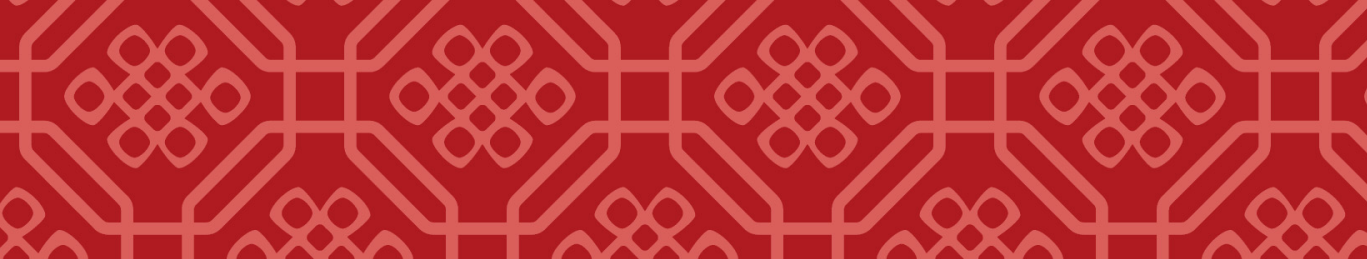

8

0800

$0 \div 20$

$0>0$

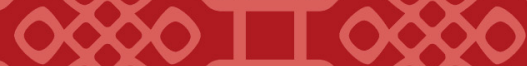

$0 \times 10$

$0 \% 0$

10000

\section{Appropriation and \\ Representation}

FENG MENGLONG AND THE CHINESE

VERNACULAR STORY

\section{Shuhui Yang}

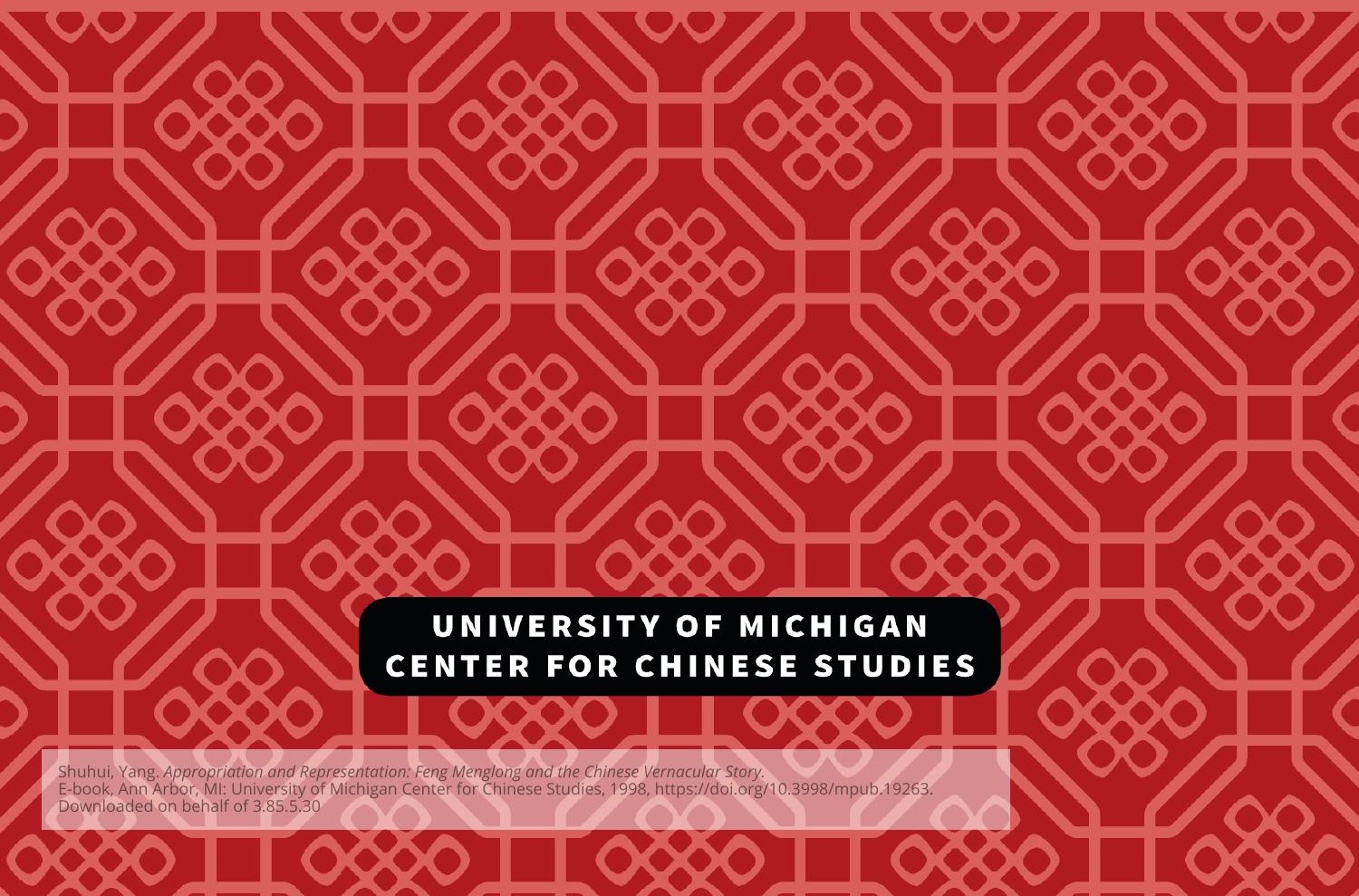




\title{
Appropriation and Representation
}

\author{
Feng Menglong \\ and the \\ Chinese Vernacular Story
}

Shuhui Yang

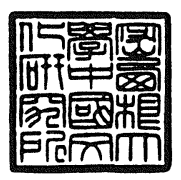

CENTER FOR CHINESE STUDIES THE UNIVERSITY OF MICHIGAN ANN ARBOR 
Open access edition funded by the National Endowment for the Humanities/ Andrew W. Mellon Foundation Humanities Open Book Program.

\title{
MICHIGAN MONOGRAPHS IN CHINESE STUDIES \\ ISSN 1081-9053 \\ SERIES ESTABLISHED 1968 \\ VOLUME 79
}

Published by

Center for Chinese Studies

The University of Michigan

Ann Arbor, Michigan 48104-1608

C1998 The Regents of the University of Michigan

Printed and made in the United States of America

\section{Library of Congress Cataloging-in-Publication Data}

\author{
Yang, Shuhui. \\ Appropriation and representation : Feng Menglong \\ and the Chinese vernacular story / Shuhui Yang \\ p. \\ $\mathrm{cm} .-$ \\ (Michigan monographs in Chinese studies ; 79) \\ Includes bibliographical references and index. \\ ISBN 0-89264-125-8 (alk. paper)
}

1. Feng, Meng-lung, 1574-1646- Criticism and interpretation.

2. Feng, Meng-lung, 1574-1646. Yü shih ming yen.

3. Feng, Meng-lung, 1574-1646. Ching shih t'ung yen.

4. Feng, Meng-lung, 1574-1646. Hsing shih heng yen.

5. Folk literature, Chinese- History and criticism.

$$
\begin{gathered}
\text { 6. Women in literature. } \\
\text { I. Title. II. Series } \\
\text { PL2698.F4Z98 } 1998 \\
\text { 895.1334609-dc21 CIP } \\
\text { ISBN 978-0-89264-125-3 (hardcover) } \\
\text { ISBN 978-0-472-03810-7 (paper) } \\
\text { ISBN 978-0-472-12756-6 (ebook) } \\
\text { ISBN 978-0-472-90151-7 (open access) }
\end{gathered}
$$

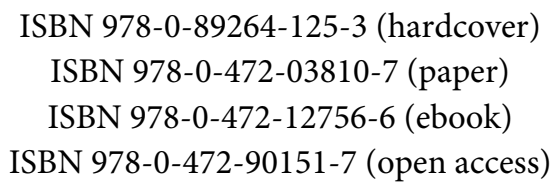

The text of this book is licensed under a Creative Commons Attribution-NonCommercial-NoDerivatives 4.0 International 
To Yunqin 


\section{Contents}

Acknowledgments

Notes on Romanization and Citations

Introduction

Elite Uses of Popular Material. Theoretical Perspectives: Dialogism and Ventriloquism. Evolution of the Chinese Vernacular Story, ca. $1550-1660$.

\section{The Politics of Literati Representation}

The Preface to Stories Old and New. The Problem of the Intended Audience. Authorship of the Sanyan Collections. The Myth of Folk Songs as Political Capital. The Storyteller's Manner.

2. Ventriloquism through a Storyteller

Who is Moralizing - Narrator or Author? Use of the Playful and Unreliable Narrator: The Moral Consequence of Two Paired Stories. Balancing the Moral Equation: The Adulteress Versus Her Husband. The Victim Versus the Cunning Schemer. The Husband and the Lover. The Concept of Fate and the Sense of Inevitability. The Narrator as Spokesman.

3. Ventriloquism through the Companion Story

4. Ventriloquism through Women Characters

Feng Menglong's Attitude Toward Women. Femininity and Yin. Sources of Literati Trans-gender Expression. Gendered Expressions of Anxiety in the Sanyan. Female Superiority in the Sanyan. Feng Menglong's "Beauty and Flower" Strategy. Women as Zhiyin.

Conclusion

Appendix: Sanyan Stories in This Work

Works Cited

Glossary-Index 


\section{Acknowledgments}

I have accumulated many debts of gratitude in the preparation of this book, and I would like to take this opportunity to thank all my teachers at Fudan University and Washington University, and all the friends who have encouraged, inspired and helped me. My biggest debt is to Robert E. Hegel, my mentor and advisor at Washington University when I was a graduate student. Without his advice and support, which I continue to benefit from, it would be impossible for me to be where I am now academically. I am also grateful to William Matheson and Emma Kafalenos for their advice during my graduate study. I owe special thanks to Tony Chang for always providing me with timely and accurate bibliographical information in my research. I also must thank Martin W. Huang (now at the University of California, Irvine) and Guan Daoxiong (now at the University of California, Santa Barbara) for generously sharing their expertise and resources on Chinese literature.

I am grateful to David L. Rolston, who did a thorough and careful reading of the entire book manuscript and offered many helpful suggestions. My thanks also go to Katherine Carlitz for her insightful comments on the second chapter at the 1995 AAS Conference in St. Louis, Missouri. I also wish to thank the two anonymous readers for the Center of Chinese Studies who made abundant useful suggestions, and my copyeditor Terre Fisher who provided expert assistance during the final stages of manuscript preparation. I have benefited greatly from these suggestions, although I have not been able to incorporate all of them, and if any errors remain in the book, I take complete responsibility for them.

Last but not least, I wish to thank Yunqin Yang, who helped to make my life meaningful during extended periods of stress and who contributed so much intellectually and emotionally to this study. To her this book is dedicated. 


\section{A Note on Romanization and Citations}

The romanization system used in this book is pinyin. For the convenience of readers who are more accustomed to the Wade-Giles system of spelling, here is a quick reference for the most difficult consonants:

$$
\begin{aligned}
\mathrm{c} & =\mathrm{ts} \\
\mathrm{q} & =\mathrm{ch} \\
\mathrm{x} & =\mathrm{hs} \\
\mathrm{z} & =\mathrm{tz} \\
\mathrm{zh} & =\mathrm{ch}
\end{aligned}
$$

For the spelling of Chinese words of two or more characters (or syllables), this book follows the rules of Xiandai Hanyu cidian (Beijing: Shangwu, 1979). Apostrophes are used between two vowels, or between one consonant and one vowel, but not between two consonants. For example, an apostrophe appears in "Tian'anmen," but not in "shange."

For the sake of consistency, romanized words in citations are all changed to pinyin, with the exception of published titles.

Citations from the Sanyan collections in this volume come from the following editions: Yushi mingyan, Xu Zhengyang, ed. (Beijing: Renmin wenxue, 1987); Jingshi tongyan, Yan Dunyi, ed. (Beijing: Renmin wenxue, 1987); and Xingshi hengyan, Gu Xuejie, ed. (Beijing: Renmin wenxue, 1987). Facsimile reprints of Ming editions of Gujin xiaoshuo, Jingshi tongyan, and Xingshi hengyan, edited by Li Tianyi (Taipei: Shijie shuji, 1958-59) are used only for citing the extra-textual commentary, which does not appear in the more recent editions.

Source materials that I compare with the stories edited and published by Feng Menglong come, in the main, from Tan Zhengbi's Sanyan Liangpai ziliao (Shanghai: Shanghai guji, 1980). All citations from the above works are my own translations unless otherwise noted. 


\section{Introduction}

This study addresses the role played by Feng Menglong (1574-1646) in compiling the famous Sanyan collections and his important position in the evolution of the Chinese vernacular short story. I will examine Feng's methods of selecting source materials and demonstrate how, as part of his narrative strategy, he creatively manipulated elements of both popular and literati cultures to elevate this then-underrated literary genre.

The term Sanyan, literally meaning "three words," refers to three Ming dynasty collections of huaben (vernacular short stories), entitled respectively, Stories Old and New (Gujin xiaoshuo) or Illustrious Words to Instruct the World (Yushi mingyan), ${ }^{1}$ Comprebensive Words to Warn the World (Jingshi tongyan) and Constant Words to Awaken the World (Xingshi hengyan). ${ }^{2}$ Scholars generally agree that these collections of forty stories each were published in 1620,1624, and 1627, and were edited by Feng Menglong, a member of the late Ming literati class recognized as the most knowledgeable connoisseur of popular literature of his time.

\footnotetext{
${ }^{1}$ It is generally agreed that when Gujin xiaoshuo was reprinted in 1626 or 1627 it was retitled Yushi mingyan; see Patrick Hanan, The Chinese Vernacular Story (Cambridge: Harvard University Press, 1981), p. 230 n. 4. For the dissenting view that Gujin xiaoshuo was originally meant to be the general title for all three collections, see Lu Shulun, Feng Menglong yanjiu (Shanghai: Fudan daxue, 1987), pp. 89-94.

2 The collection to which an individual story belongs will be indicated by GJ (for Gujin xiaoshuo / Yushi mingyan), TY (for Jingshi tongyan), or HY (for Xingshi hengyan), followed by a number indicating the story's ordinal position in the collection. On the first mention of a story I will give a full translation of its title and use a shortened title thereafter.
} 


\section{2 / Appropriation and Representation}

Chapter 1 of this study historicizes Feng Menglong's motivations for promoting the vernacular short story while denying his own "authorship" in the Sanyan collections; it also explores Feng's handling of vernacular stories in light of the literati tradition of collecting folk songs. Each of the succeeding three chapters addresses one outstanding feature of the Sanyan stories. Chapter 2 examines Feng's various strategies for appropriating the storyteller-narrator to his own ends; this appropriation not only aims at convincing the reader of the oral origins of the text, but more importantly, it sets up the rhetorical and ideological manipulation of the narrator's voice and the values it represents. Chapter 3 discusses how Feng arranged his stories in pairs, particularly his self-conscious use of the second story as an implicit comment on the first. Chapter 4 is primarily concerned with the way women are represented in the Sanyan collections. It explains why it is often the heroine, not the hero, who initiates the struggle against the restrictions of conventional morality. It also explores to what extent Feng Menglong was involved in elevating the image of women in these stories and what the elevation of women by this male "author" reveals.

The remainder of this introduction will lay out the theoretical framework for my discussion of Feng's involvement with the Sanyan collections. As a point of departure, I will address the elite uses of popular materials by reviewing Robert Redfield's model of "great tradition" (elite culture) versus "little tradition" (popular culture), with special attention to the interflow between these two "traditions." I then propose reading the Sanyan stories in light of Mikhail Bakhtin's dialogism and Michael Holquist's ventriloquism: these theories justify my focus on the literati editor Feng Menglong as a conscious manipulator of his literary materials, rather than on the popular sources of the stories. And finally, I will modify Holquist's paradigm of the ownership of meaning/language to describe the evolution of the Chinese vernacular story (from ca. 1550 to 1658) in terms of literati "authorship," and to show the importance of Feng Menglong's Sanyan in this belletricizing process. 


\section{Elite Uses of Popular Materials}

In his classic anthropological study, Robert Redfield points out that certain societies have two cultural traditions, a "great tradition" of the educated few and a "little tradition" of the uneducated masses:

The great tradition is cultivated in schools or temples; the little tradition works itself out and keeps itself going in the lives of the unlettered in their village communities. The tradition of the philosopher, theologian, and literary man is a tradition consciously cultivated and handed down; that of the little people is for the most part taken for granted and not submitted to much scrutiny or considered refinement and improvement. . . . The two traditions are interdependent. The great tradition and little tradition have long affected each other and continue to do so. ... Great epics have arisen out of elements of traditional tale-telling by many people, and epics have returned again to the peasantry for modification and incorporation into local cultures. ${ }^{3}$

Of course, more than one great tradition may coexist in a given society-as Islam and Sanskritic Hinduism are both present in Indiaand there may be several subdivisions of a great tradition, or numerous regional or ethnic little traditions. Redfield himself admits that he speaks of "two" for the sake of simplicity. ${ }^{4}$ The notion of cultural stratification that Redfield introduces is important because it draws attention to the cultures of long neglected social strata and gives them value. Even more important is his point about traffic between the two (or more) traditions. This traffic may not be symmetrical; the flow in one direction may be much greater than in the other. But there is always movement or interaction between the two, and a careful study of it may lead to a better understanding of both.

${ }^{3}$ Robert Redfield, Peasant Society and Culture (Chicago: University of Chicago Press, 1956, rpt. 1967), pp. 41-42.

${ }^{4}$ Ibid. p. 85. 


\section{4 / Appropriation and Representation}

In recent years, many scholars have applied Redfield's model in their own fields, usually with qualifications or with different emphases. ${ }^{5}$ The more recent expressions, "elite culture" and "popular culture," have now largely replaced Redfield's original phrases in discussion. Recent interest also seems to have shifted more to popular culture. Muchembled's Popular Culture and Elite Culture in France deals with elite culture in only a limited way, in spite of the comparison implied in its title. Natalie Zemon Davis also focuses mainly on popular culture, while Peter Burke qualifies Redfield's model, claiming,

There was a group of people who stood in between the great and the little traditions and acted as mediators. A case could be made for describing the culture of early modern Europe as three cultures rather than two. . . . Between learned culture and traditional oral culture came what might be called 'chap-book culture,' the culture of the semi-literate (p. 63).

However, it is interesting that in the study of Chinese history, Redfield's model nicely coincides with the traditional Chinese notions of $y a$ and $s u$, terms that have been used for more than two millennia to distinguish cultural strata corresponding roughly to two social groups, the literati $(s h i)$ and the commoners $(\min )$. Yu Yingshi even argues that during the Qin and Han dynasties (221-207 B.C.; 206 B.C.- A.D. 220) the literati class often took assimilation of the little tradition and dissemination of the great tradition as their social responsibility. ${ }^{6}$ In other words, they worked deliberately to stimulate the interchanges between the cultural strata.

Inspired by the writings of Antonio Gramsci, David Johnson advocates a more refined mode of analysis, based on the criteria of an individual's education and his/her position in the "structure of domination." He identifies nine social-cultural groups in late imperial

\footnotetext{
${ }^{5}$ See, for example, Robert Muchembled, Popular Culture and Elite Culture in France: 1400-1750, trans. Lydia Cochrane (Baton Rouge: Louisiana State University Press, 1985); Natalie Zemon Davis, Society and Culture in Early Modern France (Stanford: Stanford University Press, 1975); Peter Burke, Popular Culture in Early Modern Europe (London: Temple Smith, 1978).

${ }^{6}$ Yu Yingshi, Shi yu Zhongguo wenhua (Shanghai: Shanghai renmin, 1987), pp. 132-35.
} 
China, starting with the classically educated and legally privileged population, and ending with those who were illiterate and dependent. Still, Johnson thinks the broad terms "popular culture" and "elite culture" are indispensable, so long as we are aware of the complex social realities that they denote.?

This distinction between "elite culture" and "popular culture" or ya and $s u$, serves as a point of departure for this study because the Sanyan stories to be discussed represent an important intersection of these cultures. Traditionally, Chinese vernacular fiction-which includes both the vernacular short story, a genre to which the Sanyan collections belong, and the full-length vernacular novel-has been regarded as an outgrowth of the popular tradition. Consequently, it is often studied as a major genre of folk literature. On the surface, this academic orientation seems justified. First, most works of these genres are written in baibua (vernacular Chinese), a language closer to everyday speech, instead of wenyan (classical Chinese), a formal writing system that had always been the trademark of a literati education. Second, most vernacular works contain tales or episodes that were known even among the illiterate. Third, almost all of these stories are related by a "storyteller-narrator,"

\footnotetext{
${ }^{7}$ See his "Communication, Class, and Consciousness in Late Imperial China," in Popular Culture in Late Imperial China, ed. David Johnson et al. (Berkeley: University of California Press, 1985), pp. 56, 68.

This "popular/elite" conception has been hotly debated in the China field in the past few years. Catherine Bell, in her review article "Religion and Chinese Culture: Toward an Assessment of Popular Religion" explores the relationship of these terms to the issues of Chinese unity and diversity and to theoretical models of culture and society. She has mapped out the three typical positions that have emerged historically in studies of Chinese religion in the last two decades (though with no intent to attach any teleological significance to that sequence). The dichotomies of "elite/folk," "great/little," or "rational religion/superstitious supernaturalism" constituted much of the framework of the first generation of scholarship on Chinese religion; the second-stage position challenged these dichotomies by emphasizing the underlying unities within Chinese culture, and the thirdstage approach suggests that culture involves the "internal generation of both distinctions and unities," "the 'production' of meanings," or "the 'construction' of history and community." See History of Religion 29 (1989): 35-57, esp. 40-43.
} 


\section{6 / Appropriation and Representation}

using expressions borrowed from the popular storytelling tradition. That tradition is supposed to be the ultimate provenance from which these works derived. ${ }^{8}$

Recently, however, several important studies have demonstrated that although the source materials and certain narrative techniques of major vernacular works can be closely linked to the popular tradition, "the process through which each of them takes on its mature generic shape in the sixteenth century remains primarily in the hands of sophisticated literati artists, and is only marginally connected with any sort of popular audience." The author of this statement, Andrew Plaks, suggests that

the great Chinese novels ... lend themselves to the most meaningful interpretation when they are treated not as examples of a 'popular' counter-culture, but rather as major documents in the mainstream of Ming and Qing literati culture. $^{10}$

Further, in his recent study The Four Masterworks of the Ming Novel, Plaks has convincingly demonstrated how literati authors deliberately manipulate and subvert the elements of popular literature, working them into narrative strategies that elevate their works to a higher level of literary sophistication.

How then did Feng Menglong treat the values, both aesthetic and ethical, of popular literature and the other traditions embedded in the Sanyan stories? This question might also be turned around: Why did Feng, a member of the literati class, borrow so substantially from folk literature in the first place? I will address these issues below as I compare

\footnotetext{
${ }^{8}$ For a brief historical account of the basic motivations for Chinese intellectuals to accept this hypothesis since the turn of this century, see Robert E. Hegel, The Novel in Seventeenth Century China (New York: Columbia University Press, 1981), pp. 2-3.

9 Andrew H. Plaks, "After the Fall: Hsing-shib yin-yüan chuan and the SeventeenthCentury Chinese Novel," Harvard Journal of Asiatic Studies 45.2 (1985): 546.

${ }^{10}$ Andrew H. Plaks, "Full-length Hsiao-shuo and the Western Novel," in China and the West: Comparative Literature Studies, ed. William Tay et al. (Hong Kong: Chinese University Press, 1980), p. 167.
} 
the source materials for the Sanyan stories with the versions that Feng edited and published.

To be sure, Feng was not the sole "author" of the one hundred and twenty stories-author in the sense of creating a work from whole cloth-although it is clear that he did substantially rewrite a fair number of them. Most noteworthy in this regard is the extreme care with which Feng selected, rearranged, and altered his source materials, making the three collections unique works of art. ${ }^{11}$ Even where the original works were left unamended, Feng the editor gave new meanings to old texts. As Robert E. Hegel observes in his discussion of the fashion for editing and anthologizing in seventeenth-century China, "to the extent that one's view of a work is affected by the context in which it is read . . editors played a significant role in the interpretation of earlier literature." ${ }^{12}$ Of course, scholarship can also shape the interpretation of a work or body of work, and the theoretical framework that I propose in the following section, although derived from a study of European literatures, will hopefully throw new light on old problems in the field of Chinese vernacular fiction. As the Chinese idiom ta shan gong cuo suggests, "stones from other mountains may serve to polish the jade from this one."

\section{Theoretical Perspectives: Dialogism and Ventriloquism}

In his discussion of Mikhail Bakhtin, Michael Holquist notes that there are three dominant ways language has come to be understood in departments of literature. These may be most succinctly characterized by how each conceives of the ownership of meaning. The first view of language, which Holquist calls "personalist," holds that "I own meaning,"

\footnotetext{
${ }^{11}$ Cf. Andrew Plaks' concern in reading Jin Ping Mei and its source materials, see his The Four Masterworks of the Ming Novel (Princeton: Princeton University Press, 1987), pp. 7071. See also Patrick Hanan, "Sources of the Chin P'ing Mei," Asia Major 10.2 (1963): 23-67. ${ }^{12}$ Hegel, The Novel in Seventeenth Century China, p. 58.
} 


\section{8 / Appropriation and Representation}

implying that "a close bond is felt between the sense I have of myself as a unique being and the being of my language." The personalist view assumes that "I can, by speaking, appropriate to my own use the impersonal structure of signs, which is always already there." Deeply implicated in the Western humanist tradition, this view is the polar opposite of the second, "deconstructionist" view, which holds that "No one owns meaning," and considers the human voice "merely ... another means for registering differences." Between these two poles is a third view, which Holquist terms "dialogism." It holds that "We own meaning," or to be more precise,

I can mean what I say, but only . . in words I take and give back to the community according to the protocols it establishes. My voice can mean, but only with others: at times in chorus, but at the best of times in a dialogue. ${ }^{13}$

If personalists maintain that the basis of meaning is the unique individual and deconstructionists locate it in the "structure of difference" outside the realm of the personal voice, then for the dialogists "meaning is rooted in the social, but the social conceived in a particular way."14

To give a concrete example of this dialogist view, Holquist turns to Bakhtin's idea of "hybrid construction," and for illustration, cites Bakhtin's comment on a passage from Charles Dickens's Little Dorritt. Here we must quote both Dickens and Bakhtin to understand how Holquist reaches his conclusion:

[Dickens:] That illustrious man and great national ornament, Mr. Merdle, continued his shining course. It began to be widely understood that one who had done society the admirable service of making so much money out of $i t{ }^{15}$ could not be suffered to remain a commoner. A baronetcy was spoken of with confidence; a peerage was frequently mentioned [book 2, ch. 24].

[Bakhtin:] [There is first of all the author's] fictive solidarity with the hypocritically ceremonial general opinion [held by most people] of Merdle.

\footnotetext{
${ }^{13}$ Michael Holquist, "The Politics of Representation," in Allegory and Representation, ed. Stephen J. Greenblatt (Baltimore: The Johns Hopkins University Press, 1981), p. 165.

${ }^{14}$ Holquist, "The Politics of Representation," pp. 163-64.

${ }^{15}$ Bakhtin's italicization.
} 
All epithets referring to Merdle in the first sentences derive from [such a] general opinion, that is, they are the concealed speech of another. The second sentence- "it began to be widely understood" etc.-is kept within the bounds of an emphatically objective style, representing not subjective opinion, but the admission of a . . . completely indisputable fact. [However,] the phrase "who had done society the admirable service" is completely at the level [once again] of common opinion, repeating its official glorification; but the subordinate clause attached to that glorification ("of making so much money out of it") is made up of the author's words (as if put into parenthesis) [but actually without any distinguishing punctuation at all]. The last sentence then picks up again at the level of common opinion. [That is] a typical hybrid construction, where the subordinate clause is in an authorial speech that is relatively direct [by contrast with] the main clause [which is] in someone else's speech. The main and subordinate clauses are constructed in different semantic and axiological conceptual systems. ${ }^{16}$

This dialogic representation of one voice-idea by another in Holquist's reading of Bakhtin acquires an almost universal significance for human speech:

Dialogism argues that what ... is often written off as mere irony, actually constitutes a paradigm for all utterances: I can appropriate meaning to my own purposes only by ventriloquating others.

A first implication of this principle is that as speakers we all participate in the rigors of authorship: we bend language to represent by representing languages. ${ }^{17}$.

One could argue whether Bakhtin's dialogic paradigm is really so universally applicable as Holquist claims. In fact, the other two views in Holquist's schema-the personalist as well as the deconstructionist views-would make the same claim: that each is comprehensive in

\footnotetext{
${ }^{16}$ Holquist, "The Politics of Representation," pp. 168-69. Also see Mikhail Bakhtin, "Discourse in the Novel" in The Dialogic Imagination: Four Essays by M. M. Bakbtin, ed. Michael Holquist (Austin: University of Texas Press, 1981), p. 306.

${ }^{17}$ Holquist, "The Politics of Representation," p. 169. Emphasis added.
} 


\section{0 / Appropriation and Representation}

nature and applies to all literature. In practical application, however, we often find that theories seem more productive with some texts than with others, more capable of accounting for some types of literature than others. Holquist obviously has noticed this gap between theory and practice, for toward the end of his essay he returns to the three views of language and suggests that each view results in its own characteristic genre:

Personalism has a natural affinity with the Bildungsroman; it is full of "Great Expectations." Deconstructivism has an affinity with lyric and fragment. . . . Dialogism has a taste for carnival and comedy, an affinity perhaps best caught in Bakhtin's lifelong affection for the first story of the Decameron. ... ${ }^{18}$

While not all of the Sanyan stories are comedies, Bakhtin's dialogic paradigm does appear to be an appropriate mode of analysis for them. For one thing, nearly all of the source materials for the Sanyan stories are literally from "others," or from "other social groups." For another, Feng Menglong as the finalizer of the texts can be justifiably studied as an "author" who appropriated their meaning to his own purposes, not so much by "creative writing" (in its narrow sense) but by revising preexistent source materials, by speaking through others' words. ${ }^{19}$ Interestingly enough, in seventeenth-century Chinese vernacular narratives, "the reworking and expansion of pre-existent traditional material, and the editorial work of weaving together these sources, may have been as important as any purely creative work undertaken by the individuals responsible for the final versions of the material. . . ."20

\footnotetext{
${ }^{18}$ Ibid. p. 182.

${ }^{19}$ Cf. André Lévy's concern for the problem of authorship in the study of traditional Chinese vernacular fiction: "... can we deal with the question of authorship as a simple problem of identification with an individual? Can we take as granted that the work is the product of a single mind through the channel of brush and paper? I am afraid we cannot." "On the Question of Authorship in Chinese Traditional Fiction," Hanxue yanjiu 6.1 (1988): 259.

${ }^{20}$ David L. Rolston, "Editor's Preface," in How to Read the Chinese Novel, ed. David L. Rolston (Princeton, New Jersey: Princeton University Press, 1990), p. xiv.
} 
The idea that a writer could express his own feelings by using materials from others is crystallized in a famous phrase attributed to Li Zhi (1527-1602), who greatly influenced Feng Menglong and other fiction writers: duo taren zbi jiubei jiao ziji zbi leikuai (to borrow the other man's wine glass to assuage one's own troubles). ${ }^{21}$ Many similar Chinese phrases suggest something like Bakhtin's notion of "hybrid construction," for example, jie bua xian Fo (to present Buddha with borrowed flowers), jie shi buan bun (to find reincarnation in another's corpse), and jie gu feng jin (to use the past to disparage the present). ${ }^{22}$

With its emphasis on the importance of the "author" in producing the final version of a text, ${ }^{23}$ Bakhtin's dialogism also seems to have an affinity with the Chinese literati's way of reading traditional vernacular fiction. An important critical method of traditional fiction commentators was their strategy of identifying with the author in their interpretations. Jin Shengtan (1608-1661), known for taking "the audacious step of making himself responsible for providing a positive explanation for all the features of each of the texts" he commented on, ${ }^{24}$ claimed at the beginning of his famous commentary on The Water Margin (Shuibu zbuan): "When reading a book the first thing to be taken

\footnotetext{
${ }^{21} \mathrm{Li}$ Zhi, "Zashuo," quoted in Zhongguo wenxue piping shi, ed. Wang Yunxi and Gu Yisheng (Shanghai: Shanghai guji, 1981), 2:425.

${ }^{22}$ The phrase "jiuping zhuang xinjiu" (fill the old bottle with new wine), although of biblical origin, began to be widely used by Chinese writers in the May Fourth era, probably because of its affinity with traditional Chinese idioms mentioned above, Hanyu da cidian, 12 vols. (Shanghai: Hanyu da cidian, 1986-94), 8:1302. Chang-tai Hung's essay, which deals with the Chinese left-wing writers' use of traditional popular literature in mobilizing the masses against Japanese invasion in the 1930's and 40's, has this revealing phrase in its title: "New Wine in Old Bottles: The Use of Folk Literature in the War of Resistance Against Japan," Hanxue yanjiu 8.1 (June 1990): 401-23.

${ }^{23} \mathrm{Cf}$. literary theories that tend to deny the role of the author: "The Intentional Fallacy" in The Verbal Icon by W.K. Wimsatt and Monroe C. Beardsley (University of Kentucky Press, 1954), pp. 3-18, and "The Death of the Author" by Roland Barthes, in his ImageMusic-Text, trans. Stephen Heath (New York: Hill and Wang, 1977), pp. 142-48.

${ }^{24}$ David L. Rolston, introduction to chapter 2, in Rolston, How to Read, p. 128.
} 


\section{2 / Appropriation and Representation}

into account is the state of mind of the author when he wrote it." ${ }^{25}$ Zhang Zhupo (1670-1698) also held that "the commentator's job (and the reader's as well) was to retrace the author's steps and reconstruct the completed work by probing and asking searching questions at every bend in the road, no matter how inconspicuous." ${ }^{26}$ Zhang commented on The Golden Lotus (Jin Ping Mei): "If the reader would not read the book as an account of Ximen Qing's [the main character of the novel] affairs, but employ his own literary imagination in the attempt to discover retroactively the secrets of the author's marvelous effects, it would be more valuable to him than reading the Records of the Grand Historian (Shiji) in its entirety." ${ }^{27}$

In terms of speaking through pre-existing materials, there is an affinity between Bakhtin's dialogism and another Chinese literary practice: the millennia-old strategy of "using antiquity" (yong gu). Poets of the Song dynasty (960-1279), particularly those of the Jiangxi School, elevated yong $g u$ in reaction against the incremental achievements of the previous dynasty's poets, the Tang masters. Huang Tingjian (1045-1105), for example, advocated a poetics that "recognized and incorporated the textual histories of words in order to create new meanings, meanings with his [Huang's] imprimatur." ${ }^{28}$ It was a poetics of appropriation exemplified by Huang's famous metaphors for poetic composition: duo tai buan gu (to drive off the soul of the foetus and take its place, or more literally, to evolve from the embryo, changing the bone) and dian tie cheng jin (to change iron into gold [through alchemical transformation]). ${ }^{29}$ The

\footnotetext{
${ }^{25}$ See item 1 of his dufa (how to read) essay for the novel, John C. Y. Wang trans., "How to Read The Fifth Book of Genius," in Rolston, How to Read, p. 131.

${ }^{26}$ David L. Rolston, "Formal Aspects of Fiction Criticism and Commentary in China," in Rolston, How to Read, p. 71.

${ }^{27}$ See item 82 of his dufa essay for the novel, trans. David T. Roy, "How to Read the Jin Ping Mei," in Rolston, How to Read, p. 238.

${ }^{28}$ David Palumbo-Liu, The Poetics of Appropriation: The Literary Theory and Practice of Huang Tingiian (Stanford, California: Stanford University Press, 1993), p. x.

${ }^{29}$ English translation from Adele Austin Rickett, "Method and Intuition: The Poetic Theories of Huang T'ing-chien," in Chinese Approaches to Literature from Confucius to Liang Ch'i-ch'ao, ed. Adele Austin Rickett (Princeton, New Jersey: Princeton University Press, 1978), pp. 109-10.
} 
Bakhtin/Holquist concepts of dialogism, hybrid construction, and ventriloquism, then, are not only compatible with traditional Chinese critical methods, they have been developed to treat the very issues of voice and authorship that present themselves in the Sanyan collections.

\section{Evolution of the Chinese Vernacular Story (ca. 1550-ca.1660)}

Although Holquist's paradigm on the ownership of meaning/language is non-teleological, it can with slight modifications be used to describe an important aspect of the evolution of the Chinese vernacular story in the sixteenth and seventeenth centuries. First, we must change the scheme into a timeline that simultaneously represents the historical appearance of the major story collections and the views of authorship that informed their compilation. At the timeline's starting point (ca. 1550) is the deconstructionist view that "no one owns meaning," or what I would term "the least apparent presence of the 'T' (author/editor)." Since at its other extreme (ca. 1660) is the personalist view or "the most apparent presence of the "I," the dialogist view "I can appropriate meaning by ventriloquating others" remains between the two poles (see Figure 1 below).

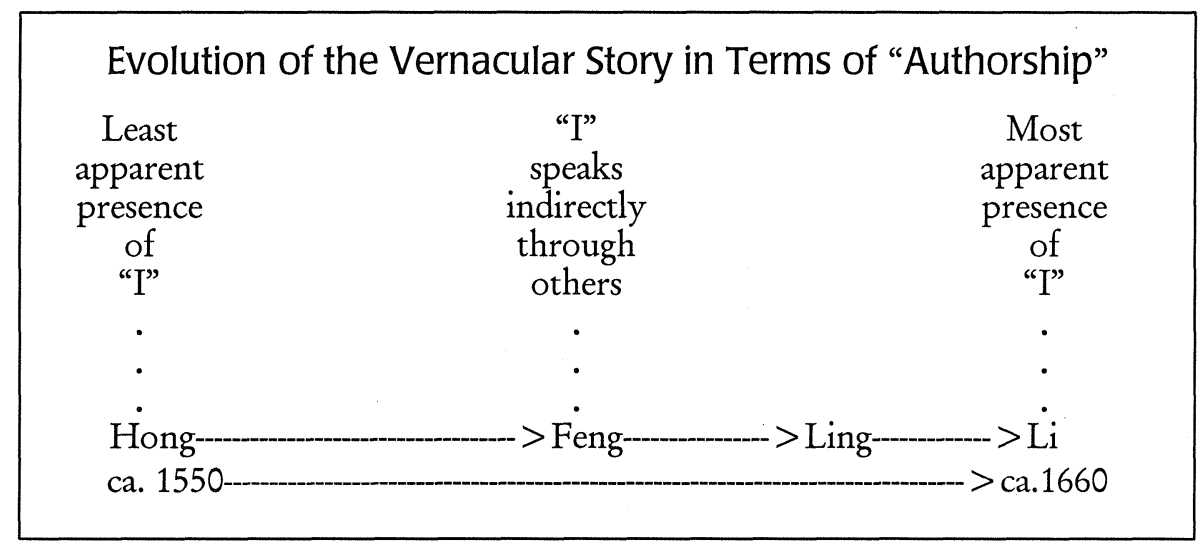

Figure 1 


\section{4 / Appropriation and Representation}

Near the starting point, appears Sixty Stories (Liushijia xiaoshuo), the earliest surviving anthology that contains a substantial number of vernacular short stories, published by Hong Pian around 1550. These stories were all written by anonymous writers or writers who cannot be identified, and Hong Pian's editorial work appears to have been minimal. The extent twenty-nine stories (some of them fragmentary) "have the loosest organization imaginable." ${ }^{30}$ For example, they are not numbered and the printing format differs even among stories in the same section. With the exception of one section, they seem to have been put together "without any obvious selection or arrangement by author, theme, source, or date." ${ }^{\prime 1}$ The collection even includes stories written in classical Chinese. Hong Pian may have done some superficial editing, such as providing titles-e.g., "Rainy Window Collection" ("Yuchuang ji"), "Leaning on the Pillow Collection" ("Qizhen ji") and "Relief From Boredom Collection" ("Jiexian ji")- for the six groups of ten stories that comprise the anthology. But even these titles suggest that the stories were indiscriminately collected and were meant for casual reading.

The only exception is the "Pillow Collection," which appears to have been written by a single writer and displays "a distinct authorial personality." ${ }^{32}$ Of its seven extant stories, six are thematically arranged in pairs, their titles forming parallel couplets. ${ }^{33}$ But it is impossible to know who the author was, and it would be a mistake to identify him or her with the editor Hong Pian.

On the whole, one gets the impression that Hong Pian did not leave much personal imprint in his anthology, although the mere fact of its publication may have greatly inspired Feng Menglong. In contrast, Feng's Sanyan may represent the first self-conscious literati effort to rework folk stories and develop the vernacular story into a literary genre. Feng added the storyteller's manner, supplied the texts with marginal and interlinear commentary (see chapter 2 below), and arranged

\footnotetext{
${ }^{30}$ Hanan, The Chinese Vernacular Story, p. 56.

${ }^{31}$ Ibid. p. 57.

${ }^{32}$ Ibid.

33 This feature was later to be developed further by Feng Menglong and will be fully discussed below in chapter 3 .
} 
the stories consistently in pairs. For reasons to be discussed in chapter 1, Feng preferred to speak indirectly, staying behind his source materials and denying his own "authorship"; he thus occupies the middle position in my paradigm. ${ }^{34}$

Ling Mengchu's (1580-1644) Slapping the Table in Amazement (Pai'an jingqi) and Slapping the Table in Amazement, Second Collection (Erke Pai'an

34 The conspicuous absence of both "Langxian" and "Aina" in my schema for the evolution of the Chinese vernacular story should be addressed here since they have received substantial treatment in Patrick Hanan's The Chinese Vernacular Story. Hanan has demonstrated that twenty-two stories in Constant Words, the third Sanyan collection, were probably written by X, whom he tentatively identifies as the Master of the Ink-Wild Studio (Molang zhuren), the collator of Constant Words, and as Langxian, the compiler of The Rocks Nod Their Heads (Shi dian tou), a collection of fourteen stories for which Feng Menglong wrote a preface.

I have left Langxian out for two reasons. First, Hanan's view is still a hypothesis, though a reasonable and persuasive one in general; but even Hanan himself says that it "cannot be regarded as proven." (The Chinese Vernacular Story, p. 230 n. 5). Second, even if we agree that Langxian authored twenty-two stories and collated (jiao) Constant Words, so long as Feng Menglong can be identified as the chief editor and therefore the finalizer of the collection, we can still justify studying it as Feng Menglong "ventriloquating" through others (including Langxian) in the sense suggested by Bakhtin's dialogism or Holquist's ventriloquism.

Further, Pi-ching $\mathrm{Hsu}$ argues that Hanan ignores differences between the stories he attributes to Langxian in Constant Words and those in Shi dian tou, while overemphasizing the differences between these collections on the one hand and the first two Sanyan collections on the other. Hsu also asserts that even if Langxian did write some of the stories in Constant Words, Feng Menglong must have rewritten them to a certain degree to make them more compatible with the general ethics and aesthetics of the Sanyan. See Hsu, "Celebrating the Emotional Self: Feng Meng-lung and Late Ming Ethics and Aesthetics," Ph.D dissertation, University of Minnesota, 1994, pp. 207-14.

Finally, "Aina," the author of Idle Talk Under the Bean Arbor (Doupeng xianbua), is left out for two reasons. First, his collection was published after 1668, more than ten years after the belletricizing process reached its peak in $\mathrm{Li} \mathrm{Yu}$; and second, the new narrative framework explored in this collection was ignored by later writers in the eighteenth and nineteenth centuries. See Hu Shiying, Huaben xiaoshuo gailun (Beijing: Zhonghua shuju, 1980), p. 649, and Hanan, The Chinese Vernacular Story, p. 191. 


\section{6 / Appropriation and Representation}

jingqi ${ }^{35}$ published in 1628 and 1632, respectively, and collectively known as Liangpai or Erpai-may be rightly placed between Feng and the terminal pole "I own meaning." Unlike Feng, Ling wrote all of the nearly eighty stories himself and made no attempt to hide his authorship. One could take this as a sign that the vernacular story was a firmly established genre by the time Ling started to write, thanks to Feng Menglong's success. In the preface to his first collection of stories, Ling states that since Feng had already exhausted all the old texts, he can only take "those miscellaneous and scattered pieces of the past and present that can refresh one's views and understandings . . . and expand and elaborate them into a number of stories." ${ }^{36}$ The narrator in Ling's stories appears to have a single fairly consistent personality, and is often found "equating himself with the author, in the sort of comment we might expect to find in a preface or in the author's own editorial notes." 37

If Ling Mengchu was still dependent on pre-existing anecdotes for his stories, $\mathrm{Li} \mathrm{Yu}(1611-1680)$ insisted on the value of originality in literature. Of the stories he published in Silent Operas (Wusheng xi, 1655/56), in Silent Operas, Second Collection (Wusheng xi erji, 1656[?]) and in Twelve Towers (Shi'er lou, 1658), none is clearly based on any previous source material, ${ }^{38}$ and all distinctly bear his individual stamp. One of the most outstanding features of his stories is the replacement of the

\footnotetext{
35 The most complete extant edition of the second collection (the Shangyou tang edition) contains thirty-nine stories and one play (juan 40). Also, the twenty-third story is exactly the same as the twenty-third of the first collection. It is suggested, however, that the Shangyou tang edition may not be the first edition. See Zhang Peiheng, "Jiaodian shuoming" (Editorial explanations), in Erke Pai'an jingqi, ed. Zhang Peiheng and Wang Gulu (Shanghai: Shanghai guji, 1983), pp. 1-2.

${ }^{36}$ Ling, "Pai'an jingqi xu," Chuke Pai'an jingqi, ed. Zhang Peiheng and Wang Gulu (Shanghai: Shanghai guji, 1982), p. 1; translation from Liu Wu-chi, An Introduction to Chinese Literature (Bloomington: Indiana University Press, 1966), p. 224, with some modifications.

${ }^{37}$ Hanan, The Chinese Vernacular Story, p. 150.

${ }^{38}$ This does not mean that he did not make plays out of his own stories; see Liu Hongjun, "Li Yu xiaoshuo chuangzuo tong xiju chuangzuo de guanxi," Xinyang shifan xueyuan xuebao 1996.2:57-58; reprinted in Zhongguo gudai jindai wenxue yanjiu (Renmin daxue fuyin ziliao) 1996.7:98-99.
} 
traditional storyteller with a literati persona who often sounds "like a vernacular version of Li Yu the essayist ... sly, mocking, ingenious, self-congratulatory- and even self-contradictory." ${ }^{39}$

Li Yu's stories are comedies, and perhaps theoretically it is more appropriate to read them in light of Bakhtin's "hybrid construction." But my point here is that $\mathrm{Li}$, as a writer, seems to have subscribed to a theory very close to the personalist view:

In half a lifetime's writing, I have not filched a single word from other people. There have been times when I have been ashamed of my shallowness and times when I have invited ridicule for unsound views, but when it comes to following the beaten path, to chewing other men's spittle and claiming it as the fresh blossoms of my own tongue, not only am I confident that I am innocent, but distinguished scholars throughout the land all realize that I would never stoop so low. ${ }^{40}$

I see no contradiction between Li Yu's personalist view of language and the dialogist texts he produced. To Li, inversions of literary stereotypes and reversals of accepted situations and ideas-all stock features of his comedies- were not a matter of one voice-idea manipulating another, but simply innovative, original and new.

Li Yu's firm belief in the writer's ownership of language/meaning and in his total independence in writing fiction marks the completion of an important phase in the belletricizing process of the vernacular story, a process that increased "authorial" presence and decreased dependence on pre-existing materials, popular or elite. Although we cannot know the precise debt the vernacular story owes to folk storytelling, we can at least

\footnotetext{
${ }^{39}$ Patrick Hanan, "Introduction," in Silent Operas, ed. Patrick Hanan (Hong Kong: Chinese University of Hong Kong, 1990), p. vii.

${ }^{40} \mathrm{Li} \mathrm{Yu}$, "Fan li qi ze" (Seven general principles), in Xianqing ouji, vol. 3 of $L i Y u$ quanji (Hangzhou: Zhejiang guji, 1991), p. 3; translation from Patrick Hanan, The Invention of Li Yu (Cambridge: Harvard University Press, 1988), p. 48.
} 


\section{8 / Appropriation and Representation}

say that by Li Yu's time it had clearly been incorporated into literati culture. ${ }^{41}$

${ }^{41}$ For a detailed study of Ling Mengchu and Li Yu, see Hanan, The Chinese Vernacular Story, chapters. 7 and 8, pp. 140-90; and Hanan, The Invention of Li Yu, passim. 


\section{1 \\ The Politics of Literati Representation ${ }^{1}$}

This chapter explores Feng Menglong's motivations for promoting the vernacular short story while denying his own "authorship" in the Sanyan collections; here I also propose studying Feng's activities in light of the Chinese literati tradition of collecting folk songs. I begin with a close reading of Feng's preface to Stories Old and New, then discuss writings by the late Ming literati, Li Zhi and Yuan Hongdao (1568-1610), both of whom greatly influenced Feng. I contend that since Feng was deeply involved in the idealistic tradition of the liberal literati, his disclaimer of personal authorship was motivated mainly by a desire to "borrow" authority from traditional popular literature. Feng's position must be considered against the ultra-conservative archaist literary trend dominant in his day. Thus, his editing and publishing of the Sanyan stories can be usefully understood as a kind of political act, an expression of literati concerns to a literati audience, rather than a representation of common people's lives in a broadly popular genre. Drawing on the literati tradition of imitating and appropriating folk songs, I will also suggest several likely reasons for Feng's adopting the form of the streetside storyteller's narrative in the Sanyan. For Feng, a vernacular story should not be a direct imitation of life, but a representation of the storyteller's oral account of reality.

\section{The Preface to Stories Old and New}

Before we examine the stories themselves, let me turn to the preface of the first Sanyan collection. This preface has generally been

1 The title of this chapter was inspired by Holquist's essay. 


\section{0 / Appropriation and Representation}

credited to Feng Menglong, although it was signed with a pseudonym. ${ }^{2}$ Since authors or editors often lay out their purposes and principles in a preface or introduction, this piece may well shed light on Feng's motivations for producing the Sanyan. Since no complete English version is available, I translate it here in full:

Fiction [xiaoshuo] began to rise when the tradition of historiography showed signs of decline. It started to take shape in the Eastern Zhou period [770-256 B.C.], flourished during the Tang dynasty [A.D. 618907], further developed and became widespread in the Song dynasty [960-1279]. People such as Han Fei [ca. 280-233 B. C.] and Lie Yukou [ca. 450-375 B.C.] were its progenitors. Although the Spring and Autumn Annals of $W u$ and $Y u$ [Wu Yue chunqiu] and other works were compiled during the Han dynasties [206 B.C.-A.D. 220], yet in general few [fictional] works were produced after the book burning of the Qin dynasty [221-207 B.C.]. It was not until after the Kaiyuan reign period [A.D. 713-742] that men of letters began to take an active part in writing fiction. As to the colloquial novel [yamyi], it is not known how it originated. What is known, however, is that there were storytellers [shuobua ren] affiliated with the Bureau of Court Services of the Southern Song dynasty [A.D. 1127-1279], not unlike the marketplace storytellers [shuoshu zhi liu] of our day. Their language was simple and easy to understand but there is no way to verify the authorship of their stories.

When the Song Emperor Gaozong abdicated his throne [in A.D. 1163], he took pleasure, in the hours of relaxation which his long life of virtue had earned him, in reading stories [buaben]. He ordered his eunuchs to find him a new story every day, and if the story was to his liking, the person who provided it would be richly rewarded with cash. Hence the eunuchs were always on the look-out for strange tales of the old days and for idle talk of the countryside. Then they would commission men to elaborate this material into stories to present to the Emperor for his pleasure. But once read, the stories were discarded, so that in the end many disappeared into the recesses of the palace, and not more than one or two out of ten ever came to circulate among the

\footnotetext{
2 Hanan, The Chinese Vernacular Story, p. 216. Zhang Zhupo makes the following comments on authors' hesitancy to sign their novels with their own names: "The writers of novels never divulge their names, either because they have some ax to grind in their works or because they contain covert references to real people. ..." in "Jin Ping Mei dufa" ("How to Read the Jin Ping Mei"), section 36, trans. David T. Roy in Rolston, How to Read, p. 222; also see Hegel, The Novel in Seventeenth-Century China, p. 60.
} 
people. Yet some of them, such as "Wanjiang Tower" ["Wanjiang lou"] and "The Double-Fish Pendants" ["Shuangyu zhui"], are so shallow and vulgar that telling them soils one's teeth. ${ }^{3}$ In the Yuan dynasty [A.D. 1271-1368] both Shi Nai'an and Luo Guanzhong advocated and practiced [vernacular fiction], and works such as Romance of the Three Kingdoms [Sanguozhi], The Water Margin [Shuibu] and The Quelling of Demons [Pingyao] became the landmarks of fiction. ${ }^{4}$ In general, however, until the years of peace and prosperity, vernacular stories developed without receiving the amount of attention they deserved, much like jade hidden in rocks.

The arts have been carried to such a high stage of advancement under the aegis of our Imperial Ming, that there is no school but has flourished, and in popular literature the writing often reaches a standard far above that of the Song dynasty. Those who reject the style of such works as unfit for comparison with the writings of the Tang period are in error. People fond of peaches need not reject the apricot. Fine linen, silk gauze, plush, and brocade, each has its proper occasion. To hold that Song writing should model itself on that of the Tang is to hold that the Tang should model itself on the Han, and the Han in turn on the times of the Spring-Autumn and Warring States periods [770-221 B.C.], the logical conclusion being to confine all within the scope of a solitary brush mark by the divine Fuxi [the legendary ruler reputed to have discovered mystic diagrams on the back of a tortoise, which prompted him to invent writing]. That is an absurd proposition.

\footnotetext{
3 "Wanjiang Tower," originally included in Sixty Stories and some Ming miscellanies (see Patrick Hanan, The Chinese Short Story: Studies in Dating, Authorship, and Composition [Cambridge: Harvard University Press, 1973], p. 8), appears drastically changed in Feng's Stories Old and New. "The Story of Double-Fish Pendants" is not included in any of Feng's three collections. Of course, the works in Sixty Stories are not purely popular literature, free of literati manipulation; but here Feng Menglong seems to think that they are, or tries to convince his readers so.

4 I follow Patrick Hanan in translating the term juguan as "landmarks of fiction," although it may also mean "full length," as opposed to the short story; see The Chinese Vernacular Story, p. 22. Sanguozbi [yamyi] and Shuibu [zhuan] are two of the four fulllength vernacular novels that Andrew Plaks discusses in his Four Masterwoorks. The former has been traditionally attributed to Luo Guanzhong and the latter to Shi Nai'an, alone or together with Luo. Scholars generally believe that it was Feng Menglong himself who rewrote Pingyao [zhuan], by making many significant changes. The earliest extant editions are in twenty chapters and are attributed to Luo Guanzhong, but Feng brought out an expanded forty chapter version. For a dissenting opinion, see Ouyang Jian, "San sui pingyao zhuan yuanben kaobian," Zhonghua wenshi luncong 3 (1985): 149-65.
} 
In general terms, Tang writers fashioned their phrases to appeal to the literary mind; Song writers used the colloquial to accord with the common ear. Now, literary minds of this world are few, but common ears many; and fiction lends itself more to the popularizer than to the stylist. Just ask the storytellers to improvise on the spot: they will gladden you, startle you, make you weep for sorrow, make you dance and sing; they will prompt you to draw your sword, or make you want to bow in reverence, or break someone's neck, or donate money. The coward will be made brave, the profligate pure, the miser generous, the callous ashamed. Although a man may read aloud the Classic of Filial Piety and the Analects of Confucius every day, he will not be moved so swiftly nor so profoundly as by these storytellers. Can such results be achieved by anything but popular colloquial writing? The Unofficial Historiographer of Maoyuan [Maoyuan yeshishi] has amassed a huge collection of stories old and new. Upon the request of a merchant, he selected for publication a collection of forty stories which may appeal to the common ear. I was so delighted to see it that I picked up a pen and wrote this preface.

Inscribed by

Master of the Green Sky Studio

[Lütian guan zhuren $]^{5}$

\section{The Problem of the Intended Audience}

Feng Menglong's defense of the vernacular story in this preface sets out "for the first and virtually the only time" in premodern writing on Chinese fiction, the "terms of a fascinating topic," 6 i.e., the comparison of the vernacular story with the classical tale. In his loose, pseudo-historical account, Feng stresses the different origins of these two fictional genres: one derives from the active literary participation of the literati in the eighth century, the other grows out of the popular storytelling practice of the twelfth century. Logically, therefore, one

\footnotetext{
5 The translations of the first half of paragraphs two and three, and all but the final sentences of paragraph four are based on Cyril Birch's introduction to Stories from a Ming Collection: The Art of the Chinese Story-teller (New York: Grove Weidenfeld, 1958), pp. 7-8 and 11. One correction is made. See also Liu Wu-chi, An Introduction to Chinese Literature, p. 216, n. 3.

${ }^{6}$ See Patrick Hanan, The Chinese Vernacular Story, p. 24.
} 
appeals to the "literary mind," and the other to the "common ear." But since literary minds are far outnumbered by common ears, and the vernacular story has a greater impact on its audience, he argues for the need to champion a literary genre that would be more effective for the majority.

But to whom was Feng Menglong addressing his preface- the "literary minds" or the "common ears"? While the forty stories are indeed written in a more colloquial language that "common ears" presumably would have understood, the preface itself is written-as prefaces to vernacular fiction always are-in classical Chinese, the language of the tales enjoyed exclusively by "literary minds." To say that Feng is merely following convention hardly explains away the contradiction. The convention of writing a preface in classical language expressly excludes the "common ears" from the preface at least, if not also from the stories accompanied by the preface. Feng's advocacy of vernacular fiction, therefore, was a discourse that circulated strictly among the literati. The "I" in the last few lines of the preface- who as one of the first readers of the collection is delighted at the stories-is obviously not "a common ear." Nor was the Song emperor, the earliest recorded devotee of the vernacular story, according to Feng's history of the genre. Further, anyone who "reads aloud the Classic of Filial Piety and the Analects of Confucius every day" cannot rightly be regarded as a commoner either. The comparison of belles-lettres to the peach and colloquial fiction to the apricot also points to the intended audience of the collections: the apricot is a good alternative for the eater of peaches. In other words, the person with a literary mind may also have a common ear, which may demand literary satisfaction of a different type.

This reading of Feng's preface contradicts the traditional notion that the Sanyan stories were published for common people in the cities. While no one can completely deny Feng's egalitarian ideal, we should remember that Feng, as a member of the literati class, had his elite standards, which inevitably limited the size of his audience. The promotion of his literary views in the classical language is only one example. Another example involves the quality of workmanship in the production of his short story collections. Patrick Hanan points out that "all of the editions Feng prepared were handsomely produced 


\section{4 / Appropriation and Representation}

with fine illustrations, copious notes, and elaborate punctuation."7 Ota Tatsuo's conclusion that lavishly produced works of fiction like Feng's could only be purchased by the highest classes is confirmed by existing information about late Ming book prices. For example, a copy of The Investiture of the Gods (Fengshen yanyi), a novel of one hundred chapters, bore the price tag of two liang (roughly two ounces) of fine silver, while a 125 juan encyclopedia sold for one ounce. ${ }^{8}$ Robert E. Hegel has described elsewhere the types of publishing houses active during the late Ming period, which included official (government-supported), commercial, private (run by collectors and scholars), and academic publishers. Although the commercial book dealers were the more prolific in the number of titles and their volume of production, scholarly collector-printers who catered to the refined tastes of their class produced the finest books. ${ }^{9}$

It seems clear then, that Feng Menglong's major concern in the preface is to promote the vernacular story among the literati as a worthy alternative to traditional literary forms. His assertion that this genre may reach a much larger audience through the accessibility of its simple language sounds like a rhetorical strategy employed to convince his literati readers, and perhaps even himself, of its worth. ${ }^{10}$ Further, by blurring the distinction between written literature and oral storytelling, by using the term "common ears" instead of "common eyes," and by describing the effect of a storyteller's oral performance on his audience rather than that of a vernacular text on a reader, Feng creates the

\footnotetext{
7 See Hanan, The Chinese Vernacular Story, p. 99.

8 W. L. Idema, "Storytelling and the Short Story in China," T'oung Pao 59 (1973): 32.

${ }^{9}$ Hegel, The Novel in Seventeenth-Century China, p. 11. For a more detailed account of book production in Chinese, see He Guli (Robert E. Hegel), "Zhanghui xiaoshuo fazhan zhong sheji dao de jingji jishu yinsu," Hanxue yanjiu 6.1 (1988): 191-97. On the audiences for different types of vernacular fiction, see his "Distinguishing Levels of Audiences for Ming-Ch'ing Vernacular Literature," in Johnson et al., Popular Culture in Late Imperial China, pp. 112-42.

10 This idea that the vernacular was more accessible and could reach a larger audience had been around for at least two hundred years before Feng Menglong used it to justify his stories. See the opening scene of Qiu Jun's (1420-1495) Wu lun quan bei (The five relationships complete and perfected), rpt. in Quan Ming chuanqi (Taipei: Tianyi, 1983), 14.1a-2b.
} 
impression that these written texts are just as accessible and have the same affective power as their oral versions. In truth, most people in the late Ming were not able to read, either in the classical or vernacular language, although literacy had increased greatly.

Feng's duplicity regarding the intended audience also appears in the stories. For example, "Loach Fan's Double Mirror" (TY 12) contains a couplet that shows his awareness of the importance of writing for a broad public: "A story must cater to the general public if it is to circulate afar. / Speech must deal with moral principle if it is to move men's hearts." 11 On the other hand, however, a marginal comment in "Fifteen Strings of Cash and the Jest That Leads to Disaster" (HY 33) addresses rather exclusively future office-holders like himself: "This should be your motto when [you] hold office" (zwo guan shi zhi zwo you ming)." 12

While recognizing the duplicity in Feng's preface, we can better appreciate Sanyan's historical significance if we examine his advocacy of vernacular fiction in relation to the earlier literary discourses of his predecessors. In the late Ming cultural environment, Feng's very act of publishing vernacular stories can be regarded as both an argument against prevailing conservative literary doctrines and a challenge to the domination of the cultural scene by the extreme archaism of the "orthodox masters." The so-called Former Seven Masters (qian qi zi) and Latter Seven Masters (bou qi zi), of whom the most well-known were Li Mengyang (1472-1527), He Jingming (1483-1521), Li Panlong (1514-1570) and Wang Shizhen (1526-1590), represented an almost one-hundred-year-long literary movement called "the restoration of the past" $(f u g u)$. They held that to create outstanding prose in the present age one should emulate only the styles of the Western Han masters (206 B.C.-A.D. 24), and for poetry, only masters of the High Tang such as $\mathrm{Li}$ Bai and $\mathrm{Du} \mathrm{Fu}$ will do (wen bi Xi Han, shi bi sheng Tang). ${ }^{13}$ Towards the end of the sixteenth century, when Feng was

\footnotetext{
11 Jingshi tongyan, ed. Yan Dunyi (Beijing: Renmin wenxue, 1987), 1:166, translation from Hanan, The Chinese Vernacular Story, p. 119.

${ }^{12}$ Emphasis mine. Xingshi hengyan, ed. Li Tianyi (Taipei: Shijie shuju, 1959), 33.17a.

13 "Wang Shizhen" (Biography of Wang Shizhen), in "Wenyuan san" (The literary arena, Section 3), in Ming shi (Ming history), compiled by Zhang Tingyu et al. (Beijing:
} 


\section{6 / Appropriation and Representation}

nearly twenty and about to acquire his shengyuan degree, the most influential figure in Chinese literature was the erudite archaist leader Wang Shizhen, who dominated the literary arena for twenty years with much critical acclaim and numerous enthusiastic followers. ${ }^{14}$

This archaist trend in literature proved intolerable to certain of the more liberal-minded literati, such as Li Zhi, Yuan Hongdao and his two brothers, as well as to Feng Menglong. The philosophical foundation of their anti-archaist literary theories and practices was the notion of "innate knowledge" (liangzhi) advocated by Wang Yangming (1472-1529), the acknowledged leader of the School of the Mind. Based on Mencius' doctrine of the goodness of human nature, Wang's "innate knowledge" laid emphasis upon the individual mind as opposed to the external forms of social rules: knowledge of the good is inborn in the mind of the individual and one should follow it spontaneously wherever it leads. Naturally, once this philosophical theory was applied to literature, spontaneity came to be highly valued. As a reaction against the influence of the archaists' superficial imitation of the past masters of prose and poetry, the liberal literati exhibited an unprecedented enthusiasm for folk literature because it could, in light of Wang Yangming's theory, be considered "the most natural, the most spontaneous, emotional expression of the ordinary

Zhonghua shuju, 1974), 287.7381. The phrase also appears in Li Mengyang's biography, Ming shi, 286.7348.

14 See "Wang Shizhen," in Ming shi, 287.7381. For a detailed study of these archaist masters' literary theories, see Richard John Lynn, "Orthodoxy and Enlightenment: Wang Shih-chen's Theory of Poetry and Its Antecedents," in The Unfolding of NeoConfucianism, ed. Wm. Theodore de Bary et al. (New York: Columbia University Press, 1970), pp. 217-66. See also Liao Kebin, Mingdai wenxue fugu yundong yanjiu (Shanghai: Shanghai guji, 1994). Ironically, Wang Shizhen is still commonly believed to have written the Jin Ping Mei as an act of revenge against a personal enemy identified either as Yan Shifan (1513-1565) or Tang Shunzhi (1507-1560) in varying accounts. This idea was strongly challenged by Wu Han more than sixty years ago ("Jin Ping Mei de zhuzuo shidai ji qi shehui beijing" [1933]; rpt. in Dushi zhaji [Beijing: Sanlian 1956], pp. 1-38). For a recent re-evaluation, see Zhou Juntao, "Lun Wu Han xiansheng Jin Ping Mei yanjiu de shiwu: Jin Ping Mei zuozhe Wang Shizhen shuo bei fouding le ma?" in his Jin Ping Mei tanmi yu yishu shangxi (Changchun: Jilin wenshi, 1990), pp. 1329. 
people." 15 The idea of what is good literature and what is not according to such a notion was most clearly expressed by Li Zhi in his famous essay "On the Childlike Mind":

The childlike mind is the true mind, the original mind. If it is lost, the true mind is lost and the true person is lost. ... Once people's minds have been given over to received opinions and moral principles, what they have to say is all about these things, and not what would naturally come from their childlike minds. No matter how clever the words, what have they to do with oneself? What else can there be but phony men speaking phony words, doing phony things, writing phony writings? Once the men become phonies, everything becomes phony.... And the phonies have destroyed so much good literature in the world! . . The best literature always comes from the childlike mind. ${ }^{16}$

$\mathrm{Li}$ Zhi is arguing for a more spontaneous literature, a literature of sincerity and genuine feelings. What is true is defined as true to one's own inner self and what is false as blindly following received ideas and conventional literary models. For Li Zhi, it is this distinction between true and false that is the most important criterion for good literature and good literary men. ${ }^{17}$

Among the literati writers who made great contributions to enhancing the liberal cultural atmosphere of the late Ming, the most

15 See Hua-yuan Li Mowry, Chinese Love Stories from "Ching-shib" (Hamden, Connecticut: Archon Books, 1983), p. 2.

16 Translation from Wm. Theodore de Bary, "Individualism and Humanitarianism in Late Ming Thought," in Self and Society in Ming Thought, ed. Wm. Theodore de Bary (New York: Columbia University Press, 1970), p. 195, with some modification. For Li Zhi's influence on Feng Menglong, see Wang Ling, Jiren, qingzhong qipinguan (Fuzhou: Haixia wenyi, 1992), pp. 59-72.

17 It is clear that Li Zhi's essay was aimed at the archaist masters and their followers. But in his other writings ("You yu Jiao Ruohou" [Again to Jiao Ruohou], "Fen shu" [Book for burning], juan 2 of $L i$ shi fen shu, Xu fen shu [Kyoto: Chinese Language Press, 1971], p. 55.) he also called into question the motives of another type of literary men, the so-called "mountain men" (shanren), who lived, or pretended to live, as independent artists and poets. He regarded them as equally "phony" because "their hearts are those of merchants'." Translation by de Bary, p. 205. On "mountain men," see James Cahill, The Compelling Image: Nature and Style in Seventeenth-Century Chinese Painting (Cambridge: Harvard University Press, 1979), p. 137 and Chen Wanyi, WanMing xiaopin yu Mingii wenren shenghuo (Taipei: Da'an, 1988), pp. 42-64. 
noteworthy were Yuan Hongdao and his two brothers, Yuan Zongdao (1560-1600) and Yuan Zhongdao (1570-1623). Echoing Li Zhi's theory of the "childlike mind," the Yuan brothers advocated a literary theory of spontaneity and launched a conscious literary movement against orthodox archaism. They believed that the most essential ingredient of literature is "emotional genuineness, or sincerity."18 Yuan Hongdao, the most famous of the three brothers, placed special emphasis upon emotion and one's personal nature (xingling), as is clear in this passage from his preface to the collected poems of his younger brother, Yuan Zhongdao:

Most of his [prose and poetry] uniquely express his personal nature and are not restricted by conventions. Unless they come from his heart, he will not write them down. Sometimes, when his emotion encounters the right environment, he can write a thousand words in a moment, like water pouring eastward [into the sea]. ${ }^{19}$

In the same preface, Yuan Hongdao remarks that the contemporary literary works most likely to be passed down to posterity were folk songs, because they were composed by ordinary people whose "original true minds" had not been given over to received opinions or constrained by conventional literary models:

These are still the works of true people [zhenren], who are not knowledgeable or erudite; hence they are full of true voices [zhensheng]. Neither affecting the manners of the Han and Wei, nor following in the footsteps of the High Tang, their words reflect the free bent of their nature, and express their joy, anger, sadness, pleasure, appetites, and desires. $^{20}$

18 Mowry, Chinese Love Stories, p. 3.

19 "Xu Xiaoxiu shi” (Preface to Yuan Zhongdao's poems) in Zhongguo lidai wenlun xuan, Guo Shaoyu, comp., 4 vols. (Shanghai: Shanghai guji, 1979), 3:211. Translation by James J. Y. Liu, Chinese Theories of Literature (Chicago: University of Chicago Press, 1975), p. 80. The term xingling is translated as "naturalness and sensitiveness" by Mowry (p. 3) and as "innate sensibility" by Chih-p'ing Chou in his Yüan Hung-tao and the Kung-an School (Cambridge: Cambridge University Press, 1988), p. 11.

20 Guo, Zhonggno lidai wenlun xuan, 3:211. Translation by James Liu, Chinese Theories of Literature, pp. 80-81, with slight modifications. 
It can be argued whether Yuan's advocacy of popular literature was mainly aimed at discrediting the archaist masters, or whether it was just the desire of a connoisseur for novelty. But his literary theory certainly had a great impact on the liberal literati, with its emphasis on spontaneity and on being true to one's own feelings, as opposed to the restrictions of convention. ${ }^{21}$

Unlike his senior contemporary Yuan Hongdao, who argued directly against orthodox archaism in his essays, Feng Menglong's reaction to archaism was primarily manifested in his passion for publishing works of such underrated genres as folk songs and vernacular fiction. To a certain extent, his anti-archaist literary ideas were also expressed in the prefaces he wrote for these works. In his "Preface to Rules of Dramatic Prosody" ("Qulü xu"), he deplores the bad influence of the archaists' superficial imitation of the past masters of prose and poetry, "the most abused literary genres today are classical poetry and prose (jindai zhi zuilanzhe, shi wen shi yi)." 22 In his preface to Shange (Folk songs), he emphasizes the value of "authenticity of feeling" (qingzhen) and makes it clear that his preference for folk songs is a reaction against the false feeling in imitative works of the canonized genres: "Although in our era of decline there is an abundance of false poetry and prose, there are no false folk songs (qie jin sui jishi, er dan you jia shizeen, wen jia shange)." ${ }_{23}$ This statement also implies an evolution of genres, the inevitable succession of one after another. This notion is also suggested in Yuan Hongdao's remarks above regarding what was best in contemporary work. If poetry had had its day in the Tang dynasty and prose in the Qin and Han dynasties, the Ming was the time when other new genres could flourish. Since classical poetry and prose were on the decline, it was time to promote the folk song and other genres that captured "authentic feelings."

\footnotetext{
21 On Yuan Hongdao's literary theory and practice, see Jonathan Chaves, Pilgrim of the Clouds: Poems and Essays by Yüan Hung-tao and His Brothers (New York: Weatherhill, 1978), pp. 11-25 and Chih-p'ing Chou, Yüan Hung-tao and the Kung-an School.

22 "Qulü xu," in Guo, Zhonggno lidai wenlun xuan 3:194.

23 "Xu Shange," in Guo, Zhongguo lidai wenlun xuan 3:231.
} 


\section{0 / Appropriation and Representation}

It may also be helpful to consider the promotion of folk songs and vernacular fiction against the cultural domination of the archaist masters in terms of Harold Bloom's "anxiety of influence." ${ }^{24}$ The tension between these literary and cultural movements of the late Ming was certainly tremendous, one orthodox and dominant, the other new and rebellious. ${ }^{25}$ As early as 1949, the Chinese critic Qian Zhongshu observed that emerging literary movements tend to emphasize the newness of their approach and their difference from those dominant currently or in the immediate past, while also claiming derivation from traditions in the distant past to establish their legitimacy. ${ }^{26}$ In Feng's case, he defied the domination of archaism by claiming authority from literature of popular origin while also "borrowing authority" (jieguang) from other sources, such as the tradition of historiography, for vernacular fiction.

Returning to the preface of Stories Old and Nere, one easily notices the conspicuous absence of references to what the archaists most honored, poetry and classical prose. Also conspicuous are the rhetorical means Feng employs to elevate the vernacular story. The grand tradition of historiography is described as the origin of all fiction. The vernacular story is not only placed on a par with the classical Tang tale, but is also given greater educational and moral power than even the Classic of Filial Piety and the Analects of Confucius.

Even Feng's pseudonym "Lütian guan zhuren"- a penname very close to that of the prominent Shanghai scholar-official, Ye Yousheng-may represent part of Feng's strategy to enhance the social status of his vernacular stories through "indirect borrowing." By calling his library Green Sky Studio, a name that virtually any scholar might choose for his study, Feng avoided possible charges of filching

\footnotetext{
24 See Harold Bloom, The Anxiety of Influence: A Theory of Poetry (New York: Oxford University Press, 1973). For brief discussions of Bloom's ideas on the anxiety of influence, see Emer Borklunk, Contemporary Literary Critics (Detroit: Gale Research Company, 1982), pp. 74-80 and The Yale Critics: Deconstruction in America, ed. Jonathan Arac et al. (Minneapolis: University of Minnesota Press, 1983), pp. 119-126.

${ }^{25}$ See Guo Shaoyu, Zhongguo wenxue piping shi (Shanghai: Shanghai guji, 1979), p. 416. ${ }^{26}$ Qian, "Zhongguo shi yu Zhongguo hua," in Qian Zhongshu lunxue wenxuan, ed. Shu Zhan (Guangzhou: Huacheng, 1990), 6:2-3.
} 
famous studio names to promote his book sales. Still, because his pseudonym may also have been associated with Ye Yousheng, this association would have lent a certain panache to Feng's book and entire project. Indeed, Yang Xiaodong has gone so far as to suggest that Ye might really be the author of the Stories Old and New preface. ${ }^{27}$ However, although she shows that Ye's father owned a house called Green Sky Studio and Ye himself published a book entitled Green Sky Studio Collection (Lütian guan wenji, no date) she does not produce evidence that Feng and Ye knew each other. ${ }^{28}$

One may notice in the preface a tension between Feng's egalitarian impulse in promoting what he thought of as folk literature and his elite standards. Not all vernacular stories were aesthetically acceptable: "Wanjiang Tower" and "Double-Fish Pendants" would "soil one's teeth." Even works such as Romance of the Three Kingdoms and The Water Margin needed to be refined by Luo Guanzhong and Shi Nai'an before they could become "great landmarks of fiction." The implication seems clear: talented scholars were needed to shape the final version of quality vernacular fiction. The image of "jade concealed in rock" in the preface thus perfectly represents Feng's attitude toward folk literature. Although vernacular literature represented the pure and natural expression of the "folk" - a quality admirable enough to argue for its promotion in lieu of the "inauthentic feeling" of classical works-Feng's concealed jade image also implies the need for an artist's effort to transform folk materials into sophisticated works of art. This, then, leads to the question of authorship.

\footnotetext{
27 See Yang's “Gujin xiaoshuo xu zuozhe kaobian," Wenxue yichan 1991.2:102-7.

28 Yang reports that $\mathrm{Ye}$ came in first at the juren level of the civil service examinations in Yingtian (Nanjing) in 1615, became a jinshi and went to Minhou (near Fuzhou), Fujian province to assume his official post in 1616, about four years before Stories Old and New was published. Ye stayed in his post until 1625 when he was promoted and transferred to Beijing. Even if he had known Feng well, as a busy official far from where the book was published, Ye Yousheng would have had little opportunity to write the preface, and much internal evidence shows that the preface was Feng's own writing. See Hu Wanchuan, "Sanyan xu ji meipi de zuozhe wenti," rpt. in his Huaben yu caizi jiaren xiaoshuo zbi yanjiu (Taipei: Da’an, 1994), pp. 123-38.
} 


\section{Authorship of the Sanyan Collections}

Feng Menglong claims in his preface that the forty vernacular short stories in Stories Old and New are selected from the library of a private collector, the Unofficial Historiographer of Maoyuan, which is, most scholars agree, one of Feng's own pseudonyms. While Feng never draws a clear distinction between oral and written vernacular stories, he does make it clear that they all derive from storytellers, both ancient and modern, and therefore, "there is no way to verify the authorship of the stories" (qi zuozbe mo ke kao). Feng seems to want his readers to believe that as a publisher or editor, he has done nothing more than collect these stories and make them available to the public.

But collecting and publishing were certainly not his only concern. Fifteen years after he had published the last collection of the Sanyan stories, he admitted that he was the actual "begetter" of one story. ${ }^{29}$ In fact, scholars generally agree that Feng Menglong made extensive modifications to most of the stories he collected, and incorporated many of his own stories and some from his friends in the Sanyan collections..$^{30}$ According to Patrick Hanan, who applies rigorous stylistic criteria in his studies on the dating and authorship of Chinese vernacular stories, Feng is the probable author of nineteen stories in the first collection, sixteen in the second, and one or two in the third.31 As to the stories he rewrote or modified extensively, most of them derive not from popular literature sources, but rather from materials written in classical Chinese.

\footnotetext{
${ }^{29}$ See his 1642 preface to Bi Wei's play San bao'en, which is an adaption of the story in question, "The Old Protégé Pays His Debts of Gratitude" (TY 18), in Feng Menglong quanji, ed. Wei Tongxian (Shanghai: Shanghai guji, 1993), 19:2852.

30 Y. W. Ma, "Feng Meng-lung" in The Indiana Companion to Traditional Chinese Literature, ed. William H. Nienhauser et al. (Bloomington: Indiana University Press, 1986), p. 381.

31 Patrick Hanan, The Chinese Vernacular Story, p. 104; and The Chinese Short Story, pp. 76-86. The stories Hanan identifies as attributable to Feng Menglong are GJ 1, GJ 2, GJ 5, GJ 6, GJ 8, GJ 9, GJ 10, GJ 12, GJ 13, GJ 14, GJ 17, GJ 18, GJ 21, GJ 22, GJ 27, GJ 31, GJ 32, GJ 39, GJ 40, TY 3, TY 4, TY 5, TY 11, TY 12, TY 15, TY 17, TY 18, $T Y 22, T Y 23, T Y 25, T Y 26, T Y 31, T Y 32, T Y 34, H Y 2$ and $H Y 19$.
} 
The question here, then, is not how to examine the Sanyan stories in their original popular form, but rather, how to understand Feng's motivations for making his disclaimer.

Feng's "writing himself off" as merely publishing vernacular stories appears strikingly similar to Mikhail Bakhtin's strategy of "plagiarism in reverse." According to Michael Holquist, three of Bakhtin's books published in the Soviet Union in the 1920's, including the now well-known Marxism and the Philosophy of Language, were published under the names of three other men-Volosinov, Medvedev and Kanaev-figures associated with either Marxism or the Communist Party. It would have been impossible for Bakhtin himself, known within the tight circle of the Leningrad intelligentsia as a devout Orthodox Christian, to publish anything. ${ }^{32}$ But Bakhtin, the real author, successfully conveys his own message by presenting his forbidden Christian ideas in the Marxist idiom of the day, using, for example, Volosinov's "Marxist voice to ventriloquate a meaning not specific to Marxism." "33 For Bakhtin, Marxist terms, and his various Marxist masks, were "a kind of convenient ... but above all, necessary ... flag under which to advance his own views." ${ }^{34}$

If for Bakhtin this indirect way of representing himself and his thought was a means to deceive the censors, for Feng Menglong it was as much an aesthetic exercise as a political act, as we will see below when we explore just how Feng "ventriloquated" in the Sanyan stories. Assuming the mask of folk literature- with its vitality and egalitarian aura-might indeed have been an effective strategy for dethroning the slavishly imitative classical poetry and prose of the late Ming. But there was also great aesthetic pleasure in speaking from behind a mask while experimenting with a relatively new genre- the vernacular story. For Feng Menglong, editing the Sanyan meant assimilating this folk literature in the way folk songs had been assimilated by the literati for

\footnotetext{
32 Holquist, "The Politics of Representation," pp. 170, 173.

33 Ibid., p. 174.

34 Ibid., p. 173. His theory about the authorship of these books has been challenged; see Gary Saul Morson and Caryl Emerson, Mikhail Bakbtin: Creation of a Prosaics (Stanford: Stanford University Press, 1990), pp. 101-19.
} 


\section{4 / Appropriation and Representation}

centuries. In other words, we may understand Feng's disclaimer better if we view it in light of the traditional literati attitudes toward folk songs.

\section{The Myth of Folk Songs as Political Capital}

The History of the Former Han Dymasty (Hanshu) by Ban Gu (A.D. 32-92), a work commonly read by literati of Feng Menglong's time, records the establishment of a government office called the Music Bureau (Yuefu) by Emperor Wu of the Han dynasty around 120 B.C.35 One of the duties of this institution was to collect folk songs or ballads-also called yuefu-from various parts of the country:

Since the Music Bureau was established by Emperor Wu to collect folk songs, many of them from the areas of Zhao, Dai, Qin and Chu have been preserved. The songs were all inspired by sorrows and joys, and spurred by events of the day; therefore, they can be used to observe the [common people's] customs and to learn [their] praises and criticisms [of the government]. ${ }^{36}$

The mention of the names of four areas is obviously a metaphor, meaning "everywhere in the empire." ${ }^{37}$ Although Emperor Wu's motivation for sending officials to collect folk songs is not explained, the idea that folk songs represent the people's voice is made very clear. In fact, literati ardently promoted this view of folk songs in many preHan and Han texts. These scholars advised the ruler to listen to the collected songs as a means of keeping in touch with the sentiments of

\footnotetext{
35 "Yiwen zhi" (Monograph on literature), Hanshu (Beijing: Zhonghua shuju, 1962), 30:1756.

36 Ban $\mathrm{Gu}$ states that this institution was established by Emperor Wu, but other historical evidence indicates that it was set up much earlier. However, scholars now generally agree that "Emperor Wu was instrumental in expanding the scope of the Music Bureau, if not responsible for its inception." Joseph R. Allen, In the Voice of Others: Chinese Music Bureau Poetry (Ann Arbor: Center for Chinese Studies, University of Michigan, 1992), p. 38.

37 See Yao Daye, Han Yuefu xiaolun (Tianjin: Baihua wenyi, 1984), p. 1.
} 
the ruled, even those in remote provinces. ${ }^{38}$ "Thus the king, without going to the window or leaving the door, knows fully the sufferings in his realm." ${ }^{39}$ Ban Gu's assertion that folk songs "can be used to observe the [common people's] customs and to learn [their] praises and criticisms" actually owes its origin to Confucius's remark that the Book of Songs (Shijing), China's earliest collection of songs and hymns, "can be used to observe (guan)." 40

Whether this view was based on historical fact is open to question, but as Anne Birrell notes, it soon "became a potent political myth, for it promised that public opinion might be divined." 41 Liu Xiang (77-6 B.C.), a Confucian scholar, went even farther, developing a theory of "poetic omens" (sbiyao) in which folk songs are endowed with predictive power. James J. Y. Liu explains:

According to this theory, when the ruler is tyrannical and the subjects are too frightened to air their grievances, then popular songs and ballads will appear to portend evil, and these are called "poetic omens." The belief in omens was of course not confined to China . . . but it seems a peculiarly Chinese belief that omens ... can take the form of anonymous folk songs (as distinct from divine oracles), and Chinese historical works are full of examples of "poetic omens" that augured ill and reflected the abnormality of the times. ${ }^{42}$

In fact, folk songs, particularly ditties sung by children, were generally believed to predict good luck and bad. The good luck of one politician or political group might be the bad luck of another; it all depended on how the songs were interpreted. Whether Liu Xiang's theory was proposed to protect the best interests of the court or to check the

38 For a brief discussion of such passages in Guoyu (Conversations of the states), Liji (Book of rites), Shiji (Records of the Grand Historian) and Hanshu, see Jean-Pierre Diény, Aux origines de la poésie classique en Chine (Leiden: E. J. Brill, 1968), pp. 5-8.

39 See The Gongyang Commentary Annotated by He Xiu (Chunqiu Gongyang zhuan He shi jiegu), in Sibu beiyao, 16.11a, commentary, 15th year of Duke Xuan: Gu wangzhe bu chu youbu, jin zhi tianxia ku, bu xia tang er zhi sifang. Translation by Anne Birrell, Popular Songs and Ballads of Han China (London: Unwin Hyman, 1988), p. 15.

${ }^{40}$ Analects (Luryu), 17.8. Translation by James J. Y. Liu, Chinese Theories of Literature, p. 65.

41 Birrell, Popular Songs and Ballads, p. 15.

42 Liu, Chinese Theories of Literature, p. 65. 


\section{6 / Appropriation and Representation}

ruler's political power on behalf of the literati is difficult to say; nonetheless, it was later appropriated by Ban $\mathrm{Gu}$ in his interpretation of dynastic events. In History of the Former Han, he explains that the phenomenon of prophetic songs dates from the Zhou period and works on the principle that "an arcane pronouncement will 'come true' and reveal its mystery long after its first utterance." $\$ 3$

Although it is difficult to discern exactly how representative and influential Ban Gu's account of folk songs was, we do know that over the next few hundred years literati continued to show great interest in them. ${ }^{44}$ Some poets were so enthusiastic about emulating folk songs that in the major yuefu anthology compiled by Guo Maoqian (fl. twelfth century) literati imitations far outnumber folk poems. ${ }^{45}$ Other poets, such as the famous Bai Juyi of the Tang (772-846), used the term xin ynefu (new ynefu) for their poems of social criticism. And of course, imitation folk songs were put to politically shrewd and utilitarian uses throughout Chinese history. In fact, making one's own poems pass for folk songs became a common way of criticizing the court and bad officials, or of setting up other political maneuvers. In other words, folk songs, in fact and in name, were almost always subject to appropriation, alteration and manipulation in the process of their assimilation by the literati. This was possible in spite of-or rather because of-their relatively respectable, sometimes even sanctified, position in official ideological discourses.

Let me cite an example to demonstrate the extent to which literati and other elites could use the reputation of folk songs for their own ends. Comprehensize Records of Affairs Within and Outside the Court (Chaoye qianzai) relates that before starting a coup d'état against the empress

\footnotetext{
43 "Wuxing zhi" (Records of the five phases), Hanshu 27.1379-96; see also Birrell, Popular Songs and Ballads, p. 101.

44 This penchant for collecting folk songs has extended well into this century. Gu Jiegang describes his excitement at working on his first anthology of folk songs collected from the Wu area. See his 1935 preface to Feng Menglong's Shange in Minsu congshu, ed. Lou Zikuang (Taipei: Dongfang wenhua, 1970), 2:1.

45 So much so that Joseph R. Allen argues that without literati imitation, "early 'folk' poems would have been simply absorbed into the broader category of shi poetry." See In The Voice of Others, p. 58.
} 
Wu Zetian (624-705), the Tang general Xu Jingye (?-684) sought advice from the famous poet Luo Binwang (640?-?) on the possibility of enlisting military support from the prime minister, Pei Yan (?-684). Luo Binwang wrote an imitation children's song, which was secretly taught to children throughout the capital:

One fire, two fires,

Yi pian buo, liang pian buo,

Boy in red garments sits in the Hall. Feiyi xiao'er dang dian zuo.

The two "fires" refer to Pei Yan's given name, which consists of two "fire" symbols. "Red" and "garment" are homophones for the two parts that form the character of Pei's family name. "In the [imperial] Hall" alludes to the emperor's seat. To an attuned ear therefore, the message is quite clear: Pei Yan will become emperor. Children began to sing the song everywhere, and when Pei Yan heard it, he agreed to join forces with $\mathrm{Xu}$ Jingye.46

That Feng Menglong's handling of vernacular short stories can be better understood in light of the literati tradition of collecting and appropriating folk songs is supported by the fact that Feng himself published a folk song collection Songs to the Tune 'Guazhir' (Guazhir), ${ }^{47}$ followed by a second, Folk Songs (Shange, literally "Mountain Songs"), shortly before the publication of the first collection of Sanyan stories. ${ }^{48}$

46 See Chen Dingru and Lai Zhenghai, Gudai mimyao zhuxi (Nanchang: Jiangxi renmin, 1985), p. 101. On the use of portents, see Wolfram Eberhard, "The Political Function of Astronomy and Astronomers in Han China," in Chinese Thought and Institutions, ed. John K. Fairbank (Chicago: University of Chicago Press, 1957), pp. 33-70. Eberhard concludes: "The question whether the educated elite of the Han believed in portents or not is hard to decide. The fact that some portents were fabricated, that others were used in factional struggles to prove the arguments of one or the other side, makes us inclined to assume that at least some persons did not believe in portents at all" (p. 69).

47 For a discussion of the date of its publication, see Hanan, The Chinese Vernacular Story, pp. 88 and 224-25 n. 57 and Mowry, Chinese Love Stories, pp. 30-31.

48 The date of its publication is uncertain, but clearly later than Guazbir. For a complete translation of the Shange preface, see Kathryn Lowry, "Excess and Restraint: Feng Menglong's Prefaces on Current Popular Songs," Papers on Chinese History (The Fairbank Center for East Asian Research, Harvard University), 2 (Spring 1993): 107. 
Both are carefully edited and their selections are interspersed with literati imitations, including Feng's own. ${ }^{49}$ It is important to note that in the minds of Ming literati, contemporary folk songs were very much in the tradition of those in the Book of Songs and in the yuefu anthologies. Songs to the Tune 'Guazhir' was later included in a larger anthology entitled $A$ Selection of Today's Yuefu (Jin yuefu xuan) ) $^{50}$ and in the preface to Folk Songs Feng Menglong clearly draws an analogy between the Book of Songs and the folk songs he himself collected. ${ }^{51}$

The problem of authorship in Feng Menglong's collections of folk songs is just as complicated as that in the Sanyan. Guan Dedong argues that since Feng Menglong clearly points out for the reader the twelve imitation songs in the first collection in his commentary and annotation, he must have had strict editorial principles in mind as he distinguished literati imitations from genuine folk songs. ${ }^{52}$ The problem with Guan's theory is that an admission of authorship for a few songs does not necessarily mean that the rest were immune from manipulation, especially if we take into consideration the literati's traditional license with them. Gu Jiegang suggests that Feng had a much greater role in these collections. Comparing two of the Guazhir songs supposedly collected from the Northern dialect area with two works from Folk Songs supposedly from the Wu dialect area, he shows that save for their being rendered in those respective dialects, each pair features the same themes, the same imagery, and a similar presentation. The possibility that the editor actually created the two pieces in Folk Songs by transforming the two in Guazhir is too great to be ignored.53 Andrew Plaks even argues that Feng's Folk Songs "should be read as literati exercises in the imitation of popular song" and "where a preface to Feng's collection speaks of the 'pure and true' (qingzhen) quality of his 'mountain songs,' we should understand that this is just

\footnotetext{
${ }^{49}$ See Patrick Hanan, The Chinese Vernacular Story, p. 88.

50 See Guan Dedong's preface to the reprinting of Guazhir, in Ming-Qing minge shidiao ji, ed. Guan Dedong (Shanghai: Shanghai guji, 1987), 1:8.

51 Ibid. 1:269-70.

52 Ibid., pp. 18-19.

$53 \mathrm{Gu}$ Jiegang, "Preface to Shange," pp. 2-4.
} 
one jaded connoisseur's reconstruction of popular expression, and not any simple gathering of pristine material." ${ }_{54}$

Feng Menglong even published a collection of admittedly imitation folk songs entitled Oleander (Jiazhutao), which he probably wrote himself although he does not explicitly claim authorship. Interestingly, apart from the typography of the verse form in this collection (four four-syllable lines typical of Book of Songs versesbetween four seven-syllable lines typical of Tang regulated verse), its title Oleander is also suggestive of the literati attempt to assimilate folk expressions. In addition to indicating a variety of Asian oleander, the word juazhutao literally points to "a hybrid of peach and bamboo" in the $\mathrm{Wu}$ dialect that was Feng Menglong's mother tongue. The preface poem also speaks to this hybridization: "Three lines of mountain song and one line of shi poetry are interspersed with four lines of the new $c i$ poetry. Stealing from the new to replace the old is a scheme that comes from an ingenious mind." 55

It is also interesting to note that Feng Menglong's attitude toward folk songs can be detected in some of the Sanyan stories he wrote or revised. "Loach Fan's Double Mirror," begins with a ci poem..$^{56}$ After explaining that the concluding line of the poem is "borrowed from a Wu folk song," the narrator cites the four-line song in its entirety and comments: "This song originated in the Jianyan period of the Southern Song dynasty, and depicts suffering of the common people caused by separation and social disorder." He then continues with a description of the horrible war situation at that time, which leads to the unfolding of his main story. This folk song can also be found in Feng Menglong's Folk Songs, where the editor's notes and comments make no mention

\footnotetext{
54 Plaks, Four Masterreorks, p. 40. The "preface" Plaks refers to in his quote is Feng Menglong's preface to Shange. The term qingzhen should be translated as "authenticity of feeling," but this does not affect Plak's argument.

${ }^{55}$ See Jiazbutao in Guan, Ming-Qing minge shidiao ji, 1:455. Jiazbutao is generally attributed to Feng Menglong (see Lu Shulun, Feng Menglong yanjiu, p. 85), but Wei Tongxian has expressed doubts about it. See Wei Tongxian, "Introduction," in Feng Menglong quanji, 1:32.

${ }^{56}$ According to Hanan, this story was possibly written by Feng Menglong; see his The Chinese Short Story, p. 240. The story is in Jingshi tongyan, 1:162-172.
} 
of its date of composition or the period of its circulation. Nor is there textual evidence in the song itself to suggest that it might be a Song dynasty piece. Further, Feng has "borrowed" the first line of the Folk Song version for the concluding line of the ci poem in the Sanyan story; in the former this line is an affirmative sentence while in the latter it is a question. ${ }^{57}$

This suggests certain guidelines Feng seems to have followed in his appropriation of folk songs for his stories. First, the traditional notion that a folk song reflects the sentiments of the people is quite apparent in the narrator's comments. Although a narrator's voice does not necessarily coincide with that of the author, it is probable that Feng Menglong thought this notion would be widely accepted by his contemporaries. Second, information about a song, such as its date of composition or time of circulation might be omitted (as in Folk Songs) or provided when needed (as in this Sanyan story). Third, a folk song, or any part of it, could be freely quoted, altered, and incorporated into a literati poem, and might be used for purposes other than appreciation of the song itself, e.g., as part of an introduction to a story.

Examples of "poetic omens" and non-believers' utilization of them can also be found in stories attributable to Feng Menglong. In "Wang Xinzhi Dies to Save the Entire Family" (GJ 39), the protagonist finally fails to stay out of trouble and dies tragically, exactly as predicted in a song sung by village children in the middle of the story. In "Zheng Huchen Seeks Revenge in Mumian Temple" (GJ 22), the evil minister Jia Sidao has his political enemies killed through circu-

57 The song in Shange runs like this in English: "The crescent moon is shining upon the nine regions (jiuzbou). / Some families are rejoicing, some grieving. / Some couples are united in their homes, / Some are torn apart and adrift in distant lands." In the story the first line is framed as a rhetorical question: "Upon how many regions is the crescent moon shining?" (yuezi warwan zhao jizhou). "Jiuzhou," literally "the nine regions," is a poetic term for China that originated from the Spring and Autumn period. (So we see traces of a literati attempt at refinement already in this "folk song"!) Legend has it that in ancient times China was divided into nine administrative regions. To describe the chaotic situation of the early Southern Song period, it would be more suitable to change the term into "how many regions" because some of the "nine regions," though not all of them, were occupied by the Jurchen invaders. See Jingshi tongyan, 1:162 and poem number 3, juan 5 "Za yong si ju" (Four-line miscellaneous songs) in Shange, Guan, Ming-Qing minge shidiao ji, 1:341-42. 
lating a children's song of his own devising, while in "Shen Xiaoxia Encounters the Expedition Memorials" (GJ 40), the notoriously evil Ming minister, Yan Song, is removed from his position because the emperor hears "poetic omens" against Yan. ${ }^{58}$

Feng Menglong's flexible way of handling "folk" songs, both genuine ones and literati imitations, suggests that he may have held a similar attitude toward the source materials for his vernacular stories. If his "mountain songs" should be read as exercises in the imitation of popular literature as Plaks suggests, then by the same token, so should his Samyan stories. In fact, useful parallels can be drawn between folk songs and the type of colloquial story Feng Menglong describes or idealizes in his preface to Stories Old and New. Both are of oral origin; both remain irretrievably anonymous in authorship; both derive basically from the common people, and both are authorized in history by either a "sage" or an emperor-the Book of Songs was reputedly edited by Confucius, ynefu were first collected under Emperor Wu, and according to Feng, the vernacular story was encouraged by the Song emperor Gaozong.

For Feng, the vernacular story's most important aspect was its folk origin. Because it was believed to come from the people, it carried, as did its sister genre the folk song, the legitimating aura of general sentiment. So that it looked like folk literature, the vernacular story had to be presented as anonymous, and it needed to display some evidence of orality. In other words, a vernacular story should essentially be a written rendition of a storyteller's oral representation, rather than a direct imitation of life. If a printed folk song could appear to have been recorded verbatim from an oral performance, so should a vernacular story. This brings us to the most interesting of the rhetorical features of Chinese vernacular fiction, the storyteller's manner.

58 See Yushi mingyan, 2:361, 639, 646, and 678-79, respectively. These three stories are all attributable to Feng Menglong, according to Patrick Hanan, The Chinese Short Story, pp. 238-39. 


\section{The Storyteller's Manner}

Patrick Hanan has referred to the textualized storyteller as a sort of "simulated context," or "the context of situation in which a piece of fiction claims to be transmitted." ${ }_{59}$ This simulacrum is used in the Sanyan stories and other Chinese vernacular fiction. Like a streetside storyteller addressing his audience orally, the storyteller-narrator asks questions of his simulated audience, engages them in simulated dialogue, makes explicit references to his own stories, and intersperses his narrative with songs in verse form. Usually the narrator begins with one or more prologue stories or poems, a device that allows his audience time to "gather" before the main piece in his performance has started. Of course, in written literature this streetside storyteller pose is only a pretense in which "the author and reader happily acquiesce in order that the fiction can be communicated." 60 Feng Menglong provides plenty of textual signs of orality as part of this pretense. If a written vernacular story ought to appear as if transcribed verbatim, the storyteller's manner was obviously the most appropriate, even necessary, narrative device that could be adopted to lend the stories verisimilitude and to help pass them off as the products of real streetside storytellers in the Song and Ming dynasties.

W. L. Idema argues from a different angle that the storyteller's manner was deliberately developed in literati imitations, and Feng Menglong was not the only person to do so. According to Idema, the conspicuous use of the storyteller's manner in the Sanyan collections is "a consequence mainly of Feng Menglong's reinterpretation of the genre and due to his overall rewritings." Idema explains that whereas the "storyteller's manner" is almost absent in Sixty Stories, many of which served as the sources for Sanyan stories, it can be found in nearly all the texts in the Sanyan. ${ }^{61}$

\footnotetext{
${ }^{59}$ Hanan, "The Nature of Ling Meng-ch'u's Fiction," in Chinese Narrative: Critical and Theoretical Essays, ed. Andrew H. Plaks (Princeton: Princeton University Press, 1977), p. 87.

${ }^{60}$ Hanan, “The Nature of Ling Meng-ch'u's Fiction," p. 87.

61 W. L. Idema, "Storytelling and the Short Story in China," T'oung Pao 59 (1973): 3.
} 
Idema also points out that Feng tried to reconstruct what he saw as the original form of the vernacular novel, first created by Luo Guanzhong. Many writers of the late sixteenth and early seventeenth centuries accepted the proposition (which may have been a misunderstanding) that in its original form The Water Margin had had chapter preambles known as zhiyn or yan. Thus, to recapture the "original form" of the novel, Feng Menglong provided prologue pieces for many chapters of his expanded version of the novel The Quelling of Demons. ${ }^{62}$ Feng Menglong also believed that the short story belonged to the same genre as these novels but was more limited in scope. Therefore, he prefixed almost all of the Sanyan stories with introductory stories. Clearly, it was Feng Menglong who established the prologue as an essential element in seventeenth-century vernacular fiction. ${ }^{63}$

But the use of the "simulated context" of oral narration is intended not only to lead the reader to acquiesce over the putatively oral source of the written text, more importantly, it also allows the writer to engage in substantial rhetorical manipulation. In other words, there is a discrepancy between the "assumed pose of the street storyteller interested only in holding the audience's attention" and the "cultural perquisites of the scholar composing werzhang [writing] in his studio," ${ }^{\prime 4}$ and it is this discrepancy that gives the literati writer ample opportunity to demonstrate his literary sophistication in the text.

62 Feng refers to this work in his preface to Stories Old and New as one of the three great novels by Luo Guanzhong and Shi Nai'an-perhaps an attempt to make his expanded version of the novel pass for the original.

${ }^{63}$ Idema, "Storytelling and the Short Story in China," pp. 35-39. See also Robert E. Hegel, "Sui T'ang yen-i and the Aesthetics of the Seventeenth-Century Suchou Elite," in Plaks, Chinese Narrative, pp. 149-150 n. 66. For Feng's idea about the distinction between the novel and the short story, see the notice on the title page of Stories Old and New: "Works such as the Sanguo zbi and the Shuibu zbuan are considered the great landmarks of fiction. But the kind that concerns itself with a single character in a single action and which serves to provide entertainment should not be neglected, any more than the zaju as compared with the chuanqi." Translation by Hanan, The Chinese Vernacular Story, p. 22.

${ }^{64}$ Andrew Plaks, "Towards a Critical Theory of Chinese Narrative," in Plaks, Chinese Narrative, p. 328. 


\section{4 / Appropriation and Representation}

In the following chapter, I will draw examples from the Sanyan collections to show how skillfully Feng Menglong manipulated the storyteller-narrator and his source materials to suit his own purposes. As the phrase "jie shi buan bu" (to find reincarnation in another's corpse) is realized in one Sanyan story when the hero's soul enters the woman protagonist's body and she slaps his enemy's face, so too do Feng's rewritten narratives take his part. We will see how Feng appropriates meaning to his own purposes by revising or simply recontextualizing his source materials. ${ }^{65}$

65 See "Wan Xiuniang Is Revenged With Toy Pavilions" (TY 37). Instances of a soul possessing another person's body can also be found in the following Samyan stories: GJ 2, GJ 24, GJ 38, TY 15, TY 25, TY 27, and TY 33 . 


\section{2 \\ Ventriloquism through a Storyteller}

Feng Menglong's use of the storyteller-narrator leaves room for substantial rhetorical and ideological maneuvering around issues brought out in his stories. He can play down his narrator's authority or even discredit the traditional values the storyteller-narrator represents, such as chastity or the belief in heavenly retribution. Feng can also deploy his narrator as a personal spokesman when addressing values he holds dear, such as friendship. In other words, the reliability of Feng Menglong's storyteller-narrator depends on the particular moral issues involved in a story. This chapter will examine the distinction between the author and the narrator in the Sanyan stories and Feng's employment of more-or-less reliable narrators as he presents the reader with different moral issues.

My view of "reliability" in the Ming storyteller-narrator has been shaped by the work of Wayne C. Booth, and Seymour Chatman, as well as by that of Mikhail Bakhtin. ${ }^{1}$ While the terms "reliable narrator" and "unreliable narrator" do not correspond to established terms in premodern Chinese criticism, and perhaps sound too modern and too Western to some readers, I believe that a literary phenomenon may exist long before its concept is verbalized in criticism and I hope the discussion in this chapter will provide a telling instance of this. As David Rolston points out,

\footnotetext{
1 See Booth, The Rhetoric of Fiction (Chicago: University of Chicago Press, 1961), esp. chapter 8, "Telling as Showing: Dramatized Narrators, Reliable and Unreliable," pp. 211-40 and Chatman, Story and Discourse: Narrative Structure in Fiction and Film (Ithaca: Cornell University Press, 1978), esp. chapter 5, "Discourses: Covert versus Overt Narrators," pp. 196-262.
} 


\section{6 / Appropriation and Representation}

This failure of criticism to predict or precede is natural; it is only in recent years with the growth of narratology that emphasis has been put on discovering and naming all possible narratorial techniques and distinctions, regardless of whether they have already been tried, are equally important, or even if they are possible to put into practice. ${ }^{2}$

\section{Who is Moralizing-Narrator or Author?}

Opinions are divided about who is really doing the moralizing in the Sanyan stories. C. T. Hsia seems to hold the narrator responsible for the ambivalent moral attitude in these texts. He criticizes "the storyteller's uncertainty as to how far to push the claims of love and nature: in story after erotic story, he inevitably pulls himself and his audience from the brink of sexual license to assert the importance of law and order." ${ }^{3}$ W. L. Idema, on the other hand, seems to believe that the stories were designed by Feng Menglong to convey truth or morality. In editing and publishing the Sanyan, Feng "tried to tell history-made-logical [sic] that would be important as a mirror, not for the management of the state, but for everyone, for concrete particular persons in the management of their private lives. He tried to retell facts, but he bent them to his will when the expediency of Truth required him to do so." 4

Timothy C. Wong, however, denies that there is any didacticism in the Sanyan at all. To demonstrate that what appears to be sermonizing by the narrator is really little more than "casual banter," Wong gives an example from the opening paragraph of "Yang Balao Meets his Family in the Land of Yue" (GJ 18). The narrator begins the story with a poem citing well-known historical examples of the vicissitudes of fortune and then says:

\footnotetext{
2 David Rolston, "Point of View' in the Writings of Traditional Chinese Fiction Critics," Chinese Literature: Essays, Articles, Reviews 15 (1993): 113-42, esp. 122.

3 "Society and Self in the Chinese Short Story," The Classic Chinese Norel: A Critical Introduction (New York: Columbia University Press, 1968), p. 302.

${ }^{4}$ Idema, "Storytelling and the Short Story in China," p. 55.
} 
This ancient-style poem says that human poverty is always determined by fate, which ordains that some will first be rich and then poor, or first lowly and then exalted, in the manner of shifting clouds changing their complexions at a moment's notice, well beyond the ability of the human intellect to discern. It's like Lü Mengzheng of the Song dynasty, who led a straitened existence while he was still a student aspiring to officialdom. Not having eaten for three days, he managed to buy a melon on credit on Tianjin Bridge. But as he tried to knock it open against the bridge post, it slipped from his hands and flowed away on the current, never reaching his mouth. Afterward, he finished first in the palace examinations, rose to the rank of prime minister, and built the Fallen Melon Pavilion to acknowledge his time of poverty and misfortune. So you see, even someone destined to become the top graduate and prime minister still may not be lucky enough to hold onto a single melon if his time has not come. When the melon fell, had someone announced "This person will in time be exalted," it isn't too much to suppose that his comment would have brought on ten thousand sneers, and he would have been splattered with a thousand catties of spittle. Who would have believed him?5

As Timothy Wong points out, the "light-hearted and conversational tone of the piece" is evident, while the "seriousness of a preacher, or even a teacher" is not, despite the pedantic pose the narrator assumes. Wong further observes that since the narrator is merely agreeing with the old poem rather than pretending to offer ideas of his own, it is "impossible to believe that he is intent on teaching his imaginary listeners anything." 6

Wong is right in pointing out that the narrator's preaching should not be taken too seriously: "The casual diction, the light and detached tone, put us at ease... . The mode of expression . . . is lively and vivid, making us envision someone cringing under a battery of sneers (literally, guilian, "devil faces") and drowning in an ocean of spittle." But Wong's conclusion that "these stories are designed to subordinate

\footnotetext{
5 Yushi mingyan, 1:274; translation from Timothy C. Wong in "Entertainment as Art: An Approach to the Ku-Chin Hsiao-Shuo," Chinese Literature: Essays, Articles, Reviewes, 3.2 (July 1981): 243, with slight changes.

6 Wong, "Entertainment as Art," p. 243.

7 Ibid. p. 244.
} 
all didactic elements to entertainment" ${ }^{8}$ needs more explanation. Wong does not make a distinction between the narrator and the author in these stories, and he does not make clear who their intended reader/ audience was, the Ming dynasty masses who swarmed to hear oral storytelling in the market place, or literary connoisseurs like Feng Menglong who enjoyed reading stories in their private studios. "Entertainment" may have meant very different things to these two social groups with their different educational backgrounds. Wong also overlooks the range of effects possible with didacticism-from the confirmation of values already ostensibly held by the audience to the covert teaching of new standards that either directly or indirectly challenge the old. ${ }^{9}$

According to Patrick Hanan, Feng Menglong wrote "Yang Balao Meets His Family"10 from source materials written in the classical language. ${ }^{11}$ The storyteller's manner and his prologue must be understood as deliberately added by Feng. As I noted earlier, this addition may serve dual purposes, lending Feng's compositions the air of real street stories, and providing an opportunity to make innovative use of his chosen "simulacrum." For a general audience, the storyteller-narrator's pose secured for him "an air of authority which makes his omniscient intrusions easy to accept." 12 But to a sophisticated reader of the literati class, the presentation of a pedantic, garrulous storyteller might have seemed a parody. Therefore, the facetious sermonizing by the narrator in "Yang Balao Meets His Family" should be understood as a parodic strategy on the part of the author to weaken the authority of his storyteller-narrator.

Feng Menglong not only plays down the authority of the storyteller-narrator, but more importantly, he sometimes tries to discredit the traditional values the storyteller represents by subverting his

8 Ibid.

${ }^{9}$ Cf. A. P. Foulkes, Literature and Propaganda (London: Methuen, 1983), pp. 1-18; and Terry Eagleton, "Literature and Politics Now," Critical Quarterly 20.3 (1978): 65-69.

10 Hanan, The Chinese Short Story, p. 85; also see Hanan, The Chinese Vernacular Story, p. 117.

11 See Tan Zhengbi, Sanyan Liangpai ziliao, 1:95-97.

12 Wong, "Entertainment as Art," p. 242. 
credibility. To demonstrate Feng's strategy of subversion, I will discuss the stories that are significantly placed as the opening pair of the first collection, "The Pearl Shirt Re-encountered" (GJ 1), ${ }^{13}$ better known in English as "The Pearl-sewn Shirt," ${ }^{14}$ the title by which I will refer to it, and its companion story "Censor Chen Ingeniously Solves the Case of the Gold Hairpins and Brooches" (GJ 2). ${ }^{15}$

\section{Use of the Playful and Unreliable Narrator The Moral Consequence of Two Paired Stories}

Like "Yang Balao Meets His Family," "The Pearl-sewn Shirt" is believed to have been "rewritten" into a vernacular story by Feng Menglong himself. It does not derive from a piece of oral literature as was once assumed, but is actually based on the classical tale, "Zhushan" ("The Pearl Vest") by Feng Menglong's senior contemporary Song Maocheng (1569-ca. 1620). ${ }^{16}$ The discovery of this intertextual evidence is important, for it gives us an opportunity to better understand Feng's way of handling the short story genre.

Patrick Hanan provides this concise summary of the plot line in the source material, "The Pearl Vest":

A young wife is seduced while her husband is away on business. On discovering the fact, he divorces her but refrains from making her adultery public. She is thus able to marry again, this time as a concubine to an official. When her former husband is brought before this official

\footnotetext{
13 See the English translation by Jeanne Kelly in Traditional Chinese Stories: Themes and Variations, ed. Y. W. Ma and Joseph S. M. Lau (New York: Columbia University Press 1978), pp. 264-92.

${ }^{14}$ See Cyril Birch's translation in Stories from a Ming Collection, pp. 45-96.

15 For a translation of the main story, see P. C. Yao, "The Case of the Gold Hairpins," Renditions 5 (Autumn 1975): 118-36. For a translation of the basic story of the prologue, see Conrad Lung, "Nieh Yi-tao the Magistrate," in Ma and Lau, Traditional Chinese Stories, pp. 465-66.

16 The tale is translated into English by Patrick Hanan as "The Pearl Vest." For a summary of the historical facts behind "The Pearl Vest," and for its English translation, see Hanan, "The Making of The Pearl-sewen Shirt and The Courtesan's Jerwel Box," Harvard Journal of A siatic Studies 33 (1972): 124-133.
} 


\section{0 / Appropriation and Representation}

on a murder charge, she threatens suicide unless his life is spared. The official manages to dismiss the charge and allows the pair to remarry. ${ }^{17}$

Feng Menglong's rewritten version of the story essentially follows the same plot line, but with more details and a few added scenes, to which we will soon turn. However, given the source tale's unobtrusive, omniscient narration, Feng's addition of the storyteller-narrator is probably the most striking change he makes to this story. With this addition comes the entire set of "paraphernalia" associated with the storyteller personae: the gnomic verses and proverbs, a relish of descriptive detail, and a preoccupation with moral preaching consonant with the conventional moral attitudes he is supposed to represent. ${ }^{18}$ $\mathrm{He}$ actually begins the story with moralizing comments on the importance of being "content with one's lot" (anfen shouji) and the dangers of the four vices, "drink, lust, riches and anger" (jiu se cai qi). ${ }^{19}$ Then he continues his homily with particular emphasis on lust and adultery:

... of the four words, none is so dreadful as lust.... If you should set your mind to scheming, going against the canons of society while seeking only a moment of pleasure for yourself with no regard for the long-cherished love between a husband and wife-in short, if your own charming wife or favorite concubine were lured astray by the clever

17 See Hanan, The Chinese Vernacular Story, p. 105.

18 In Keith McMahon's discussion of "The Pearl-sewn Shirt" and other late Ming vernacular stories, the storyteller-narrator's "paraphernalia" is regarded as part of what he terms "linking devices" or simply, "narrative devices" which operate on a "purely compositional level" in the story. In "The Pearl-sewn Shirt," the mechanics of plot, according to McMahon, develop "from one interstitial juncture to another by means of proverbs, natural and symbolic figures, and allusions to ritual and legend.... These devices also function as precedents or excuses or temporary ledges of support on the way to inevitable conclusion." See McMahon, Causality and Containment in Seventeenth-Century Chinese Fiction (Leiden: E. J. Brill, 1988), pp. 14-50, esp. 27 and 43.

I also refer to some of these "devices" in my reading of the story later in this chapter, especially such symbols and allusions as "rain," "heat," and "the festival of the Herd Boy and Weaving Maid." However, my emphasis is on how Feng Menglong manipulates these "devices" to win the reader's sympathy for the adulteress, whereas McMahon is more concerned with what structurally produces the causality of the adultery and less interested in making a distinction between author and narrator.

19 Yushi mingyan, ed. Xu Zhengyang (Beijing: Renmin wenxue, 1987), 1:1; Kelly translation, p. 264. 
artifices of another, how would you feel? ... Dear audience, listen today while I tell you the tale of "The Pearl Shirt," and you will see that retribution is inevitable. . . . ${ }^{20}$

Here his statement of purpose for telling this story seems quite clear: The story condemns adultery and confirms moral retribution. To some extent, what happens in the story tallies with his introductory words, i.e., Chen Dalang, the young man who seduces another man's wife, does die as a result of "heavenly retribution." But even a quick reading reveals that the story is much more concerned with the adulteress Wang Sanqiao than with Chen, who seems to serve only as her foil in the story. Thus one feels that the narrator's homily, which addresses itself mainly to Chen's case, is somewhat off the mark. ${ }^{21}$ It is true that elsewhere the narrator also comments negatively on the woman's adultery: "Deplorable indeed is the fickle nature of woman, / She calls a wild bird to supplant the gentle dove." ${ }^{22}$ But she is not punished as severely as a Ming dynasty adulteress would have been for the same moral offence: after an act of redemption, she returns to her husband and lives with him happily ever after. At the end of the story, the narrator makes a last effort to stretch Wang Sanqiao's situation tofit his retribution scheme. He asserts in the concluding verse that she has not entirely escaped punishment, for she is demoted to second wife:

A loving couple are joined for a lifetime.

But how shameful when the wife returns as a concubine.

Blessings and misfortunes come not without design.

Heaven above is the just official easiest to come by. ${ }^{23}$

But we feel that the burden of this final poem is, as Hanan says, "grotesquely inadequate." ${ }^{24}$ In the story, the reduction of her status in the family does not impress us as a punishment for her previous

20 Yushi mingyan, 1:1; Kelly translation, p. 264.

21 See Hanan, "The Making of The Pearl-sewn Shirt and The Courtesan's Jewel Box," p. 136.

22 Yushimingyan, 1:25; Kelly translation, p. 281.

23 Yushi mingyan, 1:39; Kelly translation, p. 292.

${ }^{24}$ Hanan, "The Making of The Pearl-seren Shirt and The Courtesan's Jewel Box," p. 137. 


\section{2 / Appropriation and Representation}

adultery. The major concern is that she is one year younger than the new first wife Madam Ping-an assertion of the proper Confucian order in seniority. There were perhaps other technical obstacles to a complete restoration of her previous position: for instance, it would be ridiculous for her to again go through the ritual of matchmaking and the wedding (mingmei zhengqu) required for the position of the first wife. But she is simply too happy about coming back to care about such family status distinctions. In other words, what the narrator regards as a "misfortune" has little negative effect on her feelings at the end of the story. Whatever position she has in the family, we are given the impression that her husband will love her better than anyone else in the world. ${ }^{25}$

In fact, in Feng's rewriting of this story, we see great effort exerted to secure the reader's sympathy for the adulteress, an attitude contrary to what the storyteller-narrator explicitly claims with his conventional view of adultery and his scheme of "heavenly retribution." Feng deliberately added these elements only to challenge them with the many other changes and additions he made in the story. In the discussion that follows, I will cite examples showing how Feng Menglong recast Wang Sanqiao in a more favorable light to subvert the narrator's conventional views. We must understand that, in this story, the more sympathy Feng shows toward the adulteress, the greater the challenge posed to the authority of the narrator's claims. My analysis of Feng's effort to win the reader's sympathy for Sanqiao proceeds in four parts.

\footnotetext{
25 Compare this with the attitude (most probably Feng's own) toward the difference between wife and concubine in the general commentary on juan one of Qingshi (Anatomy of love), a collection of miscellaneous anecdotes believed to have been compiled by Feng himself: "In ancient times, if a marriage took place with proper rituals, the woman was a wife. In the absence of rituals, the woman was a concubine. In the latter case, the marriage was motivated by love [qing]. Thus, a marriage with correct rituals was one lacking in love [qing]." (Gu zhe pin wei qi, ben wei qie. Fu benzhe, yi qing ben ye; ben wei qing, ze zhen wei feiqing ye). See also Lu Shulun, Feng Menglong yanjiu, p. 35 .
} 
Balancing the Moral Equation: The Adulteress Versus Her Husband

Feng Menglong's first stratagem is "to adjust a moral imbalance which he has apparently detected" in "The Pearl Vest": "the husband is too much in the right, the wife too much in the wrong." ${ }^{26}$ In Feng's version of the story, Jiang Xingge, the husband, is described as partially responsible for her adultery. After all, it is his leaving home to make money that makes the seduction possible. Ironically, this is pointed out by the narrator in a commentative poem: "For only a tiny fly's head of profit / $\mathrm{He}$ abandoned the love nest and a happy marriage." ${ }^{27}$ On his way home, Jiang Xingge's own thoughts run along the same lines: "In the beginning there was such love and affection between us. That this horrible thing should have happened is entirely due to my greed for a pittance of profit, which caused me to leave her living virtually the life of a young widow. I'm to blame for this disgrace. . ."."28 The wife is described as strongly opposed to her husband's leaving and the tears "rolling down both her cheeks" do persuade him to give up his venture several times. As Hanan points out, she finally has to let him go because he makes his departure a fait accompli by having completed all the preparations in secret. ${ }^{29}$ Even so, she makes him promise to return the following year when the toon tree in front of their house puts forth buds again.

Of course his failure to return on time is mainly due to his illness in Guangdong, but this illness can also be seen as his fault because "he had quite depleted his health while at home" 30 by having too much sex. Even after he is fully recovered, he still has no intention of hurrying through his business and returning home as soon as possible. Instead, he is described as attracted on his way home by the beautiful scenery

\footnotetext{
${ }^{26}$ Hanan, "The Making of The Pearl-sewn Shirt and The Courtesan's Jewel Box," p. 136. The expression "balance a moral equation" is also borrowed from Hanan, p. 137. He, however, does not discuss the other three aspects as part of the author's efforts to win the reader's sympathy for Sanqiao.

27 Yushi mingyan, 1:6; Kelly translation, p. 268.

28 Yushi mingyan, 1:27; Kelly translation, p. 283.

${ }^{29}$ Hanan, "The Making of The Pearl-sewn Shirt and The Courtesan's Jewel Box," p. 136.

30 Yushi mingyan, 1:6; Kelly translation, p. 267.
} 


\section{4 / Appropriation and Representation}

of Suzhou, where he spends at least five extra months. This added episode effectively shifts part of the blame to the husband. Obviously, at least during this period of time, sightseeing seems more important to him than his wife's "grass widowhood" at home. By contrast, Sanqiao is depicted as sorely missing her husband. On New Year's eve, when all her neighbors are happy with their family reunions, "the sight of all this filled Sanqiao with grief, and she thought of her husband. What a dismal night it was!" 31 After consulting the fortune-teller, who erroneously predicts Jiang Xingge's return, Sanqiao becomes increasingly anxious. Feng's description of her situation shows a great understanding of human psychology:

Most people, as long as they don't cherish high hopes, will remain untroubled. Once they get their hopes stirred, then all sorts of foolish wishes and silly ideas start coming to them, making the time drag by. Merely because she put stock in the words of the fortune-teller, Sanqiao now thought of nothing but her husband's return, and from this time on often went to the front of the house, where she sat gazing up and down the street from behind the curtain. ${ }^{32}$

If we believe in "the principle that deeper understanding would also yield deeper sympathy," 33 then this kind of "epigrammatical understanding of the human heart" 34 added by Feng in the quoted passage must have been intended to win the reader's sympathy for the woman. In general, the wife in Feng's revised version appears to be in sharp contrast with her husband: he chooses his schedule; she is dependent upon him.

\section{The Victim Versus the Cunning Schemer}

Had her husband returned at the promised time, Sanqiao would never have had the chance to accept the lover imposed on her. Similarly, if it were not for the unusually cunning stratagems of

\footnotetext{
31 Yushimingyan, 1:6; Kelly translation, p. 268.

32 Yushi mingyan, 1:8; Kelly translation, p. 269.

33 Wong, "Entertainment as Art," p. 249.

34 Hsia, "Society and Self," p. 317.
} 
Granny Xue, who acts as procuress for the seducer Chen Dalang, Sanqiao would not have been seduced. Still, the seduction takes about five months and comprises more than one third of the story. It is clear that the author does not allow a quick submission, which would make Sanqiao appear cheap. Feng Menglong provides all the details of the process, drawing the reader step by step to the seduction scene. These narrative details, as Keith McMahon observes, "can also be said to justify or excuse her behavior," because they "make it appear as if things could have happened no other way." ${ }^{35}$ Feng also reminds the reader repeatedly of Sanqiao's innocence in his extra-textual commentary about the seduction: Sanqiao is invariably characterized as "falling into [Granny Xue's] trap" (dwo qi ji le or zhong ji le). ${ }^{36}$

Granny Xue first attracts Sanqiao's attention by showing off her gems as she pretends to bargain with Chen Dalang in front of Sanqiao's house. When she is brought into the house, she is very careful not to overstay her welcome on that first visit; she leaves quickly without even drinking a cup of tea, but leaves her jewel box and promises to come back soon. On her second visit, by selling her jewels at a reduced price and with such unctuous flattery as "you're a good judge of value, ${ }^{37}$ she gradually wins Sanqiao's confidence.

On her third visit, Granny Xue brings good food and wine to the house. Since she is sure that they are on closer terms than before, she begins to refer to Sanqiao's loneliness in the middle of drinking. Then she suggests Jiang Xingge's possible infidelity during his travels. Subtle as it is, the message of her suggestion is very clear: if the husband is not faithful, there is no need for the wife to be. When the hot weather sets in, Granny Xue makes another major advance: she is allowed to sleep in Sanqiao's room. This makes it possible for Xue not only to repeat all the salacious gossip of the neighborhood, but also to go into the details of her own illicit love affairs. It seems only natural that Xue's lewd talk has a profound effect on the lonely young woman. Finally, seeing Sanqiao aroused, Xue offers to show her how one

\footnotetext{
35 Mc Mahon, Causality and Containment, p. 45.

36 See Gujin xiaoshuo, ed. Li Tianyi (Taipei: Shijie shuju, 1958), 1.18a, 20a, 21a, 22a, 24b.

37 Yushimingyan, 1:15; Kelly translation, p. 274.
} 


\section{6 / Appropriation and Representation}

woman can satisfy another, puts out the light with her fan and in the darkness leads Chen Dalang into Sanqiao's bed in her place. The minute details of conversations and actions provided by the author throughout make the course of events seem inevitable.

As C. T. Hsia points out, in accepting a lover on her birthday night, Sanqiao is "only doing what cannot be helped." ${ }^{38}$ If we believe that she is a victim of Xue's scheme, we are already in sympathy with her. The vivid and lengthy description of the seduction should be understood as designed to win the reader over to Sanqiao's side.

\section{The Husband and the Lover}

If the lover Sanqiao accepts were a faithless man or a notorious rake who only indulges in carnal pleasure, it would certainly lower her image in the mind of Feng Menglong's intended reader. ${ }^{39}$ Instead, Chen Dalang is presented as a worthy lover, whose love for Sanqiao, though illicit, is ardent and genuine. But more importantly, as C. T. Hsia points out, Sanqiao "accepts her lover whole-heartedly because she loves and misses her husband so much." 40 In her husband's prolonged absence, she takes a lover, but she accepts him more as a husband than as a lover-this suggests that Sanqiao has not betrayed her husband emotionally even though she has committed adultery. The author tries to make this point clear by describing Jiang Xingge and Chen Dalang as similar in many respects. Both of them have lost their parents. Both are travelling merchants by profession. Both are handsome young men: Chen is twenty-four and Jiang between twentythree and twenty-four. Even their names have something in common: both ge and lang are used by girls to address their lovers, possibly an indication of their great capacity for love. Feng Menglong even provides the detail that Chen Dalang's childhood name, Xige, also has

\footnotetext{
${ }^{38} \mathrm{Hsia}$, "Society and Self," p. 318.

39 Cf. a similar episode in which Pan Jinlian, a sexually unsatisfied wife, is seduced by Ximen Qing with the help of a go-between in chapters 24-26 of Shuibu zhuan. Since the author does not want the reader to sympathize with either the adulteress or the seducer, both are portrayed as shameless in their desire for each other.

${ }^{40}$ Hsia, "Society and Self," p. 319.
} 
a ge in it..$^{41}$ And they look so much alike that Sanqiao actually mistakes Chen for her husband:

On his head was a Suzhou-style palm-leaf hat, and he wore a robe of Huzhou silk, white as a fish's belly, which happened to be just like the one Xingge usually wore. Catching sight of him from a distance, Sanqiao thought that he was her husband returning. ... . ${ }^{42}$

This scene is found in the source text, "The Pearl Vest," but in Feng's version their resemblance is emphasized and more details added, such as their shared sartorial preferences. Feng Menglong's effort to heighten their similarities suggests that when Sanqiao commits adultery during her husband's long absence, she succumbs in part because she sees her husband in her lover; therefore, in a sense she remains emotionally true to her husband.

\section{The Concept of Fate and the Sense of Inevitability}

In this story we find a number of symbols and allusions that also suggest Wang Sanqiao's seduction is predestined. This concept of fate, popular during the late Ming dynasty, is used - not unlike the way the predictive power of folk songs was used-to extenuate Sanqiao's "sin" or to absolve her from blame in the story. If a person's wrongdoing is explained as predestined, this logically implies that he or she is not free to make choices, and therefore should not be considered morally responsible; or at least the wrongdoing should be pardonable. Although the lead-in to the final seduction scene is presented in a jocular tone, the symbols and allusions that foreshadow the seduction are used so frequently that the reader is gradually primed to accept Sanqiao's adultery as inevitable, ${ }^{43}$ as if it were predetermined.

Early in the story, odd numbers appear with a much higher frequency than even numbers, particularly the figure "three." ${ }^{\prime 4}$ In the

\footnotetext{
41 Yushimingyan, 1:8. Notice that Xige and Xingge have the same initial consonant.

42 Yushi mingyan, 1:8; Kelly translation, p. 269.

${ }^{43}$ Cf. McMahon, Causality and Containment, p. 45.

${ }^{44} \mathrm{Cf}$. McMahon's notion of the number three as a narrative pattern, epitomized in the Chinese idiom "Things are not complete without (happening) three (times)." Causality and Contairment, pp. 22-23.
} 


\section{8 / Appropriation and Representation}

first few paragraphs, we find four "threes": the new bride is nicknamed "Third Eldest" (Sandar) and is also called "Blessed Third" (Sanqiaor); after the third day (sanzhao zbibou) the bridegroom changes into clothes of a lighter hue; and his father's business in Guangdong has been neglected for three years (sannian). Since these four threes are all directly related to Wang Sanqiao and her marriage and are all added by Feng Menglong, it is reasonable to believe that they are meant to convey symbolic meanings. They may indicate a love triangle between Jiang Xingge, Wang Sanqiao, and Chen Dalang, or imply that Sanqiao is going to be loved by three men in her life: Jiang, Chen, and Magistrate Wu. By contrast, in the second half of the story, which is mainly concerned with the love between Jiang and Sanqiao, the most important number is sixteen: there are sixteen cases that are sent to Sanqiao and later brought back to Jiang as a token of love between the two. Sixteen is an even number, of course, one that is the product of four twos (pairs) or the sum of eight twos; therefore, it strongly suggests the idea of "coupling" (chengshuang zuodui).

The information that Sanqiao was born on the seventh day of the seventh month, the festival of the Herd Boy and the Weaving Maid, was also added by Feng Menglong. According to legend, these mythical characters are passionate lovers, but are permitted to meet only once a year on that day. That Sanqiao's birthday happens to fall on this Chinese version of Valentine's Day suggests that her sexual life is bound to be blissful but full of interruptions. ${ }^{45}$

In setting up the seduction scene, Feng employed many symbols that foreshadow the story's erotic developments. The first time Sanqiao goes to the window to look out is on New Year's Day, which obviously points to a new beginning or turn of the situation. But as the first day of spring (according to the traditional Chinese lunar calendar), it may also suggest the beginning of the mating season for wildlife, as well as human love and sex. Similarly, when Sanqiao first sees Chen Dalang, the toon trees (chun) are beginning to bud and her husband should have returned home but has failed to do so. Feng may have

45 Cf. Pan Qiaoyun, a woman who has an extramarital relationship in chapter 44 of Shuibu zhuan, has the same birthday and the word qiao in her name. 
selected the word "toon," which has chun (literally, "spring") as its right half, for its sexual connotations. Also, the rain that occurs during Granny Xue's second visit may easily remind us of the standard literary expression for sexual intercourse yumy ("clouds and rain"). The umbrella Granny Xue brings to Sanqiao's house may also be intended as a sexual symbol. ${ }^{46}$ Another element introduced into the second visit is wine (jiu), which is often associated with sex (se)-especially extramarital sex-in Chinese literature, as in the narrator's homily at the beginning of this story. Wine is also considered a kind of aphrodisiac or something that leads to sexual activity, as in the idiom jiu shi se meiren (wine is the go-between for sex). Although wine also plays a role in the source story, it is given more prominence in Feng's version and appears with much greater frequency in association with Sanqiao. Sanqiao is described as having a "considerable" capacity for wine, ${ }^{47}$ and her drinking with Xue is described in detail, particularly on the day of the seduction. It is also worth noting that Feng explains Granny Xue's moving into Sanqiao's room with reference to the weather "steadily becoming hotter." ${ }^{48}$ The heat imagery functions on the symbolic as well as on the mimetic level, for it is frequently used in Chinese literature to denote sexual desire and sexual activity.

Finally, that the seduction falls on the night of Sanqiao's birthday, the festival of the Herd Boy and Weaving Maid, a day that had also been rainy, is obviously Feng's attempt to absolve her from blame for her adultery. When Granny Xue says that morning that in the evening she is going to "watch the Herdboy pay his visit to the Weaving Maid," ${ }^{49}$ she is speaking in double entendre. And after the consummation of their affair, she says "... I pitied the young lady

\footnotetext{
46 Patrick Hanan describes the umbrella added by Feng Menglong in the story as a supererogatory detail, "The Making of The Pearl-seren Shirt and The Coutesan's Jewel Box," p. 139. San (umbrella), or more often its collocational verb cheng, is used as a euphemism for an erect penis in almost all varieties of the $\mathrm{Wu}$ dialect, Feng Menglong's native dialect, though I do not know whether it can be traced as far back as the Ming period, nor have I found explicit usage of it in any literary works.

47 Yushimingyan, 1:16; Kelly translation, p. 275.

48 Yushimingyan, 1:19; Kelly translation, p. 276.

49 Yushimingyan, 1:20; Kelly translation, p. 277.
} 
spending her nights alone in the springtime of her youth. ... You two were destined for union. It had nothing to do with me." ${ }_{50}$ Of course, she is using the concept of fate to justify her involvement in the scheme, but Feng Menglong is doing something similar: by attributing her seduction to fate through his array of love-related elements and coincidences, Feng tries to justify to the reader Sanqiao's adultery and also his efforts to absolve her from blame.

If the authority of the storyteller-narrator is eroded by his facetious tone in "Yang Balao Meets His Family," in "The Pearl-sewn Shirt" it is subverted by the discrepancy between the narrator's prediction of heavenly retribution and what eventually happens to Wang Sanqiao, as well as by the disjunction between his condemnation of "the fickle nature of women" and the author's sustained effort to secure the reader's sympathy for the adulteress. Feng Menglong's ironic setup of his storyteller-narrator, placing him in the forefront with ostensible control over his material only to call his reliability into question with other narrative and rhetorical elements, highlights Feng's innovativeness in playing with ethical conventions and popular beliefs. By making the conventionally didactic storyteller-narrator unreliable, Feng implies that the conventional morality this narrator promotes is equally open to question.

Feng Menglong introduced a major plot change into "The Pearlsewn Shirt" that also deserves explanation. In the classical source tale, the seducer's death and his wife's subsequent remarriage to the adulteress' first husband are detached from the tale itself and appear in a postscript introduced with the words "Other sources say. ..." The author then comments: "If this is true, the Way of Heaven is simply too close, governing us in everything!" ${ }_{11}$ The idea of heavenly retribution is present but greatly weakened because the reliability of the sources cannot be guaranteed. As we have seen, Feng incorporated this postscript into the main plot, and with its incorporation, the

50 Yushi mingyan, 1:23-24; Kelly translation, p. 280.

51 Tan Zhengbi, Sanyan Liangpai ziliao, 1:5 and Hanan, "The Making of The Pearl-seren Shirt and The Courtesan's Jewel Box," p. 133. 
theme of heavenly retribution is not only part of the narrator's preaching but is also implied in the narrative itself: the man who seduces another's wife is eventually punished by losing his own wife to his lover's husband.52 If we regard what happens in the story as a manifestation of the author's conscious choice, as against what is explicitly stated by the storyteller-narrator, then does this change in the plot line reflect Feng Menglong's "acceptance" of the idea of "heavenly retribution," or a compromise he makes with it? Or does it mean that this popular view is somehow reaffirmed, rather than problematized, in the rewritten story?

First, as we noted above, the narrator's warning of heavenly retribution becomes problematic not because of its prediction regarding Chen Dalang's final punishment, but rather because of its irrelevance to what eventually happens to the main character, Wang Sanqiao. Second, although Feng's change of plot line actually helps validate the explicit rhetoric of his storyteller-narrator, we should primarily understand it as part of his strategy to pass off the rewritten text as a storyteller's story. When Patrick Hanan comments that "the vernacular story abhors loose ends, especially when villains are allowed to go unpunished," 53 he is suggesting that "heavenly retribution" is a hallmark of the genre. Robert E. Hegel also notes the striking relationship between "heavenly retribution" and Chinese vernacular fiction:

... the world view most commonly expressed and structurally embodied in Ming-Qing novels is that of 'popular' Confucianism, an unsophisticated version of Confucian cosmology that began in the Han (overlain with a sense of 'karmic justice' incorporated from Buddhism) and that is still visible in morality books for the masses produced in Taiwan and Hong Kong even at the present time. This view assumes that the universe is structured and that structures have moral value, that virtue

52 Cf. Timothy Wong's comment on this change in "Entertainment as Art," p. 249. Wong argues that the attraction of incorporating this turn of events into the plot lies in its creating a symmetry that "goes beyond the purely aesthetic to appeal to the reader's... sense of propriety and justice."

${ }^{53}$ Hanan, The Chinese Vernacular Story, p. 105. 
will be rewarded and wrong-doing will be punished, and that the universe is ultimately comprehensible in moral terms." ${ }^{54}$

If Feng wanted to give his stories a semblance of popular narrative, building this popular view into the very structure of the plot was a helpful, and perhaps necessary, part of his game of make-believe. But like Feng's storyteller-narrator, his theme of retribution is meant not only to lend verisimilitude to the story as a "popular" creation, but also to be questioned, and ultimately subverted.

Other instances of Feng Menglong's explicit acceptance and implicit subversion of this popular belief can be found in many of his other writings. For example, in his reworking of the novel The Quelling of Demons, he provides a vernacular introduction that illustrates fate and karmic justice:

Take two students. One is highly talented and an exceptional scholar, yet his life is a failure; he never finds anyone who appreciates him, and ends his days in obscurity. The other, at a tender age when he can barely mumble a few lines, let alone write decent prose, passes all the examinations on his first attempt and is applauded and lionized. The man who fails says the examiners are blind and the heavens deaf; little does he realize that the youth may have studied and done good deeds in some previous existence, thus accumulating [karma for] the early success and distinction he enjoys in this life..$^{55}$

No doubt this passage is ironic to anyone who knows of Feng Menglong's perennial frustration in the civil service examinations. Even if we lacked information about the author's personal experience, it still makes good ironic reading because the concept of karmic justice is absurdly stretched to include one's study in a previous life. Had the youth retained what he studied in his previous life, he should be able

\footnotetext{
${ }^{54}$ Robert E. Hegel, "Unpredictability and Meaning in Ming-Qing Literati Novels," in Paradoxes in Chinese Literature, ed. Eva Hung (Hong Kong: The Chinese University Press, 1994), p. 148. Also see Keith McMahon's comment on the concept of "fate" (ming) and the related term "karmic retribution" (yinguo baoying), as well as the more abstract "cosmic regularities" or "Heavenly Principle" (tianli), which also operate as agents of retribution. Causality and Containment, pp. 14-15.

55 Xin Pingyao zhuan, in Feng Menglong quanji, 29.2b. English translation from Patrick Hanan with slight changes, The Chinese Vernacular Story, p. 100.
} 
to do better than "barely mumble a few lines"; presumably, then, what he studied in that life was insignificant-and in that case, he hardly deserves a successful official career in this one.

Keith McMahon, in his discussion of the concept of fate in Chinese fiction, has found in The Quelling of Demons another instance where Feng Menglong subverts the popular belief in heavenly retribution by pretending to defend and rationalize it. In chapter 37 , the narrator makes a tongue-in-cheek reply to a question raised by the simulated audience about how it is possible for the whole human race- "as numerous as the sands of the Ganges"- to fit into the moral registries of the Jade Emperor in heaven. "Only people of note, i.e., the very good and the very bad, are registered, whereas the deeds of the main mass of humanity are not recorded-they simply rise and fall with the times." ${ }^{56}$

Let us return to Feng Menglong's attitude toward fate and heavenly retribution in "The Pearl-sewn Shirt." I have demonstrated how Feng plays with the concept of fate, turning it to his own purposes, such as to extenuate the adulteress' "sin" in the reader's mind. We have also seen that Feng subverts the notion of heavenly retribution presented by his storyteller-narrator by making it irrelevant to what actually happens to the main character. But Feng Menglong's subversion of heavenly retribution in this story may also be understood through an intertextual reading of its companion story, "Censor Chen Ingeniously Solves the Case of the Gold Hairpins and Brooches."

A brief summary of the plot line of the "Gold Hairpins and Brooches" runs as follows: A young girl commits suicide upon finding that she has lost her virginity to a man who impersonated her fiancé, his cousin, at a secretly arranged meeting. After the imposter is tracked down and executed, his former wife is adopted by the dead girl's parents and married to their daughter's fiancé instead.

${ }^{56}$ McMahon, Causality and Containment, pp. 14-15. See Pingyao zhuan, Siyou ji, ed. Yang Jialuo (Taipei: Shijie shuju, 1962), p. 233. For literati uses of gong guo ge (the ledgers of merit and demerit), see Cynthia J. Brokaw, The Ledgers of Merit and Demerit: Social Change and Moral Order in Late Imperial China (Princeton: Princeton University Press, 1991), esp. pp. 229-40. 


\section{4 / Appropriation and Representation}

These two stories are paired, not simply because they seem to share a similar subject matter, what Cyril Birch has called "realist love," ${ }^{77}$ but also because they both treat the themes of heavenly retribution and the Ming convention of chastity. In "The Pearl-sewn Shirt," the heavenly retribution theme structures the symmetrical plot line, in which the man who seduces another's wife finally loses his own to his lover's husband; similarly, in "Gold Hairpins and Brooches," we find an almost identical narrative pattern: a rogue who has, through deception, deflowered his cousin's fiancée eventually loses his own wife to that cousin. The theme of retribution is made explicit in the rhetoric of the storyteller-narrator, which Feng Menglong has again brought into the story. ${ }^{58}$ The narrator first expounds his view of retribution in a prologue story: A youth named Jin Xiao finds thirty liang of silver in a public latrine. When he returns it to its owner, the owner is unwilling to give a reward to the youth for his honesty and claims that he lost fifty liang instead of thirty. The dispute is referred to a judge, who punishes the owner by taking away the thirty liang and awarding them to the youth..$^{59}$ Then the narrator addresses his audience:

Dear audience, let me now tell the extraordinary story of the "Gold Hairpins and Brooches," in which a married man loses a wife and a bachelor gains one, just as the traveller who coveted the silver got none,

57 Cyril Birch, "Feng Meng-lung and the $\mathrm{Ku}$ Chin Hsiao Shuo," Bulletin of the School of Oriental and African Studies 18 (1956): 82. Birch's "realist love" label for these stories may reflect the concerns of a Western reader or critic more than the author's intention or motivation.

58 Patrick Hanan attributes this story to Feng Menglong and indicates that the source of the main story was a lengthy court case tale. See Hanan, The Chinese Vernacular Story, p. 108; idem, The Chinese Short Story, p. 237; and idem, "The Authorship of Some Ku-chin hsiao-shuo Stories," Harvard Joumal of Asiatic Studies 29 (1969): 198.

59 As Keith McMahon points out, the kind of didacticism that appears frequently in Ming stories can hardly be taken at face value (Causality and Containment, pp. 60-61). This prologue story is a good example, being both scatological and facetious, as when the narrator describes everyone digging around in the privy for the lost silver. With this little detail the conventional didactic assertions of the prologue are already tacitly undermined long before they are played off in the main story. 
while Jin Xiao, who wanted none, received the full amount. Though the details differ, the Heavenly Principle [of retribution] is the same. ${ }^{60}$

Again, we see that it is the storyteller-narrator's job to illustrate the workings of the Heavenly Principle through the stories he tells. But the Heavenly Principle is not seamlessly applied in this story. Here, the narrator is not always able to balance the scales of justice for every character: there are always loopholes in his scheme of moral retribution or some discrepancy between what he claims and what finally happens in the story. At the very beginning of the story, he claims that a good person will always be rewarded in the end, suggesting that this will be the story's major thrust:

The affairs of the world spin like wheels.

Woe and weal of the moment may not be real.

Watch how in the end man is fairly judged.

When has Heaven ever failed the kind at heart? ${ }^{61}$

But even a casual reading of the story shows that the main character, Lu Xuezeng, who ends up with a good wife and a successful official career, has done nothing particularly worthy of such a heavenly reward. He does not even show the kind of simple honesty that motivates Jin Xiao in the prologue story to return the silver he had found. When he is asked why he is late for the meeting with his fiancée and her mother, he lies, ashamed to admit that he had spent two days waiting for a decent suit to wear for the occasion. Of course, he is not generally portrayed in an unfavorable light, but what he does in the course of the story cannot be said to have real positive moral significance: he goes to the meeting three days late, learns that his betrothal is dissolved, is arrested on suspicion of having murdered his fiancée after she commits suicide, and finally, is released after the real culprit, his cousin Liang Shangbin, is caught.

Thus, one has the impression that the story is more concerned with the punishment of villains than the reward of good people, despite the narrator's claims in the opening poem. Lu's cousin, Liang

60 Yushimingyan, 1:43.

61 Yushimingyan, 1:40. 
Shangbin, who is severely punished in the end, really is a depraved rogue. $\mathrm{He}$ impersonates his cousin at the meeting, pockets the betrothal money, and ravishes Lu's fiancée, an act that ultimately leads to her suicide. Still, the narrator's prediction about Liang's punishment is off the mark. For one thing, Liang is finally executed rather than merely losing his wife to his cousin. For another, "losing his wife" is in fact no punishment for Liang: he and his wife, Tian Shi, are such a mismatch that he actually initiates their divorce, a move that pleases both parties.

The person who poses the greatest problem in the narrator's scheme of heavenly retribution is $\mathrm{Lu}$ Xuezeng's fiancée, Axiu. By conventional moral standards, she is practically a paragon of virtue. When her father, in the face of his future son-in-law's embarrassing financial condition, expresses his intention to break off the engagement, Axiu speaks exactly like an exemplary woman from the official histories:

A virtuous woman serves only one man until her death [furen zbi yi congyi er zhong]. A marriage for money is nothing less than robbery. Such selfishness on Father's part is absolutely immoral and I will never go along with it. ${ }^{62}$

Her mother, Lady Meng, then explains that if $\mathrm{Lu}$ initiated the dissolution of their engagement due to his financial difficulty, it would not be improper for her to accept it. At this Axiu expresses a willingness to make a martyr of herself: "If $\mathrm{Lu}$ is too poor to get himself a wife, I will gladly preserve my chastity and remain unmarried. ... If Father pushes me too hard, I'll follow Qian Yulian's footstepsthere's nothing hard in that!" ${ }^{63}$ It is because she is so determined that her mother hatches a plan to help Lu financially by arranging a meeting with him behind the father's back. Three days after the meeting, when the real $\mathrm{Lu}$ Xuezeng comes for a visit, Axiu realizes that she has

\footnotetext{
62 Yushi mingyan, 1:44.

63 Yushi mingyan, 1:44. Legend has it that in the Song dynasty, Wang Shipeng's wife Qian Yulian protested her stepmother's forcing her to remarry a rich man by throwing herself into a river. The story was turned into a famous play called Jingchai $j i$ (Story of the thorn hairpin).
} 
lost her virginity to an imposter. Although her mother quickly suggests that she keep silent about the matter and let the past be past, her reaction is the epitome of traditional chastity and moral heroism:

Axiu was lost for words for a considerable time. A wave of mixed emotions that defies description swept over her: It was partly panic, shame, chagrin and agony, and yet it was none of these. It was as if, being stuck with needles all over, she could hardly distinguish where she felt a pinch and where a pain. To her credit, she had more moral fortitude than the average person and soon came up with a plan. "Mother," she said, "why don't you go out to the hall and meet him. I know what to do." $" 64$

What she does is hang herself. The storyteller-narrator's endorsement of her suicide is explicitly expressed in the sentence quoted above, "To her credit, she had more moral fortitude than the average person and soon came up with a plan." In the following poem the narrator praises her moral steadfastness throughout the story, from her refusal to dissolve the engagement to her self-inflicted death:

The pledge was worth a thousand in gold,

But none foresaw the deceit most foul.

With three feet of red gauze she repaid her betrothed.

Defiled though her body was, unsullied stayed her soul. ${ }^{65}$

The irony here is that although her death is lauded by the narrator, it can hardly be interpreted as a just reward. Even though at one point her ghost speaks briefly to her mother through Tian Shi's body, her death effectively ends her life in the text. If this story was intended to pass for the kind of popular story where ghosts and gods can appear to "tip the scales of justice," 66 the author could have revived her as a reward, or given her a second life, or deified her after her death. ${ }^{67}$

64 Yushimingyan, 1:52.

65 Yushimingyan, 1:54.

66 See Hsia, "Society and Self," p. 313.

67 Cf. Tang Xianzu's famous play Mudan ting (The peony pavilion), in which the woman protagonist revives three years after her death because of her intense passion for a young man who arrives for a visit. See Cyril Birch, trans., "Scene 35: Resurrection," The Peomy Pavilion (Bloomington: Indiana University Press, 1980), pp. 
Instead, she is completely replaced by another woman, Tian Shi. After Liang's execution, Tian Shi is adopted by Axiu's parents, married by them to Axiu's fiancée Lu Xuezeng, and lives happily ever after with her second husband. In other words, what should have been a reward due to Axiu, according to the principle of heavenly retribution, is actually given to Tian Shi.

It is important to note that in spite of their physical resemblance, Tian Shi and Axiu are described as having very different personalities and moral convictions. Tian Shi's father is a chivalrous scholar, a tribute student (gongsheng) unconstrained by the rules of Confucian officialdom. ${ }^{68}$ Tian Shi is able to read and write, and has inherited a measure of her father's chivalrous spirit (xiangle fuqin, ye dai sanfen xiaqi). ${ }^{69}$ If Axiu's loyalty to her fiancée is exemplary by traditional standards, Tian Shi's treatment of her unworthy husband represents a deviation from the norm. She shows no deference to him, calling him a "country bumpkin" (cunlang) 70 and refusing to take care of his clothes as a wife was supposed to. Perhaps the most unconventional thing she does is to provoke him into divorcing her because she does not love him, in sharp contrast to Axiu's cliché expression of wifely virtue "a virtuous woman serves only one man until her death."

That it is Tian Shi, not Axiu, who is finally "rewarded" with a happy life at the end of the story has many implications. It can be understood as the same strategy used in "The Pearl-sewn Shirt" to challenge the authority and reliability of the storyteller-narrator by subverting his standard theme of heavenly retribution. But while in

199-204. For a discussion of the problems of reading Chinese vernacular stories in light of Western realism, see Yun Phin Lee, "Art and World in the Chinese Short Story: San-yen Collections in the Light of Western Critical Method," Ph.D. dissertation, Washington University, 1982, pp. 131-87.

${ }^{68}$ Feng Menglong himself was once a tribute student. The chivalrous, talented scholar or poet seems to have been a kind of model personality for Feng. For his characterization of such a man, the renowned poet Liu Yong (987-1053), see Feng's rewriting of the "Wanjiang Tower" as "Courtesans Swarm to Mourn Liu Qi in the Spring Breeze." That story may offer us a glimpse of Feng Menglong's own life experience. For a detailed discussion, see chapter 4 below.

69 Yushimingyan, 1:50.

70 Yushimingyan, 1:50. 
"The Pearl-sewn Shirt" the narrator's karmic prediction is only mildly undermined by its irrelevance to the fate of the main character, the subversion of a morally structured universe in "Gold Hairpins and Brooches" appears more direct. In the latter, the "good person," described by the narrator as a paragon of conventional womanly virtue, is not rewarded at all but is simply replaced by a woman who is strikingly unconventional. Thus "Gold Hairpins and Brooches" can be read as a reaffirmation or an amplification of the duthor's subversive intent in "The Pearl-sewn Shirt." Further, that the narrator's paragon of virtue is allowed to die unrewarded suggests the author's intent not only to subvert the idea of karmic justice, but more importantly to invalidate conventional morality itself, or at least the type of chastity that Axiu represents. Axiu would not have been taken advantage of by the imposter, and would not have been forced to commit suicide had she not been so perversely dedicated to "a woman's duty to serve only one man." In contrast, the idea of chastity is questioned in a very different way in "The Pearl-sewn Shirt." If, as Patrick Hanan observes, the social meaning of "The Pearl-sewn Shirt" is that "a good woman may be a willing adulteress and yet not lose her residual love for her husband nor sacrifice entirely his love for her," ${ }^{11}$ then the conventional concept of chastity is clearly undermined by the author's approval of an "unchaste" woman. Thus in terms of social meaning and moral message, the relationship between these paired stories may be regarded as almost symmetrically complementary: one subverts conventional morality by affirming a "negative" example, the other by negating a "positive" one. ${ }^{72}$

\footnotetext{
${ }^{71}$ Hanan, "The Making of The Pearl-seren Shirt and The Courtesan's Jereel Box," p. 134.

72 Of course, "Gold Hairpins and Brooches" contains both an affirmation of a "negative" example and a negation of a "positive" example, though the latter gets greater emphasis. There is certainly no negation of a "positive" example in "The Pearl-sewn Shirt."
} 


\section{The Narrator as Spokesman}

As I suggested earlier, the role of the storyteller-narrator has become one of the great controversies in the study of traditional Chinese vernacular fiction. Patrick Hanan has cautioned us against a "close comparison with a modern, ironically conceived narrator," for he believes that the Chinese story "has nothing like the unified vision found in modern fiction." 73 Katherine Carlitz, on the other hand, argues that the problem does not lie in the organization of the stories themselves, for some of them, particularly the folly-and-consequences stories, are "tightly constructed chains of causality whose unified vision is quite clear." Rather, the problem is whether the author is aware of the "apparent lack of fit between the narrator's conventional evaluations and the larger, more ramified moral universe that the story may suppose."74 In Feng Menglong's case, there seems little reason to doubt the author's consciousness of the narrator as a voice distinct from his own. As I demonstrated above, the storyteller-narrator was not an element that Feng chose to retain from the original source materials; rather, it was deliberately added by Feng as a "hypothetical persona," and in some cases, it was elaborated beyond the demands of verisimilitude.

Authorial consciousness of the narrator in the Sanyan texts can be further proven with evidence from the marginal comments supplied by the editor for each of the stories. Scholars have generally agreed that Feng, as editor, was the person responsible for these comments. Patrick Hanan, for one, cites the marginal comments as Feng's own expression. ${ }^{75}$ Moreover, $\mathrm{Hu}$ Wanchuan has presented ample intertextual evidence that proves Feng Menglong was the "sole begetter" of

\footnotetext{
73 Hanan, "The Making of The Pearl-Seren Shirt and The Courtesan's Jewel Box," p. 138.

74 Katherine Carlitz, The Rhetoric of Chin p'ing mei (Bloomington: Indiana University Press, 1986), pp. 89, 91.

75 Hanan, The Chinese Vernacular Story, pp. 104, 109-110, 111, 112, 115, 116. For examples of this kind of "auto-commentary" in traditional Chinese fiction, see Rolston, "Formal Aspects," p. 70; and Ellen Widmer, The Margins of Utopia: Shui-bu bou-chuan and the Literature of Ming Loyalism (Cambridge: Harvard University Press, 1987), chapter 5 .
} 
the Sanyan comments. By comparing certain Sanyan comments with those made on narratives of the same source materials in other works that have been solidly identified as Feng's, $\mathrm{Hu}$ has convincingly demonstrated that these various sets of comments, although published a few years apart, were written by the same hand, i.e., by Feng Menglong. ${ }^{76}$

Playing three roles simultaneously-editor, commentator, and the secret author of a few dozen stories-Feng may have been in a better position to view his texts than most later fiction commentators. But this does not mean that Feng always said whatever he wanted to in the marginal comments, or always meant what he seemed to say on the surface. For example, in "The Pearl-sewn Shirt" the commentator is completely silent from after the seduction scene to the magistrate's return of the trousseau and Sanqiao to Jiang Xingge. In "Zhao Bosheng Meets with Emperor Renzong in a Teahouse" (GJ 11), he refuses to say anything negative about the Song emperor's flaunting his obviously inadequate knowledge of Chinese characters. And in "The Dragon and Tiger Reunion" (GJ 15), his repeated comment, "What a hero!" on the roguery of the two main characters can only be understood as ironic.7 Still, these comments provide important information about Feng's attitudes towards the narrator.

Feng has many negative things to say about his storytellernarrators in his commentary, and most of them call attention to anachronisms and other types of misinformation in their texts. ${ }^{78}$ Two of his comments show not only an awareness of the difference in the level of education between Feng and his narrators but also a moral distance. One comment appearing with "The White Falcon" (TY 19) reminds the reader that storytellers of the Song dynasty gave out misinformation in order to make more money. ${ }^{79}$ The other, found in

\footnotetext{
${ }^{76} \mathrm{Hu}$ Wanchuan, "Sanyan xu ji meipi de zuozhe wenti," Huaben yu caizi jiaren xiaoshuo zhi yanjiu (Taipei: Da'an, 1994), pp. 123-38.

77 Hanan says that at least one of these instances is "intended ironically." See The Chinese Vernacular Story, p. 111.

78 See for example, Gujin xiaoashuo (1958), 7.5a, 9b; 21.28a-b; 33.2b; Jingshi tongyan, ed. Li Tianyi (Taipei: Shijie shuju, 1958), 1.7a-b; 2.2b; 3.6b; 19.14a, 16a.

79 Jingshi tongyan (1958), 19.6a.
} 
"The Golden Eel" (TY 20), is even more revealing of Feng's dissatisfaction with an attitude associated with the conventional storyteller-a lack of moral concern or ethical standards in judging characters' behavior in their stories: "Storytellers all change their judgments with the success or failure [of the characters]" (shuobua de dou yi cheng bai lun shi). ${ }^{80}$

However, endorsements of the storyteller-narrator's disquisitions can also be found in the marginal comments. In "The Three Brothers" (HY 2) for example, the narrator's comparison of the Han dynasty recommendation system with the examination system of the Ming wins the commentator's passionate approval. ${ }^{81}$ In "Fifteen Strings of Cash" (HY 33), the narrator's harsh criticism of the irresponsible judge who sentences the wrong people to death receives full support in a marginal comment. ${ }^{82}$ In other stories, the narrator sometimes speaks so much like the commentator that the two voices are almost indistinguishable: they share exactly the same view of quack doctors in "Master Wu" (HY 28) and the same idea about the importance of having a zbiji (an understanding friend) in the prologue story to "The Old Servant Xu" (HY 35). ${ }^{83}$

But this does not mean that Feng was only occasionally aware of the narrator as a distinct voice, and put it to commentative uses only when their voices differed. On the contrary, it shows that Feng as commentator knew very well the range of values the conventional narrator represented in the Sanyan collections; he knew exactly where to agree with him and where to disagree. In other words, Feng was not only fully aware of the whole spectrum of the storyteller's values, but also of his own; not only was he cognizant of the differences between

80 Jingshi tongyan (1958), 20.12a. For an English translation of TY 20, see Anne E. McLaren, trans., "The Calamitous Golden Eel," in her The Chinese Ferme Fatale: Stories from the Ming Period (Broadway, NSW: Wild Peony, 1994), pp. 17-36.

81 Xingshi hengyan (1959), 2.4b-5a.

82 Xingshi bengyan (1959) 33.17a.

83 Xingshi hengyan (1959), 28.21a and 35.5b, 6b. For an English translation of $H Y 33$ and $H Y$ 35, see Jeanne Kelly, trans., "The Jest That Leads to Disaster" and John $\mathrm{K} w a n-T e r r y$, trans., "Old Servant Hsü" in Ma and Lau, Traditional Chinese Stories, pp. $467-78$ and $19-37$, respectively. 
them, but also of what they had in common. It was this awareness of their similarities that made possible Feng's more direct use of the narrator as his mouthpiece.

Thus the ironically conceived narrator that I noted in "The Pearlsewn Shirt" and "Gold Hairpins and Brooches" represents only one of Feng's strategies for manipulating the storyteller to his own ends. Another is his use of a largely reliable narrator as his spokesman. It is the nature of the moral message Feng intends to pass to the reader that determines the degree of the narrator's reliability in a story. In "The Pearl-sewn Shirt" and "Gold Hairpins and Brooches," a central moral issue is "chastity," about which Feng Menglong has views that differ diametrically from those of conventional morality. ${ }^{84}$ In these stories the dramatized unreliable narrator not only operates on the mimetic level, but through the irony of his comments vis-à-vis the stories' narrative development, he also gets Feng's views across to the reader. And he does so far more effectively than if Feng had simply eliminated the narrator's moralism and created a unified vision while retaining enough of the storyteller's rhetoric for the sake of pretense.

But Feng's views on other issues do not necessarily conflict with his storyteller's, particularly those on friendship, leadership, and the recognition of worthy men..$^{85}$ The narrator in stories dealing with these

\footnotetext{
${ }^{84}$ Feng's view about chastity is more clearly expressed in a marginal comment in " $\mathrm{Li}$ Xiuqing Marries With Honor the Virgin Huang" (GJ 28). This story is about a young woman named Huang Shancong who, by disguising herself as a man, works and lives together as sworn brothers with a man named Li. For seven years she does not reveal her sexual identity, not until she returns to her hometown to live with her sister. When $\mathrm{Li}$ sends a matchmaker to make his marriage proposal, Huang refuses, saying, "I must try to hold myself above suspicion in a delicate situation like this. If I were to marry him, I'd be held up to ridicule and all my efforts at preserving my chastity over those seven years would be cast to the winds, even though no impropriety was ever committed." To this Feng says sarcastically in the comment, "What a genuine woman moralist! How respectable! How very respectable!" (Que shi zhenzheng nü daoxue, kejing, kejing). (Gujin xiaosbuo [1958], 28.12b). But otherwise she is portrayed quite sympathetically; chastity, of course, is not a central issue in this story.

85 In "Gold Hairpins and Brooches" the issue of misguided authority may be as important as Axiu's cleaving to the conventional notion of chastity- it is after all the mother who sets up Axiu's tragedy. And since the narrator says as much in a serious tone, and the commentator joins him in blaming the mother (Gujin xiaoshuo [1958], $2.11 b)$, this may be another example of Feng agreeing with his narrator.
} 


\section{4 / Appropriation and Representation}

issues tends to appear reliable and authoritative; he is supported by the commentator from time to time, and noticeably lacks the jocular tone often assumed by less reliable narrators. For example, in "Penniless $\mathrm{Ma}$ Zhou Gets His Chance Through the Pancake-selling Woman" (GJ 5), another Sanyan story attributed to Feng, the narrator in the introduction acts as Feng's spokesman as he appeals for sympathy for the protagonist, a neglected talent:

[Ma Zhou] was a penniless bachelor in his thirties, living all by himself. Well-versed from an early age in the classics and histories, he was an erudite scholar with high aspirations and an unparalleled knowledge of military strategies. His poverty and lack of friends were the only reasons he had received no recommendations for office. Indeed, he was like a divine dragon bogged down in mud, unable to soar into the air. ${ }^{86}$

To this the commentator says in a marginal comment, "How sad that heroes since ancient times have all suffered the same woeful fate." 87 No real distance can be sensed between the two voices: the commentator makes a general statement which the narrator substantiates with the concrete example of Ma Zhou. But the narrator has the greater affective power in getting the message across to the reader.

"Lord Ge Sends Away the Pearl Maiden" (GJ 6), also attributed to Feng, is a story about magnanimity, a virtue in leadership that Feng regarded most highly. This theme is initiated in the prologue story with the example of a famous historical figure, King Zhuang of Chu in the Spring and Autumn period, and is further elaborated in the main story through episodes about Lord Ge Zhou, a well-respected military commander of the tenth century. Both men were known for their generosity and graciousness to their followers, and in the story Lord Ge is praised universally for this virtue among his men and "held in deep esteem by the populace." 88 In the linking passage between the prologue and the main story where one usually expects to receive only general information, the narratorial voice begins its disquisition by

\footnotetext{
86 Gujin xiaoshuo (1958), 5.1a-1b.

87 Ibid.

${ }^{88}$ Ibid., $6.11 \mathrm{~b}$.
} 
deploring the deterioration of values. This is perhaps an attempt to drive home Feng's idea of magnanimity by criticizing those who lack it:

The average man in this world is narrow-minded and mean, and takes delight in digging up dirt in other people's past in order to show his own shrewdness. If he does succeed in discovering some wrongdoing, do not expect him to show mercy! Such people harbor no benevolence in their hearts but only meanness. If it so happens that they fall into a desperate situation, no one will be there to share their worries and lend them a helping hand. ${ }^{89}$

The narrator here sounds very serious, and by forsaking the jocular tone he often assumes, he secures his didactic position and increases his importance. It is precisely this serious tone that tells the reader the author approves of, rather than questions, such values.

Feng Menglong's narrator sounds equally serious in stories dealing with the theme of friendship, another of Feng's highly regarded virtues. For example, in "Wu Bao'an Abandons His Family to Ransom His Friend" (GJ 8), a story also attributed to Feng, the narrator, after the opening prologue poem, launches into a long lecture in which he condemns the selfish and utilitarian nature of modern notions of friendship:

The lyric poem above ... laments modern men's treachery and their lack of the true spirit of friendship. When passing around the wine cups, they can be as cordial as brothers but, at the slightest clash of interests, they turn their backs on each other. Truly, wine-and-meat brothers are to be had by the thousands; but friends in [times of] distress are nowhere to be found. There are also those who are brothers in the morning but enemies by evening. Scarcely have they put down their wine cups and walked out the door before they turn on each other with bow and arrow.

To this passage the commentator says: "This is especially true of people from Suzhou. How detestable! How ludicrous!"90 Interestingly enough, here it is the commentator who substantiates the narrator's general statement with a specific, concrete example, rather than the

\footnotetext{
89 Ibid., 6.2a.

90 Ibid., 8.1a-1b. Suzhou was Feng Menglong's hometown.
} 
other way around, as in the story of "Penniless Ma Zhou" discussed above. This indicates that there is no discrepancy between the two voices in this story either. The narrator lectures for the author, (or the author speaks through the narrator), promoting Feng's ideal of friendship and criticizing behavior to the contrary.

Of the thirty-six stories attributed to Feng in the Sanyan collections, about nine can be regarded as having a serious and generally reliable narrator. It is no coincidence that each of them deals with one of Feng's favorite themes, i.e., friendship, generous leadership and the recognition of worthy men. ${ }^{91}$ It can be argued whether, technically speaking, the use of a reliable narrator as the author's mouthpiece is as complex as that of an ironically conceived narrator, or whether the reliable narrator makes as much of a demand on the reader's powers of inference. Nonetheless, this practice should be understood as another of the ways Feng manipulates the narrator to his own ends; it represents one aspect of Feng's experimentation with the storytellernarrator. ${ }^{92}$

It is interesting to note that in the first half of Stories Old and New, the numerical order of the eleven stories attributed by Patrick Hanan to Feng Menglong seems to suggest the trajectory of Feng's experimentation with the storyteller-narrator..$^{93}$ Feng tried the use of the unreliable narrator first in "The Pearl-sewn Shirt" and "Gold

91 The nine stories that can be included in this group are: GJ 9, GJ 12, GJ 39, GJ 40, $T Y 28, H Y$ 2, as well as the three discussed above, GJ 5, GJ 6 and GJ 8. In GJ 39, which deals with issues of leadership and the recognition of worthy men, the narrator takes on an ironic tone in the linking passage between the prologue and the main story. However, the irony is not intended to undermine the narrator, but rather to satirize the emperor who is unable to recognize the worth of Wang Ge, the protagonist.

92 I will examine Feng's minimizing the storyteller's rhetoric to achieve other goals below in my analysis of "Song Xiaoguan Attains a Family Reunion With the Aid of a Worn Hat." See chapter 3.

93 GJ 12 is a reworking of "Wanjiang Tower" in Sixty Stories, and should perhaps be excluded from this group. Although the revision made by Feng was so drastic that it became quite a different story, it is still very difficult to imagine that Feng himself would regard it as anything more than a reworking of an old story, i.e., a reworking from vernacular to vernacular, rather than a transformation from classical to vernacular, as with other stories in the collection attributed to him. 
Hairpins and Brooches" (GJ 1 and 2), then moved to the reliable "mouthpiece" narrator in "Penniless Ma Zhou" (GJ 5), "Lord Ge Gives Away the Pearl Maiden" (GJ 6), "Wu Bao'an Abandons His Family" (GJ 8), and "Duke Pei of Jin Returns a Concubine to Her Rightful Husband" (GJ 9) before he hit a middle range of reliability in "Magistrate Teng Settles the Case of Inheritance with Ghostly Cleverness" (GJ 10), "Zhang Daoling Tests Zhao Sheng Seven Times" (GJ 13), "Chen Xiyi Rejects Four Appointments from the Imperial Court" (GJ 14), "Shan Fulang Finds His Mate in Quanzhou" (GJ 17), and "Yang Balao Meets His Family in the Land of Yue" (GJ 18). In this last group of stories, the narrator's authority is mildly played down either by keeping the storyteller's rhetoric to a minimum (as in GJ 17), or by letting the narrator occasionally assume a jocular tone (as in GJ 10, GJ 13 and GJ 14) or even a facetious tone (as in GJ 18 demonstrated above). In "Magistrate Teng," the narrator casts the descriptive passage about the wedding night in the form of a ribald song. ${ }^{94}$ "Zhang Daoling Tests Zhao Sheng" begins with a funny doggerel and in both this story and "Chen Xiyi Rejects Four Appointments," even the commentator cannot help bantering with the narrator. ${ }^{95}$ But here as in the stories of the first two groups, it is the nature of the moral issues involved that determines what type of narrator Feng uses for a story. The thematic common denominator in the third group can only be negatively defined but seems quite clear: unlike the second group, none of the third group's stories deals with themes related to Feng's most deeply held values, nor are they related to any of the conventional moral concepts in the first group to which Feng stood opposed.

It is not clear why Feng might have organized his experiments with the storyteller-narrators this way, or more specifically, why he might have arranged the stories in terms of his use of the narrator. It may have had something to do with the relative degree of difficulty of

94 Gujin xiaoshuo (1958), 10.4b. For an English translation of GJ 10, see Susan A. Zonana, trans., "Magistrate T'eng and the Case of Inheritance" in Ma and Lau, Traditional Chinese Stories, pp. 485-501.

${ }_{95}$ Gujin xiaoshuo (1958), 13.1a, 13.14b, 14.7b. 


\section{8 / Appropriation and Representation}

these approaches: Feng may well have wanted to tackle the most complex texts and the most demanding techniques first, and so may have decided to put these texts at the very beginning of the collection. $\mathrm{Be}$ that as it may, one thing seems certain: whatever his degree of reliability, the narrator was always subject to manipulation in the process of Feng's reworking the texts. Whether a Sanyan storyteller appears ironic, serious, jocular, facetious, or unobtrusive, we can be sure that it is due to Feng's pulling the strings behind the scene. 


\section{3 \\ Ventriloquism through the Companion Story}

In the previous chapter I suggested that the editor meant the Sanyan stories to be read as pairs because they are arranged in pairs, with the two titles of each unit forming a parallel couplet. It is not clear whether this was an attempt to parody the parallelism of classical poetry and belles lettres prose, reputedly the two most honored literary genres in the Ming period, or whether it again represents an effort by Feng Menglong to elevate the vernacular story-carrying further a practice already somewhat developed in the "Pillow Collection" of Sixty Stories. On the textual level, however, it seems quite clear that one story of a given pair was often composed with the other in mind. Cyril Birch has commented on this special arrangement, noting that usually "the stories of a pair will be of a similar subject-type," and on occasion, "two stories have been paired because of some common feature of plot." 1 Fukumitsu Masahiro has also noted the paired themes in Stories Old and New. ${ }^{2}$ But the relationship between paired titles (and their stories) can be much more complex than a similarity in subject matter or plot line. They can have a contrastive or complementary relationship, or one may be a comment on the other.

Let us begin with a much-discussed Sanyan pair. "Yang Jiao'ai Throws Away His Life in Fulfillment of a Friendship" (GJ 7) and its companion "Wu Bao'an Abandons His Family" (GJ 8) apparently share

\footnotetext{
1 Birch, "Feng Meng-lung and the Ku Chin Hsiao Shuo," pp. 82-83.

2 See his "Kokkin shosetsu no hensan hoho: Sono taigu kosei ni tsuite," Chugokubungaku ronshu 10 (1981): 95-120.
} 
the theme of friendship, but the self-sacrifice described in the second story is "unequivocally superior to that of either of the friends in the first story." 3

The story "Yang Jiao'ai" is about the friendship of two scholars, Yang Jiao'ai and Zuo Botao, in the Spring and Autumn period (770481 B.C.). They set out together to seek employment from the King of $\mathrm{Chu}$, only to be caught in a snowstorm in the wilderness. Zuo gives up his clothes and what little food he has so that Yang can continue the journey. After receiving an official appointment from the King of $\mathrm{Chu}$, Yang immediately returns to bury Zuo. But that night Zuo appears in Yang's dream, saying that he is plagued by the ghost of the famous assassin Jing $\mathrm{Ke}$ (?-227 B.C.), who is buried in the neighboring grave. Since humans cannot directly interfere with the activities of ghosts, Yang kills himself to join forces with Zuo in the nether world against Jing Ke. ${ }^{4}$

But while "Yang Jiao'ai" describes the self-sacrificing friendship of two men who had only recently come to know each other, Wu Bao'an of the second story is willing to undergo tremendous hardship for the sake of a friend he has never even met. Moreover, Wu and his friend Guo Zhongxiang show their loyalty to each other over a period of years as Wu struggles to ransom his friend. In contrast, the entire course of events in "Yang Jiao'ai" takes place over less than a week. Even more impressive for the family-centered Chinese reader is Wu Bao'an's abandoning his family for ten years in his effort to save his friend Guo. By comparison it seems "easy enough" for Yang Jiao'ai and his friend Zuo Botao to die for each other because "they had no families for whom they were responsible." Margaret John is certainly

\footnotetext{
${ }^{3}$ Margaret John, "Parallelism in the Vernacular Short Story: Reading 'Yang Jiao'ai sheming quanjia' and 'Wu Bao'an qijia shu you' as Pair Stories," unpublished paper presented at the American Association for Chinese Studies 34th Annual Conference at Novi, Michigan, University of Michigan, 1992, p. 13.

${ }^{4}$ For an English translation of GJ 7, see William Dolby, "Yang Jiao Throws Away his Life in Fulfillment of a Friendship," in his The Perfect Lady by Mistake and Other Stories by Feng Menglong (London: Paul Elek, 1976), pp. 144-58. For an English translation of GJ 8, see John Kwan-Terry, "Wu Pao-an Ransoms His Friend," in Ma and Lau, Traditional Chinese Stories, pp. 4-18.
} 
right to conclude that "the characters and situations in the second story seem meant to resonate with those of the first story," and that Feng Menglong "might have purposefully crafted the second story in a pair to echo the first." 5

We may find, however, that the relationship between these two stories is even more complex. Their publication history actually involves the pairing of another two stories. "Yang Jiao'ai" was adapted from "Yang Jiao'ai Kills Himself to Fight Jing Ke" ("Yang Jiao'ai sizhan Jing Ke") in the "Pillow Collection" section of Hong Pian's Sixty Stories," where it was originally paired with "The Chicken-andMillet Dinner of Fan and Zhang in Life and Death" ("Shengsi jiao Fan Zhang jishu"). This pairing is understandable since, as Timothy C. Wong points out, "the two stories show an almost perfect identity of structure and theme. Both present high-minded individuals entering ... into a bond of friendship for which each eventually offers up his life." ${ }^{8}$ If the similarity of subject-type or structure was Feng Menglong's main criterion for pairing off stories, one would expect these stories to appear also as a pair in the Sanyan. That they were actually printed separately and each was paired with a different story suggests that Feng Menglong may have had other concerns in mind. What is more significant is that "Wu Bao'an Abandons His Family," which replaces "The Chicken-and-Millet Dinner" in the pair with "Yang Jiao'ai," was

\footnotetext{
${ }^{5} \mathrm{John}$, "Parallelism in the Vernacular Short Story," pp. 1, 2, 13, 15.

${ }^{6}$ For a Chinese version of the extant incomplete text of "Yang Jiao'ai sizhan Jing Ke," see Qingpingshan tang buaben, ed. Tan Zhengbi (Shanghai: Gudian wenxue, 1957), pp. 272-79.
}

7 For a Chinese version of the extant incomplete text of "The Chicken-and-Millet Dinner," see Tan Zhengbi, Qingpingshan tang huaben, pp. 280-88. For an English translation of the Sanyan version of the story, see John Lyman Bishop, trans., "Fan Chu Ch'ing's Eternal Friendship," in his The Colloquial Short Story in China: A Study of the San-Yen Collections (Cambridge: Harvard University Press, 1965), pp. 88-99. For information on the sources of this story, see André Lévy, Inventaire analytique et critique $d u$ conte chinois en langue vulgaire (Paris: Presses Universitaires de France, 1978), 1:9596.

8 "Morality as Entertainment: Altruistic Friendship in the Ku-chin bsiao-shuo," Tamkang Review 13.1 (Fall 1982): 59. 
based on a Tang dynasty classical language tale that Feng thoroughly rewrote. ${ }^{9}$

While he made certain stylistic improvements on "Yang Jiao'ai," Feng Menglong makes it clear that this work appears as a reprint from an earlier anthology of popular fiction, Sixty Stories. ${ }^{11}$ He retained its original title in a note and also left two errors in the text unchanged. One appears in the self-introduction of the main character to his new friend: "My family name is Yang, given name Jiao'ai" (xiaosheng xing Yang, shuangming Jiao'ai). ${ }^{12}$ But the real historical figure on whom this story is based had the double-character family name "Yangjiao" and the single-character given name "Ai." ${ }^{13}$ The other error is a glaring anachronism: the famous assassin Jing $\mathrm{Ke}$ was born toward the end of the Warring States period (475-221 B.C.), a few hundred years after the death of the two friends. ${ }^{14}$

9 On Feng's authorship of the story see Hanan, The Chinese Vernacular Story, pp. 110 and The Chinese Short Story, p. 77. According to Hanan, the story's immediate source was not the version in Taiping guangi, but that in Heke sanzhi. But the two versions are only minimally different; their titles and attributions differ. See Hanan, The Chinese Short Story, p. 77 n. 35. For the Taiping guangii version of the Tang classical tale see Tan Zhengbi, Sanyan Liangpai ziliao, 1:42-46; for an English translation of the tale, see Cyril Birch, trans., "The Story of Wu Pao-an," in his Stories from a Ming Collection, pp. 121-28.

10 See Tan Zhengbi, Qingpingshan tang huaben, pp. 278-79. Feng also added a poem in the middle of the story, probably to intensify the storyteller's rhetoric. Whether the prologue poem, the prologue story, and the concluding poem were also added by Feng is impossible to ascertain because the first and last few pages of the original version in Sixty Stories are missing.

11 As I mentioned before, the works in Sixty Stories were not pure popular literature, free of literati manipulation. But in Feng Menglong's preface to Stories Old and New, it appears that he thought they were, or that he wanted to convince his readers that they were. "The Wanjiang Tower," which Feng criticizes as a bad example of storyteller literature in his preface is the first piece in Sixty Stories.

12 Yushi mingyan, 1:121. This mistake is repeated later in his interview with an official; 1:124.

13 See Cibai (Yuci fence) (Shanghai: Shanghai renmin, 1977), p. 2076. I have consistently translated his name as "Yang Jiao'ai," for I believe the Samyan editor left the mistake uncorrected on purpose. It may be common to drop one character from a two-character family name as an abbreviation, but to say that his surname is Yang, not Yangjiao, is certainly wrong.

14 For an account of Jing Ke's abortive assassination of the First Emperor of Qin, see 
It would clearly have been an easy matter for Feng Menglong to "amend the story so as to exclude the offending anachronism," well as to correct the main character's name. Feng himself made a marginal note on this anachronism, saying that the writer of "Yang Jiao'ai" "probably wanted to vent his own wrath at Jing Ke for failing in his assassination plot, and has 'borrowed' the character of Yang Jiao'ai to enact vengeance on him."16 But this explanation can hardly be taken at face value; it actually draws more attention to the mistake. In a note in History of the Latter Han (Hou Han shu), the ghost who molests the dead Zuo is only ambiguously identified as "General Jing." ${ }^{17}$ Feng could have easily changed "Jing Ke" back to "General Jing."

One might argue that Feng's thinking was affected by the assumptions of the genre. What Feng Menglong did in his rewriting of a historical novel, $A$ New History of the States (Xin Lieguo zhi), shows that he was concerned about the believability, if not the authenticity, of the historical events described in fiction. In the preface to this novel he criticizes the "village schoolmasters" (com xuejiu) for making up unbelievable historical episodes that "can rouse tired farmers in the fields but cannot be told even to the moderately literate" (danke ... xing chuli keshui, weike wei shaotong wenlizhe dao ye). ${ }^{18}$ Thus it seems reasonable to assume that Feng Menglong deliberately left the two obvious mistakes in "Yang Jiao'ai" unchanged-just as he kept the original title in the note- to mark the story as a narrative piece deriving directly from popular literature. But this handling of the work may also imply the editor's intention to undermine the authority of its popular origin in

Burton Watson, trans., Records of the Historian: Chapters from the Shib chi of Ssu-ma Ch'ien (New York: Columbia University Press, 1969), pp. 55-67.

15 This was pointed out decades ago by Cyril Birch in his "Feng Meng-lung and the Ku Chin Hsiao Shuo," p. 82.

16 Gujin xiaoshuo (1958), 8.9b; translation by Margaret John, in her "Parallelism in the Vernacular Short Story,” p. 17 n. 21.

17 See Tan Zhengbi, Sanyan Liangpai ziliao, 1:38.

18 Preface, Xin Liegno zhi (Shanghai: Shanghai guji, 1987), p. ii. Most of the bad examples Feng criticizes in the preface are anachronisms similar to the one in "Yang Jiao'ai." 


\section{4 / Appropriation and Representation}

the reader's mind. ${ }^{19}$ Pairing it with a literati imitation that he himself had written suggests that not only is the friendship represented in "Wu Bao'an" unequivocally superior to that in "Yang Jiao'ai," but the second story is itself far superior to the first artistically. Feng Menglong may have deliberately crafted "Wu Bao'an" for this pairing, not merely to echo or resonate with "Yang Jiao'ai," but to overshadow or outshine it.

It is interesting to note that "The Chicken-and-Millet Dinner," the original companion story to "Yang Jiao'ai" in Sixty Stories, is included in Stories Old and New as "Fan Juqing Attends the Chicken-Millet Dinner as a Friend in Life and Death" (GJ 16), without any indication of its origin. There it appears as the companion story to a romance of political success (faji biantai), "The Meeting of Dragon and Tiger" (GJ $15)$, but these two stories seem to have almost nothing in common. "The Meeting of Dragon and Tiger" describes an emperor and a general at the beginning of their careers as ruffians and thieves while "The Chicken-and-Millet Dinner" is about two scholar friends who kill themselves for each other. While there is conceivably irony in the first story, there is none in the second. The first story's narrator constantly refers to his protagonists as "destined to rise to the highest dignities," but he portrays them as "loafers and social outcasts." ${ }^{20}$ Therefore, it seems likely that the second story, with its lofty themes of self-sacrifice and noble friendship, is purposely set against the first to cast the future rulers' abject behavior in stark relief. It is a kind of indirect criticism of the ruling class, or of a specific Ming ruler and his ministers.

To further demonstrate the possibility that Feng Menglong set up the second story of a pair as a comment on the first-either to question its ostensible moral message or to intensify its irony-let us

${ }^{19}$ Feng also made a marginal note to Zuo's death, saying that Zuo died in Heyang County, not in Liangshan, Gujin xiaoshuo (1958), 7.5a. This note actually draws attention to this minor error, which might otherwise be overlooked by the reader.

20 Jaroslav Průšek, "The Beginnings of Popular Chinese Literature; Urban Centersthe Cradle of Popular Fiction," in his Chinese History and Literature (Dordrecht, Holland: Reidel, 1970), p. 413. Průšek also observes that "the mythical aureole of the 'Son of Heaven,' of divine origin and enthroned in celestial heights, is transformed into the picture of a rude man of violence" in the "Meeting of Dragon and Tiger," $p$. 413. 
examine in detail another pair of stories. These come from the second Sanyan collection, Comprehensive Words, "The Song Founder Escorts Jingniang a Thousand $L i$ " (TY 21) and "Song Xiaoguan Attains a Family Reunion with the Aid of a Worn Hat" (TY 22). ${ }^{21}$

"The Song Founder" is not generally considered to be Feng Menglong's own work. It is classified by Patrick Hanan as belonging to a group of six Sanyan stories whose authorship is difficult to ascertain. There are "some slight reasons for linking several of these stories" to Feng Menglong, says Hanan, but "they are not sufficient." However, Hanan also observes, "it seems likely that most of them were either by Feng or his associates." 22 Since the text of "The Song Founder" refers to itself with a title different from the one Feng gives this story in his collection, there is reason to doubt its attribution to Feng. As Hanan notes, the story "may come from some prior collection." 23

This is certainly a reasonable conclusion. Some Sanyan stories that refer to themselves by alternate titles do come from earlier collections, such as "Yang Jiao'ai" and "Yue Xiaoshe Seeks His Mate at the Risk of His Own Life" (TY 23). ${ }^{24}$ However, since we know that Feng Menglong tried to pass off the Saryan stories as popular literature that predated him, the extra title mentioned in "The Song Founder" may have been added to give the story more of a folk appearance, especially since elsewhere the story shows strong signs of literati input. ${ }^{25}$ It is also possible that by the time the story reached Feng, it had already

\footnotetext{
${ }^{21} T Y 21$ is translated into English by Lorraine S. Y. Lieu, Y. W. Ma and Joseph S. M. Lau as "The Sung Founder Escorts Ching-niang One Thousand $L i$ " in Ma and Lau, Traditional Chinese Stories, pp. 58-76. TY 22 is translated into English by Yang Xianyi and Gladys Yang as "The Tattered Felt Hat" in their The Courtesan's Jewel Box: Chinese Stories of the Xth through the XVIIth Centuries (Beijing: Foreign Languages Press, 1981), pp. 197-225.

22 Hanan, The Chinese Short Story, p. 85.

${ }^{23}$ Hanan, The Chinese Short Story, p. 85. The different title the narrator refers to in the text is "Zhao gongzi danao Qingyou guan, qianli song Jingniang" (Master Zhao disrupts the Clear Oil Monastery, then escorts Jingniang a thousand li), mentioned towards the end of the story, Jingshi tongyan, 2:316.

${ }^{24}$ A different title for "Yue Xiaoshe Seeks His Mate" (TY 23) is also listed in a note, but its source is untraceable.

${ }^{25}$ Hanan, The Chinese Short Story, p. 85.
} 


\section{6 / Appropriation and Representation}

undergone enough literati revision to meet Feng's standards. Or the story may have really sprung from popular sources but was significantly changed by the Samyan editor before it was reprinted. No matter how complicated the problem of authorship is, the story we have today appears strikingly similar in tone to others that clearly were rewritten by Feng, particularly those in which an unreliable storytellernarrator invites an ironic reading of the story and points to the subversion of certain conventional values.

The irony of "The Song Founder" becomes more explicit when compared with a later version of the same material, chapters 18 and 19 of The Complete Biography of the Flying Dragon (Feilong quanzhuan), a sixtychapter novel rewritten by Wu Xuan and published in 1768. ${ }^{26}$ Both narratives follow the same plot line, and a brief synopsis runs as follows: In the chaotic period after the collapse of the Tang empire, Zhao Kuangyin, the future founder of the Song dynasty, by chance finds a beautiful maiden named Jingniang in a Taoist temple, where she had been imprisoned by two bandits. He rescues her and decides to personally escort her home. Over the course of this thousand $l i$ journey, he kills the two bandits and she falls in love with him. Near her home she offers to marry him or to work for him as a maidservant, but he flatly refuses. To counter her family's suspicions that she has slept with him, she finally hangs herself.

"The Song Founder" differs from the novel mainly in the narrative and rhetorical elements that could lead to an ironic reading. ${ }^{27}$

\footnotetext{
${ }^{26}$ No extant source material for "The Song Founder" has been identified, although the same material was evidently drawn on in early Ming drama. See Hanan, The Chinese Short Story, p. 240 and Tan Zhengbi, Huaben yu guju (revised ed. Shanghai: Shanghai guji, 1985), p. 35. "The Song Founder" and the two chapters in Feilong quanzhuan may derive from the same source, but more likely the former may be the source of the latter because they share a great number of identical expressions. For information about Feilong quanzhuan, see Zhongguo tongsu xiaoshuo zongmu tiyao, ed. Jiangsu shehui kexue yuan Ming-Qing xiaoshuo yanjiu zhongxin wenxue yanjiusuo (Beijing: Zhongguo wenlian, 1990), pp. 530-32. See esp. p. 531 for its comment on the novel's style: it "retains to a certain extent the straightforward style of oral popular history." For the Chinese text of the two chapters, see Tan Zhengbi, Sanyan Liangpai ziliao, 1:296-306.

27 Although Wu Xuan's novel is the only extant material available for a meaningful comparison with Feng's version, I do not think it is right to assume that Wu used only
} 
It is understandable that Wu Xuan, as a Han Chinese writer in the Manchu (Qing) dynasty, would have had a more positive attitude towards Zhao Kuangyin, the founder of an ethnically Han dynasty, than Feng Menglong or his associates. The military weakness for which the Song government was notorious was not likely to win approval among the late Ming literati, who themselves felt the impending threat of the Manchus. But in the Qing period, a Chinese literatus nostalgic for the past glory of the Ming dynasty (particularly its early victory over the Mongols) would likely find a parallel between the Song and the Ming: both were Chinese dynasties that were threatened and finally overthrown by "barbarians" from the north. Zhao Kuangyin has always been a controversial figure in Chinese history. In the extant yongshi shi (poems on history) on Zhao, he is eulogized by some and satirized directly or indirectly by others, although none of the poems mentions his escorting a woman home. ${ }^{28}$

The most apparent difference between the two versions is that while the Sanyan narrator does his usual moralizing, the narrator in the novel seems more concerned with telling a straightforward story, and consequently appears more reliable, at least in the two chapters in question. "The Song Founder" begins with a prologue story in which a talented and learned old man, having retreated into the mountains after the Mongol conquest of Song China, engages in a discussion with three scholars about the rise and fall of past dynasties. He convinces them that although the Song was notorious for the deficiency of its

the Sanyan version as the basis for his novel, and simply deleted all the incongruous elements. Rather, I think it more reasonable to assume that many different versions or forms of the same material were current in the late Ming and early Qing periods and available to both Feng and Wu. In the end, it was probably their personal feelings about Zhao Kuangyin that inclined Feng and Wu to accept some versions (or episodes) rather than others.

Also extent is an early Qing chuanqi play, Fengyn hui, attributed to $\mathrm{Li} \mathrm{Yu}$ (ca. 1591-ca. 1671), in which Jingniang does not fall in love with Zhao and does not commit suicide either (scenes 16 and 17). An early Ming zaju play on the Song founder, Song Taizu longhu fengyn hui, attributed to Luo Guanzhong, does not mention Jingniang at all; see Quan Ming zaju, ed. Yang Jialuo (Taipei: Dingwen, 1979), 1:1-3.

28 See Lidai rencen shishi, ed. Jiang Weishui (Xizhi, Taiwan: Heping, 1977), 5:244-249 and Yongshi shi zhuxi, ed. Jiang Daren and Zhang Renjian (Taiyuan, Shanxi: Shanxi renmin, 1985), pp. 398-401. 


\section{8 / Appropriation and Representation}

military defenses, it was superior to even the most powerful Chinese dynasties in one respect: "its emperors were not preoccupied with women and sex." ${ }^{29}$ Although the juxtaposition of the collapse of the Song and its founding emperor's "virtue" may seem satirical, the narrator pushes the virtue argument into center stage:

I just mentioned that the Song emperors did not have a weakness for women, and this was due to the good example set by Emperor Taizu [Zhao Kuangyin]. Once he became emperor, he went to court early, stopped the usual banquets, and visited his harem only occasionally. Even before he came to power he was already an iron-willed hero, straight and forthright. Listen to this story, "Escorting Jingniang One Thousand $L i$," and you'll understand. Indeed:

When this story is told, his righteousness [yz] echoes through a thousand ages;

When it is mentioned, his valor soars into the highest heavens.

$\mathrm{He}$ is the true ruler of the eight hundred commanderies,

Showing his courage and gallantry with a cudgel..$^{30}$

At the end of the story the narrator concludes his speech with another poem praising Zhao for being "invulnerable to feminine charms." ${ }_{11}$ But again, what happens in the story does not completely bear out what the narrator tells the reader to expect. Zhao's real motivation for refusing Jingniang's love is partly revealed when he tells her,

${ }_{29}$ Jingshi tongyan, 2:298; translation by Lorraine S. Y. Lieu et al. in Ma and Lau, Traditional Chinese Stories, p. 59.

30 Jingshi tongyan, 2:298-99; Lieu translation, p. 60. The word yi is usually translated into English as "righteousness," which is close to the original meaning in the Analects. It is also explained as "the desirability of doing what is exactly right"; see Lien-sheng Yang, "The Concept of Pao as a Basis for Social Relations in China," in Chinese Thought and Institutions, ed. John K. Fairbank (Chicago: University of Chicago Press, 1957), p. 306. Martin Huang observes that yi gradually acquired the implication of "personal honor"-the reputation won as a result of the relentless pursuit of $y i$; see his "Dehistoricization and Intertextualization: The Anxiety of Precedents in the Evolution of the Traditional Chinese Novel," Chinese Literature: Essays, Articles, Reviewes 12 (Dec. 1990): 60. The $y i$ used in stories discussed in this chapter has this implication of "personal honor."

31 Jingshi tongyan, 2:316; Lieu translation, p. 76. 
Sister, it's not that I'm a man without feelings. It was out of my sense of righteousness that I decided to escort you on foot over this thousand- $l i$ journey. Now I wouldn't be any different from those two bandits if I'd come to have evil designs on you. My original sincerity would look deceitful and I'd become the laughingstock of all the heroes. ${ }^{32}$

Clearly, it is his fear of jeopardizing his good reputation that keeps him away from "feminine charms." Even his early decision to escort Jingniang home is not entirely free from thoughts of enhancing his reputation. When his uncle warns him of the dangers of the journey, his reply, in which he identifies himself with Guan Yu, the embodiment of loyalty and righteousness in popular belief, suggests an attempt at self-elevation:

"At the end of the Han dynasty, during the time of the Three Kingdoms," Kuangyin said, laughing, "Guan Yunchang [Guan Yu] singlehandedly saw his two sisters-in-law on a thousand-li journey to safety. $\mathrm{He}$ went through five passes and killed six generals, going all the way to Gucheng to join Lord Liu. This kind of action shows him to be a hero. If I can't even rescue one lady, what kind of man am I?"33

Thus Jingniang's distress becomes for him a good opportunity to prove to the world that he is a real "hero." On the journey Zhao continues to emulate Guan Yu, or at least pretends to do so. For example, on the first night of their journey he tries to guard Jingniang by standing all night in the moonlight outside her bedroom. This is in direct imitation of the way Guan $\mathrm{Yu}$ guarded his sisters-in-law in popular accounts; only Zhao's effort is interrupted by a horse thief, an episode meant to mock his pretense.

Wu Xuan's lack of interest in Zhao's emulation of Guan Yu may be complex. Probably Wu felt this was not the right way to present a real hero, or perhaps he detected in it a degree of irony toward Zhao. On one hand, it portrays Zhao as obsessed with fame. On the other, it seems to show Zhao as really loyal to no one but himself, in sharp contrast to Guan Yu. In other words, the comparison may actually

32 Jingshi tongyan, 2:313; Lieu translation, with slight changes, p. 73.

33 Jingshi tongyan, 2:303; Lieu translation, pp. 64-65. 
lower Zhao's image rather than raising it. Further, a future emperor (Zhao Kuangyin) is a cut above a royal sworn brother (Guan Yu) in social status, but since Zhao is not portrayed in a favorable light, to the careful reader of the Saryan version, his emulation of Guan may result in not only undercutting himself, but also in diminishing Guan Yu. All this may have discouraged Wu from resorting to it in his reworking of the story.

Jingniang in the Sanyan version knows quite well Zhao Kuangyin's obsession with his reputation. When she is contemplating suicide, she says to herself: "Not only did I fail to repay Master Zhao's kindness, but his good name has suffered because of me. It's all my fault that his chivalry has been misinterpreted." ${ }_{34}$ Believing that only death can restore her name, and thereby his name, she hangs herself, leaving a poem on the wall. The last couplet shows her awareness of how important it is in Zhao Kuangyin's mind to achieve a good reputation: "Tonight I die to repay Master Zhao, / So that our good names can be redeemed." 35

The Sanyan version of this story includes many details absent from the novelist's version. These give the impression that, for Zhao Kuangyin, achieving a good name is not an end in itself, but rather a necessary means to realize his political ambitions. In the middle of the story, we find a seemingly supererogatory episode that subtly reveals Zhao's long-cherished ambition to become the "Son of Heaven." On the first night of their journey, as Jingniang sleeps in the hostel, Zhao Kuangyin spots a man trying to steal his horse. In his pursuit of the thief, he catches sight of an old man reading in a hut. He goes over and asks what he is reading:

"The Scripture of Heavenly Redemption," replied the old man.

"What use is there in reading that?"

\footnotetext{
34 Jingshi tongyan, 2:315; Lieu translation, p. 75.

35 Jingshi tongyan, 2:316; Lieu translation, p. 75. The last line: bici qingming tiandi zhi could be more directly translated as "So that our good names can be known by heaven and earth," or "So that our good names can be known by the world." Jingniang's thoughts about their good names are not found in the novel, which may mean that Wu did not like their possibly satirical implications.
} 
"Since the world is falling apart, I hope the Son of Heaven will soon come forth to restore order and deliver the people from their misery."

Zhao was delighted when he heard this, for it matched his own thoughts. ${ }^{36}$

The next morning, when Zhao and Jingniang come to the same spot, the hut has disappeared, and in its place stands a temple to the local earth deity. On realizing that the old man who spoke with him the previous night was actually the local earth deity, Zhao thinks to himself: "He called me 'sir' and dared not take the main seat in my presence, so I must be someone extraordinary. If I rise to power someday, I will certainly give him a title." ${ }^{37}$ (This episode does not appear in the novel. Instead, the idea that Zhao is predestined to be emperor is prefigured without Zhao's knowledge in a dream by Jingniang's father. This suggests that Zhao had no ambition to be emperor until his men declared him such, draping the imperial yellow robe on him as he slept at the desk in his field tent).

In the Sanyan version, Zhao Kuangyin is presented not only as well aware of his own ambitions, but also as knowing very well how to achieve his goals. Although the narrator frequently says that Zhao is a straightforward man, what he actually does on the journey reveals him to be a shrewd and self-centered person. In the novel version, Zhao is said to have killed each of the two bandits in accidental encounters, relying entirely on his physical prowess. But in the Saryan version, he first makes a reconnaissance of the place where the bandits are bound to stop. He then pretends to be one of their orderlies to get a good meal, after which he sets up an ambush and kills the unprepared bandit chief.

The way Zhao then treats the chief's followers shows that he has all along been planning to seize political power, even as he followed Guan Yu's example of "righteousness" by escorting Jingniang the thousand $l i$ home. When the bandit followers throw down their weapons and surrender to Zhao once their chief has been killed, he befriends Chen Ming, a man known for his ability to walk three

\footnotetext{
36 Jingshi tongyan, 2:306; Lieu translation, p. 67.

37 Jingshi tongyan, 2:308; Lieu translation, p. 68.
} 
hundred $l i$ a day, and sends him to gather information in the capital city about his political status there. Zhao arranges for Chen to report to him in person at a Taoist temple in half a month. ${ }^{38}$

Thus, when at the end of their journey Zhao furiously rejects the marriage proposal made by Jingniang's parents, his claim that he escorted Jingniang home only for the sake of "righteousness" sounds dubious. Especially since he then immediately "rides off. . . through the night" ${ }^{39}$ to meet with Chen Ming and get his report, a report that proves critical to Zhao's plans to ascend the imperial throne. By contrast, in Wu Xuan's version, Zhao is so angry with the marriage proposal that he immediately departs Jingniang's home on foot, completely forgetting that he has a horse tethered nearby. ${ }^{40}$

In the final analysis, by suggesting that Zhao is a calculating man obsessed with ambition for the throne, the story has subverted virtually all the merits that the storyteller-narrator attributes to him. The only exception is perhaps Zhao's physical prowess and valor, attributes characteristic of a stereotypical popular hero. But even this merit is subtly undermined by the old man's discussion in the prologue story of the infamous military vulnerability of the dynasty that Zhao founded. Ironically, it is the mention of the Song's crushing military defeat by the Mongols that precedes and gives rise to the old hermit's praise of the Song emperors' invulnerability to "feminine charm," which in turn is followed by the narrator's eulogy of Zhao Kuangyin's heroic feats. ${ }^{41}$

We have seen that the Sanyan version of Zhao's story "The Song Founder" includes many rhetorical and narrative elements that help to suggest an ironic reading of the story and undermine the image of Zhao Kuangyin as a popular hero, although we are not sure just to

38 The absence of Chen Ming and Zhao's concern about his prospects in the capital in the later version suggests that Wu Xian probably thought the implications of these story elements would do more harm than good to Zhao's heroic image.

39 Jingshi tongyan, 2:316; Lieu translation, p. 75.

40 Tan Zhengbi, Sanyan Liangpai ziliao, 1:305.

41 Yun Phin Lee, "Art and World in the Chinese Short Story," p. 47, also finds the prologue story ironic when the Song emperors' "sexual virtue" is mentioned in the same breath with their military weakness. 
what extent the text was altered and adapted by Feng Menglong to achieve that effect. But Feng, it seems, was not content with undermining the heroism of this future emperor in this story alone. ${ }^{42}$ By juxtaposing it with its companion story, "Song Xiaoguan," a story that praises true and abiding affection, Feng seems to support an ironic reading of "The Song Founder" from outside the text; he further deflates the heroic image of the emperor from an intertextual perspective.

Based on a classical tale, the story "Song Xiaoguan" is attributed by Patrick Hanan to Feng Menglong himself. ${ }^{43}$ The main character is a seventeen-year-old youth named Song Jin who is reduced to beggary after his father's early death. Boatman Liu, sympathetic at his sorry situation, lets Song work and live in his boat. As Song Jin always works diligently, Liu and his wife come to like him so much that they marry their only daughter to him and let the young couple live with them in the same boat. They all get along very well until a couple of years later when Song becomes seriously ill over the death of their infant daughter. Having grown impatient with Song's failing health, Liu and his wife finally desert him on an uninhabited island without their daughter's knowledge. The island happens to be a secret pirate hideout and Song Jin is eventually able to return on a passing ship to the city with a great fortune. When he has completely recuperated, he returns to the boat to claim his wife, who has been in full mourning for him all these months. He forgives his parents-in-law for their wrongdoing and they live happily together afterward in a magnificent house in Nanjing.

Among the few alterations Feng Menglong has made-supposing he was mainly responsible for the vernacular version of the story-the most apparent addition is again the setting up of the storytellernarrator and his scheme of karmic retribution. Song Jin's father is

\footnotetext{
42 For an explanation of Feng Menglong's ambivalent attitude towards emperors in general, see chapter 4 below.

43 See Hanan, The Chinese Short Story, p. 240. The source story is from Ertan. A similar version is included in Qingshi leilüe (A classified outline of the history of qing), also known as Qingshi (The anatomy of love), an anthology of love tales generally believed to have been edited by Feng Menglong; see Mowry, Chinese Love Stories, pp. 22-35. For the tale from Ertan, see Tan Zhengbi, Sanyan Liangpai ziliao, 1:308-311.
} 


\section{4 / Appropriation and Representation}

rewarded with six more years to live and a son, because he donated a coffin to a dying Buddhist monk. But again the retribution scheme is problematic. The monk, an arhat in his previous life, had been a very pious and humble Buddhist, but died a miserable death in his old age. $\mathrm{He}$ is reincarnated as Song Jin. One would expect Song Jin to be a great hero or sage, since most heroes in popular literature have some sort of divine origins. But he is just an ordinary person, not even equipped with enough knowledge to cope with the bad luck that dogs him. Even at the end of the story when he is at the peak of his fortunes, he is merely a wealthy merchant, with not a single heroic accomplishment to his name. ${ }^{44}$ It is true that when he is deserted on the island, an old monk comes to talk to him, but the monk only gives him a copy of The Diamond Sutra and then disappears, leaving him to solve his own problems. We may say that this loophole in the heavenly scheme is again intended to undermine the authority of the narrator and to parody popular narrative heroes in general. But since this story is paired with "The Song Founder," the parodic thrust might be directed more specifically at its companion story. That Song Jin remains a commoner throughout the story in spite of his divine origin may mock Zhao Kuangyin's excessive ambition and his hubristic sense of predestination to the throne. The old monk, on the other hand, with his gift of The Diamond Sutra, stands in sharp contrast to the local earth deity who stimulates Zhao's ambition by revealing too much to him. ${ }^{45}$

It is interesting, however, that although the narrator here is as problematic as in many other Sanyan stories, he is much less intrusive. Most of the sixteen poems he cites in the text describe scenes, objects, and characters, without making any obvious value judgments or predictions. The opening quatrain, which makes a claim about the predestination of marriage and love, sounds didactic and functions as a vague prediction of what happens to the main characters in the story.

44 It is significant that the source story ends in a different way: the merchant puts down a rebellion by recruiting soldiers with his money, and is awarded with an official position. The author of the vernacular story, however, lets him remain a commoner. Tan Zhengbi, Sanyan Liangpai ziliao, 1:309-311.

45 There is no monk in the Ertan source tale. 
But then, instead of elaborating on the theme of the poem with more illustrations and comments as he does in other Sanyan stories, the narrator plunges into the story itself. The concluding poem seems even more atypical of the narrator's usual practice: it simply summarizes in a matter-of-fact way what has happened in the story. ${ }^{46}$

Thus we see that instead of being dramatized and then undermined as in the stories we have already discussed, the storytellernarrator here is made to play only a minimal role in preaching and predicting the course of the story. As a result, his vulnerability to subversion by the author is reduced proportionately. The implications of this are two-fold: on the one hand the rhetorical stance of the narrator cannot be completely discarded because the story must have the semblance of a streetside storyteller's tale. On the other hand, with a less intrusive narrator, there is less of a discrepancy within the story itself to occupy the reader's attention, and so the thrust of its message contrasts more sharply with the irony of its companion story.

That the story "Song Xiaoguan" may be intended as a negative comment on its companion story "The Song Founder" is implied in the correlation of their titles. First, Song Jin's family name is changed from "Jin" in the source tale into "Song," which is the same character as the dynastic title of the Song house that Zhao Kuangyin founded (Zhao is usually referred to as Song Taizu). This name change seems gratuitous, except that it points to the relatedness of the two protagonists, and consequently, to the necessity of "reading together" the two stories. Second, since the two titles are supposed to be a perfect match syntactically, any deviation would suggest a deliberate attempt by the editor to send a special signal to the intended reader. The two titles in the Chinese original runs as follows:

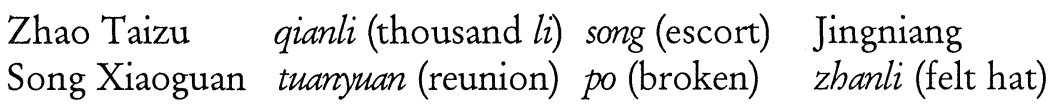

46 Another Sanyan story that uses the concluding poem as a summary is "Artisan Cui and His Ghost Wife" (TY 8). It is not a summary of the plot however, but of each character's personality. See Conrad Lung's translation in Ma and Lau, Traditional Chinese Stories, pp. 252-63. 


\section{6 / Appropriation and Representation}

We find perfect correspondences except for the third lexical unit in the second title. ${ }^{47}$ Po can be used both as an adjective meaning "broken," "worn," or "ragged," and as a verb meaning "to break," or "to cut." For the second title to match the first syntactically, it should be taken as a verb. But since the worn felt hat, which triggers recognition in the reunion scene of the story, is already "broken" with no one trying to "break" it further, the object of the verb po must be something else. Reasonably, it could be the couplet's first line, which, as the first story's title, represents the story itself. More specifically, $p o$ may be directed at its counterpart in the first title, song (escort), which happens to be a homophone with "Song" of the dynastic title. All of this may imply that the second story is designed to "break" ( $p o$ ) or belittle the significance of the Song founder's escorting the maiden home. I hold that this is one of many instances of significant wordplay in the Sanyan, and I will discuss others in chapter 4 below.

Two alterations made in the plot line of the second story also contribute to this intertextual subversion. In the source tale, Song Jin is described as intending to buy a concubine for himself once he has money and his health has returned. It is only by accident that he sees his father-in-law's boat and finds his wife in it. But in the Sanyan version, Song Jin has no other woman in mind but his wife, and he makes a special trip to their hometown to look for her. When the neighbors tell him that Liu has sailed to another place, he follows his trail. Clearly, the author is trying to elevate Song Jin by describing him as a youqing ren, a man of both passion and constancy, a man who knows the importance of love between man and woman in life. ${ }^{48}$

Feng Menglong has also added an episode. Early in the story, Song Jin is lucky enough to be hired by an official but is soon thrown out into the street and reduced to poverty because of the conspiracy of jealous colleagues. This example of the fickleness of fortune highlights

\footnotetext{
47 This does not mean that they are semantically a perfect match. "Thousand $l i$ " and "reunion" are certainly not in the same semantic category (although they are both nouns); neither are "Jingniang" and "felt hat."

48 That a classical version of the story is included in the first chapter of Qingshi, the chapter about faithful love, is surely significant. See Qingshi, ed. Zhang Fugao et al. (Shenyang: Chunfeng wenyi, 1986), pp. 7-8.
} 
the significance of Song Jin's blissful reunion with his wife after many vicissitudes at the end of the story. The implication is that only qing (love) can bring meaning to life as it brings the couple together.

Qing, variously translated into English as "feeling," "emotion," "passion," "affinity" or "love," is a ruling value in Feng Menglong's writings. In his preface to Folk Songs he makes it clear that the genuine qing between a man and a woman is what he will use to expose the "phony medicine" of Confucianism (jie namnü zbi zhenqing, fa mingïao zhi weriyao). ${ }^{49}$ In his preface to another collection, Anatomy of Love (Qingshi leilïe), he admits that he has a reputation for being qing-crazy, and glorifies qing as binding the myriad things in the universe together:

Had heaven and earth had no qing they would not have produced the myriad things....

The four great elements [si da] are all but illusion; only qing is neither empty nor false. When there is qing the separated are close; when there is no qing the intimate become estranged. The difference between having qing and not having qing is immeasurable....

The myriad things are like scattered coins; qing is the string that binds them together. When the once-scattered coins are at last strung together, even those at opposite ends of the world become of one family.... ${ }^{50}$

Clearly, "Song Xiaoguan" is one of those Sanyan stories that can be regarded as dramatizations of Feng Menglong's concept of qing. Since there is qing between Song Jin and his wife, they are finally reunited. It is qing that eventually brings the scattered characters together, including the not-always-kind-hearted boatman Liu, to live happily as one family. In contrast, Zhao Kuangyin's refusal of Jingniang's love, which consequently brings about her suicide, is an act lacking in qing

\footnotetext{
${ }^{49}$ Guan, Ming-Qing minge shidiao ji, 1:286-87.

50 English translation from Mowry, Chinese Love Stories, pp. 12-13. For a brief discussion of the influence of Wang Yangming's notion of "innate knowledge" on Feng Menglong's concept of qing, see Hanan, The Chinese Vernacular Story, pp. 78-79 and Chen Wanyi, "Feng Menglong 'qingjiao shuo' shilun," in his Wan Ming xiaopin yu Mingï wenren shenghuo, pp. 165-83.
} 


\section{8 / Appropriation and Representation}

according to Feng's moral standards..$^{51}$ By pairing "Song Xiaoguan" with "The Song Founder," Feng negates the value of Zhao Kuangyin's ostensibly moral action, action that brings about the death of an innocent woman. The irony of Zhao's repeated claim of righteousness is thus heightened. If the extra rhetorical and narrative elements in "The Song Founder" undercut Zhao's heroic image by exposing his hypocrisy in pursuing "righteousness" to realize his political ambitions, an intertextual reading of the first story in light of the second further challenges Zhao's claims. By casting the inhumanity and destructiveness of his actions in stark relief against the qing manifested in the second story, Feng Menglong retroactively destroys ( $p o$ ) the "phony medicine" of "righteousness" in the first.

\footnotetext{
51 In the later version, Jingniang's ghost, still in love with Zhao Kuangyin, escorts him one whole night through the wilderness as a repayment for Zhao's escorting her home. Nothing of the sort exists in the Sanyan version, where it would undercut the irony of Jingniang's suicide and help to justify Zhao's claim that righteousness was his only motivation for escorting her home.
} 


\section{4 \\ Ventriloquism through Women Characters}

In his essay "The Realistic and Lyric Elements in the Chinese Mediaeval Story," Jaroslav Prǔšek observes that "compared with the modern European novel . . . and all modern literature where ... a work often serves no other purpose than the self-expression of its author" . . "Chinese mediaeval stories" (by which he means to include most of the Sanyan stories) do not "express personal feelings and judgments." ${ }^{1}$ Průšek's observation might hold true if confined to the storyteller-narrator whose judgment is "a kind of consensus omnium and not a personal opinion." ${ }^{2}$ But as we have demonstrated in previous chapters, the storyteller-narrator's judgment does not necessarily coincide with that of the implied author, and the impersonality or the public stance of the narrator may well be part of the author's strategy to express himself or hide his anxieties or problems. Robert E. Hegel points out in his essay "An Exploration of the Chinese Literary Self" that "the study of self in literature can reveal in extreme detail two variants on the primary entity, created selves and revealed selves." The former are "those fabricated individuals who people narratives and other literary forms" and the latter are "those features of individual writers' psyches unwittingly or deliberately manifested as self-expression in their work."

\footnotetext{
${ }^{1}$ Průšek, in his Chinese History and Literature, pp. 385-95, especially p. 391.

${ }^{2}$ Ibid. p. 391.

3 "An Exploration of the Chinese Literary Self," in Expressions of Self in Chinese Literature, ed. Robert E. Hegel and Richard C. Hessney (New York: Columbia University Press, 1985), pp. 3-4.
} 
Viewed in this light, both the storyteller-narrator and the women characters in the Sanyan stories can be seen as "created selves" through which we can better understand the conscious or inadvertent expression of the "revealed selves," the writers/editors of these narrative texts. This chapter will explore how Feng Menglong in particular reveals his anxieties and concerns- his sense of marginality and anxiety of service-by identifying with major women characters in the Sanyan, and by "ventriloquating" through them. I will review certain concepts in French feminist theory and the yin-yang paradigm from the Chinese tradition to provide a theoretical framework for my textual analysis, and then discuss the "beauty and flower" (meiren xiangcao) literary tradition in relation to the social positions of the literati class in Chinese history.

My discussion of these issues must be based on an understanding of Feng's attitude toward women in general. In the immediately following pages I will first show that Feng's sympathy lay with women he saw as oppressed and powerless in society, women whose position he felt paralleled his own.

\section{Feng Menglong's Attitude Toward Women}

One of the most impressive characteristics of many Sanyan stories is their deeply sympathetic treatment of women. In chapter 2, I showed how Feng Menglong went to great lengths in his rewriting of the "Pearl Vest" to secure the reader's sympathy for the adulteress Wang Sanqiao. This attitude implies "a subversion of male centrality, of the established sexual privilege of the man." ${ }^{4}$ Other Sanyan stories notable for their positive treatment of women characters include "Courtesans Swarm to Mourn Liu Qi in the Spring Breeze" (GJ 12), "Shan Fulang Finds His Mate in Quanzhou" (GJ 17), "The Honest Clerk" (TY 16), "Yutang Chun in Distress Encounters her Husband" (TY 24), "An Eternal Prisoner under the Thunder Peak Pagoda" (TY 28), "The Pavilion of Lingering Fragrance" (TY 29), "A Century of Sorrows for

\footnotetext{
${ }^{4}$ Keith McMahon, Causality and Containment, p. 7.
} 
Wang Jiaoluan" (TY 34), and "The Oil Peddler Courts the Courtesan" ( $H Y$ 3), to name just a few of the more well-known. ${ }^{5}$

What is more, the women in these stories are sometimes portrayed not only with great sympathy, but also as superior in many respects to their lovers, husbands, or other men. I believe that female superiority in the Sanyan collections should be studied in light of the literati "anxiety of service," and will examine Feng's use of this theme in detail below.

In most Sanyan love stories, the woman is far more determined than her man in pursuing personal happiness in the face of arranged marriages and other social injustices. This determination is apparent in "Strange Encounter in the Northern Capital" (GJ 24), "Shen Xiaoxia Encounters the Expedition Memorials" (GJ 40), "Artisan Cui and His Ghost Wife" (TY 8), "Wu Qing Meets Ai'ai at Jinming Pond" (TY 30), as well as in some of the stories mentioned above, such as "The Honest Clerk" and "An Eternal Prisoner." "Shen Xiaoxia" provides a fascinating account of the "pluck and ingenuity" shown by the title character's concubine, who saves her husband from being murdered by agents of the evil prime minister, Yan Song. ${ }^{6}$ In "Su Xiaomei Baffles Her Bridegroom Thrice" ( $H Y$ 11), which begins with a list of renowned women writers in Chinese history, the woman poet $\mathrm{Su}$ Xiaomei is shown to be intellectually far superior to her husband Qin Guan, who is already a famous poet by the time they get married. She is even described as able to solve with ease problems that baffled her older brother Su Shi (1037-1101), one of the greatest poets in Chinese history.? In another story from the third collection, "Scholar Dugu

\footnotetext{
${ }^{5}$ For a brief discussion of the sympathetic portrayal of women for the Jingshi tongyan stories in this list, see Cheng Hong, "Jingshi tongyan zhong de aiqing gushi," MingQing xiaoshuo yanjiu lunwenji (Beijing: Renmin wenxue, 1959), pp. 1-7.

${ }^{6}$ Hanan, The Chinese Vernacular Story, p. 114. According to Hanan, Feng Menglong himself may have written this story.

7 The story, of course, is fictional. As Kang-I Sun Chang points out, the historical Su Xiaomei could not have met the Song poet Qin Guan; she died long before Qin Guan became an adult and came to study with Su Shi. Moreover, the wife of the historical Qin Guan was surnamed $\mathrm{Xu}$ rather than Su. Obviously, the author of the story "purposefully distorted the historical facts in order to create an image of a talented
} 
Has a Wild Dream on his Way Home" (HY 25), Miss Bai Juanjuan, niece of one of the best known Tang dynasty poets, Bai Juyi (772-846), is depicted as a highly educated woman, well versed in all forms of literature. "If she were allowed to take the civil service examinations," says the narrator, "she would easily take first place." The idiom "intelligent women outshine men" (youzbi furen, saiguo nanzi) or its variants appear frequently in the Sanyan collections; it occurs, for instance, in "Li Xiuqing Marries With Honor the Virgin Huang" (GJ 28), "Wang Xinzhi Dies to Save the Entire Family" (GJ 39), "Squire Gui Repents in Poverty" (TY 25) and "Zhao Chun'er Makes the Cao Family Thrive Again" (TY 31). ${ }^{9}$ In other stories, the woman is presented as morally superior to her man. For example, in such famous stories as "The Courtesan's Jewel Box" (TY 32) and "Jin Yunu Beats Her Faithless Lover With Sticks" (GJ 27), as well as in "A Century of Sorrows" mentioned above, "the woman of integrity is moral victor over the weak-willed man. . . The man is more attracted by wealth and social rank than by the woman's genuine human qualities."10

Liu Wu-chi has noted that the stories of romantic love between young scholars and beautiful maidens celebrated in the so-called 'beauty and genius' novels of the period are strikingly absent from the Sanyan collections. ${ }^{11}$ But there is another important thematic absence

woman whose poetic skills surpass those of her husband." Chang also observes that the story of Su Xiaomei is reminiscent of Virginia Woolf's fictional creation of a woman poet called Judith Shakespeare, the great playwright's "wonderfully gifted sister." See Chang's The Late-Ming Poet Ch'en Tzu-lung: Crises of Love and Loyalism (New Haven: Yale University Press, 1991), pp. 14, 136 n. 35.

${ }^{8}$ Xingshi hengyan, Gu Xuejie, ed. (Beijing: Renmin wenxue, 1987), 2:515.

${ }^{9}$ Yushi mingyan, 2:444, 642; Jingshi tongyan, 2:395, 496, respectively.

${ }_{10}$ McMahon, Causality and Containment, p. 56. Hanan also observes that in the betrayal stories attributed to Feng Menglong, the betrayer is always a man; "there is no equivalent of the disloyal woman of the middle period story" (The Chinese Vernacular Story, p. 119). For a discussion of the superiority of women in Qing fiction, see Louise P. Edwards, Men and Women in Qing China: Gender in the Red Chamber Dream (Leiden: E. J. Brill, 1994), pp. 50, 54.

${ }^{11}$ Introduction to Chinese Literature, p. 217. Liu's attribution of this absence to Feng Menglong's adherence to "the tastes and demands of the rapidly growing urban population" may need some clarification. I assume that Feng had in mind the tastes of 
within the moral and social universe of the Sanyan that has gone unnoticed by Sanyan critics thus far: the theme of the shrew. This theme was widespread in Chinese literature of the Ming and Qing periods, but does not appear in any of the one hundred and twenty Sanyan stories. ${ }^{12}$ Yenna Wu has rather exhaustively documented the great popularity of the shrew figure in both vernacular and classical seventeenth-century literature, and has summed up the three distinctive characteristics of the Chinese shrew: she is typically childless, jealous, and murderously violent. ${ }^{13}$ Yet strangely enough, none of the major or minor women characters in the Sanyan fits that description. This conspicuous absence is even more significant when compared with $\mathrm{Pu}$ Songling's (1640-1715) Liaozhai's Records of the Strange (Liaozhai zhiyi), a voluminous seventeenth-century collection of classical tales that is permeated with the theme of the shrew, as

a highly sophisticated audience that was largely urban, and so he refused to include shallow, stereotyped "beauty and genius" stories in his collections. It is interesting to note, however, that this type of fiction became very popular after Feng's time. For a study of the "Beauty-Scholar" romances, see Richard C. Hessney, "Beautiful, Talented, and Brave: Seventeenth-Century Chinese Scholar-Beauty Romances," Ph.D. diss., Columbia University, 1979 and Keith McMahon, Misers, Shrewes, and Polygamists: Eighteenth-Century Chinese Fiction (Durham: Duke University Press, 1995), pp. 99-125.

${ }^{12}$ In TY 2, Zhuangzi's wife is described as being eager to marry a handsome young man only a few days after Zhuangzi's fake death. But this can be regarded at most as a case of betrayal and the breaking of her oath of faithfulness.

${ }^{13}$ Quoted in Judith T. Zeitlin, Historian of the Strange: Pu Songling and the Chinese Classical Tale (Stanford, California: Stanford University Press, 1993), p. 128; see Yenna Wu, "Marriage Destinies to Awaken the World: A Literary Study of Xingshi yinyuan zhuan," Ph.D. dissertation, Harvard University, 1986, chap, 2. Also see Wu's essay based on the second chapter of her dissertation, "The Inversion of Marital Hierarchy: Shrewish Wives and Henpecked Husbands in Seventeenth-Century Chinese Literature," Harvard Journal of Asiatic Studies 48.2 (Dec. 1988): 363-82. In her recent book The Chinese Virago: A Literary Theme (Cambridge: Council on East Asian Studies, Harvard University, 1995), pp. 5-6, Wu chooses to use the term "virago" instead. Also see McMahon, Misers, Shrewes, and Polygamists, pp. 55-81. McMahon's definition of shrew is much broader than that of Wu's. 
Judith Zeitlin points out. ${ }^{14}$ Sixty Stories, one of the major sources of materials used in the Sanyan, contains a vernacular story entitled "The Garrulous Girl Li Cuilian" ("Kuaizui Li Cuilian ji"), in which the main character bears a strong resemblance to a shrew. ${ }^{15}$ Feng Menglong's apparent refusal to include this story in the Sanyan, just as he refused to accept "The Double-Fish Pendants" in the preface to Stories Old and New, suggests that the theme of the shrew was offensive to his literary taste. Since the story "Li Cuilian" relies heavily upon this theme, it was perhaps formally and ideologically beyond repair; in other words, it would probably have been difficult to keep the characterization of $\mathrm{Li}$ Cuilian vivid if the shrew theme were removed. ${ }^{16}$ Yet, Feng Menglong's self-conscious exclusion of the shrew from the Sanyan does not necessarily mean that he was motivated exclusively by a philogynous tendency. As Yenna $\mathrm{Wu}$ points out, the criticism implied in stories of the shrew actually cuts both ways: it censures violently rebellious wives but also deprecates spineless husbands. More importantly, such traditionally comic stories suggest that "henpecking is a deviation from the norm, a source of disorder that should not be tolerated." ${ }^{17}$

However, Feng Menglong did include in the Sanyan collections a few stories in which women characters are portrayed in a negative light. Some notable examples are "Han Wuniang Sells Her Charms at the New Bridge Market" (GJ 3), "He Daqing Leaves his Mandarin-

\footnotetext{
${ }^{14}$ Zeitlin, Historian of the Strange, p. 128. Zeitlin also makes reference to the social implication of the shrew in literature: "the shrew is a justification for and a vindication of the most misogynist views of women," p. 130.

${ }^{15}$ Tan Zhengbi, Qingpingshan tang huaben, pp. 31-40; for an English translation, see $\mathrm{H}$. C. Chang, trans., "The Shrew," in his Chinese Literature: Popular Fiction and Drama (Edinburgh: Edinburgh University Press, 1973), pp. 23-56. Note that Chang's title characterizes Li Cuilian as a "shrew," although she may not be a typical shrew by Wu's definition.

${ }^{16}$ Feng Menglong did touch upon the problem of uxoriousness in Happiness Complete (Wanshi $z u$ ), his drastic reconstruction of an old play that he held in low esteem. However, he blamed the uxoriousness on the weakness of men rather than on their wives. See Wu, "Inversion of Marital Hierarchy," pp. 366-67.

${ }^{17}$ Wu, "Inversion of Marital Hierarchy," p. 381.
} 
Duck Girdle After Death" (HY 15), "Two Magistrates Vie to Marry the Orphan Girl With Honor" ( $H Y$ 1), and "Li Yuying Appeals to the Court While Imprisoned" ( $H Y$ 27). ${ }^{18}$ These stories can be divided into two groups: the first two share the misogynistic femme fatale theme, and the last two deal with the image of the wicked stepmother. "Han Wuniang Sells Her Charms" actually begins with a series of historical anecdotes on how imperial consorts destroyed their emperors. In the main story, Han Wuniang, an unofficial prostitute, seduces a young merchant and almost drains him of his life force. 19 "Mandarin Duck Girdle" carries this theme to extremes: a rake named He Daqing wanders into a nunnery and within the span of only a few months is exhausted to the point of death by four sexually ravenous nuns. This emphasis on the destructiveness of female sexuality may reflect, as Yenna Wu observes, "the male fear of women's supposedly superior sexual power." ${ }^{20}$

In "Two Magistrates," when the husband is away from home, the wife maliciously abuses their adopted daughter and finally even sells her off as a slave. In "Li Yuying Appeals to the Court," the stepmother is nothing less than a villain: After her husband's death, she not only brutally mistreats the four young children, three daughters and one son, but also tries to murder one of them and frame the others.

\footnotetext{
${ }^{18}$ There are other Sanyan stories in which women are presented unfavorably, such as GJ 38, TY 2, TY 13, TY 20, TY 25, TY 33, TY 38, and $H Y$ 30; but these characters are often minor ones or have only minor personality flaws or their men are described as equally bad. Thus they can hardly be cited as evidence of a negative attitude toward women on the part of the editor Feng.

${ }^{19}$ For an English translation, see Robert C. Miller et al., trans., "Han Wu-niang Sells Her Charms at the New Bridge Market," in Ma and Lau, Traditional Chinese Stories, pp. 312-24, where it appears in a section entitled "The Femme Fatale."

20 "Inversion of Marital Hierarchy," pp. 377-78. In traditional Chinese sexology, a man's semen was considered to be strictly limited in quantity, while a woman is an "inexhaustible receptacle of Yin essence," R. H. van Gulik, Sexual Life in Ancient China: A Preliminary Survey of Chinese Sex and Society from ca. 1500 B.C. till 1644 A.D. (Leiden: E. J. Brill, 1961), p. 46.
} 


\section{/ Appropriation and Representation}

There is no indication that these four stories were written by Feng Menglong himself. ${ }^{21}$ But Feng must have had certain criteria in mind, both aesthetic and ideological, as he selected, edited, and rewrote preexisting stories for his collections; his exclusion of "The Double-Fish Pendants" and stories about shrews demonstrates as much. The very fact that he included the four stories above suggests that their negative portrayal of certain women characters was at least acceptable to Feng, if not exactly in line with his own views.

Is there, then, a contradiction in Feng Menglong's general attitude toward women? Liu Wu-chi's general observation about the Sanyan collections gives us a significant clue:

There is little doubt that the authors' sympathies are mostly with the weak and oppressed in society, particularly with those of the female sex. Chief among the latter are the innocent, lovely, but helpless maidens of rich official families; the hard pressed but steadfast and courageous women of humble origin; and the much maligned and injured sing-song girls in the houses of ill-fame. ${ }^{22}$

Liu suggests that Feng's attitude towards women is closely associated with their relative social positions. Feng sympathizes with women, but only with those who are "weak and oppressed in society." He has no compassion for women who have power over others, whether in sexual or social terms. Han Wuniang and the nuns, by destroying young men with their sexual power, become victimizers themselves, whether consciously or inadvertently. Similarly, the two stepmothers, empowered by the absence or death of their husbands, become literally the oppressors of their helpless children. In fact, in the entire history of Chinese literature, stepmother and mother-in-law figures have rarely been treated with compassion, even though they are female. Instead, the reader is almost always encouraged to sympathize with the stepchild or the daughter-in-law, the disempowered or the oppressed in

\footnotetext{
${ }^{21}$ According to Hanan, two of them, $H Y 15$ and $H Y 27$, might have been written by Langxian, Feng's associate; see The Chinese Short Story, pp. 243-44.

${ }^{22}$ Liu, Introduction to Chinese Literature, p. 218.
} 
each set of relationships. ${ }^{23}$ Clearly, Feng Menglong's sympathy with women goes beyond a simple distinction between male and female. For him, a woman is not an abstraction, but a social being intricately enmeshed in a net of specific interpersonal relationships. To deepen my analysis of Feng's ideas about women and his motivation for representing them as superior to men, let me first turn to feminist theory and the yin-yang paradigm, before proceeding to the underpinnings of the "beauty and flower" literary tradition in literati culture. Armed with the insights these provide, I will probe several stories attributed to Feng to illuminate the ramifications of his women characters.

\section{Femininity and Yin}

Feminist criticism takes gender as a fundamental organizing category of experience. It has been defined as "the cultural meaning attached to sexual identity," ${ }^{24}$ or "the social classification into 'masculine' and 'feminine."' 25 Thus the terms "masculinity" and "femininity" are understood as socio-cultural constructs, as patterns of sexuality and behavior imposed by cultural and social norms, not as something "natural," or given. The sense of being a "woman" is conceived not as an "essence which precedes the social organization of life, but as a category or construct produced by a society and mediated

${ }^{23}$ The most famous literary piece in this regard is probably "Southeast the Peacock Flies" ("Kongque dongnan fei"), a long narrative poem written by an anonymous poet near the end of the Latter Han dynasty (ca. A.D. 220). After suffering abuse at his mother's hands, a son and his wife commit suicide, an act often interpreted as a protest against the oppressive power of the mother figure. For an English language analysis of this poem in a comparative perspective, see Liao Ping-hui, "The (M)other in the Hall: Figures and Discourse of Mastery and Control," Tamkang Reviewe, 20.3 (1990): 237-63.

${ }^{24}$ This is Sally McConnell-Ginet's definition in her "Linguistics and the Feminist Challenge," in Women and Language in Literature and Society, ed. Sally McConnellGinet et al. (New York: Praeger, 1980), p. 16.

${ }^{25}$ Anne Oakley, Sex, Gender and Society (Aldershot: Gower, 1985), p. 16. 


\section{8}

\section{/ Appropriation and Representation}

in the discourses which it circulates about itself." 26 "One is not born, but rather becomes a woman," as the pioneer French feminist writer Simone de Beauvoir says, "it is civilization as a whole that produces this creature." ${ }^{27}$

Recent French feminist scholarship has investigated the antiquity and ubiquity of the masculine/feminine binary in Western thought. The earliest Western use of polarity relating sex to other differences is attributed by Aristotle to the Pythagoreans: it sets "male" against "female," "light" against "darkness" and "good" against "evil." ${ }^{28}$ Hélène Cixous elaborates the metaphorical and metaphysical dimensions of woman and the feminine:

Where is she?

Activity/Passivity

Sun/Moon

Culture/Nature

Day/Night

Father/Mother

Head/Heart

Intelligible/Palpable

Logos/Pathos.

Form, convex, step, advance, semen, progress.

Matter, concave, ground where steps are taken, holding and dumping ground.

Man

Woman

Always the same metaphor: we follow it, it carries us, beneath all its figures, wherever discourse is organized. If we read or speak, the same

\footnotetext{
${ }^{26}$ K. K. Ruthven, Feminist Literary Studies (Cambridge: Cambridge University Press, 1984), p. 36.

${ }^{27}$ Simone de Beauvoir, The Second Sex, trans. H. M. Parshley (New York: Knopf, 1968), p. 267.

${ }^{28}$ Ian Maclean, The Renaissance Notion of Woman (Cambridge: Cambridge University Press, 1980), pp. 2-3; also see Ruthven, Feminist Literary Studies, p. 40.
} 
thread or double braid is leading us throughout literature, philosophy, criticism, centuries of representation and reflection. ${ }^{29}$

All these binary oppositions correspond to the underlying opposition, man/woman. Yet what is stressed here is that they are locked not in horizontal complementarity but in vertical hierarchy, with the masculine side invariably valorized and privileged, and the feminine marginalized and denigrated. For Cixous and many other French feminist theorists, Western thought has always been caught up in this continuous process of hierarchical binary structures, which always come back to the man/woman opposition. ${ }^{30}$ Viewed from this perspective, the meaning of gender, which is inscribed in all discourses in Western culture, is " not simply 'difference,' but . . . division, oppression, inequality, interiorized inferiority for women." ${ }_{11}$

The concept that women have been as marginalized and oppressed as other underprivileged social groups leads to an attempt to define femininity not as an essence, but as a position, a culturally produced position of marginality in relation to patriarchal society. ${ }^{32}$ Julia

${ }^{29}$ Hélène Cixous, "Sorties: Out and Out: Attacks/Ways Out/Forays," in The Feminist Reader: Essays in Gender and the Politics of Literary Criticism, ed. Catherine Belsey and Jane Moore (New York: Basil Blackwell, 1989), p. 101.

${ }^{30}$ In "Castration or Decapitation?" Cixous makes the same argument: "In fact, every theory of culture, every theory of society, the whole conglomeration of symbolic systems- everything that is, that's spoken, everything that's organized as discourse, art, religion, the family, language, everything that seizes us, everything that acts on us-it is all ordered around hierarchical oppositions that come back to the man/woman opposition." See her "Castration or Decapitation?" Annette Kuhn, trans., Signs: Journal of Women in Culture and Society 7.1 (1981): 44.

${ }^{31}$ Michele Barrett, Women's Oppression Today: Problems in Marxist Feminist Analysis (London: Villiers, 1980), pp. 112-13.

${ }^{32} \mathrm{~K}$. K. Ruthven offers a clear explanation of the relation between the position of women and that of underprivileged social groups in a society where the hierarchical binary pattern is the pervasive mode of thought: "Binary systems which sort people into winners and losers or oppressors and oppressed tend to be imagined in two dominant forms. One is a 'vertical' model which . . . visualizes hierarchy as the placing of a 'higher' above a lower. . . . The other is a 'horizontal' model which has a center occupied by an elite, and hoi polloi banished to its margins. ... Each social group from whose underprivileged conditions feminists have troped the oppression of women is 
Kristeva sees femininity simply as "that which is marginalized by the patriarchal symbolic order." This relational definition allows her to argue that men can also be constructed as marginal to the symbolic order, as her analysis of such avant-garde writers as Mallarmé and Joyce has suggested. ${ }^{33}$ Cixous claims in her essay "La jeune née" that "women and thieves ... share the same algebra of the imagination, that of marginal, peripheral people condemned by society to relative being." 34

Kristeva and Cixous have also tried to promote the idea of bisexuality as an attempt to subvert and go beyond the rigid hierarchical order of sexual classification. Their focus has moved from the difference between apparently separate terms to the difference within one individual, one sex or one text. Cixous describes her concept of bisexuality as "the location within oneself of the presence of both sexes, evident and insistent in different ways according to the

itself marginalized by the centering of an exclusive hegemony which blacks identify as 'ethnocentric,' Third World peoples as 'Eurocentric' and women as 'androcentric' (or phallocentric)," K. K. Ruthven, Feminist Literary Studies, pp. 50-51.

${ }^{33}$ See Toril Moi, "Feminist, Female, Feminine," in Belsey and Moore, The Feminist Reader, pp. 126-27. For Kristeva's comments on Mallarmé and Joyce, see her Revolution in Poetic Language, Margaret Waller, trans. (New York: Columbia University Press, 1984), p. 88. Ann Rosalind Jones has also noted the relation between marginality and femininity and the popularity of some male writers among French feminist critics: “. . . certain male writers' marginality to mainstream sexual and socialliterary conventions leads them to produce 'feminine' writing. Proust and Genet are heroes to many Franco-feminist critics." See Ann Rosalind Jones, "Inscribing Femininity: French Theories of the Feminine," in Making a Difference, ed. Gayle Greene and Coppélia Kahn (London: Methuen, 1985), p. 96. For some other critics however, Kristeva's theory of both the so-called male avant-garde and sexual difference is far too equivocal and even implies an "anti-feminist stance." For instance, Elizabeth Grosz remarks that Kristeva's call for "a feminism that is not confined to sexual differences" implies "the annihilation of women's struggles for sexual specificity and autonomy," Sexual Subversions (Sydney: Allen \& Unwin, 1989), p. 97. For a defense of Kristeva's position, see John Lechte, Julia Kristeva (London \& New York: Routledge, 1990), pp. 203-8.

${ }^{34}$ Quoted in Rosette C. Lamont, "The Off-center Spatiality of Women's Discourse," in Theory and Practice of Feminist Literary Criticism, ed. Gabriela Mora and Karen S. Van Hooft (Ypsilanti, Michigan: Bilingual Press, 1982), p. 139. 
individual, the nonexclusion of difference or of a sex. . . ."35 Kristeva relates bisexuality to her formulations of textual dynamics: "All speaking subjects have within themselves a certain bisexuality which is precisely the possibility to explore all the sources of signification, that which posits a meaning as well as that which multiplies, pulverizes, and finally revives it." ${ }^{36}$

Although the French feminists' critique of the patriarchal binary schemes is directed against Occidental culture, the new perspective it offers provides a convenient tool for examining the sex-gender system of the Chinese tradition as embodied in Chinese texts. The binary system that permeates Chinese culture with almost equal ubiquity can be traced to the ancient yin-yang concept which polarizes masculinity and femininity, activity and passivity, heat and cold, brightness and darkness, etc. ${ }^{37}$ However, if for the French feminist critics all binary structures finally "come back to the man/woman opposition," ${ }^{38}$ for the Chinese it is the yin-yang principles that represent or underlie the relative differences and mutual interdependence of every pair of oppositions, including that of man and woman. ${ }^{39}$ Although the relationship between the two is not necessarily a non-hierarchical one, the emphasis is generally on the interplay or the interaction of $y$ in and yang..$^{40}$ It is also believed that yin-yang interplay takes place in the

${ }^{35}$ Cixous, “Sorties: Out and Out," p. 104.

${ }^{36}$ Kristeva, "Oscillations between Power and Denial," trans., Marilyn A. August, in New French Feminisms: An Anthology, ed. Elaine Marks and Isabelle de Courtivron (Amherst: Univ. of Massachusetts Press, 1980), p. 165.

${ }^{37}$ Fung Yu-lan, A Short History of Chinese Philosophy, Derk Bodde, ed. (New York: Macmillan, 1961), p. 138.

${ }^{38}$ Hélène Cixous, "Castration or Decapitation?" p. 44.

${ }^{39}$ Wing-tsit Chan's etymological study does not lead to a definite conclusion: "we are not sure whether the terms 'yin' and 'yang' originally referred to physical phenomena (clouds shading the sun and the sun shining, respectively) or the female and male." See Wing-tsit Chan, A Source Book in Chinese Philosophy (Princeton: Princeton University Press, 1963), p. 244.

${ }^{40}$ Andrew Plaks has listed four characteristics of the Chinese logical method for dealing with the problem of duality: (1) bipolarity, (2) ceaseless alternation, (3) 


\section{2 / Appropriation and Representation}

human body, ${ }^{41}$ which obviously makes "sexual difference . . . a relative and flexible bipolarity in natural philosophy." 42 This belief, as Robert E. Hegel points out, "finds expression as male and female aspects of a personality" in Chinese literature, ${ }^{43}$ and may explain why gender identity is sometimes treated as fluid in the Chinese literary tradition. It also justifies drawing on the French feminist idea of bisexuality to understand the late Ming literati notion of gender identity.

However, when the yin-yang theory is applied in the realm of social ethics by Confucians as a metaphysical justification of the social order, the hierarchical nature of the Chinese binary system becomes blatantly obvious. For instance, Dong Zhongshu (ca. 179-ca. 104 B.C.), one of the most influential Confucian theorizers described the doctrine of the "three bonds" (sangang) ${ }^{44}$ this way:

... the relationships between ruler and subject, father and son, husband and wife, are all derived from the principles of the yin and yang. The ruler is yang, the subject yin; the father is yang, the son yin; the husband is yang, the wife yin. ..." 45

presence within absence, and (4) infinite overlapping. All four stress the interaction of the two poles. See Andrew H. Plaks, Archetype and Allegory in the Dream of the Red Chamber (Princeton: Princeton University Press, 1976), pp. 46-47.

${ }^{41}$ Fung Yu-lan, The Spirit of Chinese Philosophy, E .R. Hughes, trans. (Westport, Connecticut: Greenwood, 1970), p. 122.

${ }^{42}$ Charlotte Furth, "Androgynous Males and Deficient Females: Biology and Gender Boundaries in Sixteenth- and Seventeenth-Century China," Late Imperial China 9.2 (Dec. 1988): 1.

${ }^{43}$ Hegel, "An Exploration," p. 30; also see Max Kaltenmark, Lao Tzu and Taoism, trans. Robert Greaves (Stanford: Stanford University Press, 1969), pp. 60, 63.

${ }^{44}$ The term sangang refers specifically to three major sets of interpersonal relationships.

${ }^{45}$ Dong Zhongshu, "Jiyi” (Basic principles), in Zhongguo zhexue shi, ed. Beijing daxue zhexue xi (Beijing: Zhonghua, 1980), p. 208; translation from Fung Yu-lan, The Period of Classical Learning in A History of Chinese Philosophy, trans. Derk Bodde (Princeton: Princeton University Press, 1953), 2:42-43. 
Harmony or order is stressed, but obviously at the expense of the yin side: subject, son, and wife are only "secondary appendages of ruler, father, and husband." ${ }^{46}$

Before discussing the pervasiveness of the "three bonds" paradigm in Chinese culture, we must review the construction of gender in Confucian ideology, a construction that was grounded in strictly hierarchical kinship roles. ${ }^{47}$ In the "three bonds" schema, a woman has little choice but to occupy a yin position, playing the role of daughter and wife. Of course, in reality there have always been more than three sets of social relationships, and surely it is significant that there is no mother's role among the "three bonds." Had there been one, a mother might have taken over the father's authority outright in his absence or after his death, despite the conservative Confucian advocacy of the "three obediences and four virtues" for women. ${ }^{48}$ In social practice, a mother commanded considerable respect from her son and his peers. In 1856, a British interpreter, Thomas Taylor Meadows, noted that upper-class mothers could wield real power:

Woman is still more of a slave of man among the Chinese than among Anglo-Saxons. The quality of her slavery is, however, much tempered by the great veneration which Confucian principles require sons to pay both parents. The Imperial Government dare not refuse leave of absence to a mandarin if he, as an only son, requires it in order to tend his widowed mother during her declining years; even though the government may know that the real cause of his asking for leave, is to

\footnotetext{
${ }^{46}$ Fung Yu-lan, A History of Chinese Philosophy, 2:43.

${ }^{47}$ Furth, "Androgynous Males and Deficient Females," p. 1.

${ }^{48}$ The "three obediences" (sancong) include a woman's obedience to her father (before marriage), to her husband (when married), and to her sons (in widowhood). The "four virtues" (side) include chastity, physical charm, propriety in speech, and proficiency in needlework. See Mowry, Chinese Love Stories, p. 153. Dorothy Ko, however, argues that sancong should be translated into English as "thrice following," rather than "three obediences," for the latter "oversimplifies the workings of gender relations and the Confucian ethical system"; sancong "deprived a woman of her legal and formal social identity but not her individual personality or subjectivity." See her Teachers of the Inner Chambers: Women and Culture in Seventeenth-Century China (Stanford: Stanford University Press, 1994), pp. 6-7.
} 


\section{4 / Appropriation and Representation}

escape from some impending official difficulty. . . . Introductions to mothers are ... not infrequent. The friend introduced then performs the kow-tow to the lady. ... The son does not prevent him, but he returns the salute by kneeling and kow-towing to his friend. Thus two men, and often, of course, gray-bearded men of high station, will in China be found knocking their heads against the floor in honour of a woman of their own class in society. Add to this that if a mother accuses her son before the magistrate, the latter will punish him as a black slave is punished in an American flogging-house, i.e. without inquiry into the specific offence." ${ }^{49}$

However, a man - a man of the literati class - might be either yin or yang in the "three bonds" paradigm, depending on the particular relational context. He is yin in relation to the ruler or the center of political power, but he is yang in relation to his wife (or wives) and children. In moments of political frustration or career failure, his sense of being yin or marginalized is intensified, and is perhaps further intensified when it is contrasted to his sense of being yang in the familial context. When in a yin position vis-à-vis some higher authority, it is reasonable to assume that a man might sometimes identify with women who are perpetually in a yin position according to the "three bonds." If Kristeva's emphasis on marginality allows us to see Western repression of the feminine in terms of positionality, it also throws light on the affinity between a frustrated man of the literati class and women. The notion of marginality is key to understanding the literati's potentially subversive attitude towards certain social conventions and the established social hierarchy. ${ }^{50}$

\footnotetext{
${ }^{49}$ Quoted in Lien-sheng Yang, "Female Rulers in Imperial China," rpt. in Studies of Governmental Institutions in Chinese History, ed. John L. Bishop (Cambridge: Harvard University Press, 1968), pp. 155-56.

${ }^{50}$ Judith Butler questions in a different way the assumption that the term woman denotes a common identity. "If one 'is' a woman," she says, "that is surely not all one is; the term fails to be exhaustive, not because a pregendered 'person' transcends the specific paraphernalia of its gender, but because gender is not always constituted coherently or consistently in different historical contexts, and because gender intersects with racial, class, ethnic, sexual, and regional modalities of discursively constructed identities. As a result, it becomes impossible to separate out 'gender' from the political and cultural intersections in which it is invariably produced and maintained." See her
} 
It is clear that the yang figure is always referred to as the one who has the higher social status and is often the more powerful. Although the yin-yang paradigm may also have moral and psychological dimensions, clearly the yang figure does not necessarily represent moral superiority. In the eyes of a yin figure, especially when he/she feels unfairly put into an inferior position by those with power, moral superiority may belong to those marginalized or yin. It is largely the moral superiority or sense of justice assumed by the yin figure that explains his/her developing a subversive attitude toward yang figures, or what yang represents. ${ }^{51}$

Surely Feng Menglong was just this sort of marginalized man. Below I will demonstrate how the complex anxieties from this marginality are consciously or inadvertently revealed through his identification with now yin, now yang, positions or gender identities in different Sanyan stories. However, before turning to Feng's stories, we should address the historical affinity between the literati class and yin (or women's) positions in China's power structure, and examine the pervasive meiren xiangcao (beauty and flower) poetic tradition, with which Feng as a literary man must have been familiar.

\section{Sources of Literati Trans-gender Expression}

Traditional Chinese literature was so intimately related to politics that it is no exaggeration to claim that in China the art of literature was "an epiphenomenon of politics." ${ }^{2}$ Chinese men of letters were almost invariably members of the bureaucracy or candidates for government posts and they "simply transferred their endeavors from a

Gender Trouble: Feminism and the Subversion of Identity (New York: Routledge, 1990), p. 3.

${ }^{51} \mathrm{Cf}$. Julia Kristeva's theory of "marginality, subversion and dissidence," especially as set forth in her "Un nouveau type d'intellectuel: le dissident," Tel Quel, 74 (Hiver, 1977): 3-8; see also Toril Moi, Sexual/Textual Politics: Feminist Literary Theory (London and New York: Methuen, 1985), pp. 163-67.

${ }^{52}$ Laurence A. Schneider, A Madman of Ch’u (Berkeley: University of California Press, 1980), p. 65. 


\section{6 / Appropriation and Representation}

political to a literary plane." ${ }^{53}$ Stephen Owen's observation on the literati's anxiety of service is important for a deep understanding of the political nature of Chinese literature in general:

Traditional Chinese literature and civilization cannot be understood without grasping the unique emotional power which government and public service exercised over men's lives and imaginations. That power is sometimes expressed directly; sometimes it is only implicit; it lurks behind the celebration of drunken insouciance or the joys of retreat no less than it dominates the plea for preferment. If invisible in the text itself, the public context will often be supplied as the secret frame of reference by commentators and readers. ${ }^{54}$

Stephen Owen's explanation of this "emotional power," this special bond between Chinese literati's psychological needs and public office, is full of insight. He says that "the Chinese tradition offered no constant and divine witness of the human soul, who saw instantly into the hearts of men and measured their worth. ... To receive knowledge of human nature there could only be mortal witnesses, zhiyin, the 'understanders." He goes on to assert that seeking "recognition through a poem was an act for others, a public act, and it often referred the reader to the largest public context, the imperial government." 55

But this anxiety of service may also need to be understood in terms of the special "marginalized" social position-to use Julia Kristeva's notion again-in which the literati had found themselves ever since the beginning of Chinese history. Historians now generally agree that shi as a social group (usually translated into English as "literati" or "scholars") originated with the class of educated knights who made up the lowest levels of the aristocracy during the Spring and Autumn period (770-476 B.C.). Although their social positions were

\footnotetext{
${ }^{53}$ William H. Nienhauser, Liu Tsung-yuan (New York: Twayne, 1973), p. 15.

${ }^{54}$ Stephen Owen, Traditional Chinese Poetry and Poetics: Omen of the World (Madison: University of Wisconsin Press, 1985), p. 252. Owen's emphasis.

${ }^{55}$ Ibid., pp. 251, 252.
} 
higher than those of the commoners (sburen), they served only at the grass-roots level and were not regarded as part of the ruling class. ${ }^{56}$

In the succeeding Warring States period (475-221 B.C.) the literati were increasingly marginalized. Their social status was reduced to the highest of the four commoner classes (simin zbi shou), and their relationship with the ruling class became more volatile. ${ }^{57}$ The terms "travelling literati" (youshi) and "dependent literati" (yangshi) that emerged in this period points to the political dilemma of the literati. "Travelling" (you) suggests that they were socially rootless and had no power base either individually or collectively; "dependent" (yang) means that they had to depend on a ruler or the ruling class for economic support and a political career..$^{58}$

In the Former Han period (206 B.C.-A.D. 8), the literati class attempted to stabilize their status by securing institutional recognition. They were successful to a certain extent, but their victory was "doubleedged," as Hellmut Wilhelm points out: "Their position ... was based upon the premise of their dependence upon government." ${ }^{39}$ Thus, career security and the realization of their political ideals remained beyond reach. ${ }^{60}$ Ironically, the unification of China actually consolidated and enhanced the emperor's power, removing the possibility that the literati might choose their own master. ${ }^{61}$ From the Sui-Tang periods (589-618 and 618-907) onward, entry into officialdom through the civil service examinations became the principal form of upward social mobility for this group.

\footnotetext{
${ }^{56} \mathrm{Yu}$ Yingshi, "Gudai zhishi jieceng de xingqi yu fazhan," in his Shi yu Zhongguo wenbua, pp. 6, 9.

${ }^{57} \mathrm{Yu}$ Yingshi, "Gudai zhishi jieceng," p. 20.

${ }^{58} \mathrm{Xu}$ Fuguan, "Zhongguo zhishifenzi de lishi xingge he lishi mingyun," in Zhou Yangshan, ed., Zhishi fenzi yu Zhongguo (Taipei: Shibao wenhua, 1980), p. 206.

${ }^{59}$ Hellmut Wilhelm, "The Scholar's Frustration: Notes on a Type of 'Fu," in Fairbank, Chinese Thought and Institutions, p. 316; my emphasis.

${ }^{60}$ For a brief discussion of the Chinese literati's general tendency to regard secular, political affairs with religious passion, see $\mathrm{Yu}$ Yingshi, "Daotong yu zhengtong zhijian," Shi yu Zhongguo wenhua, pp. 107-8.

${ }^{61} \mathrm{Yu}$ Yingshi points out that although Confucianism was officially canonized in the Former Han dynasty, the emperors' control over the Confucian scholars actually became much tighter; "Daotong yu zhengtong zhijian," pp. 110-12.
} 


\section{8 / Appropriation and Representation}

It is no wonder that this sense of precariousness, of marginality, frequently found expression in literati writings. The notion sbi bu yu (a scholar's not encountering [an opportune time for public service], or the scholar's frustration) is a perennial theme in traditional Chinese literature. ${ }^{62}$ This anxiety was often expressed allegorically through a woman's voice or through the representation of a woman in relation to her lover or husband. We frequently see the analogy drawn between a deserted or neglected wife and a frustrated scholar whose talents and inner worth go unrecognized and unappreciated by the sovereign. There seems little doubt that the sense of marginality, of being yin and dependent upon the whims of the sovereign for a political career, made the literati so obsessed with this analogy. Bai Juyi's (772-846) poem "The Road to the Taihang Mountains" ("Taihang lu") almost too clearly illustrates the sense of "misrecognition" and betrayal shared by frustrated scholars and deserted wives. It even bears the subtitle "A Satire on the Unpredictable Sovereign-Subject Relation in Terms of the Husband-Wife Relation" ("Jie fufu yi feng junchen zhi buzhong ye"):

Over the road to the Taihang

Carts and barrows break;

But compared with the hearts of men,

The going is smooth;

In the five years of our married life,

We have drifted apart,

Like the Herd Boy and the Weaving Maid,

Like stars that never meet.

${ }^{62}$ Hellmut Wilhelm observes that shi bu yu seems to "have been the problem that monopolized the literary mind in that period [the Han dynasty] to the exclusion of almost everything else," "The Scholar's Frustration," p. 311. Dong Zhongshu and Sima Qian each wrote a $f u$ on this theme; for an English translation of these $f u$, see James Robert Hightower, "The Fu of T'ao Ch'ien," Harvard Journal of Asiatic Studies 17.1-2 (June, 1954): 200-203 and 197-200, respectively. For more examples of sbi bu yu in poetry, see Han Jingtai, "Lun Zhongguo gudian shige de beijuxing mei," rpt. in Zhongguo gudai jindai wenxue yanjiu 1990.7:263-79. This theme is also expressed as "worthy men never realize their aims" (xianren bu dezbi); see Eric Henry, "The Motif of Recognition in Early China," Harvard Journal of Asiatic Studies, 47.1 (June 1987): 28. 
Loss of beauty, so it is said,

Means desertion by men,

To the regret of erstwhile beauties.

But my face in the mirror is the same as before.

It is your heart that has changed.

In this world, do not be a woman,

For her joys and sorrows

Lie in the hands of others.

...

It is the same for busbands and wives

As it is for the Emperor and bis councilors.

The ministers who serve in the court

Are granted favors in the morning

But told to die by evening. ... ${ }^{63}$

This use of a gendered, role-based allegory for the sovereign-subject relationship, the so-called "beauty and flower" tradition, can be traced back to Qu Yuan (343?-278 B.C.), who is considered to be the first man to have represented himself as a woman in poetry and to have used romantic love as a metaphor for his complex feelings for his sovereign. ${ }^{64}$ This practice of equating politics with gender- or reading

${ }^{63}$ From Quan Tang shi, (Beijing: Zhonghua shuju, 1960), 7:426.4694; English translation based on Rewi Alley, trans., Bai Juyi: 200 Selected Poems (Beijing: New World Press, 1983), pp. 109-11; my emphasis.

${ }^{64}$ See David Hawkes, Ch'u Tz'u: The Songs of the South (Oxford: Clarendon Press, 1959), pp. 211-12; Schneider, pp. 32-33; and also see You Guo'en, "Chuci nüxing zhongxin shuo," in his Chuci lunwen ji (Hong Kong: Wenchang, 1955), pp. 191-92. For a discussion of the ambiguous gender identity of the persona in Chu ci (not only does the speaker's gender identity constantly shift, sometimes (s)he regards the king as female- a phenomenon not found in the subsequent "beauty and flower" tradition), see Yang Jun, "Chenqie yishi yu nüxing renge-gudai shidafu wenren xintai yanjiu zhiyi," rpt. in Zhongguo gudai jindai wenxue yanjiu 1991.11:20-29. Yang Jun argues that the concept of gender in ancient Chu culture was close to that of the Arapesh (i.e., there was no major distinction between masculine and feminine) as described in Margaret Mead's Sex and Temperament in Three Primitive Societies (New York: William Morrow, 1935), pp. 134-61. Yang's point is very interesting but needs additional anthropological and archeological evidence. 
love poetry as political allegory-soon developed into a poetic convention. Arthur Waley was obviously greatly impressed with this peculiar literary phenomenon when he introduced traditional Chinese poems to his Western audience some seventy-five years ago:

... love-poetry addressed by a man to a woman ceases after the Han dynasty; but a conventional type of love-poem, in which the poetry speaks in the person of a deserted wife or concubine, continues to be popular. The theme appears to be almost an obsession with the Tang and Song poets. In a vague way, such poems were felt to be allegorical ... the woman typifies the Minister, and the lover the Prince, so in those classical poems the poet in a veiled way laments the thwarting of his own public ambition. ${ }^{65}$

There are too many such poems to enumerate, but let me cite one example here to show just how close the relationship could be between a poet's anxiety of service and his identification with (the yin position of women.

On The Eve of the Government Examinations, to Secretary Zhang

Last night in the wedding-chamber red candles stood.

At dawn in state the bride will meet your parents.

She has finished preparing and asks you meekly

Whether her eyebrows are painted in fashion. ${ }^{66}$

${ }^{65}$ Arthur Waley, A Hundred and Seventy Chinese Poems (New York: Knopf, 1919), p. 20. Waley does not relate the psychological need "to be known" to public office as Owen does, nor does he mention the involvement of the yin-yang theory in this literary phenomenon. It is uncertain why among the "three bonds" the father-son relation was much less preferable to represent the sovereign-subject relation. Zhang $\mathrm{Fa}$ explains that the father-son relation differs from the other two in the fact that no one can choose his/her father. See Zhang $\mathrm{Fa}$, Zhongguo wenhua yu beiju yishi (Beijing: Zhongguo renmin daxue, 1989), p. 23. I would suggest that while the position of a sovereign or husband should not or cannot be occupied by a subject or wife, every man is encouraged to be a father in traditional Chinese society. In other words, the understanding that almost every son will have his turn to be a father makes it a less suitable analogy to the sovereign-subject relation.

${ }^{66}$ Translation based on Witter Bynner, quoted in One Hundred Quatrains by the Tang Poets: English Translations, ed. Lü Shuxiang (Changsha: Hunan renmin, 1980), p. 78. 
This much-anthologized poem was written by the Tang dynasty poet Zhu Qingyu (fl. 826). On the mimetic level, it is about a bride's anxious state of mind before meeting her husband's parents for the first time on the morning after the wedding. She is asking her husband whether she looks proper for that critical occasion. If she makes a good first impression, she has a better chance of being accepted and enjoying a relatively harmonious relationship with them.

But the title of the poem explicitly demands a different level of reading. The bride's anxiety is a metaphor for the parallel uneasiness the poet experiences "on the eve of the government examinations." This poem also had a practical purpose: to send a message to Secretary Zhang that demonstrated the poet's qualification for government service. According to the Qing commentator He Wenhuan, who supplied this poem's public context, Secretary Zhang Ji was Zhu Qingyu's patron, a man who "appreciated" his literary talent as a zhiyin (one who truly understands). He replied to Zhu's inquiry with another poem, which compares Zhu to a beautiful woman who "sings" so well that her songs are enjoyed by everyone. Thus, the message was sent back: Zhu would be accepted into the Chinese bureaucracy, and soon thereafter he was appointed to an official post. ${ }^{67}$

A few points can be made here that may sharpen our reading of gender issues in the Sanyan stories. First, the primary force at work in this poem is the poet's anxiety of service. Second, when pressed by this anxiety of service, the poet is likely to project himself onto his idea of woman. The implication of this analogy is that, in his mind, a woman depends on the appreciation of her man, much as he depends on the acknowledgement of his worth by his patron and/or government. Third, the patron or senior official remains symbolically a man; only the protégé or applicant, who is still this side of officialdom, is constructed as a woman by both parties in both poems. In other words, in a hierarchically structured relationship involving two men, it is always the man in the lower position who is identified as a "woman."

\footnotetext{
${ }^{67} \mathrm{He}$ Wenhuan, ed., Lidai shibua, 1770, rpt. (Beijing: Zhonghua, 1980), 1:151; also see Tangshi jianshang cidian, ed. Xiao Difei et al. (Shanghai: Shanghai cishu, 1983), pp. 98586.
} 


\section{2 / Appropriation and Representation}

Finally, the practical, epistolary nature of these two "poems on social occasions" suggests that this gender allegory had gone beyond the generic boundary of poetry. ${ }^{68}$ As Pauline $\mathrm{Yu}$ points out, "the categorical correspondence between wife and minister was a deeply rooted cultural assumption, so that any allusion to one would unavoidably implicate the other." ${ }^{99}$ This correspondence can be found in many different types of writing. In philosophy, it can be traced to the works of Shen Buhai, a thinker of the fourth century B.C., ${ }^{70}$ and a cosmological equation of ministers and females can be found in as early a text as the Book of Changes (Yijing). In the commentary on the hexagram kun in the Appendixes to that work, we find the same type of "correlative thinking" that was later refined and elaborated through the appropriation of the yin-yang theory by Dong Zhongshu:

Although [the subject of] this divided line has excellent qualities, he [does not display them, but] keeps them under restraint. 'If he engages with them in the service of the king, and be successful, he will not claim that success for himself'- this is the way of earth, of a wife, of a minister. ${ }^{71}$

Here we see that the wife-minister analogy is much more than a literary trope or a rhetorical device; it is practically a mode of thought, a special way of looking at the universe. In historical writings as early as the Chronicles of Zuo (Zuo zhuan), there are many instances of a

${ }^{68}$ For a discussion of Chinese occasional poetry, see Stephen Owen, Traditional Chinese Poetry and Poetics, pp. 211-12, 225-42, 249.

69 The Reading of Imagery in the Chinese Poetic Tradition (Princeton: Princeton University Press, 1987), p. 123; my emphasis.

${ }^{70}$ Herrlee G. Creel, Shen Pu-hai: A Chinese Political Philosopher of the Fourth Century B.C. (Chicago: University of Chicago Press, 1974), p. 45.

${ }^{71}$ James Legge, trans., The Yi King or Book of Changes, in The Sacred Books of China: The Texts of Confucianism (New York: Charles Scribner's Sons, 1899), p. 420, my emphasis; see also You Guo'en, Chuci lunwen ji, p. 192. For an excellent discussion of Chinese "correlative thinking," i.e., objects and humans were all categorized through their corresponding relations to others, see A. C. Graham, Yin-Yang and the Nature of Correlative Thinking (Singapore: The Institute of East Asian Philosophies, 1986), esp. 1-24. See also Joseph Needham and Wang Ling, Science and Civilization in China (Cambridge: Cambridge University Press, 1956), 2:279-80. 
minister adopting a woman's persona when making allegorical use of a Book of Songs (Shijing) love poem." The famous saying, "A scholar devotes his life to the one who appreciates him; a woman adorns herself for the one who delights in her" (shi wei zbijizbe si, nü wei yuejizhe rong), attributed to Bi Yurang (mid-fifth century B.C.) and first recorded in Intrigues of the Warring States (Zhanguo ce), ${ }^{73}$ was reiterated in Han times by Sima Qian (ca. 145-ca. 87 B.C.) in his Records of the Grand Historian. ${ }^{74}$

Even more directly related to our reading of the Sanyan stories in terms of this sort of "correlative thinking" is "The Story of Wang Qiang" (better known as Wang Zhaojun), or rather the reading convention for this story, which fully testifies to the cross-generic pervasiveness of the wife-minister analogy. It is a semi-fictional account, attributed to Ge Hong (ca. 281-341), relating on the mimetic level a Han dynasty emperor's mistaken banishment of a beautiful court lady-Wang Zhaojun - to a remote area where, for reasons of diplomacy, she was to marry a Tartar chieftain. ${ }^{75}$ The story proved so irresistibly fascinating to generations of Chinese readers that it was presented over and over again in almost all forms of traditional literature: poems, songs, oral stories and plays. $^{76}$ As Eric Henry points

72 See Eric Henry, “The Motif of Recognition,” p. 29.

${ }^{73}$ Zhanguo ce (Shanghai: Shanghai guji, 1978), 18.585-93, 597-600.

${ }^{74}$ Sima Qian, "Cike liezhuan" (Biographies of assassins) Shiji (Beijing: Zhonghua shuju, 1972), 86.2519. When applying the phrase to his own case in his letter to Ren An, Sima Qian changes the wording slightly (but significantly) by substituting yong (to serve or to be employed) for Bi Yurang's si (to die). Hence it becomes "a scholar acts on behalf of the one who appreciates him, as a woman adorns herself for the one who delights in her." See Eric Henry, "Motif of Recognition," p. 12; and Sima Qian, "Letter to Jen An (Shao-ch'ing)," J. R. Hightower, trans., in Cyril Birch, ed., Anthology of Chinese Literature: From Early Times to the Fourteenth Century (New York: Grove Weidenfeld, 1965), p. 103. For Bi Yurang's story, see “The Biography of Yü Jang," William H. Nienhauser, Jr., trans., in Ma and Lau, Traditional Chinese Stories, pp. 41-42.

${ }^{75}$ Ge Hong, "Wang Qiang," Xijing zaji, juan 2, rpt. Gudai duanpian xiaoshuo xuanzhu (Beijing: Beijing chubanshe, 1983), 1:19-21.

${ }^{76}$ See Li Xiusheng, "Ma Zhiyuan," Zhongguo da baike quanshu: xiqu quyi (Shanghai: Zhongguo da baike quanshu chubanshe, 1983), p. 240. The most famous play on this 


\section{4 / Appropriation and Representation}

out, beginning with "Wang Zhaojun," "neglected-beauty stories were read as if they were actually neglected genius stories, so close was the literary identification of concubines with ministers." 77 Lü Zhenghui even goes so far as to say that "no literatus could refrain from sighing and weeping after reading Wang Zhaojun's story if he believed his inner worth was as great as hers, and felt as frustrated and lonely as she did." ${ }^{7}$

\section{Gendered Expressions of Anxiety in the Sanyan}

Let us return to Feng Menglong and examine the ways his anxieties play out in the Sanyan collections. We know that the anxiety of service among scholars in the Ming dynasty was greatly intensified as competition in the civil service examinations became increasingly fierce. This was particularly true in the lower Yangzi valley, a wealthy area with high levels of education and cultural sophistication, the area

theme is of course, Ma Zhiyuan's (ca. 1260-ca. 1325) Hangong qiu (Autumn in the Han palace).

${ }^{77}$ Eric Henry, “The Motif of Recognition,” p. 29.

${ }^{78}$ Lü Zhenghui, “'Neilian' de shengming xingtai yu 'gujue' de shengming jingjie,” in his Shuqing chuantong yu zhengzhi xianshi (Taipei: Da'an, 1989), p. 214. According to Yang Jun, there was a tendency since the Song dynasty to emphasize the absoluteness of a minister's loyalty to the government he served by using this wife-minister analogy. Sima Guang's (1019-1086) saying "A loyal minister does not have two sovereigns, a loyal wife does not have two husbands" is a good example (English translation from A. W. Sariti, "Monarchy, Bureaucracy, and Absolutism," Journal of Asian Studies 32 [Nov. 1972]:61). Yang Weizhen (1296-1370), a well-known Han Chinese poet in the fourteenth century, served as a minor official towards the end of the Mongolian Yuan dynasty (1260-1368). When the Chinese Ming dynasty was established and the new emperor invited him to the new court to serve, Yang refused, saying that an old woman should not get married again. Then he wrote a poem "Lao kefu yao," in which he speaks in a widow's voice, missing her husband. Yang Jun thinks that Yang Weizhen's refusal could hardly be explained away by any other theories-it was neither a matter of ethnicity nor of vested interests- except that he had internalized the value manifested in Sima Guang's saying; see Yang Jun, "Chenqie yishi yu nüxing renge," pp. 27-28. 
where Feng Menglong was brought up. ${ }^{79}$ As Robert E. Hegel points out:

The frustration caused by failure in the examinations was compounded by the relatively high shengyuan quotas maintained during most of the seventeenth century [normally, shengyuan, the lowest degree holders, were never appointed to official positions]; the population had doubled from the late fourteenth century to 1600 , but the numbers of recipients of this lowest degree multiplied by twenty-fold. The bureaucracy did not grow accordingly; the number of jinshi degrees awarded remained virtually constant [normally jinshi holders were appointed to official positions]. . . . Those unable to pass beyond the lowest level remained a large and disgruntled group. Quotas also favored culturally backward areas, concentrating the frustrated would-be official-gentry, including presumably men of considerable talent, in the areas of highest cultureparticularly the lower Yangzi valley. It is not surprising that the novel developed there at this time, for many novelists were from precisely this group. Significantly, frustrated holders of the lower degrees and aspirants thereto figured prominently among the leadership of rebel bands and revolutionary forces throughout the Ming and Qing. ${ }^{80}$

From the limited biographical information available, we know that when Feng Menglong finished publishing the last of the Sanyan collections in 1627 at the age of fifty-three, he was still holding a degree of the lowest level, with no official appointment anywhere on the horizon. ${ }^{81}$ Like most scholars of his time, his "highest ambition was to hold office himself"; 82 and like them, he must have experienced a great

\footnotetext{
79 For a brief account of the intensification of scholars' frustration, see Hegel, The Novel in Seventeenth-Century China, pp. 12-17, esp. 14-15. On the civil service examination system in Ming and Qing times, see Ho Ping-ti, The Ladder of Success in Imperial China: Aspects of Social Mobility: 1368-1911 (New York: Columbia University Press, 1962).

${ }^{80}$ Hegel, The Novel in Seventeenth-Century China, pp. 14-15.

${ }^{81}$ For Feng Menglong's biographical information see Hanan, The Chinese Vernacular Story, pp. 80-82; Mowry, Chinese Love Stories, pp. 29-34; and Ye Ru, "Guanyu Feng Menglong de shenshi," Ming-Qing xiaoshuo yanjiu lunwen ji (Beijing: Renmin wenxue, 1959), pp. 34-38.

${ }^{82}$ Hanan, The Chinese Vernacular Story, p. 80.
} 


\section{6 / Appropriation and Representation}

deal of frustration and emotional suffering for his repeated failures. It is no wonder that this sense of exclusion from the political center found expression in his writings. ${ }^{83}$

In the three Sanyan collections, stories that deal directly with the civil service examinations and official careers, or relate explicitly to them, constitute a fairly large portion of the collections-a little over 40 percent. In many of them, the protagonist or main character has finally passed the examinations or is promoted to the very top of officialdom. ${ }^{84}$ In others, although the main characters may not be able to choose the civil service as a profession because they lack the proper education, or because as women they were excluded from the examinations, they are in the end able to share in the honor and glory of their sons' or grandsons' career success in the bureaucracy ${ }^{85}$ There are also a number of stories, which, although not directly related to examinations or promotions, reveal the literati desire to be known and appreciated through an elaboration on the theme of "looking for a zhiyin." ${ }^{\circ 6}$

\footnotetext{
${ }^{83}$ This does not mean that he never had any moments of happiness in his life. He must have been happy, for example, when he was deeply in love with the famous courtesan Hou Huiqing before 1596, or when he was shown respect for his literary talent; see Gao Hongjun, "Guazhir chengshu kao ji Feng Menglong Hou Huiqing lianli yuanwei," rpt. in Zhongguo gudai jindai wenxue yanjiu, 1992.7:195-200.

${ }^{84}$ See, for example, GJ 5, GJ 9, GJ 11, GJ 23, GJ 31, GJ 34, TY 6, TY 12, TY 15, TY 17, $T Y$ 18, TY 23, TY 24, TY 27, HY 5, HY 7, HY 8, HY 9, HY 11, HY 18, HY 19, HY 20, $H Y$ 22, $H Y$ 25, $H Y$ 28, $H Y 30 H Y$ 31, and $H Y$ 32, totaling twenty-eight stories. According to Patrick Hanan, eight of them are attributable to Feng Menglong (GJ 5, GJ 9, GJ 31, TY 12, TY 15, TY 17, TY 18 and $T Y$ 23). See Hanan, The Chinese Short Story, pp. 233-45.

${ }^{85}$ See, for example, GJ 2, GJ 4, GJ 10, GJ 17, GJ 28, GJ 39, GJ 40, TY 5, TY 11, TY 17, $T Y 22, T Y 23, T Y 25, T Y 29, T Y 31, H Y 1, H Y 2, H Y 3, H Y 17, H Y 22, H Y 28$ and $H Y$ 36, totaling twenty-two stories. Eleven of them can be attributed to Feng Menglong (GJ 2, GJ 10, GJ 17, GJ 39, GJ 40, TY 5, TY 11, TY 17, TY 22, TY 25 and $T Y$ 31); see Hanan, The Chinese Short Story, pp. 233-45.

${ }^{86}$ See for instance, GJ 7, GJ 8, GJ 12, GJ 16 and TY 1. GJ 8 and GJ 12 are attributed to Feng by Hanan; see Hanan, The Chinese Short Story, p. 237. That the theme of zhiyin is closely related to the anxiety of service is testified by a line of poetry in $T Y 17$, a story attributable to Feng Menglong himself: "With no zhiyin, he was in distress for ten
} 
The most revealing of these stories is "The Old Protégé" (TY 18), a story that Feng Menglong admitted writing himself. ${ }^{87}$ Xianyu Tong, the main character, fails every examination held over fifty years in spite of his exceptional talents. Naturally, he cannot help complaining about the unfairness of the examination system. He grumbles,

The trouble is that this is an examination world. If Confucius had taken the examinations and failed, who would be telling us about his genius? If a village lad who roughly memorizes a few obsolete eight-legged essays meets up with a purblind examiner who marks haphazardly and becomes a jinshi [holder of the highest degree] in his sleep, people will all declare themselves his disciples. ${ }^{88}$

Finally at the age of sixty-one Xianyu Tong succeeds in passing the examinations and obtaining an official position. He believes he owes his success to his "patron," who happens to have been the examiner for all of the three levels of examinations he had sat for. The irony is that this examiner always tried to pass young candidates and flunk old ones like Xianyu Tong; but in his very effort to do so, he unwittingly awarded Xianyu first place all three times.

The story is surprisingly close to Feng Menglong's own experience. Feng continued to fail in the examinations until he was granted the status of tribute student in 1630 at the age of fifty-six or fifty-seven; he was finally appointed to a minor official position in 1634 when he was sixty or sixty-one. ${ }^{89}$ Although, as Hanan points out, Feng was "still able to regard his frustrations with humor," Old Protégé" is basically a comedy, it cannot be denied that the

years" (shinian luopo shao zbiyin), i.e., "for ten years, there was not a single examiner who could appreciate his talents by letting him pass," see Jingshi tongyan, 1:254.

${ }^{87}$ See his 1642 preface to Bi Wei's play San bao'en, which is an adaption of this story, in Wei, Feng Menglong quanji, 19:2852.

${ }^{88}$ Jingshi tongyan, 1:257; translation from Hanan, The Chinese Vernacular Story, p. 116.

${ }^{89}$ See Hanan, The Chinese Vernacular Story, p. 116; see also Ye Ru, "Guanyu Feng Menglong de shenshi," pp. 34-35.

90 Hanan, The Chinese Vernacular Story, p. 117. Humor may also be regarded as a defense mechanism of the author here, or as an attempt to transcend his frustrations. 
primary force at work in the story is the author's frustration. Through his representation of the protagonist, Feng Menglong is surely presenting his own concerns and problems. In the first part of the story, he seems to attribute his own repeated failures to the injustice of the examination system as well as to fate, and he clearly takes vicarious pleasure in the success of the protagonist at the end. It is also significant that the "patron," who is obviously in a yang position in relation to his "protégé," is not portrayed in a favorable light: he does not understand how to appreciate a talented man's worth and he follows absurd standards in performing his duties.

Feng Menglong's anxiety of service is also revealed in another story attributed to him, "Sima Mao Disrupts Order in the Underworld and Sits in Judgment" (GJ 31). It was based most probably on the opening section of an early version of The Story of the Three Kingdoms (Sanguo zhi pinghua), but Feng made a significant change in the plot. In the source work, Sima Mao is summoned to the Underworld because of his complaint about the injustice done by Heaven to the world, i.e., Heaven's approval of such a despot as the First Emperor of the Qin dynasty to rule and devastate the empire. But in Feng's version, Sima Mao's poems of complaint are about the injustice done to himself. $\mathrm{He}$ is a prodigy, but he is disqualified from the civil service examinations because the examiner is offended by his blunt remarks. When it comes to recommendation for office, he has no way to compete with those who enjoy strong political backing. When offices are sold, he does not have the money to buy one. He has no better luck in his career even at the age of fifty, regardless of his talent and erudition. In the Underworld, he confronts the Yama King and criticizes him vehemently for the unjust treatment of the talented and virtuous in the human world. The commentator makes a revealing remark in a marginal note here, saying that Sima Mao "has voiced all the complaints pent up in my bosom." ${ }^{11}$ This is very strong evidence that Feng Menglong sometimes did choose to express his own feelings and personal experiences, particularly his frustration with the civil service

${ }^{91}$ Gujin xiaoshuo (1958), 31.5b. 
examinations, through his fictional characters, or through the materials from other literary sources.

Also revealing in this story is Feng's attitude toward authority figures associated with yang. When Sima Mao is given a chance to be a judge for half a day in the Underworld, he rules that Liu Bang, the first emperor of the Han dynasty known for his ill-treatment of loyal ministers, should be sentenced to rebirth as a puppet emperor and molested by his ministers in his next life.

Feng's repeated failures obviously increased his sense of exclusion from service and marginalization from the center of political power. One can surmise that this sense of marginality made him more likely to identify with $y i n$, and by logical extension, with its most prominent representative in the human arena-woman. Here, of course, "yin" and "woman" are to be understood in terms of the "three bonds" paradigm. Feng Menglong certainly would not identify with those women characters who have the power and authority to abuse others. Nor does it make sense to see the "yin" with which Feng identifies as that from the more general Taoist yin-yang theory where yin and yang are fully complementary. Nonetheless, the notion that yin-yang interplay takes place in the human body may help explain the fluidity of gender identity in many of Feng's stories.

Instances of gender-switching or cross-dressing are by no means rare in the Sanyan. For example, a man becomes a woman through reincarnation in "The Priest Yueming Saves Liu Cui's Soul" (GJ 29), and a woman is reborn as a man in "Emperor Wudi of Liang Goes to the Land of Ultimate Bliss Through Persistent Cultivation" (GJ 37). We also find instances of a man disguising himself as a woman in "Prefect Qiao Randomly Makes Marriage Arrangements" ( $H Y$ 8), “The Two Liu Brothers of Different Sexes" (HY 10), and "Mandarin-Duck Girdle"; and women characters dress up as men in "The Buddhist Abbot Mingwu" (GJ 30) and "The Two Liu Brothers."

\footnotetext{
${ }^{92}$ Judith Zeitlin observes that "The Two Liu Brothers of Different Sexes" deals with cross-dressing in explicit moral terms: "the man in the prologue impersonates a woman for base purposes (seduction and rape) and is punished by an ignominious death; the woman in the main story dresses as a man for moral purposes (filial piety) and is
} 
purposes of this discussion, "Li Xiuqing Marries With Honor the Virgin Huang". (GJ 28) is most significant for the way it relates gender identity to political motivations. ${ }^{93}$ This story apparently praises women who, disguised as men, succeed in establishing themselves in society. At the beginning the narrator states that he will relate the exciting achievements of "pretenders to masculinity who lack the yang element-or, rather, women disguised as men," and introduces his three prologue stories with the couplet, "Tales about women cheer the heart. / Words about men banish delight." ${ }^{44}$ For the first prologue story, he cites the well-known legend of Mulan who, disguised as a man, lets herself be drafted into the army in place of her sick father and achieves great military success in her ten years' service on the front. For the second story, he narrates the equally well-known episode in which Zhu Yingtai goes to Hangzhou disguised as man to study at a boarding school. Then, instead of going into the main story, as in other Sanyan pieces, he relates a third prologue story ${ }^{95}$ about a woman named Huang Chonggu who, dressed as a male scholar, goes to the prime minister with poems she has written. They turn out to be so impressive that she is immediately appointed to an official position. In

rewarded with a good marriage." Historian of the Strange, pp. 114-15. It is also interesting that the feminine-looking young man who dresses as a woman to help his sister in the main story of "Prefect Qiao" is rewarded not only with a good marriage but also with a successful career. For a discussion of women impersonating men in some eighteenth century fiction, see McMahon, Misers, Shrews, and Polygamists, pp. 109-18.

${ }^{93}$ Hanan seems to believe that there are some reasons for linking this story to Feng Menglong, although a precise source has not been discovered among many textually related classical versions. See Hanan, The Chinese Short Story, pp. 85 and 238. For possible source materials of both the main and the prologue stories, see Tan Zhengbi, Sanyan Liangpai ziliao, 1:153-57.

${ }^{94}$ Yushi mingyan, 2:445.

${ }^{55}$ Sanyan stories may have a succession of prologue poems but usually only one or two prologue stories (and TY9 has none). "Li Xiuqing Marries with Honor the Virgin Huang" is a notable exception. The only other story that may be considered to have three is "Three Brothers" ( $H Y$ 2), but they are really only short explanations for the three allusions in the prologue poem. 
her official career she (or he?) achieves complete success and enjoys great popularity.

This last prologue story can be regarded as a manifestation of the author's desire to have his own talent acknowledged by the government along the lines seen in "The Old Protégé." The only difference is the author's identification with a female, rather than male, scholar in the prologue story. This difference, however, may be merely superficial, for Feng might very well have considered himself to be identifying with yin in both cases. After all, a woman and a frustrated scholar "alike belong to the world's down-trodden" (tong shi tianya lunluo ren), as Bai Juyi's famous line runs. ${ }^{96}$ From Kristeva's perspective, subjectivities are equally "feminine" when they are in similarly subordinate or marginalized positions.

Feng's narrator then goes on: "The stories you just heard are, without exception, about women of previous dynasties. I will now tell a story that took place in recent times, during the Hongzhi reign of this dynasty." "It It also about a woman (named Huang Shancong), who makes her way in the world by dressing as a man. However, since it is set in the business world, this story may be regarded as one of the "tradesman makes good and rises in society" type, rather than one of "a young man who succeeds in the examinations and launches his

\footnotetext{
${ }^{96}$ Bai Juyi, "Pipa xing" (Song of the pipa). For the complete Chinese version and an English translation, see Wai-lim Yip, ed., Chinese Poetry: Major Modes and Genres (Berkeley: University of California Press, 1976), pp. 393-401. Bai Juyi's preface to this poem clearly describes how his sense of marginality was linked to his empathy for the woman pipa player:

In the tenth year of Yuanhe [815], I was banished to Jiujiang County to be an assistant official there. In the autumn of the next year, I was seeing a friend off at Benbu at night when I heard someone playing the pipa with the touch and style of the Capital. I asked about the player and found that she was from Chang'an and was once a student of Masters $\mathrm{Mu}$ and Cao. Aging, her beauty declining, she married herself to a merchant. I ordered more wine and food and asked her to play a few tunes. Afterward, she looked sad and started telling us about the happy days of her youth and how she had now become haggard, drifting along the rivers and lakes. It is now two years since I left the court to come here. I have felt content until tonight when ber words made me realize the very meaning of my banishment, p. 398 (my emphasis).
}

${ }^{97}$ Yushi mingyan, 2:448. 
career." $" 98$ But the transitional phrases linking the two stories and the order in which the narrator tells them suggest that they are closely related internally in spite of their differences on the mimetic level. Given the author's desire to have his own worth recognized by the powers that be, it matters little whether his vehicle is a tradesman or a scholar, male or female, so long as he or she is successful and someone with whom the author can identify, someone who began in a marginalized, or less privileged, yin position. At the end of this story, differences on the mimetic level are smoothed over as the tradeswoman's two sons gain prestige and social position through the civil service examinations, a twist that allows the mother to bask in their glory. ${ }^{99}$

\section{Female Superiority in the Sanyan}

One of the most impressive characteristics of the love stories in the Sanyan collections is that women are often portrayed not only with great sympathy, but more importantly, as superior in many

\footnotetext{
${ }^{98}$ Patrick Hanan says that the typical subject matter in the Sanyan collections is that "of love between a well-matched couple who triumph over difficulties," "of a young man succeeding in the examinations and launching his career," "the patient artisan or tradesman who makes good and is able to rise in society," or a pornographic story of debauchery leading to ruin. See his "The Early Chinese Short Story: A Critical Theory in Outline," Harvard Journal of Asiatic Studies 27 (1967): 198; see also W. L. Idema, Chinese Vernacular Fiction (Leiden: E. J. Brill, 1974), p. xxxiv.

${ }^{99}$ Huang Shancong's story was a famous didactic account widely circulated in the Ming and Qing periods. It was recorded in the first juan of "Biographies of Notable Women" ("Lienü zhuan") in the Ming History (Ming shi). See Ming shi, ed. Zhang Tingyu, et al. (Beijing: Zhonghua shuju, 1974), 25:301.7693. In its Sanyan version, the narrator says that it was also adapted into a play called The Story of Incense-selling (Fan xiang ji). The main point of Huang's story in the lienü zhuan tradition seems to be that she preserved her virginity under extremely difficult conditions. But in Feng's version, this point is eclipsed by the insertion of the third prologue story in which the woman scholar's virginity is not even at issue. The phrase in the Extensive Gleanings from the Reign of Great Tranquility (Taiping guang ji) source material stating that the prime minister "admired Huang's chastity" is completely deleted in the Sanyan. See Tan Zhengbi, Sanyan liangpai ziliao, 1:154. On Ming editions of biographies of notable women, see Katherine Carlitz, "The Social Uses of Female Virtue in Late Ming Editions of Lienü zhuan," Late Imperial China 12.2 (1991): 117-48.
} 
respects to their lovers or husbands. The more sympathetic attitude toward women in late Ming fiction has generally been attributed to the tremendous influence of Wang Yangming's branch of Neo-Confucian philosophy, known as xin xue (school of the mind) in literary circles. Li Zhi's "heretical" views about women's education and his enthusiastic enumeration of talented women in Chinese history have been repeatedly cited as evidence of a more generous attitude toward women among some literati and of a more liberal cultural atmosphere in general. ${ }^{100}$ But female superiority in fiction produced by men is probably a more complex issue than can be explained by this theory alone. Although we do have strong evidence of greater sympathy toward women in the late Ming, some scholars have pointed to facts that show an entirely different tendency. Footbinding, a vivid symbol of the subjection of women, was "more popular during the Ming dynasty than in any before it, receiving official and popular sanction." ${ }^{101}$ The cult of chaste widowhood also spread extensively in the same period. ${ }^{102}$ Moreover, a male writer's sympathy toward women

${ }^{100}$ Zhao Xingqin, "Cai yu mei: Ming-Qing xiaoshuo chutan," Ming-Qing xiaoshuo luncong 4 (1986): 20-21. For a brief discussion of the influence of Wang Yangming's notion of "innate knowledge" on Feng Menglong's concept of qing, see Hanan, The Chinese Vernacular Story, pp. 78-79; see also Chen Wanyi "Feng Menglong 'qing jiao shuo' shilun," in his Wan-Ming xiaopin yu Mingji wenren shenghuo (Taipei: Da'an, 1988), pp. $165-83$.

${ }^{101}$ See Howard S. Levy, Chinese Footbinding (New York: Walton Rawls, 1966), p. 48. ${ }^{102}$ Mark Elvin, "Female Virtue and the State in China," Past and Present 104 (1984): 111-52; and T'ien Ju-k'ang, Male Anxiety and Female Chastity: A Comparative Study of Chinese Ethical Values in Ming-Ch"ing Times (Leiden: E. J. Brill, 1988). Dorothy Ko, on the other hand, points out that although women could not "rewrite the rules that structured their lives, they [women from elite families in the lower Yangzi area] were extremely creative in crafting a space from within the prevailing gender system that gave them meaning, solace, and dignity. Their impressive array of tactics . . . ranges from reinterpreting the dicta through writing, revamping the meaning of such dicta in practice, to boring through the cracks between the morally laudable and the permissible both in writing and in practice." See Ko, Teachers of the Inner Chambers, pp. 8-9. Ko's new findings, however, are not necessarily in conflict with my argument that Feng sometimes chose to express his own anxieties by applying the poetic tradition of "beauty and flower" to his vernacular stories. For a discussion of how the fictional representation of women by some literati in the Qing period was complicated 


\section{4 / Appropriation and Representation}

may lead to a more equal treatment of male and female characters, but not necessarily to the assertion of female superiority. Even given Feng's insistence on the importance of qing (feelings or emotions), he never suggests that women's feelings should be presented as more valuable than men's. In other words, the notions of sympathy and liberality in Ming times should perhaps not be overplayed.

Recognizing the sympathy in Feng's work does not deny other ways of looking at his female characters. They may simply represent women and gender categories in general, as we saw in the stories discussed in chapters 2 and 3. Here, though, I wish to suggest another reading of Feng Menglong, one that gets beyond or beneath the mimetic level of representation. Let us assume that the author, a frustrated scholar with a keen sense of his own marginality, identifies with women in their secondary position in the "three bonds" paradigm. He transposes the literary manifestation of this identification from poetry, where it is already well established, to works of vernacular fiction. The sovereign-subject, patron-protégé, or center-margin relationship can then be played out metaphorically in terms of gender. By making his women characters morally and/or intellectually superior, the author vicariously assumes a superior position himself. In effect, this is not a male identifying with a female so much as one yin identifying with another, or sympathy between underdogs. As the yin author feels more hopelessly frustrated, the authority and dignity traditionally attached to yang figures will tend to be undercut or subverted, as we will see in the following example.

"Du Shiniang Sinks the Jewel Box in Anger" (TY 32), also known in translation as "The Courtesan's Jewel Box," was based on a classical tale composed by Song Maocheng. ${ }^{103} \mathrm{~A}$ comparison of the two versions

by their own male anxieties, see Martin Huang, Literati and Self-Re/Presentation: Autobiographical Sensibility in the Eighteenth-Century Chinese Novel (Stanford University Press, 1995), pp. 76-88.

${ }^{103}$ For an English translation see Richard M. W. Ho, "Tu Shih-niang Sinks the Jewel Box in Anger," in Ma and Lau, Traditional Chinese Stories, pp. 146-60. According to Hanan, Feng's version of this story, like "The Pearl-sewn Shirt," was based on a classical tale by Song Maocheng. See Hanan, "The Making of The Pearl-sewn Shirt and 
of this story brings to light some of Feng Menglong's motivations in rewriting it. Song Maocheng's tale begins with a brief, matter-of-fact introduction about how the scholar Li Jia falls in love with the courtesan Du Shiniang in Beijing. Feng takes Song's non-judgmental line "[Li] bought a place in the National University in Beijing"104 and expands it into a satirical account of the selection process at the National University. This not only reveals Feng Menglong's discontent with an official educational system that does not recognize his talent, it also implies a subversion of the male character. Li Jia bought a position at the university because he was not a qualified scholar and therefore does not deserve the reader's respect. In other words, the author reveals at the very outset that he has no intention of approving the manifestations of yang here- neither the National University in relation to himself, nor the male lover in relation to the courtesan $\mathrm{Du}$ Shiniang. The implication of this is unmistakable: occupying a yin position himself, he identifiies with Du Shiniang, the yin member in another set of relationships. In fact, even Feng's title for this story suggests a shift of emphasis. Song Maocheng's tale is entitled "The Faithless Lover" ("Fuqing nong"), which, regardless of its highly accusatory tone, places Li Jia squarely at the center of the narrative. By changing the title to "Du Shiniang Sinks the Jewel Box in Anger," Feng Menglong reverses the man-woman hierarchical order on the narrative level, and makes Du Shiniang, the accuser of Li Jia for his moral failure, the focal point of the story.

With this in mind, it is not difficult to see why Feng Menglong tries so hard to elevate Shiniang in terms of both moral and political power. The last scene of Song's original tale, in which Shiniang becomes a vengeful ghost after death who does harm to two innocent people, was completely left out by Feng. Instead, Du Shiniang is depicted as a heroic figure, more "calculating and impassive" in Feng's

\footnotetext{
The Courtesan's Jewel Box," pp. 124-53. For Song Maocheng's tale in Chinese, see Tan Zhengbi, Sanyan Liangpai ziliao, 1:350-55.

${ }^{104}$ Tan Zhengbi, Sanyan Liangpai ziliao, 1:350; Hanan, "The Making of The Pearl-sewn Shirt and The Courtesan's Jewel Box," p. 139.
} 
story than in Song's. ${ }^{105}$ In Feng Menglong's version, long before she even meets $\mathrm{Li}$ Jia, she has planned to leave the pleasure quarters by marrying a man of her own choice. She tests Li Jia's commitment by asking him to borrow the money needed for her release. She hides her wealth from him to make sure that he is not marrying her for money and also to force him to be more independent in financial matters. When the procuress seems to back out of her agreement to release her, $\mathrm{Du}$ Shiniang threatens suicide. In short, she makes the plan, controls the situation, and appears much more like an ideal minister acting as loyal advisor than in Song Maocheng's tale.

Feng Menglong's Li Jia, in contrast, is presented as a much more emotional man than in the earlier tale; he has become a close parallel to the weak puppet emperors frequently depicted in traditional Chinese literature, "passive and suggestible." 106 The only "positive thing" he ever does on his own initiative is ask Du Shiniang to sing a song that ironically brings about her destruction. ${ }^{107}$ Feng Menglong even adds a paragraph suggesting that Li Jia is persuaded to marry $\mathrm{Du}$ Shiniang rather than making the decision himself. But it is in the realm of moral integrity that this yang figure is more seriously undercut. $\mathrm{He}$ betrays Du Shiniang by selling her to a wealthy merchant as a means of extracting himself from a family problem, a predicament in which his fear of his father plays a part.

For Feng Menglong, Li Jia's most serious moral defect is his failure to do what is most important for a yang figure, i.e., to appreciate the inner worth of a yin figure. To make this point clear, Feng makes a significant addition to Shiniang's tirade on the boat.

\footnotetext{
${ }^{105}$ Patrick Hanan, "The Making of The Pearl-sewn Shirt and The Courtesan's Jewel Box," p. 152.

${ }^{106}$ Schneider points out that Chinese literati were consistent in their "depicting all but the sagest of kings as fools, dupes, or murderous butchers; depicting monarchy basically as a personnel bureau for recruiting virtuous talent; depicting officials as the only source of political and ethical knowledge and as the regular sacrificial victims of the kings." Madman, p. 46. This may be seen as part of the complex and perennial reaction of yin to yang and may help us understand Feng's depicting Li Jia as a foolish weakling.

${ }^{107}$ Hanan, "The Making of The Pearl-sewn Shirt and The Courtesan's Jewel Box," p. 148.
} 
Instead of jumping into the river immediately after having berated the wealthy merchant as happens in Song Maocheng's tale, Du Shiniang turns to $\mathrm{Li}$ Jia and accuses him directly of lacking faith in her: "... you did not trust me and were easily swayed by unfounded words. . . . Like jade I have kept my heart and soul pure for you, but you have eyes that cannot see.... I have not been untrue to you; it is you who have betrayed me!" 108 The narrator's comment at the end of the story is even more explicit: Li Jia is "no less than a common fool to have failed to appreciate Shiniang's [steadfast] heart," and for this he is "not even worth one's contempt." As for Shiniang, "who was such an extraordinary woman," says the narrator, "it was a tragedy that instead of finding a husband worthy of her ... she had to waste her affection on Li Jia." ${ }^{109}$ Here again, the theme of recognition (or misrecognition) in traditional Chinese literature finds expression in this story.

Feng Menglong made other alterations that may be interpreted in much the same way. First, Feng adds a new character, Liu Yuchun, whose main function, according to Hanan, is to act as an ethical norm against which Li and Shiniang's characters may be measured. ${ }^{110}$ But Liu may also serve as a contrast to Shiniang's tragic fate, her failure at finding a yang figure who appreciates her inner worth. Liu's name literally means "a willow meets the spring season," i.e., a plant lucky enough to sprout at the right time. (The idea that springtime, which fosters the growth of all plants, is traditionally a yang phase in the cycle of the four seasons, reveals all the more the implications of Liu Yuchun's name.) This contrast between a lucky plant and an unlucky courtesan, who never has the opportunity in life to "meet" $(y u)$ the right man, calls attention to the traditional notion of time or timing. Sheng bu fengshi (to be born at the wrong time), or shi bu yu (literati

\footnotetext{
${ }^{108}$ Jingshi tongyan, 2:517; Ho translation, p. 159. This change may be a weak point on the mimetic level. Hanan says that Du Shiniang "accuses Li directly of betraying his vows and lacking faith in her, a charge which rings a little odd after her demonstrated lack of faith in him," "The Making of The Pearl-Sewn Shirt and The Courtesan's Jewel Box," p. 152. Yet this change makes sense if read as the author's self-expression through the main character.

${ }^{109}$ Jingshi tongyan, 2:518; Ho translation, p. 160.

${ }^{110}$ Hanan, "The Making of The Pearl-Sewn Shirt and The Courtesan's Jewel Box," p. 149.
} 


\section{8 / Appropriation and Representation}

who fail to meet [a propitious time or a good king]), are expressions that appear frequently in the writings of frustrated scholars. They are employed to rationalize the misfortunes and failures in the political careers of literati and can be traced back to $\mathrm{Qu}$ Yuan. ${ }^{111}$ Through the image of "a plant meeting the right time," Du Shiniang's misplaced trust in $\mathrm{Li}$ Jia is also in a sense rationalized: she is not so much foolish in choosing an unreliable and unworthy man as unlucky, just as $\mathrm{Qu}$ Yuan was unlucky in serving a faithless king. In the tirade against $\mathrm{Li}$ Jia added by Feng Menglong, Du Shiniang actually complains, "Alas! I was born under the wrong star." 112

A second alteration Feng made was to remove all hints of nostalgia for her life in the north (apparently including her life as a courtesan) when $\mathrm{Du}$ Shiniang sings at Li Jia's request on the boat. Symbolically, her act of singing for the pleasure of others indicates her reversion to her former role as a singing girl or courtesan, where she is again in need of a zhiyin, one who understands her music and her song. A wife's reversion to courtesan status, being as undesirable as a scholar's loss of his king's favor, is hardly a situation for which Feng Menglong would feel or want to convey nostalgia. More importantly, it is Shiniang's worthless lover who forces her to assume this wretched yin role again.

Third, when Shiniang "disappeared into the water" in Song's tale, she is only "clutching the pearls" in her hand, ${ }^{113}$ but in Feng's story she assumes a quite different posture: ". . . clasping the casket in her arms,

\footnotetext{
111 See Schneider, Madman, pp. 12-13, 24-26, 36, and 44. Schneider points out two kinds of considerations of time related to $\mathrm{Qu}$ Yuan: "First, there is time as fate or circumstance, which, out of the reach of human will, determines whether a talented and virtuous official has a wise sovereign and is permitted to exercise and implement his abilities. Second, there is time as a measure of human mortality. . . . From the classical period onward, the lore [about $\mathrm{Qu}$ Yuan] suggests that officials, like $\mathrm{Qu}$ Yuan, may cut ... through the bonds of time with their art and literature" (p. 12). For an excellent analysis of the shi bu yu theme in the "prose-poetry" of the Han dynasty (Han fu), see Wilhelm, "The Scholar's Frustration," pp. 310-19.

112 Jingshi tongyan, 2:517; Ho translation, p. 159.

${ }^{113}$ Hanan, "The Making of The Pearl-Sewn Shirt and The Courtesan's Jewel Box," p. 146.
} 
she threw herself into the river."114 What the casket contains is her wealth, cai, a homophone of the word "talent." "Cherishing talent without being appreciated" (buai cai bu $y u$ ) is another traditional complaint of frustrated scholars. Moreover, in Feng Menglong's rendition, the suicide scene is markedly similar to that in the legend of $\mathrm{Qu}$ Yuan, who, after composing poems to lament his loss of the king's confidence, clasped a big rock in his arms and threw himself into the river. ${ }^{115}$

Another critical but more subtle change Feng made in his rewriting of the story concerns $\mathrm{Du}$ Shiniang's name. Du is called "Shiniang," which literally means "tenth sister" or "tenth lady," and is most probably not a real given name but only an indication of her seniority in the pleasure house. In other words, except for the role of courtesan, she has no other individual identity. Thus, it is significant that Feng Menglong gives her a formal given name, Mei, which means "the beautiful," and is a very uncommon character with a strong scholarly flavor. This implies that Shiniang may have come from a scholar's family, and suggests a scholar's identity for her. For similar meaning and sound, the frequently used character mei (as in meili) might be a more likely choice for a name; it is also more likely to be chosen by a non-scholarly parent. That "Du Mei" is misread as " $\mathrm{Du}$ Wei" in both the English translation cited above and in the 1981 Changchu Film Studio picture Du Shiniang suggests just how rare this character is. ${ }^{116} \mathrm{It}$ is interesting that none of the real courtesans in the Ming and Qing periods recorded in The Miscellanies of Banqiao (Banqiao zaji) and Sequel to the Miscellanies of Banqiao (Xu Banqiao zaji) has a given name as unusual as that given by Feng Menglong to Du Shiniang. Many of their given names consist of numbers only,

${ }^{114}$ Jingshi tongyan, 2:517; Ho translation, p. 159.

${ }^{115}$ See Sima Qian, "Ch'ü Yüan and Master Chia," in Burton Watson, trans., Records of the Grand Historian of China: Translated from the Shih chi of Ssu-ma Ch'ien (New York: Columbia University Press, 1961), 1:507. "With this [Qu Yuan's composition of his poem], he grasped a stone in his arms and, casting himself into the Milo River, drowned."

${ }^{116}$ Ho translation, p. 147; "Mei" is also misromanized as "Wei" in Yang Xianyi and Gladys Yang's translation, The Courtesan's Jewel Box, p. 226. 
indicating their birth order or their seniority in the pleasure house, e.g., Tang Jiu and Tang Shi ("number nine" and "number ten" of the Tang family). ${ }^{117}$ It may not be superfluous to point out that compared to Western given names, a Chinese name is more likely to give clues to the social and educational background of one's parents (and sometimes one's grandparents, since it is common for paternal grandparents to have input into the naming of grandchildren). The conversation between Jia Yucun and Leng Zixing in the second chapter of Dream of the Red Chamber (Honglou Meng) may serve as a case in point:

"One of the things I liked about the Zhen family," said Yucun, "was their custom of giving the girls the same sort of names as the boys, unlike the majority of families who invariably use fancy words like 'chun' [spring], 'bong' [red], 'xiang' [fragrance], 'yu' [jade], and so forth. How comes it that the Jias should have followed the vulgar practice in this respect?" 118

Du Shiniang's "Mei" is, of course, not a boy's name, but neither is it by any means one of those "fancy words" used by the "majority of families." Instead, its uncommonness points to the erudition of whoever named her. The last two lines of the narrator's poem about $\mathrm{Du}$ Shiniang actually give the reader a hint that she is at least from a decent family: "Alas! A pity that this flawless piece of jade / Should have fallen into the streets of ill fame." ${ }^{119}$ It is perhaps significant therefore,

${ }^{117}$ See Banqiao zaji, 3.5b-12a and Xu Banqiao zaji, 1.8a-13b, in Xiangyan congshu, ed. Chong Tianzi (Taipei: Guting shuwu, n.d.), 7:3662-75 and 9:4939-50.

${ }^{118}$ See Cao Xueqin, Honglou meng (Beijing: Renmin wenxue, 1987), 1:33; translation by David Hawkes and John Minford, The Story of the Stone (Harmondsworth: Penguin, 1973), 1:82.

${ }^{119}$ In another well-known Sanyan story, "The Oil Peddler Courts the Courtesan" (HY $3)$, there is a rather detailed description of the courtesan's family background: how the family was broken up by war, and how she was sold to the pleasure house by a man who pretended to help her. For an English translation, see Lorraine S. Y. Lieu, in Ma and Lau, Traditional Chinese Stories, pp. 177-208. For a brief account of late Ming literati's fascination and romanticization of the "courtesan type," see Kang-I Sun Chang, The Late-Ming Poet Ch'en Tzu-lung, pp. 11-18. However, Chang's citation of Patrick Hanan to the effect that Feng Menglong "befriended courtesans and regularly 
that Li Jia never seems to notice Du Shiniang's telltale given name, nor does he make any inquiries about her family background.

But since we know that this story was meant to be read, the visual effects of the word "Mei" also deserve consideration. The Chinese tradition of "ideographic analysis" known as zimi (orthography riddles) and chaizi (glyphomancy) may reveal even richer resonances for this term. ${ }^{120}$ These practices-games playing on the ideographic nature of the Chinese written language - can be traced back to such early works as the Chronicles of Zuo. ${ }^{121}$ A New Account of Tales of the World (Shishuo xinyu), a book compiled in the fifth century, contains five stories concerning the solution of orthography riddles. ${ }^{122}$ In succeeding dynasties, interest in this type of wordplay became so widespread that Wolfgang Bauer even claims, "There is scarcely a genre in Chinese literature where one does not meet graphic puns of this sort in one way or another." 123

Feng Menglong's penchant for wordplay is fully revealed in the collections of jokes and riddles he compiled and published. ${ }^{124}$ But even

supplied works for them to read" (p. 11), seems to be a misreading of what Hanan actually says (The Chinese Vernacular Story, pp. 80-81).

${ }^{120}$ The term "orthography riddles" as the English equivalent for zimi is from Lindy Li Mark, "Orthography Riddles, Divination, and Word Magic: An Exploration in Folklore and Culture," in Legend, Lore, and Religion in China, ed. Sarah Allan and Alvin P. Cohen (San Francisco: Chinese Materials Center, 1979), p. 44. Joseph Needham translates chaizi as "glyphomancy," Science and Civilization in China, 2:364.

${ }^{121}$ See Wolfgang Bauer, "Chinese Glyphomancy (ch'ai-tzu) and Its Uses in Present-day Taiwan," in Allan and Cohen, Legend, Lore, and Religion in China, p. 72 n. 2.

${ }^{122}$ Mark, "Orthography Riddles," pp. 45-46.

${ }^{123}$ Bauer, "Chinese Glyphomancy," p. 72. The imitation children's song composed by the famous Tang dynasty poet Luo Binwang discussed in chapter 1 above, is a typical example of a graphic pun on a person's name. For an account of the employment of "ideographic analysis" in two stories, "Xie Xiao'e," a famous crime tale written in the Tang dynasty (618-907), and "Poetry Solves a Crime," written by Pu Songling (16401715), see Judith T. Zeitlin, Historian of the Strange, pp. 149 and 147, respectively.

${ }^{124}$ According to Lu Shulun, Feng Menglong collected and published three collections of jokes, Xiao $f u$ (A treasury of jokes), Guang Xiao fu (A treasury of jokes, Expanded edition), and Gujin tangai (Talks old and new), and one collection of riddles. Some of these jokes and riddles were written by Feng Menglong himself. Guang Xiao fu has an 


\section{2 / Appropriation and Representation}

in the story "Du Shiniang Sinks the Jewel Box" itself, we find a clue to his interest in what is called "word magic" 125 in the concluding poem of the story: "Qing,' this single word, is too profound to comprehend." 226 Qing, the dominant theme in many of Feng's works, is not regarded as a concept, an attitude toward life, or a behavioral pattern, but as a word, a single ideographic character that has magical power over people's behavior. Is there any other single ideograph as profound and important as qing for understanding this story?

Let us return to the name given to $\mathrm{Du}$ Shiniang by Feng Menglong. Among the very few Chinese characters that share the component on the right side of the character mei, only wei, which combines this right-side element with a double-person radical, can be considered a "commonly used word" suitable for vernacular fiction. When used as an adjective, wei means "insignificant, of low social status" (perhaps suggesting the relatively marginalized positions of both Du Shiniang and, by implication, Feng Menglong himself). When used as a verb, wei means "to hide, to disguise oneself or to investigate in disguise." This suggests that not only is Feng Menglong seeking selfknowledge in this story in a woman's disguise, but the clue to this very fact is itself hidden or covered by another sign or word. It is interesting that when wei is replaced by mei, as in Du Shiniang's name, only the left part- the double-person radical-is covered by a woman radical. ${ }^{127}$

appendix entitled "Yinyu," which contains nothing but orthography riddles and playing on Chinese characters. See Lu Shulun, Feng Menglong yanjiu, pp. 109-13, 159. Whether Guang Xiao $f u$ can be attributed to Feng Menglong is still an open question, but scholars generally agree on Feng's role in publishing Xiao $f u$, in which many jokes are clearly based on "ideographic analysis." See, for example, joke number 176, about a Buddhist monk and a nun arguing about the identification of a Chinese character, see Zhu Jun, ed., Xiao fu xuan (Fuzhou: Haixia wenyi, 1987), p. 115.

${ }^{125}$ Lindy Li Mark observes that "[o]rthography riddles and glyphomancy are parts of a larger symbolic domain in Chinese culture which I shall call word magic. In contrast to the utilitarian view of writing as a man-made instrument for long-range and mass communication, word magic ascribes to the written words an intrinsic ability to affect the material world." ("Orthography Riddles," p. 62.)

${ }^{126}$ Jingshi tongyan, 2:518; Ho translation, p. 160.

${ }^{127}$ The term "double-person" (shuangren), is a popular colloquial designation which can be found in Zichu (Touching characters), compiled by Zhou Lianggong (1612-1672), 
The implication seems to be that the narration of Du Shiniang's story is a "cover" for the exploration of a two-person relationship. But if one of the parties was Feng Menglong himself, whom did Feng have in mind as he set up this word game? Ren (person or persons), or characters that have a person radical, are generally not gender-specific and could refer to men or women or both. Only when one of a pair of characters has a woman radical does the other (with the person radical) refer specifically to the male, e.g., $b o$ and shen (uncle and aunt), $f u$ and $q i$ (husband and wife). ${ }^{128}$ Thus, the two-person relationship might refer to that between Feng Menglong and Du Shiniang. In that case, the fictional character articulates what the author intends to say himself, just as in the story "Wan Xiuniang is Revenged," which I mentioned briefly at the end of chapter 1 , the female protagonist's body does the bidding of the hero's soul. Or perhaps the other person is Song Maocheng, whose tale provided the source material for "Du Shiniang Sinks the Jewel Box." In that case, Feng Menglong has "borrowed [Song Maocheng's] wine glass to assuage his own troubles," to use $\mathrm{Li}$ Zhi's expression, in rewriting this story. Or this relationship might include Feng and his intended reader, who, acting as a zbiyin, would lend a discerning ear to Feng's message. However, given the ubiquity of the wife-minister analogy in Chinese culture, it is also possible that the relationship Feng is exploring here is either that between husband and wife, or that between sovereign and subject, or both-after all, both are correlates in the yin-yang paradigm.

No matter how we interpret Feng's play on the word mei, it seems clear that the significance of Du Shiniang goes well beyond the mimetic level. For Feng, the frustrated scholar, to write about or to rewrite the character $\mathrm{Du}$ Shiniang is somehow a vicarious catharsis and a sublimation of his unfulfilled political desires and ambitions. In his

one of Feng Menglong's junior contemporaries. For two examples, see pp. 2.21a-21b and $3.10 \mathrm{a}-10 \mathrm{~b}$.

128 There are some exceptions which suggest gender fluidity or ambiguity in the language: both $z h i$ with a person-radical and $z h i$ with a woman-radical refer to "nephew on the paternal side." See Cihai (Yuci fence), (Shanghai: Renmin, 1977), pp. 211 and 1176, respectively. 


\section{4 / Appropriation and Representation}

frustration he identifies not with the woman per se, but with yin when he feels he is unwanted and in a subordinate position. In other words, a woman like Shiniang is a relational figure onto which he can project himself and inscribe his anxiety. "Woman" can be used to air, in an imaginative manner, his pent-up, unfulfilled desires. The representation of a woman in this story, then, is in fact a presentation of the disenfranchised author himself.

\section{Feng Menglong's “Beauty and Flower” Strategy}

Later works provide ample evidence of the "beauty and flower" poetic tradition applied to the representation of women in fiction; one notable example is the eighteenth-century work, Dream of the Red Chamber. ${ }^{129}$ But two stories produced by the generation of fiction writers immediately following Feng Menglong make specific reference to Feng's work, and therefore may be regarded as direct responses to his narrative strategies. I will discuss these two stories briefly as evidence to support my reading of Feng's "Du Shiniang Sinks the Jewel Box." The first story is "Xiaoqing," the first piece in the collection, $A$ Book About Talented Women (Nü caizi sbu), completed around 1659 by a literati author who preserved his anonymity behind a pen name. ${ }^{130}$ The second is "A Male Mencius's Mother Raises Her Son Properly by Moving Her House Three Times" ("Nan Mengmu jiao he san qian") by Li Yu (1611-1680), the sixth story in his Silent Operas, published in 1655 or $1656 .{ }^{131}$

If the "wife-minister" analogy is indirectly employed by Feng Menglong in "Du Shiniang Sinks the Jewel Box," in "Xiaoqing" it is

\footnotetext{
${ }^{129}$ See Martin Huang, Literati and Self-Re/Presentation, pp. 76-97.

${ }^{130}$ Yuanhu yanshui sanren, "Nü caizi xu" (Preface to Nü caizi) and Nü caizi shu, Ma Rong, ed. (Shenyang: Chunfeng wenyi, 1983), pp. i-iii and 1-13. For discussions of the lore of Xiaoqing, see Ellen Widmer, "Xiaoqing's Literary Legacy and the Place of Woman Writer in Late Imperial China," Late Imperial China 13.1 (June 1992): 111-55; and Ko, Teachers of the Inner Chambers, pp. 91-96.

${ }^{131} \mathrm{Li}$ Yu, Wusheng xi, Du Jun, ed. (Beijing: Renmin wenxue, 1989), pp. 90-111. For an English translation, see Patrick Hanan, ed., Silent Operas (Hong Kong: The Chinese University Press, 1990), pp. 97-134.
} 
presented explicitly in the opening paragraph of the story. Xiaoqing, the woman protagonist forced to become a concubine to a man who does not love her, is described as the reincarnation of $\mathrm{Qu}$ Yuan. Her husband is the reincarnation of the King of $\mathrm{Chu}$, and his jealous wife is that of the two treacherous court officials who maligned $\mathrm{Qu}$ Yuan to win the king's favor for themselves. ${ }^{132}$ But even more interesting is that the inscription praising this collection as a whole bears Feng Menglong's name, an attribution that has proved to be false. ${ }^{133}$ The anonymous author's motivation for creating this forgery is understandable. On the one hand, the inscription might increase the book's sales. On the other, the author may have truly believed that Feng Menglong, the famous literati fiction writer, would have approved of his book, which on its very first page directly applies the meiren xiangcao poetic tradition to fictional narrative.

$\mathrm{Li}$ Yu's reaction to the tradition of man speaking in woman's voice was just the opposite. "A Male Mencius's Mother" is about a homosexual marriage in which the younger partner, You Ruilang, castrates himself out of devotion to his male lover, Xu Wei, and thus transforms himself into an exemplary woman. As Patrick Hanan points out, $\mathrm{Li} \mathrm{Yu}$ manages to "parody heterosexual courtship, heterosexual marriage, chaste widowhood, and strict motherhood, all in one story." ${ }^{134}$ But this story may also be understood as a parody of the literati practice of representing themselves as women in fiction. Since Feng Menglong can be considered the first identifiable literati author to introduce the meiren xiangcao tradition to the vernacular story, it is reasonable to assume that Li Yu's parodic thrust in "A Male Mencius's Mother" may have been aimed at certain of Feng's stories, such as "Du Shiniang Sinks the Jewel Box."

In other stories, $\mathrm{Li} \mathrm{Yu}$ makes it clear that he is parodying the Sanyan. "A Client Patronizes a Prostitute and a Miserable 'Ghost' Tells of Brothel Injustice" ("Ren su ji qionggui su piao yuan"), the seventh

\footnotetext{
${ }^{132}$ Yuanhu yanshui sanren, Nü caizi shu, p. 1.

${ }^{133}$ Ma Rong, "Benshu chuban shuoming" (Note on the publication of this book), Nü caizi shu, front page.

${ }^{134}$ Hanan, The Chinese Vernacular Story, p. 175.
} 
story in Silent Operas, parodies "The Oil Peddler Courts the Courtesan" (HY 3) by inverting the cherished theme of the good-hearted courtesan. In Li's story a courtesan cheats and exploits her naive admirer Wang Si, a hair dresser. The narrator makes clear references to "The Oil Peddler," and describes the courtesan's admirer as always trying to emulate the fictional oil peddler in his courtship. At the end of the story, the narrator openly admonishes his readers not to be fooled by what is described in fiction, since they might be bilked of their hard-earned money by courtesans, just as the protagonist of this story was. In the eleventh of the stories in Silent Operas, "A Son and Grandson Abandon the Corpse While a Servant Hastens to the Funeral" ("Ersun qi haigu tongpu bensang"), the servant Baishun takes over the family property, turning upside-down the image of the selfless, loyal servant in the Sanyan story "The Old Servant Xu" (HY 35). In his comment at the end of this story, the narrator says, tongue in cheek, that Baishun's name should be spread as far as that of the servant Xu. He then adds, as if to remind his reader of the real object of his parody, that Xu's story appears in Comprebensive Words, the second of the Sanyan collections. ${ }^{135}$

Clearly, these near-contemporaries of Feng Menglong knew how to read the yin-yang relations between characters allegorically, and could sense a discrepancy between the mimetic level and the deeper meaning in certain of his stories. They knew enough to take advantage of Feng's reputation for applying the meiren xiangcao tradition to vernacular fiction, and their plays on Feng's stories suggest that by the early Qing period, the wife-minister analogy had become a deeply ingrained cultural code, a code shared by most members of the literati class in their interpretation of vernacular stories.

\footnotetext{
${ }^{135}$ To be sure, here $\mathrm{Li} \mathrm{Yu}$ slips by giving the wrong collection title. See Hanan, The Chinese Vernacular Story, pp. 123, 172; Invention of Li Yu, p. 102. For the references in Li Yu's stories to the Sanyan, see Wusheng xi, Story 7, pp. 116, 117, 125 and Story 11, p. 189. For translations of "The Old Servant Xu" and "The Oil Peddler," see Susan Arnold Zonana et al., and Lorraine S. Y. Lieu et al., in Ma and Lau, Traditional Chinese Stories, pp. 19-37 and 177-208, respectively. Pu Songling's (1640-1715) “The Human Prodigy" ("Ren yao") is also a story about a man being castrated and becoming another man's beloved concubine, see Zeitlin, Historian of the Strange, pp. 100-104.
} 


\section{Women as Zhiyin}

Feng establishes a close imaginative oneness with his woman protagonist $\mathrm{Du}$ Shiniang by applying the "beauty and flower" convention in his narrative. Yet, in another Sanyan story "Courtesans Swarm to Mourn Liu Qi in the Spring Breeze" (GJ 12), we find Feng identifying not directly with the courtesans, but with the central male character, though he remains sympathetic toward the women in the story. In other words, here the female characters simply represent women, or more specifically, courtesans, in imperial China; they are not subject to the "beauty and flower" interpretation. Feng's identification with the man in this story, however, further supports my argument that he used his female protagonist, Du Shiniang, as a literary trope by which to air his pent-up desire for recognition. It is this same desire that seems to have motivated Feng's writing of the Liu Qi story, even though in it he no longer identifies directly with the female characters.

"Liu Qi" is a story about the Song dynasty poet Liu Yong and a group of his courtesan friends; it was completely rewritten by Feng. ${ }^{136}$ In Feng's version, Liu Yong is portrayed as a gifted poet with a great capacity for qing-he is always sympathetic with the courtesans, particularly with those who are humiliated and injured by bullies. Liu Yong is presented as a "model" for-or a perfected version of-Feng Menglong himself. ${ }^{137}$ To elevate his "model" both intellectually and morally, Feng introduces many radical changes in his version. At the very outset of the main story he has his narrator highlight the extraordinary skills needed to compose ci poems and Liu Yong's great contribution to that genre:

The ci poem is ... marked by definite tonal and metrical arrangements dictated by the restrictions of the music. ... In composing a ci poem, one needs to observe the rules of prosody strictly, and with the utmost

\footnotetext{
${ }^{136}$ See Hanan, The Chinese Short Story, p. 237. Feng Menglong's version is a drastic reworking of "Wanjiang Tower," which he condemns as "shallow and vulgar" in his preface to Stories Old and New.

${ }^{137}$ Hanan, The Chinese Vernacular Story, p. 116.
} 
care, match the words with the musical notes. ... Being an unsurpassed expert in these tunes, Liu Qi added new ones to those collected and standardized by the Bureau of Music, bringing their total number to over two hundred. ${ }^{138}$

Feng Menglong also underscores Liu Yong's importance to ci poetry by completely deleting a scene in the source story in which Liu Yong claims authorship of a famous poem "Yu meiren" that was actually composed by the last emperor of the previous dynasty, Li Yu (937978). ${ }^{139}$ In another early version of the Liu Yong story, Liu offends the emperor by presenting him with a carelessly composed poem, a poem that betrays Liu's inattention to the sources of the allusive expressions he uses. ${ }^{140}$ Feng Menglong's refusal to incorporate this episode into his version of the story suggests an intention to elevate Liu's poetic talents as much as possible. Liu would never make a bad poem, however careless its composition might appear. In Feng's version, when Liu offends the prime minister by sending him the wrong poem, the poem itself is artistically superior. Toward the end of the story in the Sanyan version, Liu Yong's poetic talent even acquires an element of mystic wonder when Feng adds a hagiographic touch to his death. Liu Yong is taking a nap in a courtesan's residence when

a yellow-robed messenger from Heaven appears to him in his dream, saying: "By a decree from the Jade Emperor, you with your divine talent are to rewrite the tune, 'Song of the Rainbow and Feather Clothes,' which is outdated and needs to be reworked. Please follow me without delay." ${ }^{141}$

Other revisions in Feng's version are designed to elevate Liu Yong in moral terms. Feng defends Liu's romances with courtesans by comparing Liu to two famous historical figures in a marginal comment:

\footnotetext{
${ }^{138}$ Yushi mingyan, 1:188.

${ }^{139}$ See "Liu Shiqing shijiu Wanjiang lou ji," in Tan Zhengbi, Qingpingshan tang huaben, p. 2.

${ }^{140}$ See Tan Zhengbi, Sanyan Liangpai ziliao, 1:65.

${ }^{141}$ Yushi mingyan, 1:197.
} 
"Marshal Guo [Ziyi] and Minister Wen [Tianxiang] both devoted themselves to famous courtesans, and yet, when suddenly given power, they sacrificed themselves for their country and forgot their own families. How are pedantic moralists capable of understanding anything like this?" ${ }^{142}$ But the most significant change made in this regard is in the plot line. In the earlier Sixty Stories version, Liu Yong takes a fancy to a courtesan named Zhou Yuexian, but his advances are thoroughly rebuffed. Taking advantage of his political power as county magistrate, Liu arranges to have Zhou raped by a boatman in order to force her to become his own mistress. ${ }^{43}$ Feng Menglong certainly could not allow his "model" to be presented as so despicable. In the Sanyan version, it is a wealthy squire who arranges the rape; Liu Yong becomes the person who redeems Zhou Yuexian from the pleasure house with his own money and marries her to her lover, a poor young scholar. Here Feng even adds a marginal comment, stating that his version of the incident, so different from that in the vulgar "Wanjiang Tower," is the "authentic" one. ${ }^{144}$

However, as Feng elevates and identifies with the main character in the story, his revisions also reveal his personal anxieties. For example, the added episode in which Liu is summoned by the Jade Emperor to compose divine poems in heaven clearly registers the author's protest against the inability of emperors of the human world to appreciate literary talent. Liu Yong's talent was as ignored by the imperial court of his time as Feng's was in his. Here, the theme of shi $b u y u$ (neglected men of worth) is brought into greater prominence in a prologue story that Feng added. It involves Meng Haoran (689-740), a renowned poet who lived during the reign of Emperor Xuanzong (712-756) of the Tang dynasty. Meng was denied for life the opportunity to hold office because of a single poem that "happened not to strike the emperor's fancy." "145 The transition between the prologue

${ }^{142}$ Gujin xiaoshuo (1958), 12.12b; translation by Hanan, The Chinese Vernacular Story, p. 116.

${ }^{143}$ Tan Zhengbi, Qingpingshan tang huaben, pp. 2-3.

${ }^{144}$ Gujin xiaoshuo (1958), $12.8 \mathrm{~b}$.

${ }^{145}$ Yushi mingyan, 1:187. 


\section{0 / Appropriation and Representation}

story and the main story also suggests that the "neglected men of worth" theme will be carried over into Liu Yong's story despite the narrative's dominant theme of romantic love: "Let me now tell of another great man of talent who lost the chance for fame and fortune because of a ci poem. But after a lifetime of frustrations [he] came to enjoy wide recognition as a romantic lover." 146

Most revealing in Feng Menglong's rewriting of Liu's story is his addition of a significantly different ending, one that reveals his strong desire for recognition, and for a zhiyin who understands him and appreciates his talents and inner worth:

At the news of his dismissal, Liu burst into a roar of laughter. "Those holding office nowadays are nothing more than benighted illiterates," he said. "How can such men be expected to tolerate a gifted poet like me?" 147

In these words of Liu Yong's we can distinctly make out Feng Menglong's own voice, harping on the perennial theme of misrecognition. But Feng then describes Liu Yong as very happy after his dismissal. Although the officials have overlooked him, the courtesans of the capital passionately appreciate Liu's talents:

Of the numerous courtesans in the Eastern Capital, none did not admire him and take it as an honor to have a rendezvous with him. Any girl who had not heard of Liu Yong was laughed at as being unworthy of the company of courtesans. ${ }^{148}$

Feng Menglong even made up a ditty that circulates among the courtesans in the story to emphasize their admiration of a talent like Liu Yong:

I'd rather have Brother Liu than satins.

I'd rather be called on by him than by kings.

I'd rather possess Liu's heart than have riches.

I'd rather behold his face than see gods. ${ }^{149}$

\footnotetext{
${ }^{146}$ Yushi mingyan, 1:187.

147 Yushi mingyan, 1:196.

${ }^{148}$ Yushi mingyan, 1:188.

${ }^{149}$ Yushi mingyan, 1:189.
} 
Moreover, Liu's poems are copied and read by those courtesans who are literate. One singing girl goes so far as to write down all of the lyrics by Liu Yong she has heard of, and binds the pages into a book. Finally, the theme of courtesans as genuine zhiyin is highlighted again in the final scene, Liu Yong's burial, where the courtesans' sincerity provides a sharp contrast to the officials' inability to appreciate him:

There for all to see, nothing but white silk everywhere, for no courtesan over the length and breadth of the city was not in attendance. Their wailing made the earth tremble. The officials were so ashamed of themselves that they covered their faces and slunk away. ${ }^{150}$

In the final analysis, Feng Menglong's anxiety of service seems to have derived from his strong desire to be known and to have his personal worth recognized. In the Chinese tradition, having a zhiyin is a psychological necessity, since the zhiyin is someone who bestows "an awareness of life without which life is worth nothing; no one can live, except in the literal and miserable biological sense, until known by another." ${ }^{151}$ But the bond between a male literatus and his zhiyin was

${ }^{150}$ Yushi mingyan, 1:198. White is the color of mourning. From a different perspective, Feng and other late Ming scholars who repeatedly failed the civil service examinations had another use for the idea of "authenticity of feeling" (see chapter 1). The value of authenticity justified their devoting themselves to such activities as collecting folk songs and romancing courtesans as a way to alleviate their "anxiety of service." In his preface to Shange, too, Feng reveals this, especially in the line "folk songs disdain to be false because they do not vie for social prominence with poetry and prose" (shange bu yu shiwen zhengming, gu buxie jia). And courtesans, like folk songs, could also represent "authenticity of feeling" by standing outside the normative hierarchies. Cf. Katherine Carlitz's remarks, "The constraints of the examination system were producing generations of restless writers who developed the cult of intense emotion, or qing, as an outlet for their frustration," "Desire, Danger, and the Body: Stories of Women's Virtue in Late Ming China," in Engendering China: Women, Culture, and the State, ed. Christina K. Gilmartin et al. (Cambridge: Harvard University Press, 1994), p. 103.

${ }^{151}$ Henry, "The Motif of Recognition," p. 9. Cf. Stephen Owen's analysis cited earlier in this chapter. Owen also explains the psychological necessity of zhiyin from a comparative perspective: "The assurance of continual understanding differs from the anticipation of a moral reckoning after death before a Rhadamanthos or a Yama. To be "alone" in the Hellenic and Judeo-Christian tradition can never be quite the same thing that it was in the Chinese tradition: in the West there is always an Other," (Traditional 
not necessarily gender-specific, as is clear from Liu Yong's story. Women can be genuine zhiyin for a talented man just as other men can. ${ }^{152}$

On the other hand, however, Feng seems to want recognition from the highest public authority in Chinese society-the imperial government. This can been seen, for instance, in the high frequency of references to the civil service examinations in the Sanyan collections. It is true that scholastic recognition from imperial examiners or other officials was just one of the ways a scholar could have his inner worth recognized, but it seems to have been the most important one for most civil service candidates. ${ }^{153}$ Liu Yong's story actually points to its priority: women or courtesans- or any other commoners-can be genuine zhiyin only in the absence of recognition from the imperial government. Feng Menglong's repeated and pointed contrast of the compassionate courtesans with the unsympathetic officials reveals precisely his own problems in finding self-fulfillment in public service.

To sum up, although he may be genuinely sympathetic to women in general, Feng identifies himself with his women characters mainly by applying the "beauty and flower" poetic tradition to vernacular short stories. In other words, he uses women characters to express his own concerns and desires. Thus, in the final analysis, whether Feng identifies himself with a male scholar or a female courtesan, or whether he projects himself or a zhiyin onto the courtesan figure, what emerges most poignantly is that potent and complex literati desire for recognition-the anxiety of service.

Chinese Poetry and Poetics, p. 298 n. 2). In other words, in the absence of a personal God in the Chinese tradition, seeking zhiyin approached the significance of a religious quest.

${ }^{152}$ Feng Menglong also wrote a play Nü zhangfu (Woman hero) based on the famous Tang tale Qiuran ke zhuan (The curly-bearded hero) in which a woman called Hongfu presciently identifies extraordinary talent in an obscure man. In his preface (now missing) to the play, Feng Menglong says that "to commend Hongfu's prescience in recognizing a hero in his obscurity and marrying him, I call her "Woman Hero," quoted in Lu Shulun, Feng Menglong yanjiu, p. 119.

${ }^{153}$ Cf. Stephen Owen's observation on the emotional power which government and public service exercised over literati's lives and imaginations, quoted earlier in this chapter. 


\section{Conclusion}

The Sanyan collections have long been regarded as an outgrowth of the folk storytelling tradition, and consequently have often been studied with an emphasis on their popular nature. However, notions such as Bakhtin's dialogism and Michael Holquist's ventriloquism, as well as traditional Chinese commentators' ideas on how to read fiction, justify my focus on the literati editor, Feng Menglong. Thus, I have examined the extreme care with which he selected, pieced together, and transformed his source materials to produce works of artistic excellence, rather than focus on the source materials themselves, popular or otherwise. It should be clear by now that Feng Menglong, as the finalizer of the Sanyan texts, can also be justifiably studied as their "author"; he appropriated meaning to his own purposes not so much by "creative writing" (in its narrow sense) but by revising pre-existing source materials, by speaking through others' words. This study has demonstrated how Feng deliberately manipulated and subverted elements of popular literature as part of the narrative strategy he devised to elevate the Sanyan stories to a higher level of literary sophistication.

Feng's storyteller-narrator is used not only to convince the reader that the written text derives directly from oral sources, but more importantly, to allow the author leeway for substantial rhetorical and ideological manipulation. Feng often plays down the authority of his storyteller-narrator. Sometimes by undercutting the narrator's credibility, he even discredits traditional values and the widspread popular beliefs the storyteller represents. But Feng also uses his narrator to the 


\section{4 / Appropriation and Representation}

opposite effect: when it comes to the virtues he values most highly or issues on which he agrees with his storyteller-narrator, the narrator remains reliable and authoritative, serving directly and effectively as Feng's spokesman.

Feng's less drastic but more obvious "editing" work in the Sanyan collections is his arrangement of the stories in pairs. This may have been an attempt to appropriate the parallelism of classical poetry and belles lettres prose in order to elevate the vernacular short story. On the textual level, the paired stories often share some common features in their subject matter or plot line. Occasionally they may form a contrastive, as well as complementary, relationship. I have shown how the second story is sometimes deliberately used as a comment on the first- either to question its ostensible moral message or to intensify its inherent irony.

In his presentation of women characters, Feng Menglong also infuses his source materials with elite values and literati concerns. By applying the "wife-minister" analogy-the "beauty and flower" tradition of poetry - to vernacular fictional narrative, he sometimes identifies directly with the main woman character in order to air, in an imaginative and metaphorical manner, his own unfulfilled desires, particularly, his anxiety of service. In other stories, however, Feng Menglong does not present women as examples of frustrated talent with which he can identify, but rather as zhiyin, while he identifies himself directly with the figure of the male scholar. Yet, no matter whom he identifies with in these stories, he shows the same obsession that characterizes the Chinese literati in the absence of a personal God: a thirst for recognition of his literary talent and inner worth from other mortal beings, zhiyin, and most preferably, from the most powerful zhiyin of all, the emperor and his government.

I have also demonstrated, by way of my discussion of the literati handling of folk songs, that Feng Menglong's promoting the vernacular story while denying his own authorship in the Sanyan collections was largely motivated by-apart from the pleasures of literary ventriloquism - a desire to "borrow" authority from traditional popular literature and to challenge the dominant archaist literary trend. There were, of course, other factors that contributed to the rise of the 
vernacular story. Economic advances and the educational expansion of the late Ming period, particularly in the lower Yangzi valley, for instance, obviously played an important role in stimulating the production of fiction, both before and after Feng Menglong. ${ }^{1}$ But our concern lies with Feng and his self-conscious efforts to transform folk stories and to develop the vernacular story into a literary genre. It was precisely at this critical juncture in the belletricizing process of the vernacular story that Feng Menglong, deeply involved in the idealistic tradition of the liberal literati and greatly irritated by the prevailing archaist trend, felt the need to speak indirectly, hiding behind his source materials and denying his own authorship. By the time Ling Mengchu began writing, the vernacular short story seems to have become well established, due largely to Feng's success. Archaist dominance had been eclipsed by social events such as the Donglin movement, as well as by the rise of a more general elite concern about declining morals. ${ }^{2}$ Ironically, Feng's "ventriloquating" strategies, which contributed greatly to his success and to the development of the short story, did not remain the dominant literary techniques for later major writers of the genre. Neither Ling Mengchu nor Li Yu ever thought to deny their authorship, and they both preferred to speak more directly, replacing the impersonal storyteller-narrator with a more personalized literati-like narrator. Neither was very much interested in Feng's pairing of stories; instead, they chose to use a parallel couplet as the title for each story. ${ }^{3}$ And finally, while Li Yu parodied Feng's use of

1 See Evelyn S. Rawski, "Economic and Social Foundations of Late Imperial Culture," in Johnson et al, Popular Culture in Late Imperial China, pp. 28-29. For a study of late Ming material culture, see Craig Clunas, Superfluous Things: Material Culture and Social Status in Early Modern China (Urbana: University of Illinois Press, 1991).

2 See Dong Guoyan, Dangzi, rouqing, tongxin: Mingdai xiaoshuo sichao (Taiyuan: Beiyue wenyi, 1992), p. 272; for a brief account of the purge of the Donglin movement in 1625-1626 by the powerful eunuch Wei Zhongxian, see Hanan, The Chinese Vernacular Story, pp. 81-82.

${ }^{3}$ For Ling Mengchu's negative comment on the arrangement of paired stories, see item 1 of his "Fan li" (General principles), in Paian jingqi, ed. Zhang Peiheng, p. 3. Ling was the first to use parallel couplets for vernacular stories. Li Yu was interested in pairing stories in his first two collections, Wusheng xi and Wusheng xi erji (see David Rolston's review article of Patrick Hanan's The Invention of Li Yu, Ming Studies 29 


\section{6 / Appropriation and Representation}

the "beauty and flower" tradition, the author of "Xiaoqing" preferred to present the wife-minister analogy explicitly rather than indirectly as Feng had done in "Du Shiniang Sinks the Jewel Box."

These short story writers' motivation for diverging from Feng's "ventriloquating" strategies was necessarily overdetermined. On the social level, the changed cultural environment, with an ever-increasing literati concern for declining morals, may have compelled Ling and others to speak more directly. On the personal level, it is possible that in the face of Feng's great literary achievement, these latecomers to the field of vernacular short story writing may have suffered from "the anxiety of precedents." ${ }^{4}$ Refusing to directly imitate Feng's specific techniques may have been their strategy to claim "new territory" for themselves. We can imagine how in their eyes, the once frustrated Feng Menglong was no longer in a yin position, but had become a formidable yang figure in their field.

[Spring 1990]:62-63). But then he chose to use a parallel couplet for the title of each of the stories in his Liancheng bi, an expanded and modified edition of his previous two collections published a few years later. In his last collection, Shi'er lou, couplets are used not for story titles, but for chapter titles. See Xiao Xinqiao, "Dianjiao shuoming" (Editorial note), in Li Yu quanji, 8:i.

4 This phrase is from Martin Huang, "Dehistoricization and Intertextualization," p. 45. 


\section{Appendix}

\section{Sanyan Stories in This Work}

The stories here are entered in the Glossary-Index by their collection/number designation.

\section{Gujin xiaoshuo 古 今 小 說 (Yushi mingyan 喻世明 言)}

\section{GJ 1 “The Pearl-sewn Shirt” 蔣興哥重會珍珠衫}

2 "Censor Chen Ingeniously Solves the Case of the Gold Hairpins and Brooches" 陳 御史巧勘金鈫鈿

3 “Han Wuniang Sells Her Charms at the New Bridge Market" 新 橋 市韓五賣春 情

5 "Penniless Ma Zhou Gets His Chance Through the Pancake-selling Woman”笨馬周遭際賣館媼

6 “Lord Ge Sends Away the Pearl Maiden" 葛令公生遣弄珠兒

7 "Yang Jiao'ai Throws Away His Life in Fulfillment of a Friendship" 羊角哀捨命全交

8 “Wu Bao'an Abandons His Family to Ransom His Friend” 吳保安 棄家睸友

9 "Duke Pei of Jin Returns a Concubine to Her Rightful Husband" 裴 晉 公義 還 原 配

10 "Magistrate Teng Settles the Case of Inheritance with Ghostly Cleverness" 滕大尹鬼斷家私

11 "Zhao Bosheng Meets With Emperor Renzong in a Teahouse" 趙伯昇茶肆遇仁宗

12 “Courtesans Swarm to Mourn Liu Qi in the Spring Breeze" 衆名 姬春風吊柳七

13 “Zhang Daoling Tests Zhao Sheng Seven Times" 張道陵七試 趙昇 
14 "Chen Xiyi Rejects Four Appointments from the Imperial Court" 陳 希夷四辭朝命

15 “The Dragon and Tiger Reunion”史弘肇龍虎君臣會

16 "Fan Juqing Attends the Chicken-Millet Dinner as a Friend in Life and Death" 范巨卿雞㯟死生交

17 “Shan Fulang Finds His Mate in Quanzhou" 單符郎全州佳偶 18 “Yang Balao Meets his Family in the Land of Yue" 楊八老越國 奇逢

22 “Zheng Huchen Seeks Revenge in Mumian Temple” 木 綿萫鄭虎 臣報冤

24 “Strange Encounter in the Northern Capital" 楊思溫燕山逢 故人

27 “"Jin Yunu Beats Her Faithless Lover With Sticks" 金玉奴棒打 薄 情 郎

28 “Li Xiuqing Marries With Honor the Virgin Huang” 李 秀 卿 義 結 黃貞女

29 “The Priest Yueming Saves Liu Cui's Soul" 月明和尚度柳変

30 “The Buddhist Abbot Mingwu” 明悟禪師趕五戒

31 "Sima Mao Disrupts Order in the Underworld and Sits in Judgment" 鬧陰司司馬貌斷獄

37 "Emperor Wudi of Liang Goes to the Land of Ultimate Bliss through Persistent Cultivation" 梁武常累修歸極樂

39 "Wang Xinzhi Dies to Save the Entire Family" 汪信之一死救 全家

40 “Shen Xiaoxia Encounters the Expedition Memorial" 沈小霞相 會 出師 表

\section{Jingshi tongyan 警世 通 言}

TY8 “Artisan Cui and His Ghost Wife" 崔待詔生死冤家

12 “Loach Fan's Double Mirror" 范鰍兒雙鏡重 圓

16 “The Honest Clerk” 小夫人金錢贈年少

18 “The Old Protégé Pays His Debts of Gratitude” 老門生三世報 恩

19 “The White Falcon” 崔衙内白鷂招妖

20 “The Golden Eel” 計 押 番金鰻 產禍

21 “The Song Founder Escorts Jingniang a Thousand $L 2$ " 趙太祖千 里 㑒 京娘 
22 "Song Xiaoguan Attains a Family Reunion with the Aid of a Worn Hat”宋小官團圓破氈笠

23 “Yue Xiaoshe Seeks His Mate at the Risk of His Own Life" 樂 小 舍拼生覓偶

24 “Yutang Chun in Distress Encounters her Husband" 玉堂春落 難 逢 夫

25 “Squire Gui Repents in Poverty" 桂員外途窮㙨悔

28 “An Eternal Prisoner under the Thunder Peak Pagoda" 白娘子永 鎭雷峰塔

29 “The Pavilion of Lingering Fragrance" 宿香亭張浩遇鶯鶯

30 “Wu Qing Meets Ai'ai at Jinming Pond" 金明池吳清逢愛愛

31 “Zhao Chun'er Makes the Cao Family Thrive Again”趙春兒重旺 曹家莊

32 “Du Shinian Sinks the Jewel Box in Anger" 杜十娘怒沉百寶箱 34 “A Century of Sorrows for Wang Jiaoluan”王嬌鸞百年長恨 37 “Wan Xiuniang Is Revenged With Toy Pavilions" 萬秀娘仇報山 亭兒

\section{Xingshi hengyan 醒 世 恒 言}

$H Y 1$ "Two Magistrates Vie to Marry Off the Orphan Girl With Honor" 兩縣令競義婚孤女

2 “The Three Brothers" 三孝廉讓產立高名

3 “The Oil Peddler Courts the Courtesan" 賣油郎獨占花魁

8 "Prefect Qiao Randomly Makes Marriage Arrangements" 喬太守 亂點䉆烹譜

10 “The Two Liu Brothers of Different Sexes" 劉小官雌雄兄弟

11 "Su Xiaomei Baffles Her Bridegroom Thrice" 蘇小妹三難 新 郎

15 “He Daqing Leaves his Mandarin-Duck Girdle After Death" 赫 大 卿 遺恨鴐鴱縧

25 “Scholar Dugu Has a Wild Dream on his Way Home" 獨孤生歸 途鬧 夢

27 “Li Yuying Appeals to the Court While Imprisoned" 李玉英 獄 中 訟冤

28 “Master Wu” 吳衙内鄰舟赴約

33 "Fifteen Strings of Cash and the Jest That Leads to Disaster" 十五 貫戲言成巧禍

35 “The Old Servant Xu” 徐老僕義憤成家 


\section{Works Cited}

\section{Western Language Sources}

Allen, Joseph. In the Voice of Others: Chinese Music Bureau Poetry. Ann Arbor: Center for Chinese Studies, University of Michigan, 1992.

Arac, Jonathan, Wlad Godzich, and Wallace Martin, eds. The Yale Critics: Deconstruction in America. Minneapolis: University of Minnesota Press, 1983.

Bai Juyi. Bai Juyi: 200 Selected Poems. Trans. Rewi Alley. Beijing: New World Press, 1983.

Bakhtin, M. M. "Discourse in the Novel." In The Dialogic Imagination, ed. Michael Holquist, 259-422. Austin: Texas University Press, 1981.

Barrett, Michele. Women's Oppression Today: Problems in Marxist Feminist Analysis. London: Villiers, 1980.

Barthes, Roland. "The Death of the Author." In Image-Music-Text, trans. Stephen Heath, 142-48. New York: Hill and Wang, 1977.

Bauer, Wolfgang. "Chinese Glyphomancy (ch'ai-tzu) and Its Uses in Present-day Taiwan." In Legend, Lore, and Religion in Cbina, ed. Sarah Allan and Alvin P. Cohen, 71-96. San Francisco: Chinese Materials Center, 1979.

Bell, Catherine. "Religion and Chinese Culture: Toward an Assessment of 'Popular Religion."' History of Religion 29 (1989): 35-57.

Birch, Cyril, ed. Anthology of Chinese Literature: From Early Times to the Fourteenth Century. New York: Grove Press, 1965.

- "Feng Meng-lung and the Ku Cbin Hsiao Shuo." Bulletin of the School of Oriental and African Studies 18 (1956): 64-83.

- Stories from a Ming Collection: Translations of Chinese Short Stories Published in the Seventeenth Century. New York: Grove Weidenfeld, 1958.

Birrell, Anne. Popular Songs and Ballads of Han China. London: Unwin Hyman, 1988. Bishop, John Lyman, trans. "Fan Chu Ch'ing's Eternal Friendship." In his The Colloquial Sbort Story in Cbina. Cambridge, Mass.: Harvard University Press, 1956. 


\section{/ Works Cited}

Bloom, Harold. The Anxiety of Influence: A Theory of Poetry. New York: Oxford University Press, 1973.

Booth, Wayne C. The Rhetoric of Fiction. Chicago: University of Chicago Press, 1961. Borklund, Emer. Contemporary Literary Critics. Detroit: Gale Researach Co., 1982.

Brokaw, Cynthia J. The Ledgers of Merit and Demerit: Social Change and Moral Order in Late Imperial China. Princeton: Princeton University Press, 1991.

Burke, Peter. Popular Culture in Early Modern Europe. London: Temple Smith, 1978.

Butler, Judith. Gender Trouble: Feminism and the Subversion of Identity. New York: Routledge, 1990.

Cahill, James. The Compelling Image: Nature and Style in Seventeenth-Century Chinese Painting. Cambridge, Mass.: Harvard University Press, 1982.

Carlitz, Katherine. "Desire, Danger, and the Body: Stories of Women's Virtue in Late Ming China." In Engendering China: Women, Culture and the State, ed. Christina K. Gilmartin et al., 101-24. Cambridge, Mass.: Harvard University Press, 1994.

- The Rhetoric of Chin ping mei. Bloomington: Indiana University Press, 1986. "The Social Uses of Female Virtue in Late Ming Editions of Lienü zhuan." Late Imperial China 12.2 (1991): 117-48.

Chan, Wing-tsit, trans. and comp. A Source Book in Chinese Pbilosopby. Princeton: Princeton University Press, 1963.

Chang, H. C., trans. "The Shrew." In Chinese Literature: Popular Fiction and Drama, ed. H.C. Chang, 23-56. Edinburgh: Edinburgh University Press, 1973. Chang, Kang-I Sun. The Late-Ming Poet Ch'en Tzu-Lung: Crises of Love and Loyalism. New Haven: Yale University Press, 1990.

Chatman, Seymour. Story and Discourse: Narrative Structure in Fiction and Film. Ithaca: Cornell University Press, 1978.

Chaves, Johathan. Pilgrim of the Clouds: Poems and Essays by Yüan Hung-tao and His Brothers. New York: Weatherhill, 1978.

Chou, Chih-p'ing. Yüan Hung-tao and the Kung-an School. Cambridge, England: Cambridge University Press, 1988.

Cixous, Hélène. "Castration or Decapitation?" Trans. Annette Kuhn. Signs: Journal of Women in Culture and Society 7.1 (1981): 41-55.

- "Sorties: Out and Out: Attacks/Ways Out/Forays." In The Feminist Reader, ed. Catherine Belsey and Jane Moore, 101-16. New York: Basil Blackwell, 1989.

Clunas, Craig. Superfluous Things: Material Culture and Social Status in Early Modern China. Urbana: University of Illinois Press, 1991.

Creel, Herrlee G. Shen Pu-Hai: A Chinese Political Philosopher of the Fourth Century B.C. Chicago and London: University of Chicago Press, 1974. 
Davis, Natalie Zemon. Society and Culture in Early Modern France. Stanford: Stanford University Press, 1975.

de Bary, Wm. Theodore and The Conference on Ming Thought, eds. Self and Society in Ming Thought. New York: Columbia University Press, 1970. and The Conference on Seventeenth-Century Chinese Thought, eds. The Unfolding of Neo-Confucianism. New York: Columbia University Press, 1975.

de Beauvoir, Simone. The Second Sex. Trans. H. M. Parshley. New York: Knopf, 1968. Diény, Jean-Pierre. Aux Origines de la poésie classique en Cbine. Leiden: E. J. Brill, 1968.

Dolby, William, trans. "Yang Jiao Throws Away His Life in Fulfillment of a Friendship." In The Perfect Lady by Mistake and Other Stories by Feng Menglong, ed. William Dolby, 144-58. London: Paul Elek, 1976.

Eagleton, Terry. "Literature and Politics Now." Critical Quarterly 20.3 (1978): 65-69.

Eberhard, Wolfram. "The Political Function of Astronomy and Astronomers in Han China." In Chinese Thought and Institutions, ed. John K. Fairbank, 33-70. Chicago: University of Chicago Press, 1957.

Edwards, Louise P. Men and Women in Qing China: Gender in The Red Chamber Dream. Leiden: E. J. Brill, 1994.

Elvin, Mark. "Female Virtue and the State in China." Past and Present 104 (1984): 111-152.

Feng [Fung], Yu-lan. The Period of Classical Learning. Vol. 2 of $A$ History of Chinese Pbilosophy. Trans. Derk Bodde. Princeton: Princeton University Press, 1953.

—. A Short History of Chinese Pbilosopby. New York: MacMillan, 1961.

- The Spirit of Chinese Pbilosopby. Trans. E. R. Hughes. London: Kegan Paul, Trench, Trubner, 1947. Rpt. Westport, Connecticut: Greenwood, 1970.

Foulkes, A. P. Literature and Propaganda. London: Methuen, 1983.

Furth, Charlotte. "Androgynous Males and Deficient Females: Biology and Gender Boundaries in Sixteenth- and Seventeenth-Century China." Late Imperial Cbina 9.2 (December 1988): 1-31.

Graham, A. C. Yin-Yang and the Nature of Correlative Thinking. Singapore: Institute of East Asian Philosophies, 1986.

Greenblatt, Stephen J., ed. Allegory and Representation. Baltimore: The Johns Hopkins University Press, 1981.

Grosz, Elizabeth. Sexual Subversions. Sydney: Allen \& Unwin, 1989.

Gulik, R. H. van. Sexual Life in Ancient China: A Preliminary Survey of Chinese Sex and Society from ca. 1500 B.C. till 1644 A.D. Leiden: E. J. Brill, 1961. 
Hanan, Patrick. "The Authorship of Some Ku-chin bsiao-sbuo Stories." Harvard Journal of Asiatic Studies 29 (1969): 190-200.

. The Chinese Short Story: Studies in Dating, Authorship, and Composition. Cambridge, Mass.: Harvard University Press, 1973.

The Chinese Vernacular Story. Cambridge, Mass.: Harvard University Press, 1981.

"The Early Chinese Short Story: A Critical Theory in Outline." Harvard Journal of Asiatic Studies 27 (1967): 168-207.

. The Invention of L $i$ Yu. Cambridge, Mass.: Harvard University Press, 1988.

"The Making of The Pearl-sewn Shirt and The Courtesan's Jewel Box." Harvard Journal of Asiatic Studies 33 (1973): 124-53.

"The Nature of Ling Meng-ch'u's Fiction." In Chinese Narrative: Critical and Theoretical Essays, ed. Andrew H. Plaks, 85-114. Princeton: Princeton University Press, 1977.

Press, 1990.

"Sources of the Chin p'ing Mei." Asia Major 10.2 (1963): 23-67.

Hawkes, David. Ch'u Tz'u, The Songs of the South: An Ancient Chinese Antbology. Oxford: Clarendon Press, 1959.

Hawkes, David, and John Minford, trans. The Story of the Stone. Vol 1: The Golden Days. Harmondsworth, Eng.: Penguin, 1973.

Hegel, Robert E. 'Distinguishing Levels of Audiences for Ming-Ch'ing Vernacular Literature." In Popular Culture in Late Imperial China, ed. David Johnson, Andrew J. Nathan, and Evelyn S. Rawski, 112-42. Berkeley and Los Angeles: University of California Press, 1985.

"An Exploration of the Chinese Literary Self." In Expressions of Self in Chinese Literature, ed. Robert E. Hegel, and Richard C. Hessney, 3-4. New York: Columbia University Press, 1985.

- The Novel in Seventeenth-Century China. New York: Columbia University Press, 1981.

"Sui T'ang yen-i and the Aesthetics of the Seventeenth-Century Suchou Elite." In Chinese Narrative: Critical and Theoretical Essays, ed. Andrew H. Plaks, 124-59. Princeton: Princeton University Press, 1977.

"Unpredictability and Meaning in Ming-Qing Literati Novels." In Paradoxes in Cbinese Literature, ed. Eva Hung, 147-66. Hong Kong: The Chinese University Press, 1994.

Hegel, Robert E., and Richard C. Hessney, eds. Expressions of Self in Chinese Literature. New York: Columbia University Press, 1985. 
Henry, Eric. "The Motif of Recognition in Early China." Harvard Journal of Asiatic Studies 47 (1987): 5-30.

Hessney, Richard C. "Beautiful, Talented, and Brave: Seventeenth-Century Chinese Scholar-Beauty Romances." Ph.D. dissertation, Columbia University, 1979.

Hightower, James Robert. "The Fu of T'ao Ch'ien." Harvard Journal of Asiatic Studies 17.1 and 2 (June 1954): 169-230.

Ho, Ping-ti. The Ladder of Success in Imperial Cbina: Aspects of social Mobility, 1368 1911. New York: Columbia University Press, 1962.

Ho, Richard M. W., trans. "Tu Shih-niang Sinks the Jewel Box in Anger." In Traditional Chinese Stories: Themes and Variations, ed. Y. W. Ma and Joseph S. M. Lau, 140-60. New York: Columbia University Press, 1978.

Holquist, Michael. "The Politics of Representation." In Allegory and Representation, ed. Stephen J. Greenblatt, 163-83. Baltimore: The Johns Hopkins University Press, 1981.

Hsia, C. T. The Classic Cbinese Novel: A Critical Introduction. New York: Columbia University Press, 1968.

Hsu, Pi-ching. "Celebrating the Emotional Self: Feng Meng-lung and Late Ming Ethics and Aesthetics." Ph.D. diss., University of Minnesota, 1994.

Huang, Martin Weizong. "Dehistoricization and Intertexualization: The Anxiety of Precedents in the Evolution of the Traditional Chinese Novel." Chinese Literature: Essays, Articles, Reviews 12 (1990): 45-68.

- Literati and Self-Re/Presentation: Autobiographical Sensibility in the EighteenthCentury Chinese Novel Stanford, California: Stanford University Press, 1995.

Hung, Chang-tai. "New Wine in Old Bottles: The Use of Folk Literature in the War of Resistance against Japan." Hanxue yanjiu 8.1 (June 1990): 401-423.

Idema, W. L. Chinese Vernacular Fiction: The Formative Period. Leiden: E.J. Brill, 1974. "Storytelling and the Short Story in China." T'oung Pao 59 (1973): 1-67. John, Margaret L. "Parallelism in the Vernacular Short Story: Reading 'Yang Jiao'ai sheming quanjia' and 'Wu Bao'an qiijia shu you' as Pair Stories." Unpublished paper presented at the American Association for Chinese Studies 34th Annual Conference at Novi, Michigan, University of Michigan, 1992.

Johnson, David, Andrew J. Nathan and Evelyn S. Rawski, eds. Popular Culture in Late Imperial China. Berkeley and Los Angeles: University of California Press, 1985.

Jones, Ann Rosalind. "Inscribing Femininity: French Theories of the Feminine." In Making a Difference, ed. Gayle Greene and Coppélia Kahn, 80-112. London: Methuen, 1985. 
Kaltenmark, Max. Lao Tqu and Taoism. Trans. Robert Greaves. Stanford: Stanford University Press, 1969.

Kelly, Jeanne, trans. "The Jest that Leads to Disaster." In Traditional Cbinese Stories: Themes and Variations, ed. Y. W. Ma and Joseph S. M. Lau, 46778. New York: Columbia University Press, 1978.

"The Pearl Shirt Re-encountered." In Ma and Lau, 164-92.

Ko, Dorothy. Teachers of the Inner Cbamber: Women and Culture in Seventeenth-Century China. Stanford: Stanford University Press, 1994.

Kristeva, Julia. "Oscillations between Power and Denial." Trans. Marilyn A. August, in New French Feminisms: An Anthology. Ed. Elaine Marks and Isabelle de Courtivron, 165-167. Amherst: University of Massachusetts Press, 1980.

Revolution in Poetic Language. Trans. Margaret Waller. New York: Columbia University Press, 1984.

"Un nouveau type d'intellectuel: le dissident." Tel Quel 74 (Hiver, 1977): 3-8.

Kwan-Terry, John, trans. "The Old Servant Hsu." In Traditional Chinese Stories: Themes and Variations, ed. Y. W. Ma and Joseph S. M. Lau, 19-37. New York: Columbia University Press, 1978.

, trans. "Wu Pao-an Ransoms His Friend." In Ma and Lau, 4-18.

Lamont, Rosette C. "The Off-Center Spatiality of Women's Discourse." In Theory and Practice of Feminist Literary Criticism, ed. Gabriela Mora and Karen S. Van Hooft, 138-55. Ypsilanti, Michigan: Bilingual Press, 1982. Lechte, John. Julia Kristeva. London and New York: Routledge, 1990.

Lee, Yun Phin. "Art and World in the Chinese Short Story: San-yen Collections in the Light of Western Critical Method." Ph.D. dissertation, Washington University, 1982.

Legge, James, trans. The Sacred Books of China: the Texts of Confucianism. Oxford: Clarendon Press, 1899.

Lévy, André. Inventaire analytique et critique du conte chinois en langue vulgaire. Paris: Presses Universitaires de France, 1978.

"On the Question of Authorship in Chinese Traditional Fiction." Hanxue yanjiu 6.1 (1978): 249-68.

Levy, Howard S. Cbinese Footbinding. New York: Walton Rawls, 1966.

Liao, Ping-hui. "The (M)other in the Hall: Figures and Discourse of Mastery and Control." Tamkang Review 20.3 (1990): 237-263.

Lieu, Lorraine S. Y. et al., trans. "The Oil Peddler Courts the Courtesan." In Traditional Chinese Stories: Themes and Variations, ed. Y. W. Ma and Joseph S. M. Lau, 177-208. New York: Columbia University Press, 1978. 
- trans. "The Song Founder Escorts Ching-niang One Thousand Li." In $\mathrm{Ma}$ and Lau, 58-76.

Liu, James J. Y. Chinese Theories of Literature. Chicago: The University of Chicago Press, 1975.

Liu Wu-chi. An Introduction to Cbinese Literature. Bloomington: Indiana University Press, 1966.

Lowry, Kathryn. "Excess and Restraint: Feng Menglong's Prefaces on Current Songs." Papers on Chinese History (Fairbank Center for East Asian Research, Harvard University), 2 (Spring 1993): 94-119.

Lü, Shuxiang, ed. One Hundred Quatrains by the Tang Poets: English Translations. Changsha: Hunan renmin, 1980.

Lung, Conrad, trans. "Artisan Cui and His Ghost Wife." In Traditional Chinese Stories: Themes and Variations, ed. Y. W. Ma and Joseph S. M. Lau, 25263. New York: Columbia University Press, 1978.

—, trans. "Nieh Yi-tao the Magistrate." In Ma and Lau, 465-66.

Lynn, Richard John. "Orthodoxy and Enlightenment: Wang Shih-chen's Theory of Poetry and Its Antecedents." In The Unfolding of Neo-Confucianism, ed. Wm. Theodore de Bary et al., 217-66. New York: Columbia University Press, 1970.

Ma, Y. W. "Feng Meng-lung." In The Indiana Companion to Traditional Cbinese Literature, ed. William H. Nienhauser, 380-84. Bloomington: Indiana University Press, 1986.

Ma, Y. W., and Joseph S. M. Lau, eds. Traditional Cbinese Stories: Themes and $V$ ariations. New York: Columbia University Press, 1978.

Maclean, Ian. The Renaissance Notion of Woman. Cambridge, England: Cambridge University Press, 1980.

Mark, Lindy Li. "Orthography Riddles, Divination, and Word Magic: An Exploration in Folklore and Culture." In Legend, Lore, and Religion in Cbina, ed. Sarah Allan and Alvin P. Cohen, 43-69. San Francisco: Chinese Material Center, 1979.

Marks, Elaine, and Isabelle de Courtivron, eds. New French Feminisms: An Anthology. Amherst: University of Massachusetts Press, 1980.

McConnell-Ginet, Sally. "Linguistics and the Feminist Challenge." In Women and Language in Literature and Society, ed. Sally McConnell-Ginet, Ruth Borker, and Nelly Furman, 3-25. New York: Praeger, 1980.

McLaren, Anne E., trans. The Chinese Femme Fatale: Stories From the Ming Period. University of Sydney, 1994.

McMahon, Keith. Causality and Containment in Seventeenth-Century Chinese Fiction. Leiden: E. J. Brill, 1988. 
Misers, Shrews, and Polygamists: Sexuality and Male-Female Relations in Eighteenth-Century Chinese Fiction. Durham, Duke University Press, 1995.

Mead, Margaret. Sex and Temperament in Three Primitive Societies. New York: William Morrow, 1935.

Miller, Robert C. et al., trans. "Han Wu-niang Sells Her Charms at the New Bridge Market." In Traditional Chinese Stories: Themes and Variations, ed. Y. W. Ma and Joseph S. M. Lau, 312-24. New York: Columbia University Press, 1978.

Moi, Toril. "Feminist, Female, Feminine." In The Feminist Reader: Essays in Gender and the Politics of Literary Criticism, ed. Catherine Belsey and Jane Moore, 117-32. New York: Basil Blackwell, 1989.

Sexual/Textual Politics: Feminist Literary Theory. London and New York: Methuen, 1985.

Morson, Gary Saul, and Caryl Emersom. Mikhail Baktin: Creation of a Prosaics. Stanford: Stanford University Press, 1990.

Mowry, Hua-yuan Li. Chinese Love Stories from "Ch'ing-shib." Hamden, Conn.: Archon Books, 1983.

Munchembled, Robert. Popular Culture and Elite Culture in France: 1400-1750. Trans. Lydia Cochrane. Baton Rouge: Louisiana State University Press, 1985.

Needham, Joseph, and Wang Ling. Science and Civilization in China, vol. 2. Cambridge, England: Cambridge University Press, 1954.

Nienhauser, William H., trans. "The Biography of Yü Jang." In Traditional Chinese Stories: Themes and Variations, ed. Y. W. Ma and Joseph S. M. Lau, 41-42. New York: Columbia University Press, 1978.

- ed. and comp. The Indiana Companion to Traditional Chinese Literature. Bloomington: Indiana University Press, 1986.

- Liu Tsung-yüan. New York: Twayne, 1973.

Oakley, Anne. Sex, Gender and Society. Aldershot: Gower, 1985.

Owen, Stephen. Traditional Chinese Poetry and Poetics: Omen of the World. Madison: The University of Wisconsin Press, 1985.

Palumbo-Liu, David. The Poetics of Appropriation: The Literary Theory and Practice of Huang Tingiian. Stanford, California: Stanford University Press, 1993.

Plaks, Andrew H. "After the Fall: Hsing-shib yin-yuan chuan and the SeventeenthCentury Chinese Novel." Harvard Journal of Asiatic Studies 45.2 (1985): 543-80.

Archetype and Allegory in the Dream of the Red Chamber. Princeton: Princeton University Press, 1976. 
, ed. Chinese Narrative: Critical and Theoretical Essays. Princeton: Princeton University Press, 1977.

The Four Masterworks of the Ming Novel. Princeton: Princeton University Press, 1987.

"Full-length Hsiao-sbuo and the Westem Novel: A Generic Reappraisal." In Cbina and West: Comparative Literature Studies, ed. William Tay, Yinghsiung Chou, and Heh-hsiang Yuan, 163-76. Hong Kong: The Chinese University Press, 1980.

- "Towards a Critical Theory of Chinese Narrative." In Chinese Narrative: Critical and Theoretical Essays, ed. Andrew H. Plaks, 309-52. Princeton: Princeton University Press, 1977.

Průšek, Jaroslav. Chinese History and Literature: Collection of Studies. Dordrecht, Holland: Reidel, 1970.

Rawski, Evelyn S. "Economic and Social Foundations of Late Imperial Culture." In Popular Culture in Late Imperial China, ed. David Johnson, Andrew J. Nathan and Evelyn S. Rawski. Berkeley and Los Angeles: University of California Press, 1985.

Redfield, Robert. Peasant Society and Culture. Chicago: University of Chicago Press, 1956, rpt. 1967.

Rickett, Adele Austin. "Method and Intuition: The Poetic Theories of Huang T'ing-chien." In Chinese Approaches to Literature from Confucius to Liang Cb'i-ch'ao, 97-119, ed. Adele Austin Rickett. Princeton: Princeton University Press, 1978.

Rolston, David L., ed. How to Read the Cbinese Novel. Princeton: Princeton University Press, 1990.

- "Point of View' in the Writings of Traditional Chinese Fiction Critics." Chinese Literature: Essays, Articles, Reviews 15 (1993): 113-42.

- Review of The Invention of Li Yu. Ming Studies 29 (Spring 1990): 62-63. Roy, David T., trans. "How to Read the Jin Ping Mei." In How to Read the Chinese Novel, ed. David L. Rolston, 202-43. Princeton: Princeton University Press, 1990.

Ruthven, K. K. Feminist Literary Studies. New York: Cambridge University Press, 1984.

Sariti, A. W. "Monarchy, Bureaucracy, and Absolutism." Journal of Asian Studies 32 (November, 1972): 53-76.

Schneider, Laurence A. A Madman of Cb'u: The Chinese Myth of Loyalty and Dissent. Berkeley: University of California Press, 1980.

Tien, Ju-k'ang. Male Anxiety and Female Chastity: A Comparative Study of Chinese Etbical V alues in Ming-Ch’ing Times. Leiden: E.J. Brill, 1988. 
Waley, Arthur. A Hundred and Seventy Chinese Poems. New York: Knopf, 1919. Wang, John C. Y., trans. "How to Read The Fifth Book of Genius." In How to Read the Chinese Novel, ed. David L. Rolston, 131-45. Princeton: Princeton University Press, 1990.

Watson, Burton, trans. Records of the Grand Historian of Cbina: Translated from the Sbib chi of Ssu-ma Cbien. New York: Columbia University Press, 1961. Records of the Historian: Chapters from the Shib cbi of Su-ma Cb'ien. New York: Columbia University Press, 1969.

Widmer, Ellen. The Margins of Utopia: Sbui-bu bou-chuan and the Literature of Ming Loyalism. Cambridge, Mass.: Harvard University Press, 1987.

- "Xiaoqing's Literary Legacy and the Place of the Woman Writer in Late Imperial China." Late Imperial Cbina 13.1 (June 1992): 111-55.

Wilhelm, Hellmut. "The Scholar's Frustration: Notes on a Type of 'Fu." In Chinese Thought and Institutions, ed. John K. Fairbank, 310-19. Chicago: University of Chicago Press, 1957.

Wimsatt, W. K., and Monroe C. Beardsley. "The Intentional Fallacy." In their The Verbal Icon, 3-18. University of Kentucky Press, 1954.

Wong, Timothy C. "Entertainment as Art: An Approach to the Ku-chin bsiaosbuo." Chinese Literature: Essays, Articles, Reviews 3.2 (July, 1981): 235-50. "Morality as Entertainment: Altruistic Friendship in the Ku-chin bsiaosbuo." Tamkang Review 13.1 (Fall 1982): 55-69.

Wu, Yenna. The Chinese Virago: A Literary Theme. Cambridge, Mass.: Council on East Asian Studies, Harvard University, 1995.

"The Inversion of Marital Hierarchy: Shrewish Wives and Henpecked Husbands in Seventeenth-Century Chinese Literature," Harvard Journal of Asiatic Studies 48.2 (Dec. 1988): 363-82.

"Marriage Destinies to Awaken the World: A Literary Study of Xingshi yinyuan zhuan." Ph.D. dissertation, Harvard University, 1986.

Yang, Lien-sheng. "The Concept of Pao as a Basis for Social Relations in China." In Cbinese Thought and Institutions, ed. John K. Fairbank, 291-309. Chicago: University of Chicago Press, 1957.

"Female Rulers in Imperial China." Rpt. in Studies of Governmental Institutions in Chinese History, ed. John L. Bishop, 153-69. Cambridge, Mass.: Harvard University Press, 1968.

Yang Xianyi, and Gladys Yang, trans. The Courtesan's Jewel Box: Chinese Stories of the Xth-XVII Centuries. Beijing: Foreign Language Press, 1981.

Yao, P. C., trans. "The Case of the Gold Hairpins." Renditions 5 (Fall 1975): 118-36. Yip Wai-lim, ed. and trans. Chinese Poetry: Major Modes and Genres. Berkeley: University of California Press, 1976. 
Yu, Pauline. The Reading of Imagery in the Chinese Poetic Tradition. Princeton: Princeton University Press, 1987.

Zeitlin, Judith T. Historian of the Strange: Pu Songling and the Chinese Classical Tale. Stanford, California: Stanford University Press, 1993.

Zonana, Susan Arnold et al., trans. "Magistrate T'eng and the Case of Inheritance." In Traditional Chinese Stories: Themes and Variations, ed. Y. W. Ma and Joseph S. M. Lau, 485-501. New York: Columbia University Press, 1978.

, trans. "The Old Servant Xu." In Ma and Lau, 19-37.

\section{Sources in Chinese and Japanese}

Ban Gu 班 固 (A.D. 32-92). Hanshu 漢 書, vols. 4 and 8. Beijing. Zhonghua, 1962. Cao Xueqin 曹雪芹. Honglou meng 紅 樓夢, vol. 1. Beijing: Renmin wenxue, 1987.

Chen Dingru陳鼎如 and Lai Zhenghai 賴征海. Gudai minyao zbuxi 古代民謠注析. Nanchang: Jiangxi renmin, 1985.

Chen Hong 陳洪. Zhongguo xiaoshuo lilun shi 中國小說理論史. Hefei, Anhui: Anhui wenyi, 1992.

Chen Wanyi 陳萬盖. “Feng Menglong 'qingjiao shuo' shilun”馮夢龍 「情教說」試論. In Wan-Ming xiaopin yu Mingji wenren shenghuo 晚明小品與明季文人生活. Taipei: Da'an, 1988.

Cheng Hong程 弘. “Jingshi tongyan zhong de aiqing gushi” 警世通言中的 愛情故事. In Ming-Qing xiaosbuo yanjiu lunwenji 明清小說 研究論文集. Beijing: Renmin wenxue, 1959.

Chong Tianzi 蟲 天 子, ed. Banqiao zaji 板橋雜記. In Xiangyan congshu 香 艷 叢 書, vol. 7. Taipei: Guting shuwu, n. d.

—.Xu Banqiao zaji 續板橋雜記. In Xiangyan congsbu香艷叢書, vol. 9. Taipei: Guting shuwu, n.d.

Ci bai 圝海 (Yuci fence)語詞分册. 2 vols. Shanghai: Renmin, 1977.

Dong Guoyan 董國 炎. Dangzi, rouqing, tongxin: Mingdai xiaoshuo si chao

蕩子, 柔情, 童心: 明代小說思潮. Taiyuan: Beiyue wenyi, 1992.

Feng Menglong 馮夢龍. Feng Menglong quanji 馮夢龍全集. Ed. Wei Tongxian 魏同 賢. 43 vols. Shanghai: Shanghai guji, 1993.

. Jingshi tongyan 警世通言. Ed. Yan Dunyi 箃敦易. 2 vols. Beijing: Renmin wenxue, 1987. 
—. Qingshi 情史. Ed. Zhang Fugao 張福高 et al. 2 vols. Shenyang: Chunfeng wenyi, 1986.

- Shange 山歌. In Minsu congshu 民 俗叢書, vol. 2. Ed. Lou Zikuang 婁子匡. Taipei: Dongfang wenhua, 1960.

—. Xiao fu xuan 笑府選. Ed. Zhu Jun 竹君. Fuzhou: Haixia wenyi, 1987.

Xin lieguo zbi 新列 國 志. Shanghai: Shanghai guji, 1987.

. Xingshi bengyan 醒世 恒 言. Ed. Gu Xuejie 顧 學 頍. 2 vols. Beijing: Renmin wenxue, 1987.

—. Yushi mingyan 喻世明言. Ed. Xu Zhengyang 許政揚. 2 vols. Beijing: Renmin wenxue, 1987.

Fukumitsu Masahiro 福滿正博. “Kokkin shosetsu no hensan hoho: Sono taigu kosei ni tsuite.”古今小說の編纂方法: その對偶 構成に つ て. Chugoku bungaku ronshu 中國文學論 集 10 (1981): 95120.

Gao Hongjun 高洪 鈞. “Guąhir chengshu kao ji Feng Menglong Hou Huiqing lianli yuanwei”掛枝兒成書考及馮夢龍侯慧卿戀離原委. Zhongguo gudai jindai wenxue yanjiu 中國古代近代文學研 究 July 1992): 195-200.

Gu Jiegang 顧 頡 剛. “Preface to Shange" 山歌序. In Shange 山歌. Taipei: Dongfang wenhua, 1970.

Guan Dedong 關德 棟, ed. Ming-Qing minge shidiao ji 明清民歌時調集, vol. 1. Shanghai: Shanghai guji, 1987.

Guo Shaoyu 郭紹虞. Zhongguo wenxue piping shi 中國文學批評史. Revised ed. Shanghai: Shanghai guji, 1979.

- comp. Zhongguo lidai wenlun xuan 中 國歷代文論選, vol. 3. Shanghai: Shanghai guji, 1979.

Han Jingtai 韓 經太. "Lun Zhongguo gudian shige de beijuxing me”" 論 中國 古典詩歌的悲劇性美. Zhongguo gudai jindai wenxue yanjiu (July 1990): 263-79.

He Guli 何谷 理 [Hegel, Robert E.]. “Zhanghui xiaoshuo fazhan zhong sheji dao de jingji jishu yinsu” 章回小說發展中涉及到的經濟 技術 因 素. Hanxue yanjiu 6.1 (1988): 191-97.

He Wenhuan 何 文 煥, ed. Lidai sbibua 歷 代 詩話. Rpt. Beijing: Zhonghua, 1980.

Hong Pian 洪 梗. Qingpingshan tang buaben 清平山堂話 本. Rpt. Shanghai: Shanghai guji, 1992. 
Hu Shiying 胡士 塋. Huaben xiaosbuo gailun 話 本 小說 概 論, vol. 2. Beijing: Zhonghua shuju, 1980.

$\mathrm{Hu}$ Wanchuan 胡萬川. “Sanyan xu ji meipi de zuozhe wenti." 三言敘及 眉 批的作者問題. Rpt. in his Huaben yu caizi jiaren xiaoshuo zhi yanjiu話本與才子佳人小說之研究, 123-38. Taipei: Da'an, 1994.

Jiang Daren 降大任, and Zhang Renjian 張仁健, eds. Yongshi shi zbuxi 詠史詩注析. Taiyuan, Shanxi: Shanxi renmin, 1985.

Jiang Weishui 姜渭水, ed. Lidai renwu sbisbi 歷代人物史詩. Xizhi, Taiwan: Heping, 1977.

Li Xiusheng 李修生. “Ma Zhiyuan”馬志遠. In Zhongguo da baike quanshu xiqu quyi 中國大百科全書: 戲曲曲藝, 240-41. Shanghai: Zhongguo da baike quanshu, 1983.

Li Yu 李 漁. Li Yu quanji 李漁 全 集, vols. 3 and 8. Hangzhou: Zhejiang guji, 1991.

Wusheng xi 無聲戲. Ed. Du Jun 杜 浚. Beijing: Renmin wenxue, 1989.

Li Zhi 李 䞇. “You yu Jiao Ruohou” 又與焦弱侯. In Fen shu 焚書, juan 2 of Li sbi Fen sbu, Xu Fen sbu 李氏焚書, 續焚書, 54-56. Kyoto: Chinese Language Press, 1971.

. “Zashuo" 雜說. In Zhongguo wenxue piping shi 中國文學批評史, ed. Wang Yunxi 王運熙 and Gu Yisheng 顧易生. Shanghai: Shanghai guji, 1981.

Liao Kebin 䖉可斌. Mingdai wenxue fugu yundong yanjiu 明代文學復古 運動研 究. Shanghai: Shanghai guji, 1994.

Ling Mengchu凌濛初. Chuke Pai'an jingqi 初刻拍案驚奇. Ed. Zhang Peiheng 張培衡 and Wang Gulu 王古魯. 2 vols. Shanghai: Shanghai guji, 1982.

. Erke Pai'an jingqi二刻 拍案驚 奇. Ed. Zhang Peiheng 張 培衡and Wang Gulu 王 古魯. 2 vols. Shanghai: Shanghai guji, 1983.

Liu Hongjun 劉 紅 軍. "Li Yu xiaoshuo chuangzuo tong xiju chuangzuo de guanxi”李漁小說創作同戲劇創作的關係. Xinyang shifan xueyuan xuebao: zheshe ban 信 陽 師 範 學 院 報: 哲 社版, 1996.2:5761. Reprinted in Zhongguo gudai jindai wenxue yanjiu (Renmin daxue fuyin ziliao) 1996. 7:98-103.

Lou Zikuang 婁子匡, ed. Minsu congshu 民俗叢書. Taipei: Dongfang wenhua, 1960.

Lu Shulun 陸 樹 侖. Feng Menglong yanjiu 馮夢龍研 究. Shanghai: Fudan daxue, 1987. 


\section{Works Cited}

Lü Zhenghui 呂正惠. Sbuqing cbuantongyu zbengzbi xiansbi 抒情傳統與 政 治現 實. Taipei: Da'an, 1989.

Ouyang Jian 歐陽健. “San sui ping yao zbuan yuanben kaobian”三 逐平妖傳原本考辨. Zhongbua wensbi luncong 中華文史論叢 3 (1985): 149-65.

Qian Zhongshu 錢鐘書. “Zhongguo shi yu Zhongguo hua” 中國詩 與 中國畫. In Qian Zhongsbu lunxue wenxuan 錢鐘 書論學文選, ed. Shu Zhan 舒 展. 6:1-32. Guangzhou: Huacheng, 1990.

Qiu Jun 邱濠. $W u$ lun quan bei 伍倫全 備. Rpt in Quan Ming chuanqi 全 明 傳 奇, vol 14. Taipei: Tianyi, 1983.

Quan Tang shi 全 唐 詩, vol. 7. Beijing: Zhonghua shuju, 1960.

Sima Qian 司馬 遷. Shiji 史 記, vol. 8. Beijing: Zhonghua, 1972.

Tan Zhengbi 譚 正璧. Huaben yu guju 話 本 與 古 劇. Revised ed. Shanghai: Shanghai guji, 1985.

ed. Qingpingshan tang buaben 清 平山堂話 本. Shanghai: Gudian wenxue, 1957.

—, ed. Sanyan Liangpai riliao 三言兩拍資 料. 2 vols. Shanghai: Shanghai guji, 1980.

Wang Ling 王凌. Jiren, qingzhong, qipinguan: Feng Menglong tanyou畸 人, 情種, 七品官: 馮夢龍 探幽. Fuzhou: Haixia wenyi, 1992.

Wang Yunxi王運 熙, and Gu Yisheng 顧易生, eds. Zhongguo wenxue piping shi 中國文學 批評史, vol. 2. Shanghai: Shanghai guji, 1981.

Wang Zejun王澤君, and Chang Sichun 常思 春, eds. Gudai duanpian xiaoshuo $x$ ang $b u$ 古代短篇小說選注, vol. 1. Beijing: Beijing chubanshe, 1983.

Wu Han 吳 晗. “Jin Ping Mei de zhuzuo shidai ji qi shehui beijing”金 瓶梅的 著作時代及其社會背景. Rpt. in Dusbi zhaji 讀史箚記 1-38. Beijing: Sanlian, 1956.

Xiao Difei 婣淮非 et al., eds. Tangshi jianshang cidian 唐詩銺賞詞典. Shanghai: Cishu, 1983.

Xiao Xinqiao 蕭欣 橋. “Dianjiao Shuoming”點校說 明. In $L i$ Yu quanji 李漁 全 集. Hangzhou: Zhejiang guji, 1991.

$\mathrm{Xu}$ Fuguan 徐復觀. “Zhongguo zhishifenzi de lishi xingge jiqi lishi de mingyun"中國知識分子的歷史性格及其歷史的命運. In Zhishi fenzi yu Zhongguo 知 識 分子與 中 國, ed. Zhou Yangshan 周 陽 山, 201-20. Taipei: Shibao wenhua, 1980.

Yang Jialuo 楊 家 駱, ed. Pingyao zhuan, Siyou ji 平妖 傳, 四 游 記. Taipei: Shijie, 1962.

—, ed. Quan Ming raju全 明 雜 劇. Taipei: Dingwen, 1979. 
Yang Jun 楊 鹪. “Chenqie yishi yu nüxing renge: Gudai shidafu wenren xintai yanjiu zhiyi” 臣妾意識與女性人格: 古代士大夫文人 心態研究之一. Zhongguo gudai jindai wenxue yanjiu (November 1991): 20-29.

Yang Xiaodong 楊曉 東. “Gujin xiaoshuo xu zuozhe kaobian”古今小說 序作者考辨. Wenxue yichan 文學遺產 (Feb. 1991): 102-7.

Yao Daye 姚大業. Han yuefu xiaolun 漢 樂府小論. Tianjin: Baihua wenyi, 1984.

Ye Ru 野儒. “Guanyu Feng Menglong de shenshi”關於馮夢龍的身世. In Ming-Qing xiaosbuo yanjiu lunwen ji 明清小說研究論文集, 34-38. Beijing: Renmin wenxue, 1959.

“Guanyu Sanyan de zuanjizhe"關於三言的纂集者. In Ming-Qing xiaoshuo yanjiu lunwen ji, 29-33. Beijing: Renmin wenxue, 1959.

You Guo'en 游國恩. “Chuci nüxing zhongxin shuo”楚销女性中心說.

In You Guo'en, Cbuci lunwen ji 楚 辭 論 文集, 191-204. Rpt. Hong Kong: Wenchang shuju, 1966.

Yu Yingshi [Yu Ying-shih] 余英時. Sbiyu Zhongguo wenhua 士與中國文化. Shanghai: Shanghai renmin, 1987.

Yuanhu yanshui sanren 䳆湖煙水散人. Nü cairi sbu 女子書, ed. Ma Rong 馬 蓉. Shenyang: Chunfeng wenyi, 1983.

Zhang Fa 張發. Zhongguo wenhua yu beiju yishi 中國文化與悲劇意識. Beijing: Zhongguo renmin daxue, 1989.

Zhang Tingyu 張廷玉 et al., eds. Ming sbi 明史. Beijing: Zhonghua shuju, 1974.

Zhanguo ce 戰 國 策. Shanghai: Shanghai guji, 1978.

Zhao Xingqin 趙興 勤. “Cai yu mei: Ming-Qing xiaoshuo chutan”才與美: 明清小說初探. Ming Qing xiaoshuo luncong 明清小說論叢 4 (1986): 14-23.

Zhongguo tongsu xiaoshuo zongmu tiyao 中國通俗小說總目提要. Ed. Jiangsu shehui kexue yuan Ming-Qing xiaoshuo yanjiu zhongxin wenxue yanjiusuo 江蘇社會科學院明清小說研究中心 文學研 究 所. Beijing: Zhongguo wenlian, 1990.

Zhongguo zhexue shi 中國哲學史. Ed. Beijing daxue zhexue xi 北京大學 哲 學 系. Beijing: Zhonghua, 1980.

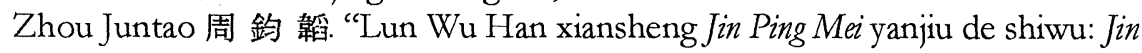
Ping Mei zuozhe Wang Shizhen shuo bei fouding le ma?” 論 吳 晗 先生金瓶梅研究的失誤: 金瓶梅作者王世貞說被否 


\section{6 / Works Cited}

定了嗎? In his Jin Ping Mei tanmi yu yishu shangxi 金瓶梅 探 謎與 藝術賞析, 13-29. Changchun: Jilin wenshi, 1990.

Zhou Lianggong 周 亮 工, ed. Zichu 字 觸. Preface dated 1667. HarvardYenching Library, Cambridge, Mass. 


\section{Glossary-Index}

Aina jushi 艾衲居士, 15 n34

anfen shouji 安分守已, 50

anxiety of influence, 30

anxiety of service, $100,101,116$,

$120,121,124,126-27 \mathrm{n} 86,151$

archaism, 25-26; liberal Ming literati

reaction to, 26-30; Feng

Menglong's reaction to, 29-30,

154. See also $\mathrm{He}$ Jingming; $\mathrm{Li}$

Mengyang; Li Panlong; Li Zhi;

Wang Shizhen; Yuan Hongdao

Autumn in the Han Palace. See Han gong qiu

Bai Juyi 白居易, 36, 102, 118, 131. See also "Pipa xing";

"Taihang lu"

baibua 白 話, 5

Bakhtin, Mikhail, 2, 7-10, 11, 12, 13, $15,17,33,45,153$

Ban $\mathrm{Gu}$ 班 固, 34, 35, 36. See also Hansbu

Barthes, Roland, 11 n23

"Basic principles." See "Jiyi"

Bell, Catherine, 5 n7

belletricization, 2, $15 \mathrm{n} 34,17,155$

Bi Yurang 畢豫 讓, 123

bici qingming tiandi zbi 彼 此清

名天地知, $90 \mathrm{n} 35$
Birch, Cyril, 22 n5, 49 n14, 64, 79, $82 \mathrm{n} 9,83$

Bloom, Harold, 30

Book of Rites. See Liji

Book of Songs. See Shiizing

Book about Talented Women. See Nü cairi sbu

Booth, Wayne C., 45

bo shen 伯嬏, 143

Cahill, James, 28n17

cai 財, 寸, 139

caizi jiaren 寸子佳 人, 102

Carlitz, Katherine, 70, 132 n99, 151

$\mathrm{n} 150$

chaizi 拆字 (glyphomancy), 141

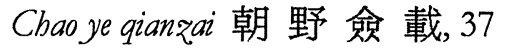

Chatman, Seymour, 45

Chen Wanyi, 97 n50, 133 n100

cheng san 撐 傘, $59 \mathrm{n} 46$

chengshuang zuodui 成雙作 對, 58

"Chicken-and-Millet Dinner of Fan and Zhang in Life and Death." See "Shengsi jiao Fan Zhang jishu"

Chronicles of Zuo. See Zuo zhuan

Chuci 楚辭, 119 n64. See also Qu Yuan

cbun 春, 59,140 


\section{Glossary-Index}

chun 椿 (toon tree), 53, 58

Chunqiu Gongyang zhuan Heshi jiegu 春秋公羊傳何氏解詁, $35 \mathrm{n} 39$

ci 詞, 39, 40, 147-48, 150

Cixous, Hélène, 108-109, 110, 111

"Client Patronizes a Prostitute and a Miserable 'Ghost' Tells of Brothel Injustice." See "Ren su ji qionggui su piao yuan"

Clunas, Craig, $155 \mathrm{n} 1$

companion story, 49 , 154; as comment, 79, 84, 85-98, 154; complementary, 79-81; contrastive, 69,79, 83-84, 154. See also Fukumitsu Masahiro Complete Biography of the Flying Dragon. See Feilong quanzhuan Comprebensive Records of Affairs Witbin and Outside the Court. See Chao ye qianzai

Comprehensive Words to Warn the World. See Jingshi tongyan

Constant Words to Awaken the World.

See Xingshi bengyan

Conversations of the States. See Guo yu cunlang 村 郎, 68

cun xuejiu 村 學 究, 83

"Curly-Bearded Hero." See "Qiuran ke zhuan"

danke ... xing chuli keshui, weike wei shaotong wenlizhe dao ye

但 可...醒鋤犁瞌 睡, 未 可爲稍通文理者道也, 83

dialogism, 2, 7-10, 11, 12, 13, 15, 153 dian tie cheng jin 點 鐵 成 金, 12 Dong Zhongshu 董 仲舒, 112, 118 n62, 122

"Double-Fish Pendants." See "Shuangyu zhui"

Doupeng xianbua 豆棚 閑 話, 15 n34

Dream of the Red Chamber. See Honglou meng

Du Shiniang 杜 十 娘, 102, 134144, 145, 156

dufa 讀 法, $12 \mathrm{n} 25,12 \mathrm{n} 27,20 \mathrm{n} 2$ duo qiji le 嶞 其計了, 55 duo tai buan gu 奪胎 還 骨, 12 duo taren zbi jiubei jiao riji zbi leikuai 奪他人之酒杯澆自己 之壘塊, 11,143

Extensive Gleanings from the Reign of Great Tranquillity. See Taiping guangji

"Faithless Lover." See "Fuqing nong"

faji biantai 發 跡 變 泰, 84 “fanli qize" 凡例 七 則 (seven general principles), $17 \mathrm{n} 40$

Feilong quanzbuan 飛 龍 全 傳, 8692

feminist theory, 100, 107-11

Feng Menglong 馮夢龍, attitude toward women, 100-107; biographical information, 125-26, 127; wordplay, 95-96, 141-43. See also Gujin tangai; Gujin xiaoshuo; Guarbir, Guang xiao fu; Jingshi tongyan; Nü zhangfu; Pingyao zhuan; qing; qing ₹ben; "Qulü xu"; 
Sanyan; Shange; Wansbi zu; Xiao fu;

Xin Lieguo zbi; Xingsbi bengyan;

Yusbi mingyan

Fengshen yanyi 封 神 演 義, 24

Fengyun bui 風 雲 會, $87 \mathrm{n} 27$

Five Relationships Complete and Perfected.

See $W u$ lun quan bei

Folk Songs. See Shange

$f u$ 賦, 117 n59, 118 n62, 138 n111

fugu 復 古, 26

Fukumitsu Masahiro, 79

fu qi 夫 妻, 143

“Fuqing nong”負 情 儂, 135 furen zbi yi congyi er zbong 婦 人

之義從一而終, 66, 68, 69

Fuxi 伏 羲, 22

"Garrulous Girl Li Cuilian." See "Kuaizui Li Cuilian ji"

ge 哥, 56,57

Ge Hong 葛 洪, 123

gender, 107. See also feminist theory

Golden Lotus. See Jin Ping Mei

gong guo ge 功過格, 63 n56

gongsheng 貢 生, 68, 127

Gongyang Commentary Annotated by $\mathrm{He}$

Xiu. See Chunqiu Gongyang zhuan

Heshi jiegu

Green Sky Studio Collection. See Lütian guan wenji

Gu Jiegang, 36 n44, 38

guan 觀, 35

Guan Dedong, 38, 39 n55

Guan Yu 關 犲 (Guan Yunchang

關 雲 長), 89-90, 91

Guang xiao fu 廣 笑 府, 141-42 n124

Guazhir 掛 枝兒, 37, 38 guilian 鬼 臉, 47

Gujin tangai 古今 譚 概, $141 \mathrm{n} 124$

Gujin xiaosbuo 古 今 小 說, title

page notice, $43 \mathrm{n} 63$; preface to,

19-25, 30-32, 104; GJ 1, 49-61,

63, 64, 68, 69, 71, 73, 76; GJ 2,

49, 63-69, 73, 76-77; GJ 3, 104, 105, 106; GJ 5, 74, 76, 77; GJ 6,

74-75, 77; GJ 7, 79-84, 85; GJ 8 , 75, 77, 79-82, 84; GJ 9, 77; GJ

10, 77; GJ 11, 71; GJ 12, 68 n68,

76 n93, 100, 147-52; GJ 13, 77;

GJ 14, 77; GJ 15, 71, 84; GJ 16,

84; GJ 17, 77, 100; GJ 18, 46-48, 49, 60, 77; GJ 22, 41; GJ 24, 101; GJ 27, 102; GJ 28, 73 n84, 102, 130-32; GJ 29, 129; GJ 30, 129; GJ 31, 128-29; GJ 37, 129; GJ 39, 40, 76 n91, 102; GJ 40, 41, 101

Guo Maoqian 郭 茂 倩, 36

Guo yu 國 語, 35 n38

Guo Ziyi 郭 子 儀, 149

gu wangzhe bu cbu youbu, jin zbi

tianxia ku, bu xia tang er z bi

sifang. 故王者不出牏戶,

盡知 天下苦, 不下堂而

知四方, $35 \mathrm{n} 39$

gu zhe pin wei qi, ben wei qie. Fu ben zhe, yi qing ben ye; ben wei qing, ze zhen wei feiqing ye 古 者

聘 爲妻, 奔爲妾. 夫奔者,

以情奔也; 奔爲情,

則貞爲非情也, 52 n25

Han Fei 韓 非, 20

Hanan, Patrick, on the Donglin

movement 155 n2; Feng 
Menglong's biographical information, $125 \mathrm{nn} 81-82$, 127; on GJ 1, $51 \mathrm{n} 21,51 \mathrm{n} 24,59 \mathrm{n} 46$; on GJ 40,101; on Guazbir and Sbange, $37 \mathrm{n} 47,38 \mathrm{n} 49$; on $\mathrm{Li} \mathrm{Yu}$, $145,146,156 \mathrm{n} 3$; on marginal comments, $71 \mathrm{n} 77$; on preface to Gujin xiaosbuo, 22 n6; on "The Pearl Vest," 49-50, 53; on qing, 97 n50, 133 n100; on Sanyan's quality of workmanship, 24; on Sanyan's subject matter, $102 \mathrm{n} 10$, $132 \mathrm{n} 98$; on sources and authorship of the Sanyan, 32, 39 n56, $41 \mathrm{n} 58,48,64 \mathrm{n} 58,76,82$ $\mathrm{n} 9,85,86 \mathrm{n} 26,93,106 \mathrm{n} 21,126$ nn84-86, 130 n93, 134 n103, 147 nn136-37; on the storytellernarrator, 42, 69, 70; translations from, 25, $43 \mathrm{n} 63,60 \mathrm{n} 51,62$, 127, $138 \mathrm{n} 113,149 \mathrm{n} 142$; on $T Y$ $32,136,137$; on the vernacular story, 61

Hangong qiu 漢宮秋, $124 \mathrm{n} 76$

Hanshu 漢 書, 34, 36

He Jingming 何景 明, 25

He Wenhuan 何文煥, 121

Hegel, Robert E., 6 n8, 7, 20 n2, 24, 43 n63, 61-62, 99, 112, 125

Heke sanzbi 合 刻 三 志, $82 \mathrm{n} 9$

Henry, Eric, 118 n62, 123, 123 n72, 123 n74, 124 n76, 151 n151

History of the Former Han. See Hanshu Holquist, Michael, 2, 7-10, 13, 15 $\mathrm{n} 34,19 \mathrm{n} 1,33,153$

bong 紅, 140

Hongfu 紅 拂, 152 n152

Honglou meng 紅 樓 夢, 140, 144
Hong Pian 洪 楩, 14. See also Liusbi jia xiaoshuo

Hou Huiqing 侯 慧 卿, $126 \mathrm{n} 83$

bou qi $2 i$ 後 七子, 25

Hsia, C. T., 46, 54 n34, 56, 67

$\mathrm{Hu}$ Shiying, $15 \mathrm{n} 34$

$\mathrm{Hu}$ Wanchuan, $31 \mathrm{n} 28,70-71$

buaben 話 本, 1,20

buai cai buyu 懷才不遇, 139

Huang, Martin W., 88 n30, 134 $\mathrm{n} 102,156 \mathrm{n} 4$

Huang Shancong 黃 善 聰, 73 n84, 131-32

Huang Tingjian 黃庭 堅, 12 "Human Prodigy." See "Ren yao" hybrid construction, 8-9, 11, 13, 17

Idema, Wilt L., 24 n8, 42-43, 46, $132 \mathrm{n} 98$

Idle Talk under the Bean Arbor. See Doupeng xianbua

Illustrious Words to Instruct the World.

See Yusbi mingyan; Gujin xicoshuo intentional fallacy, $11 \mathrm{n} 23$

Intrigues of the Warring States. See Zhanguo ce

Investiture of the Gods. See Fengshen yanyi

Jia Sidao 賈 似 道, 41

jiao 校, $15 \mathrm{n} 34$

Jiazbutao 夾竹桃, 39

jie fufu yi feng junchen abi buzbong ye

借夫婦以諷君臣之不

終也, 118

jieguang 借 光, 30

jie gufeng jin 借古諷 今, 11

jie bua xianfo 借花獻 佛, 11 
jie nannü zhi zhenqing, fa mingizao zhi weiyao 借男女之自

情, 發名教之倸藥, 97 jie shi buan bun 借 尸 還 魂, 11, 44 “Jiexian ji” 解閒 集, 14. See also Liusbi jia xiaoshuo Jin Shengtan 金 聖 嘆, 11 jindai zhi quilanzhe, shi wen shi yi 近代之最濫者, 詩文是 已, 29

Jing Ke 荆 柯, 80, 81, 82 Jingchai ji 荆 釵 記, 66 n63 Jingsbi tongyan 警 世通 言, portrayal of women in, $101 \mathrm{n} 5$; TY 8, 95 n46, 101; TY 12, 25, 39-40; TY 16, 100, 101; TY 18, 32 n29, 127-28; TY 19, 71; TY 20, 72; TY 21, 85-93, 94, 95, 97, 98; TY 22, $76 \mathrm{n} 92,85,93-98 ;$ TY 23, 85; TY 24, 100; TY 25, 102; TY 28, 100, 101; TY 29, 100; TY 30, 101; TY 31, 102; TY 32, 102, 134-44, 145; TY 34, 100-101, 102; TY 37, 44, 143

Jin Ping Mei 金 瓶 梅, $7 \mathrm{n} 11,12,20$ $\mathrm{n} 2,26 \mathrm{n} 14$ jinshi 進士, 125, 127 Jin yuefu xuan 今 樂 府 選, 38 jiuping qbuang xinjiu 舊 瓶裝新

酒, $11 \mathrm{n} 22$

jiu se cai qi 酒色財氣, 50 jiu shi se meiren 酒是色媒 人, 59 jiuzbou 九 州, $40 \mathrm{n} 57$ “Jiyi" 基 義, $112 \mathrm{n} 45$ Johnson, David, 4-5 juguan 巨觀, $21 \mathrm{n} 4$
“Kongque dongnan fei" 孔 雀 東南飛, 107 n23

Kristeva, Julia, 109-111, 114, 115 n51, 116, 131

“Kuaizui Li Cuilian ji”" 快嘴 李綷蓮 記, 104

lang 郎, 56

Langxian 浪仙, $15 \mathrm{n} 32,106 \mathrm{n} 21$ “Lao kefu yao" 老客婦謠, 124 n78

"Leaning on the Pillow Collection." See "Qizhen ji"

Li Mengyang 李夢陽, 25, $26 \mathrm{n} 13$

Li Panlong 李 攀 龍, 25

Li Yu 李 漁 (1611-1680), 16-18, $144,145-46,155$

Li Yu 李玉 (c.1591-c.1671), 87 n27

$\mathrm{Li} \mathrm{Yu}$ 李 暲 (937-978), 148

LiZhi 李 䞇, 11, 19, 26, 27, 143; on the childlike mind, 27 ; on "mountain men," $27 \mathrm{n} 17$; on women, 133

liangabi 良知, 26, $97 \mathrm{n} 50,133$ n100. See also Wang Yangming Liaozhai zbiyi

聊 齋志異 (Liaozbai's Records of the Strange), 103. See also $\mathrm{Pu}$ Songling

Lie Yukou 列 御 寇, 20

Liji 禮 記, 35 n38

Ling Mengchu 凌濛初, 15-16, 18 $\mathrm{n} 41,155$

Liu, James C. Y., 28 n19, 29 n20, 35

Liu Xiang 劉 向, 35, 36

Liu Yong 柳 永, 147-52 
Liusbi jia xiaosbuo 六十家小說 (Hong Pian), 14, 21 n3, 81, 82, $84,104,149$. See also "Wanjiang lou"; "Shuangyu zhui"; "Jiexian ji"; "Qizhen ji1"; "Yu chuang ji"

Lu Shulun, 1 n1, 39 n55, 52 n25, $141 \mathrm{n} 124,152 \mathrm{n} 152$

Luo Binwang 駱 賓 王, 37

Lütian guan wenji 綠 天 館 文 集, 31

Lütian guan zhuren 綠 天 館 主人, 20, 30-31

Ma Zhiyuan 馬志遠, 123-24 n76 "Male Mencius's Mother Raises Her Son Properly by Moving Her House Three Times." See "Nan Mengmu jiao he san qian" Maoyuan yeshishi茂苑野史氏, 22,23

Marriage that Awakens the World. See Xingshi yinyuan zbuan

McMahon, Keith, 50 n18, 55, 57 nn43-44, 62 n54, 63, 64 n59, 100 $\mathrm{n} 4,102$

Mei 媺, 139, 140, 141, 142

meili 美 麗, 139

meiren xiangcao 美人香草

(beauty and flower), 100, 107, 115, 119 n64, 144, 145, 146, 147, 154, 156

Meng Haoran 孟 浩 然, 149 $\min$ 民, 4

ming 命, 62 n54

mingmei zhengqu 明 媒 正娶, 52

Ming sbi 明 史 (Ming History), 26 n14, 132 n99

Mudan ting 牡 丹 亭, 67 n67
"Nan Mengmu jiao he san qian" 男孟母教合三遷 $(\mathrm{Li} \mathrm{Yu}$, 1611-80), 144, 145. See also Wusheng xi

New Account of Tales of the World. See Shi shuo xin yu

New History of the States. See Xin Lieguo zhi

$N \ddot{u}$ caizi shu 女才子書, 144, 145

$N \ddot{u}$ ₹bangfu 女丈, $152 \mathrm{n} 152$

"Old Woman's Song." See "Lao kefu yao"

Oleander. See Jiazbutao

Ota Tatsuo 大田辰夫, 24

Ouyang Jian, $21 \mathrm{n} 4$

Owen, Stephen, 116, 120 n65, 122 $\mathrm{n} 68,151 \mathrm{n} 151,152 \mathrm{n} 153$

"Pearl Vest." See "Zhushan"

Pei Yan 裴 炎, 37

Peony Pavilion. See Mudan ting "Pillow Collection." See "Qizhen ji" Pingyao zhuan 平妖 傳, 21, 43, 6263

“Pipa xing”琵琶行, 131. See also Bai Juyi

Plaks, Andrew H., 6, 7 n11, 21 n4, 38-39, 41, 43, 111-12 n40

Plum in the Golden Vase. See Jin Ping $\mathrm{Mei}$

"Preface to Rules of Dramatic Prosody." See "Qulü xu"

"Preface to Yuan Zhongdao's Poems." See "Xu Xiaoxiu shi"

Pu Songling 蒲 松 齡, 103, 141 n123, 146 n135. See also Liaozbai zbiyi 
qian qi i $i$ 前 七子, 25

qie jin sui jisbi, er dan you jia sbiwen, wu jia shange 且 今雖 季世, 而但 有假詩文, 無假山 歌, 29

Qin Guan 秦 觀, 101

qing 情, 52, 97-98, 134, 142, 147, $151 \mathrm{n} 150$

qing zhen 情貞 (authenticity of feeling), 29, 30, 39 n54, $151 \mathrm{n} 150$

“Qiuran ke zhuan”虯䯽客傳, $152 \mathrm{n} 152$

“Qizhen ji”" 歌枕 集, 14, 79, 81.

See also Liusbi jia xiaoshuo

qi quozhe mo kekao 其 作 者 莫 可 考, 32

$\mathrm{Qu}$ Yuan 屈原, 119, 138, 139, 145

Quelling of Demons. See Pingyao zbuan

Que shi zhenzheng nü daoxue, kejing, kejing

确是貪正女道學,

可 敬, 可 敬, $73 \mathrm{n} 84$

“Qulü xu” 曲律序, 29

"Rainy Window Collection." See "Yu chuang ji"

Rawski, Evelyn S., 155 n1 recognition, 116, 118, $123 \mathrm{n} 74,137$,

147, 150, $151 \mathrm{n} 151,152,154$

Records of the Grand Historian. See Shiji

Redfield, Robert, 2, 3

"Relief from Boredom Collection."

See "Jiexian ji"

Ren An 任 安 (Ren Shaoqing

任 少 卿), 123 n74

"Ren su ji qionggui su piao yuan"

人宿妓窮鬼訴嫖冤 $(\mathrm{Li}$

Yu, 1611-80), 145-46

“Ren yao" 人 妖, $146 \mathrm{n} 135$
"Road to the Taihang Mountains." See "Taihang lu"

Rolston, David L., 10 n20, 11 n24, 12 nn25-27, 20 n2, 45-46, 70 $\mathrm{n} 75,155-56 \mathrm{n} 3$

Romance of the Three Kingdoms. See Sanguo zhi

San bao'en 三 報 恩, $32 \mathrm{n} 29,127$ $\mathrm{n} 87$

sancong side 三從 四 德, 113

Sandar 三大兒, 58

san gang 三 綱 (the three bonds),

112, 113, 114, 120 n65, 129, 134.

See also yin-yang

Sanguo zbi 三國志, 21, 31, 43 n63

Sanguo zbi pinghua 三國志平話, 128

Sanqiao 三 巧, 58

Sanyan 三 言, 1, 2, 10, 14, 15 n34; absence of the shrew in, 103-104; attitude toward women in, 100 107; authorship of, 32-34; companion stories in, 79-99 passim, 154, 155; extra-textual commentary to, 70-72; femme fatale in, 105; storyteller-narrator in, 45-78 passim, 153-54. See also Gujin xiaoshuo; Jingshi tongyan; Xingshi bengyan; meiren xiangcao

Schneider, Laurence A., 115 n52, 119 n64, $136 \mathrm{n} 106,138 \mathrm{n} 111$

Selection of Today's Yuefu. See Jin yuefu xuan

Shange 山 歌, 29, $36 \mathrm{n} 44,37,38,39$, 40,41 ; preface to, $29,37 \mathrm{n} 48,38$, $39,97,151 \mathrm{n} 150$ 
shange bu yu shiwen zhengming, gu buxie jia 山歌不與詩文爭名, 故 不 屑 假, $151 \mathrm{n} 150$

shanren 山人, $27 \mathrm{n} 17$

Shen Buhai 申 不害, 122 sheng bu feng sbi 生不逢 時, 137 "Shengsi jiao Fan Zhang jishu"

生死交范張雞乘, 81, 84 .

See also "Qizhen ji"; Liusbi jia xiaoshuo

shengyuan 生 員, 26, 125

shi 士, 4; origins of, 116

sbi buyu士不遇, 118, 137, 149, 150

Sbi'erlou 二 二 樓, 16. See also Li Yu (1611-1680)

Shiji 史記, 12, 35 n38, 123, 139

n115. See also Sima Qian

Shijing 詩 經, 35, 38, 39, 41, 123

sbinian luopo shao zbijin 十 年

落魄少知音, 126-27 n86

Shi sbuo xin yu 世說 新語, 141

shi wei zbijizhe si, nü wei yuejizhe rong

士爲知已者死, 女爲

悅已者容, 123

shiyao 詩 妖, 35

shuangren pang 雙 人旁, 142

“Shuangyu zhui" 雙魚䜃, 20,31,

104, 106. See also Liushi jia

xiaoshuo

Shuibu abuan 水澈 傳, 11, 21, 31,

43, $56 \mathrm{n} 39,58 \mathrm{n} 45$

shuobua de dou yi cheng bai lun sbi

說話的都以成敗論事, 72

sbuobua ren 說話 人, 20

shuosbu zbi liu 說 書之流, 20

shuren 庶 人, 117
Sibu beiyao 四部 備 要, 35 n39

sida 四大, 97

Silent Operas. See $W$ usheng $x i$

Sima Guang 司馬 光, 124 n78

Sima Qian 司馬遷, 118 n62, 123,

$139 \mathrm{n} 115$. See also Shiji

simin zhi shou 四民之首, 117

Sixty Stories. See Liushi jia xiaoshuo.

Song Maocheng 宋榒 澄, 49, 134, 135, 136, 137, 143

"Song of the Pipa." See "Pipa xing"

Song Taizu longhu fengyun bui 宋 太

祖龍虎風雲會, $87 \mathrm{n} 27$

Songs to the Tune 'Guarbir.' See

Guazbir

"Southeast the Peacock Flies." See "Kongque dongnan fei"

Spring and Autumn Annals of $W u$ and

Yue. See $W u$ Yue chunqiu

Stories Old and New. See Gujin xiaoshuo

Story of the Thorn Hairpin. See Jingchai ji

Story of the Three Kingdoms. See Sanguo zbi pingbua

storyteller-narrator, 41-43, 153-54; as spokesman, 70, 72, 73-76, 154;

facetious, 47-48, 77, 78;

ironically conceived, 49-69

passim, 76, 77, 78, 153;

unobtrusive, $76 \mathrm{n} 92,78$

su 俗, 4,5

Su Shi 蘇 軾, 101

Su Xiaomei 蘇 小妹, 101

ta shan gong cuo 他 山 攻 錯, 7

“Taihang lu" 太行 路, 118-19. See also Bai Juyi 
Taiping guangii 太平廣記, $82 \mathrm{n} 9$, $132 \mathrm{n} 99$

Talks Old and New. See Gujin tangai Tan Zhengbi, on Huaben yu guju, 86 n26; on Qingpingshan tang buaben, $104 \mathrm{n} 15,148 \mathrm{nn} 139-40,149$ $\mathrm{n} 143$; on Sanyan Liangpai abiliao, $\mathrm{v}$; on source materials of GJ 1 , $60 \mathrm{n} 51$; on source materials of GJ 7-8, 81 nn6-7, 82 nn9-10, 83 n17; on source materials of $G J$ 12, $148 \mathrm{nn} 139-40,149 \mathrm{n} 143$; on source materials of $G J 18,48$ n11; on source materials of $G J$ 28, $130 \mathrm{n} 93,132 \mathrm{n} 99$; on source materials of TY 21-22, $86 \mathrm{n} 26$, $92 \mathrm{n} 40,93 \mathrm{n} 43$; on source materials of TY 32, $135 \mathrm{n} 103$, Tang Jiu, Tang Shi 湯 九, 湯十, 140

Tang Xianzu 湯 顯 祖, 67 n67 tianli 天 理, $62 \mathrm{n} 54$ tong sbi tianya lunluo ren 同 是 天 涯 淪 落 人, 131

Treasury of Jokes. See Xiao fu

Treasury of Jokes, Expanded Edition.

See Guang xiao fu

Twelve Towers. See Shi'er lou

ventriloquism, 2, 7-10, 13, $15 \mathrm{n} 34$, $45,79,99,153,154,153,154$

"Wang Qiang" 王 嫱 (Wang Zhaojun王昭 君), 123-24

Wang Shizhen 王世貞, 25-26

Wang Yangming 王 陽 明, 26, 27, $97 \mathrm{n} 50,133$
"Wanjiang lou" 拍 江 樓 ("Wanjiang Tower"), 21, 31, 68 n68, 76 n93, 149. See also "Qizhen ji"; Liusbi jia xiaosbuo

Wansbi zu 萬 事 足, 104 n16 Water Margin. See Shuibu zbuan wei 微, 139, 142 wen bi Xi Han, sbi bi sbeng Tang

文必西 漢, 詩 必盛唐, 25 Wen Tianxiang 文 天 祥, 149 wenyan 文言, 5 wenghang 文 章, 43 Woman Hero. See Nü zbangfu women characters, 154; femme fatale, 105; male author identifying with, 134-47, 154; the shrew, 103; as zhiyin, 147, 150-52, 154.

See also Feng Menglong; Sanyan; yin-yang; zhiyin

$\mathrm{Wu}$ 吳, $36 \mathrm{n} 44,38,39,59 \mathrm{n} 46$

Wu Han, 26 n14

Wu lun quan bei 伍倫 全 備, 24-25 $\mathrm{n} 10$

Wusheng xi 無聲 戲 (Li Yu, 161180), 16, 144-46, $155 \mathrm{n} 3$

Wusheng xi erji 無聲戲二集 ( $\mathrm{Li}$ $\mathrm{Yu}, 1611-80), 16,155 \mathrm{n} 3$

Wu Xuan 吳 璇, 86-92. See also

Feilong quanzbuan $W u$ Yue chunqiu 吳越春秋, 20 Wu Zetian 武則 天, 37

xiang 香, 140 xiang le fuqin, ye dai sanfen xiaqi

象了父親, 也帶三分俠 氣, 68 xianren bu dezbi 賢人不得志, $118 \mathrm{n} 62$ 


\section{6 / Glossary-Index}

Xiao $f u$ 笑 府, 141-42 n124

“Xiaoqing" 小 青, 144-45, 156

xiaosheng xing Yang, sbuangming Jiao'ai

小生姓羊, 雙名角哀, 82

xiaoshuo 小說, 20

“Xie Xiao'e" 謝 小 娥 (Pu

Songling), $141 \mathrm{n} 123$

Xige 喜 哥, 56

Xijing zaji 西京雜記, 123 n75

xingling 性 靈, 28

Xingshi hengyan 醒 世恆 言, 1,15 n34; HY 1, 105, 106; HY 2, 72, 130 n $55 ; H Y 3,101,140$ n119, 146; HY 8, 129, 130 n92; HY 10, 129; HY 11, 101; HY 15, 104 105, 106, 129; HY 25, 101-102; HY 27, 105, 106; HY 28, 72; HY 33, 25, 72; HY 35, 72, 146

Xingshi yinyuan zhuan

醒 世姻 緣 傳, $103 \mathrm{n} 13$ Xin Lieguo $2 b i$ 新列 國 志, 83 xin xue 心 學 (the school of the mind), 26, 133. See also Wang Yangming xin yuefu 新 樂 府, 36 $\mathrm{Xu}$ Jingye 徐敬 業, 37 "Xu Xiaoxiu shi"

序小修詩 (Yuan Hongdao), $28 \mathrm{n} 19$

ya 雅, 4,5

yan 艷, 43

Yan Shifan 嚴世蕃, 26 n14

Yan Song 嚴 嵩, 41, 101

“Yang Jiao'ai si zhan Jing Ke" 羊

角哀死戰荆柯 ("Yang

Jiao'ai Kills Himself to Fight Jing Ke"), 81-84. See also "Qizhen ji";
Liushi jia xiaoshuo

Yang Jun, 119 n64

yang sbi 養 士, 117

Yang Xiaodong, 31

Yang Weizhen 楊 維 楨, 124 n78

yanyi 演 義, 20

Ye Yousheng 葉 有 聲, 30-31

$y i$ 義, 88

Yijing 易 經, 122

yinguo baoying 因果 報 應, $62 \mathrm{n} 54$

yin-yang 陰 陽, 100, 107, 111-15, 120 n65, 122, 129, 143, 146, 156.

See also san gang

yin $y u$ 隱 語, $142 \mathrm{n} 124$

Yi pian buo, liang pian buo, feiyi xiao'er dang dian zuo 一 片火, 兩片

火, 緋衣小兒當殿坐, 37 yonggu 用古, 12

youqing ren 有情 人, 96

you shi 游士, 117

yourbi furen, saiguo nanzi 有 智婦 人, 賽 過男子, 102

$y u$ 遇, 137

yu 玉, 140

Yu Yingshi, 4, 117

Yuan Hongdao 袁 宏 道, 19, 26, 28-29

Yuan Zhongdao 袁 中 道, 28-29

Yuan Zongdao 袁 宗 道, 28

"Yu chuang ji" 雨窗集, 14. See also Liusbi jia xiaosbuo

Yuefu 樂 府, 34

yuefu 樂 府, 34, 36, 38, 41

yuezi wanwan zhao ji zbou 月 子

彎彎照 幾 州, 40 n57

“Yu meiren" 虞美 人, 148

yunyu 雲 雨, 59 
Yusbi mingyan 喻世明 言, 1. See also Gujin xiaoshuo

Zhang Ji 張 籍, 120-21

Zhan guo ce 戰國 策, 123

Zhang Zhupo 張竹坡, 12, $20 \mathrm{n} 2$

Zhao Kuangyin 趙匡扸, 86-93

zhenren 自 人, 28

zhensheng 真 聲, 28

z $h i$ 姪, 侄, $143 \mathrm{n} 128$

zbiji 知 已, 72

Zbiyin 知 音, 116, 121, 126, 138, 143, 147, 150, 151-52, 154

Zhou Lianggong 周 亮 工, 142 n127

Zhu Qingyu 朱 慶 餘, 120-21

“Zhushan" 珠衫, 49, 100

rimi 字 謎 (orthography riddles),

141

zuo guan shi zhi zuo you ming

做官時之座右銘, 25

Zuo zhuan 左 傳, 122-23, 141 
